The submitted manuscript has been created by the

University of Chicago as Operator of Argonne

National Laboratory ("Argonne") under Contract

No. W-31-109-ENG-38 with the U.S. Department

of Energy. The U.S. Government retains for itself,

and others acting on its behalf, a paid-up,

nonexclusive, irrevocable worldwide license in said

article to reproduce, prepare derivative works,

distribute copies to the public, and perform publicly

and display publicly, by or on behalf of the

Government.

\title{
Extended Barrel Support Saddle Design and Analysis
}

By

V. Guarino, J. Grudzinski, and E. Petereit

Argonne National Laboratory

High Energy Physics Division

Argonne, IL 60439

October 10, 2001

*Work supported in part by the U.S. Department of Energy, Division of High Energy Physics, under Contract W-31-109-ENG-38. 
Argonne National Laboratory, with facilities in the states of Illinois and Idaho, is owned by the United States Government and operated by The University of Chicago under the provisions of a contract with the Department of Energy.

\section{DISCLAIMER}

This report was prepared as an account of work sponsored by an agency of the United States Government. Neither the United States Government nor any agency thereof, nor The University of Chicago, nor any of their employees or officers, makes any warranty, express or implied, or assumes any legal liability or responsibility for the accuracy, completeness, or usefulness of any information, apparatus, product, or process disclosed, or represents that its use would not infringe privately owned rights. Reference herein to any specific commercial product, process, or service by trade name, trademark, manufacturer, or otherwise, does not necessarily constitute or imply its endorsement, recommendation, or favoring by the United States Government or any agency thereof. The views and opinions of document authors expressed herein do not necessarily state or reflect those of the United States Government or any agency thereof, Argonne National Laboratory, or The University of Chicago.

Available electronically at http://www.doe.gov/bridge

Available for a processing fee to U.S. Department of Energy and its contractors, in paper, from:

U.S. Department of Energy

Office of Scientific and Technical Information

P.O. Box 62

Oak Ridge, TN 37831-0062

phone: (865) 576-8401

fax: (865) 576-5728

email: reports@adonis.osti.gov 


\title{
Extended Barrel Support Saddle Design and Analysis
}

\author{
By
}

V. Guarino, J. Grudzinski, and E. Petereit

Argonne National Laboratory

High Energy Physics Division

Argonne, IL 60439

October 10, 2001

*Work supported in part by the U.S. Department of Energy, Division of High Energy Physics, under Contract W-31-109-ENG-38. 


\title{
Extended Barrel Support Saddle Design and Analysis
}

\author{
Argonne National Laboratory \\ Victor Guarino \\ Jim Grudzinski \\ Emil Petereit
}

October 10, 2001

\subsection{Introduction}

This paper summarizes the extensive structural analysis and design of the support saddles for the Extended Barrel of the ATLAS Tilecalorimeter that has taken place at Argonne National Laboratory over the past several months. This work has been a continuation and expansion of work that has taken place over the course of several years within the ATLAS Tilecalorimeter collaboration. This paper will be divided into four main sections. Section 1 is the introduction to the analysis and will give a brief history of the work that had previously been done.

Section 2 examines the design and structural analysis that has occurred on the support saddles. The design of the support saddles has evolved over the last few months. There are three main analyses of the saddles that are discussed in Section 2. First, the forces that act upon the support saddles and the resulting deflections and stresses are examined when the support saddle is subjected only to gravity loading. Next, the saddles are examined when subjected to a combination of gravity and a seismic load of $.15 \mathrm{~g}$ in the $\mathrm{X}, \mathrm{Y}$, and $\mathrm{Z}$ directions. Finally, the saddles are analyzed when subjected to a combination of gravity, magnetic, and seismic loading.

Section 3 describes a detailed analysis of the back cryostat support structure in the Extended Barrel. This design has evolved significantly throughout the analysis process and every design iteration and analysis is described in detail. The initial design is described in Section 3.1 that analyzed the back cryostat support only under vertical static loading. Section 3.2 then examines the stiffening of the cryostat support plate that had to be included in the design in order to provide sufficient stiffness in the case of seismic loading in the $\mathrm{X}, \mathrm{Y}$, and $\mathrm{Z}$ directions. Finally, Section 3.3 describes the final design, which has a modified stiffener.

\subsection{History of Saddle Design}

The design of the support saddle has evolved over the design life of the tile calorimeter. There have been three major analyses of the support saddle for the extended barrel. To date, there has not been a detailed study of the saddle for the barrel, but this is a currently scheduled activity. The first was a preliminary analysis that was done at the beginning of the design phase, which had the purpose of establishing the basic parameters of the support saddle for the extended barrel. The second analysis was much more detailed and consisted of an overall geometry that more closely represented reality in the extended barrel. The third, and ongoing, analysis has built upon the second. This third analysis incorporates changes to the basic design, which have been needed to facilitate the assembly of the tile calorimeter. This current design is ongoing and now includes the design of the support beam between the saddle structure and the rail system. 
The design requirements for the EB saddles are:

1 Clearance of bolts and tools for connecting plates is required. Selected a torque wrench for this evaluation.

2 Ease and cost of construction.

3 There must be access to all of the bolts that attach the connecting plates to the girder.

4 Ability to adjust for variation of connector plate angle - selected swivel bolts for this.

5 Minimization of stresses.

6 Try to stay within the existing envelope for the saddle.

7 Bearing points on the connecting plates should avoid the joint between connecting plates in $\mathrm{Z}$.

8 Bearing points on connecting plates should fall between bolts on the girder.

9 The saddle design should accommodate the lifting fixture.

10 Seismic loads from the cryostat are isolated from the EB and transferred directly to the saddle support structure.

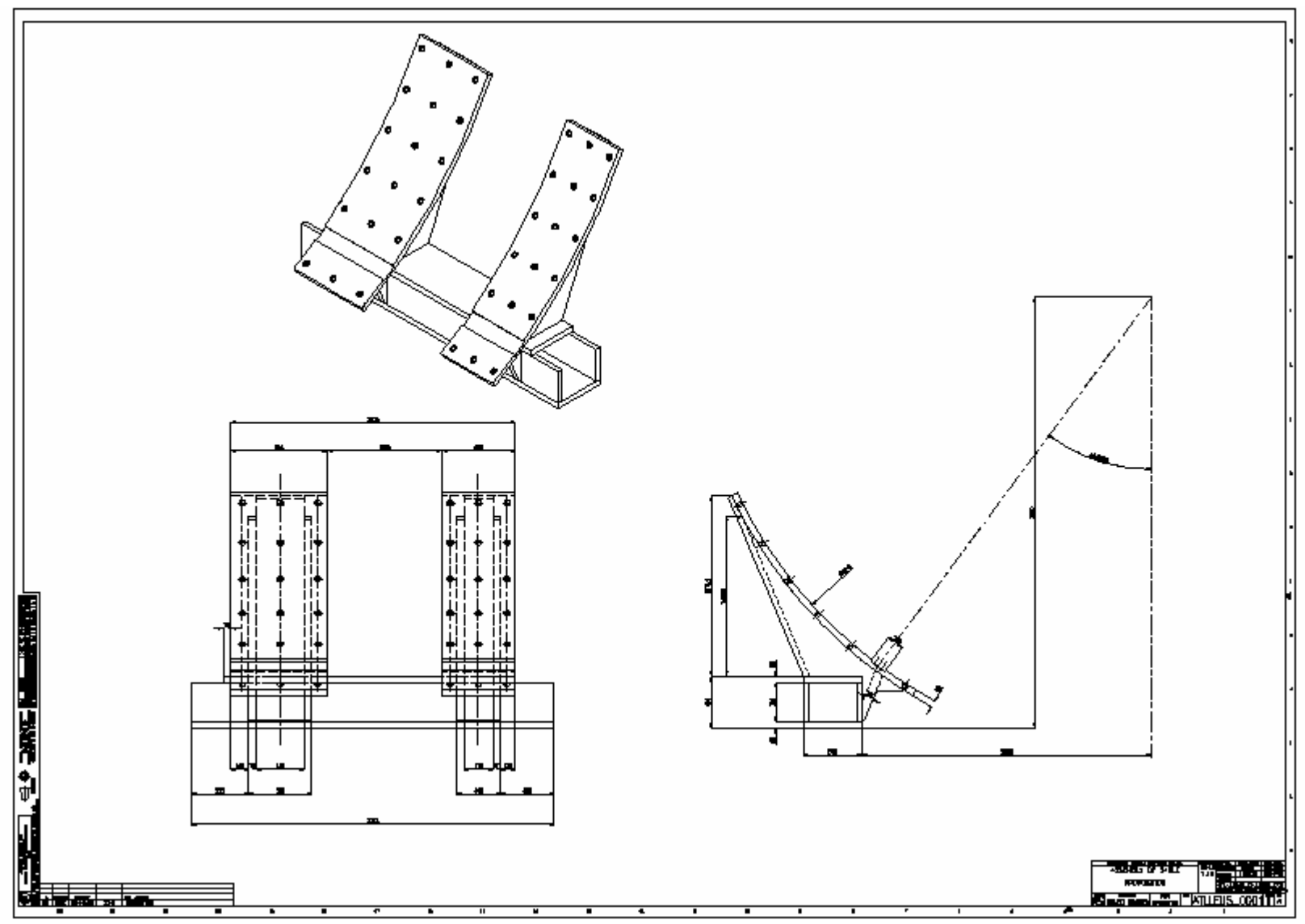

Figure 1. Initial Design of Saddle.

\subsection{Initial Design and Analysis of EB Saddles}

The second analysis was based upon the design shown in Fig. 1. This geometry consisted of a $70 \mathrm{~mm}$-thick front plate and a continuous plate at the outside as well. Loads were applied to the FE model based upon an assumed distribution of the weight of the calorimeter and cryostat onto the saddle. The static loading due to the weight of the forward calorimeters (about $9,000 \mathrm{kN}$ ) was applied with an 
earthquake load of $0.15 \mathrm{~g}$. The loads from the extended barrel were assumed to be an evenly distributed radial load over the top of the saddle with a radial and circumferential shear load occurring at the key surface on the saddle. The load from the cryostat was applied through a stiff structure that was designed to transfer the load of the cryostat directly to the saddle. In total, there were five load cases examined:

Case 1 Weight of calorimeters alone

Case 2 Calorimeter weight and earthquake conditions in direction $-\mathrm{Z}$

Case 3 Calorimeter weight and earthquake conditions in direction $+Z$

Case 4 Calorimeter weight and earthquake conditions in direction $-\mathrm{X}$

Case 5 Calorimeter weight and earthquake conditions in direction $+\mathrm{X}$

The maximum displacement and stresses are listed below:

\begin{tabular}{|c|c|c|}
\hline Case & Max. Displacement (mm) & Max. Stress (Mpa) \\
\hline Case 1 & 2.55 & 135 \\
\hline Case 2,3 & 2.70 & 150 \\
\hline Case 4,5 & 2.65 & 145 \\
\hline
\end{tabular}

There were several problems with this initial design. First, FE analysis of the EB shows that the EB deflects in the region of the saddle significantly less than the approximate $2.6 \mathrm{~mm}$ maximum deflection calculated. This is a problem, because calculations on the deflection of the EB indicated that it deflected less than $1 \mathrm{~mm}$ in the region of the saddle. Therefore, the solutions of the EB and Saddle were incompatible and, the loading conditions that were assumed, were incorrect. Second, the initial design does not meet several of the design criteria listed above. Most importantly, this initial design did not meet the design requirement that there be access to the bolts attaching the connecting plates to the girder. 

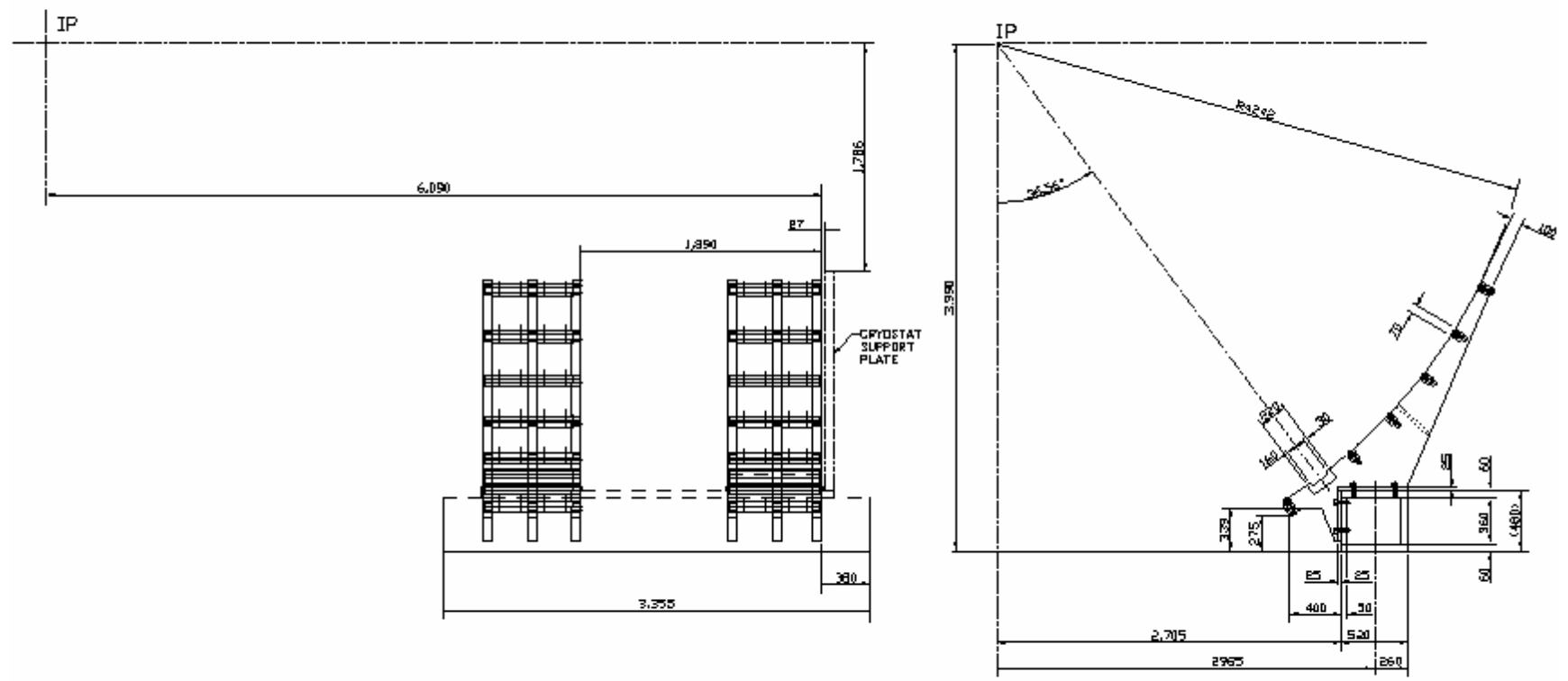

Figure 2. Alternative Design with Bars.

In order to remedy these problems, an alternative saddle was designed. This saddle design consisted of 3 gussets instead of the original 2 and the continuous front plate was replaced by a series of bars. This design is comprised of three, upright gussets that are $70 \mathrm{~mm}$ thick and are tied together by crossbars. The crossbars support swivel bolts onto which the calorimeter is supported. Swivel bolts are used to accommodate minor differences in the angles of the modules and to allow the bolts to be moved radially without galling the surface of the link plate on which they bear. The crossbars have been sized to carry the load that will be applied radially to the swivel bolts. This design is shown in Fig. 2. During the period of time between the initial design and the alternative design, the envelope that was available for the saddles was diminished so the alternative design also had slimmer gussets. Forces were applied to the swivel bolts that were calculated from an earlier analysis of the EB. While this design of the saddle met the design requirements of providing access to the mounting bolts, the saddle deflected excessively, $\sim 6 \mathrm{~mm}$. Because of this large deflection, the current design was developed, which has a continuous front plate with clearance holes drilled through it to provide access to the EB mounting bolts. This design is shown in Figs. 3 and 4. In order to eliminate extra clearance holes from being drilled into the front plate, it was decided that access to the upper bolts on the link plates would not be required. These bolts were attached before the module was put into place and no further access would be needed for them (See Fig. $3 b)$. As in all of the earlier designs, there will be two columns of swivel bolts on each saddle. Each column will consist of 6 bolts, which will provide radial support to the modules in the region of the saddle. 

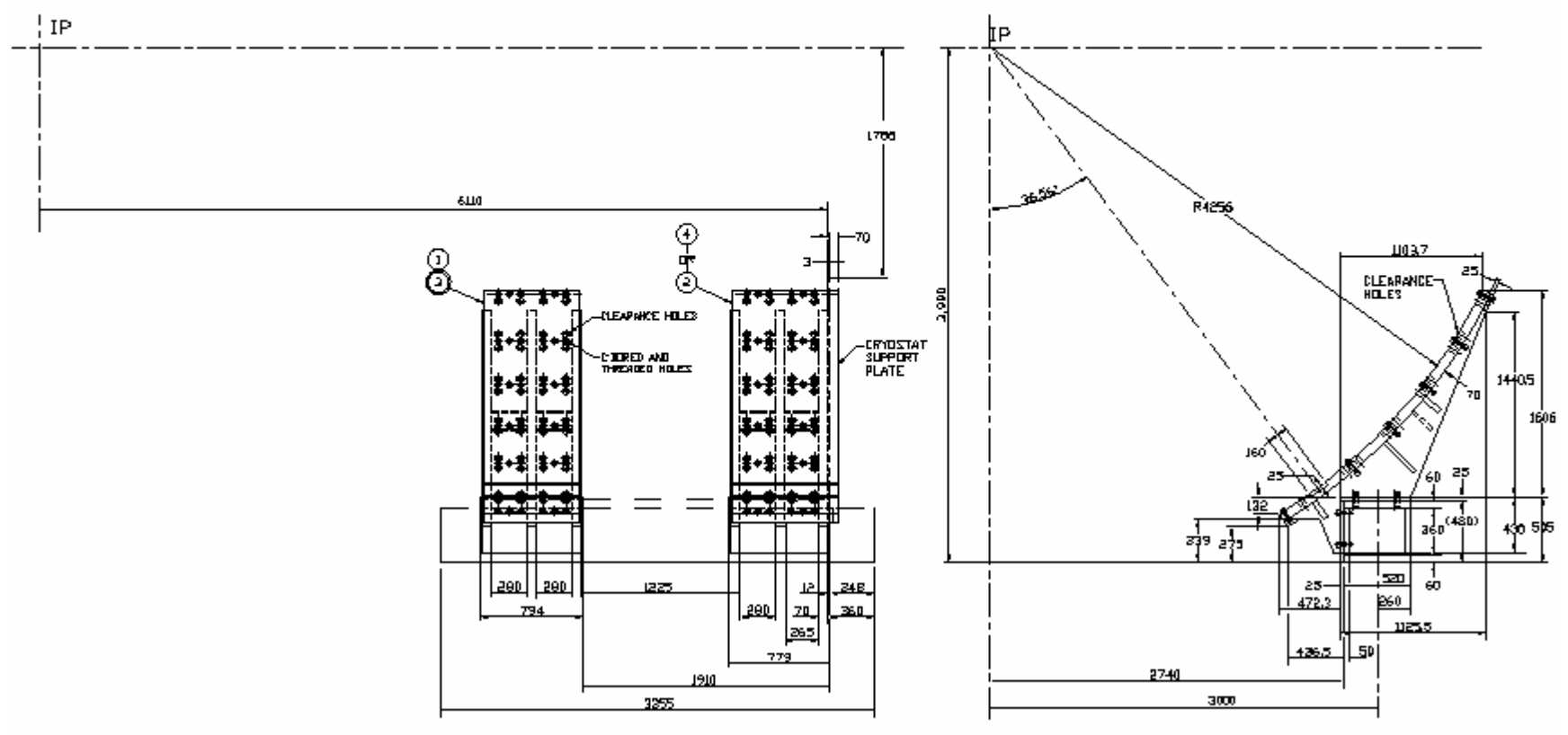

Figure 3a. Current Design of Support Saddles. 


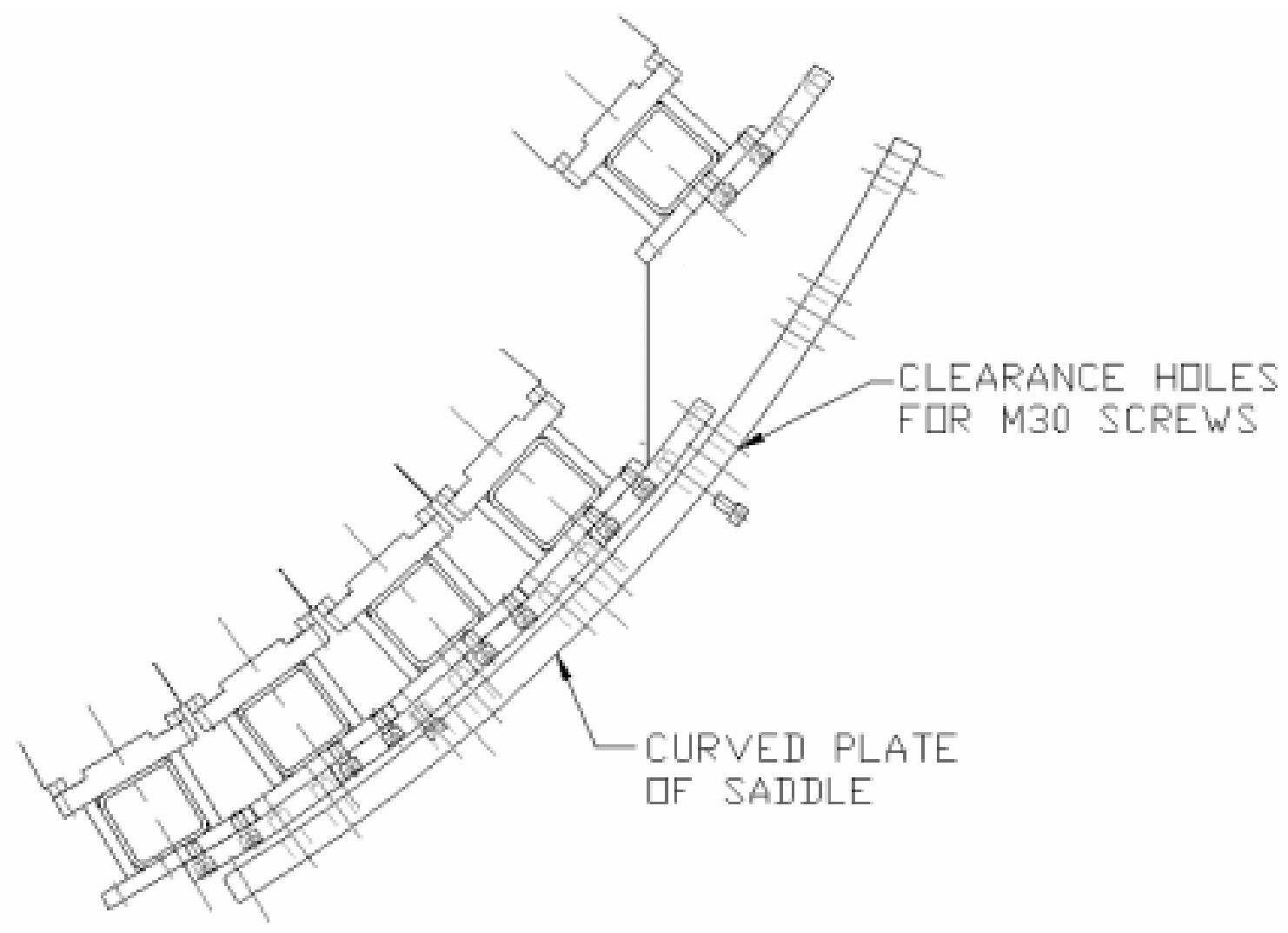

Figure 3b. Access to Link Plate Bolts during Assembly.

\subsection{Current Analysis}

As described above, the analysis of the first design of the saddle used an assumed distribution of the weight of the endcap cryostat and EB. The second analysis applied forces to a Finite Element model of the saddles that had been calculated from an earlier analysis of the EB. In both of the analysis of these earlier saddle designs, the saddles themselves deflected considerably greater than the calculated deflection of the EB. This raises doubt as to the accuracy of the load distributions that were applied to the saddles. In order to accurately model the saddles, it was decided that the EB and the saddles must be examined together. Therefore, a FE model of the EB was created, which was supported by a simplified model of the support saddles. This model utilized a combination of solid plate, and beam and truss elements. The model consisted of 78,335 elements and 76,834 nodes. Whereas the 3-D FE model of the EB and Saddle are the main method for understanding the stresses and deflections, it should be noted that all of the FE analysis has been checked and supported by simplified hand calculations to verify the accuracy of the FE results. 


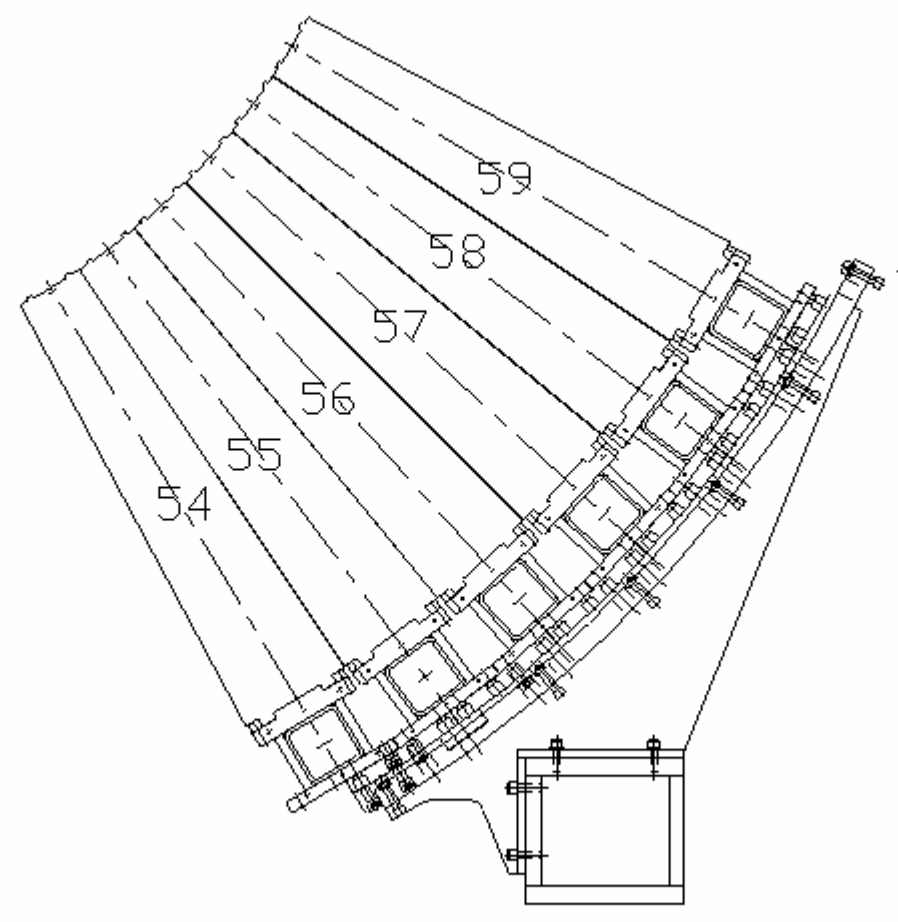

Figure 4. Modules on Saddle Support.

\subsection{Description of FE Model}

The 3-dimensional model of the EB was constructed from a series of truss, beam, and solid elements as shown schematically in Fig. 5. The additional loads from the endcap Liquid Argon Cryostat have been included for this initial study, but the seismic loads have not been included. In this analysis, a complete extended barrel was examined. As was the case for the static analysis described earlier it was assumed that the modules were connected by a bearing force at the front plate and a bearing and radial force at the outer radius. Submodules were modeled by solid elements. The stiffness of these elements was calculated by comparing the deflection of a single FE model module with the results of an actual physical test on a module. The bolts between the submodule and the girder and between the girder and connecting plate were modeled using truss elements. In the area of the girder key and between the girder and connecting plates, there were additional link elements (labeled A in Fig. 5b), which carried the shear force in this region. The area for this truss element was based upon the shear area of the key on the girder and the pins between the connecting plate and the girder, respectively. The girder was modeled by plate elements.

The saddle was modeling using shell elements in plain stress. The modules in this region were connected to the saddle by a series of truss elements, which modeled the bolts supporting the calorimeter in the radial direction. The connection and location of the truss elements is shown schematically in Fig. 6. Module \#7 is not supported by a radial bolt (truss element), but transfers a shear load through a key from the calorimeter to the saddle. This is modeled by a truss element labeled A in Fig. 6. Several views of the FE model are shown in Figs. 7-10. 
The two saddles that support the EB were tied together by a support beam. In the calorimeter, this beam is supported by hydraulic jacks on the installation rail. At this time it is not clear what the location of the jacks will be. Therefore, the displacement of the support beam connecting the saddles together was restrained at the two edges of the beam along its entire length. It was felt that by restraining the support beam in this manner it would be possible through an examination of the reaction forces to determine the optimal location for the support jacks. The support beam was only restrained in the vertical direction at its edges.

The design of the back cryostat support has changed since the initial design of several years ago. This earlier design required that the cryostat support be bolted to the girders in the EB. This would require drilling a clearance hole through the end plate of each module in the region of the cryostat support (the endplates are not structural members) and then drilling and tapping holes into the girders. Also, this configuration would apply loads directly to the modules, thereby increasing the loads between modules. In addition, any earthquake load would be directly applied to the modules. Currently, there is no part of the design of the EB to withstand such a load. Finally, large amounts of stiffening members were required by this design. It is believed that the current design can significantly reduce the stiffening and other structural pieces that are required for this support.

Several load cases were examined. The first load case was simply the calorimeter and cryostat under only a gravitational load. The second load case examined the seismic conditions. For this analysis, it was assumed that a seismic load of $15 \%$ was applied in all three directions, $\mathrm{X}, \mathrm{Y}$, and Z. In all of the load cases, the load from the cryostat onto the EB was simulated simply by applying loads at the appropriate locations to the EB. No attempt was made to model the cryostat and its stiffness. For the seismic load case, the $15 \%$ seismic acceleration was applied to the center of gravity of the cryostat and then the resulting reaction forces were calculated at the support points on the EB. It was assumed that the front cryostat support only supported loads in the vertical (Y) direction and that the left back cryostat support supported loads in the $\mathrm{X}, \mathrm{Y}$, and $\mathrm{Z}$ directions, while the right back cryostat support was restrained in only $\mathrm{Y}$ and $\mathrm{Z}$. It should be noted that the large $\mathrm{Y}$ direction loads on the front cryostat support would result in a significant friction load in the horizontal plane during an earthquake. In order to completely remove the application of $\mathrm{X}$ and $\mathrm{Z}$ direction forces from the front cryostat support, it will be necessary to insert a low friction material, such as DU, between the cryostat and the hydraulic jack at the front.

The EB was constrained at the bottom of the support beam between the saddles. The Right side of the EB was restrained in the $\mathrm{X}, \mathrm{Y}$, and $\mathrm{Z}$ directions. The Left side was restrained only in the $\mathrm{Y}$ and $\mathrm{Z}$ directions. The $\mathrm{X}$ and $\mathrm{Z}$ restraints mainly play a role during the analysis of the seismic conditions.

Cryostat Loads on EB

\begin{tabular}{|c|c|c|c|c|c|}
\hline & & \multicolumn{4}{|c|}{ Cryostat Support Point } \\
\hline Case & Direction & $\mathbf{\# 1}$ & $\mathbf{\# 2}$ & $\mathbf{\# 3}$ & $\mathbf{\# 4}$ \\
\hline \multirow{3}{*}{$\begin{array}{c}\text { Case 1 } \\
\text { Static) }\end{array}$} & $\mathrm{X}$ & 0 & 0 & 0 & 0 \\
\cline { 2 - 6 } & $\mathrm{Y}$ & -77 & -77 & -57.8 & -57.8 \\
\cline { 2 - 6 } & $\mathrm{Z}$ & 0 & 0 & 0 & 0 \\
\hline Case 2 & $\mathrm{X}$ & 20.2 & 20.2 & 0 & 0 \\
\cline { 2 - 6 }$($ Seismic) & $\mathrm{Y}$ & -88.5 & -88.5 & -66.5 & -66.5 \\
\cline { 2 - 6 } & $\mathrm{Z}$ & 11.6 & 28.0 & 0 & 0 \\
\hline
\end{tabular}


Forces Acting on the EB Support Points

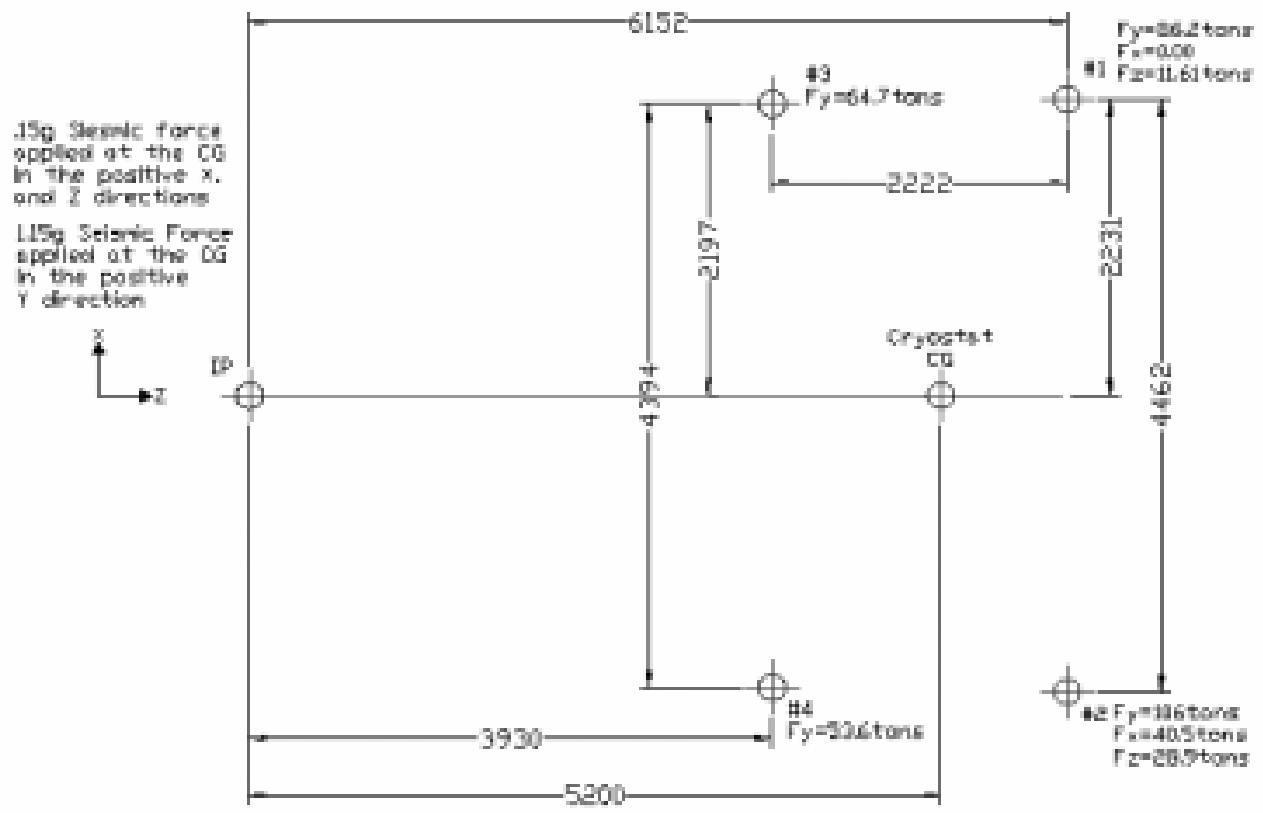

Figure 5a. Cryostat Support Points and Loads (top view). 


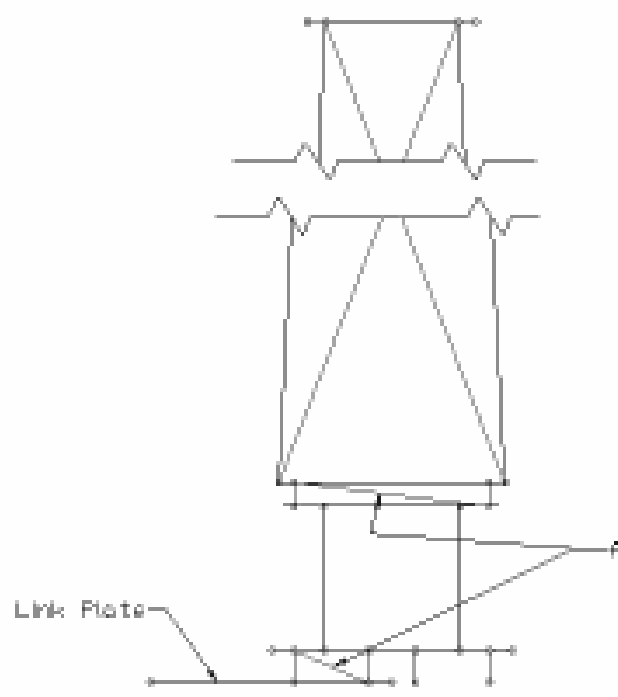

Truss Elenents are in Red Bean Elenents ore in Blue

Figure 5b. Schematic 2-dimensional Finite Element Model (not to scale).

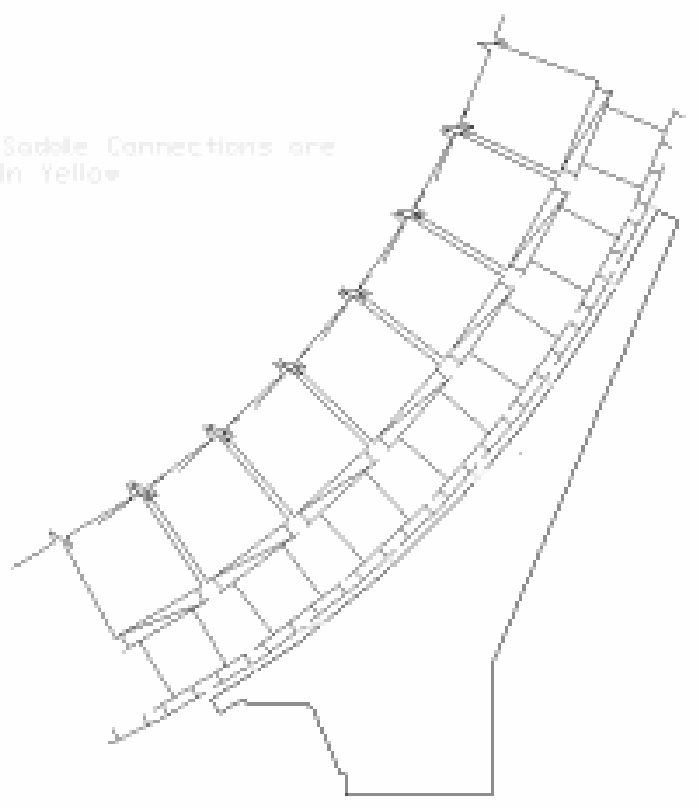

Figure 6. Schematic of FE model. 


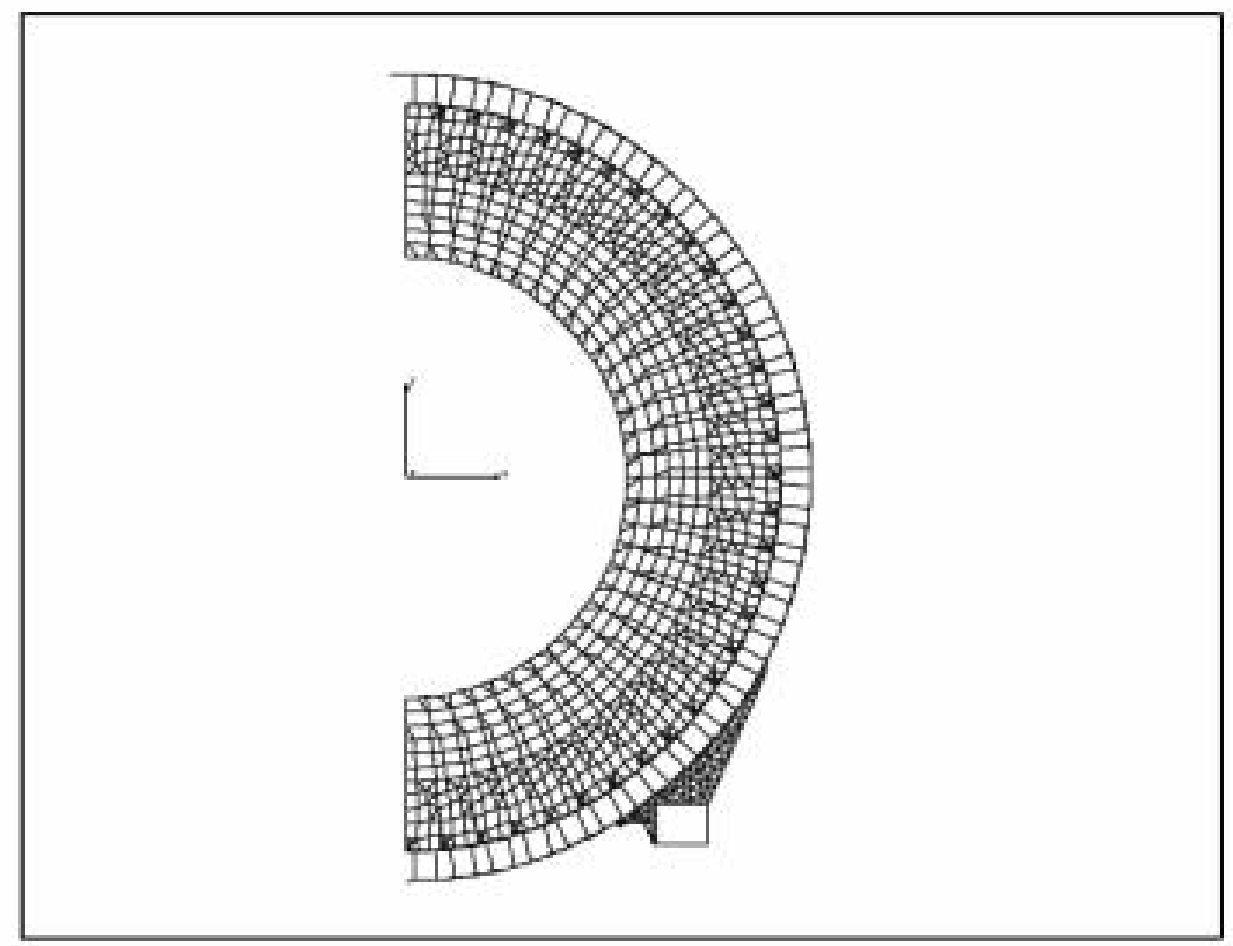

Figure 7. End View of FE Model. 


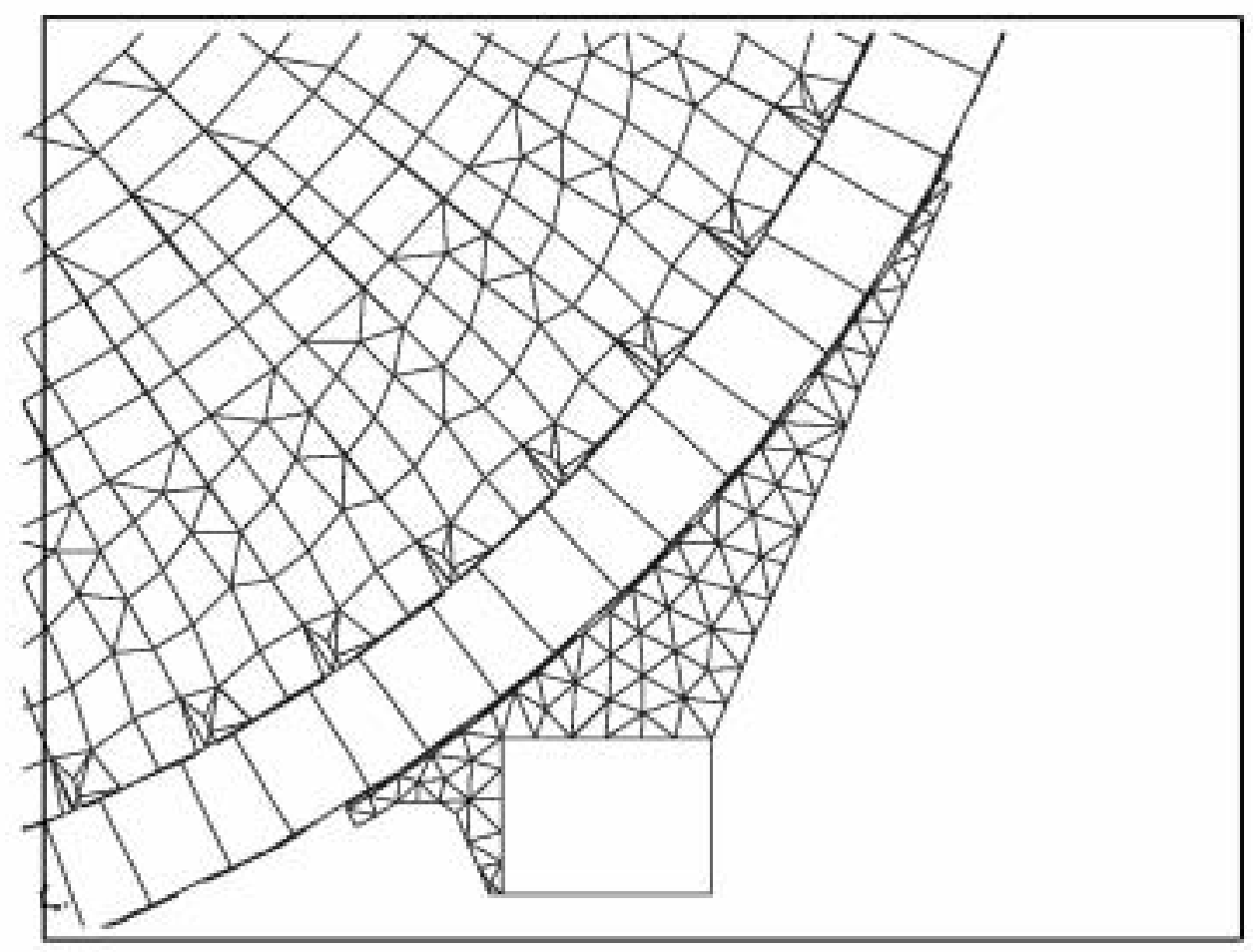

Figure 8. Close-up of the Saddle Region. 


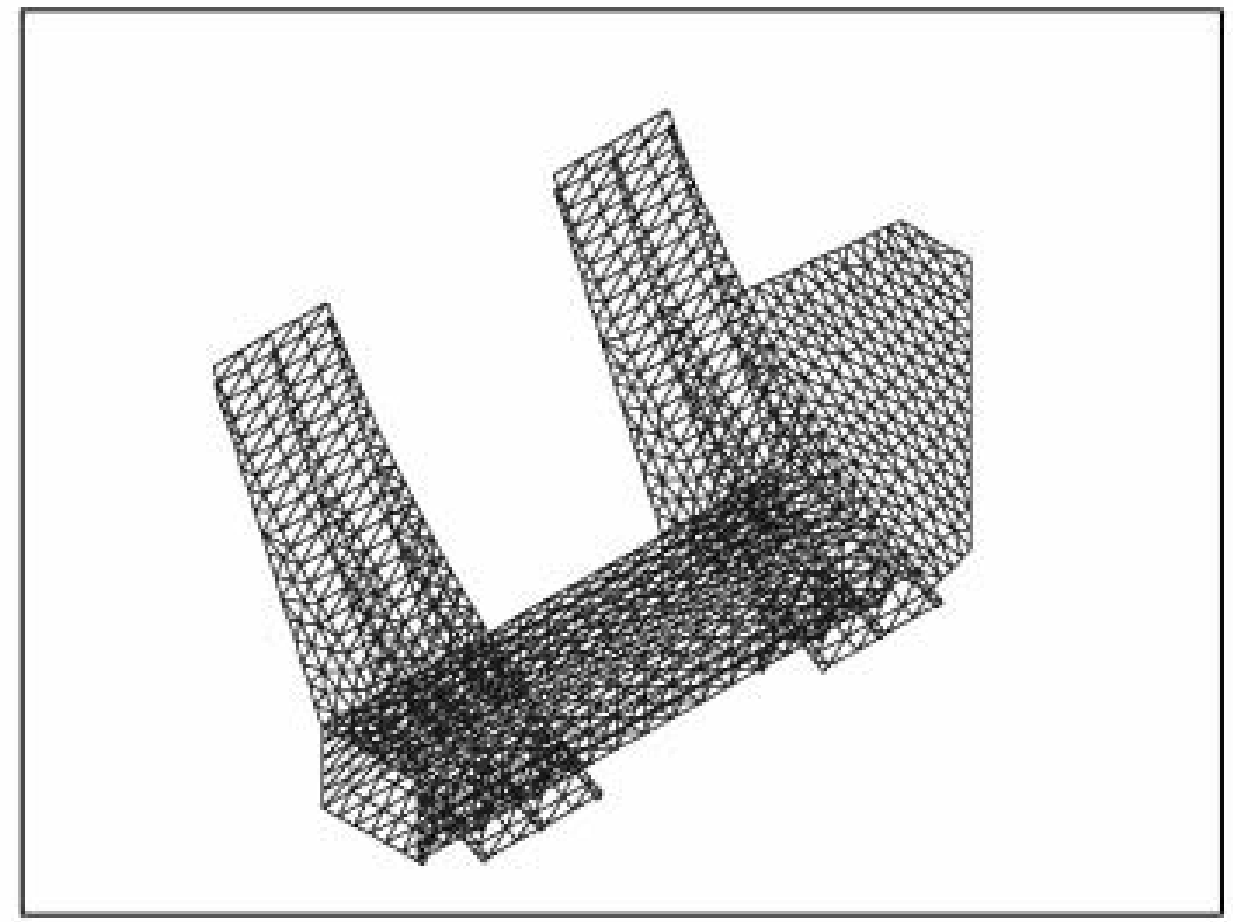

Figure 9. Isometric View of Saddles, Support Beam, and Back Cryostat Support. 


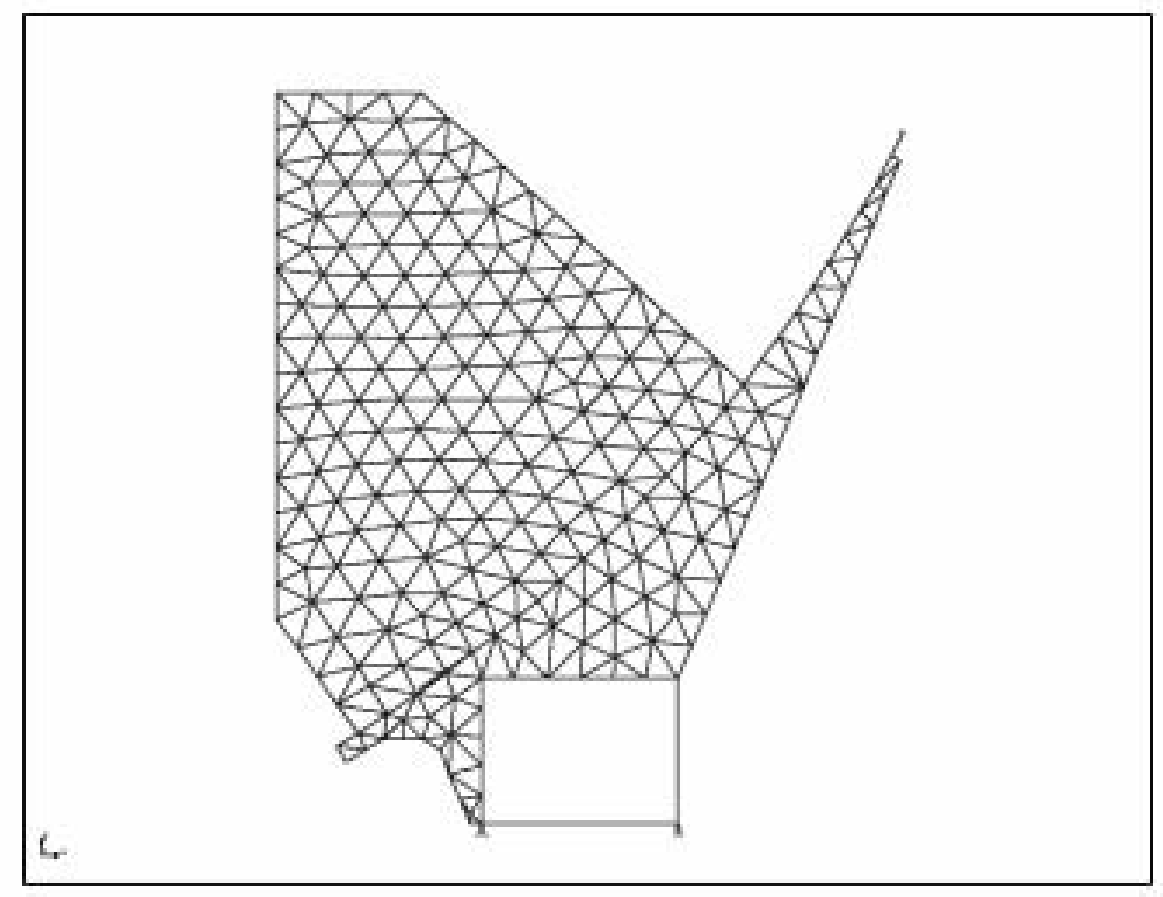

Figure 10. End View and Close-up of Back Cryostat Support and Saddle. 


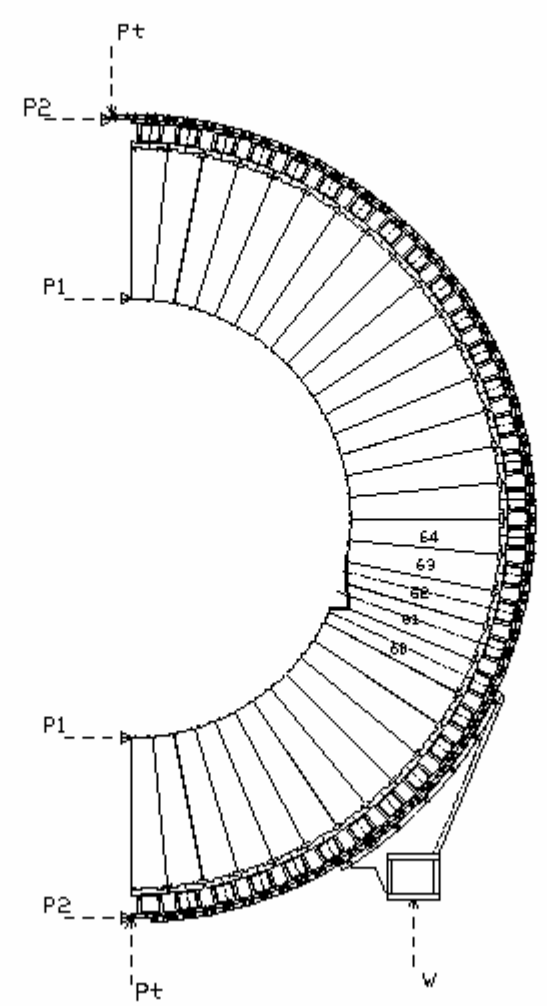

Figure 11. Schematic of Forces Acting on EB Modules.

\subsection{Gravity Loading}

\subsubsection{Forces Between Modules}

As a comparison with earlier models and analysis, the forces between the modules in the EB were examined first. In order to facilitate comparison with earlier analysis, the forces between modules are listed in Force per unit length $(\mathrm{N} / \mathrm{mm})$ for the front, center, and back of the EB. Figure 11 shows the forces that were calculated bearing contact is assumed to occur only at the inner radius, a bearing/tension connection is assumed at the outer radius, and a tangential shear connection is also assumed at the outer radius. The distribution of the bearing forces at the inner and outer radius are shown in Figs. 12-14 and listed in Table 1. The bearing load at the inner radius is in compression throughout the extended barrel. The maximum compressive force at the inner radius is $1410 \mathrm{~N} / \mathrm{mm}$ at the front of the EB in the module immediately below the application of the Endcap Cryostat load. The connection at the outer radius is initially in tension, but becomes compression at the area in which the extended barrel is supported. The maximum tensile force at the outer radius occurs below the area supported by the saddle and is 1070 $\mathrm{N} / \mathrm{mm}$ and occurs immediately below the support saddle at the front of the EB. The maximum tangential load (Pt) occurs immediately above the saddle support at the front of the EB and is $832 \mathrm{~N} / \mathrm{mm}$.

These results are very similar to the forces found in earlier calculations of the EB. Especially above the saddle the results are very similar. However, below the saddle and in the region of the saddle these forces are smaller than previously calculated forces between the modules. This difference is attributed to different methods of applying the back cryostat load; the use of different saddle design and the earlier analysis was based on a 2-D FE model. The earlier calculations of the forces between the EB 
modules used the initial design of the support saddle, which was stiffer than the current design. In addition, the earlier forces between the EB modules were calculated from a 2-D FE model. In this model, the loads from the front and back cryostat supports were concentrated over only $700 \mathrm{~mm}$ in $\mathrm{Z}$, whereas this load will probably be distributed over a much greater length thereby reducing the force between modules.

Table 1. Forces Between Modules at the Front, Middle, Back of EB $(\mathbf{N} / \mathbf{m m})$

\begin{tabular}{|c|c|c|c|c|c|c|c|c|c|}
\hline \multirow{2}{*}{$\begin{array}{c}\text { Module } \\
\#\end{array}$} & \multicolumn{3}{|c|}{ Front } & \multicolumn{3}{|c|}{ Middle } & \multicolumn{3}{|c|}{ Back } \\
\hline & P1 & P2 & $\mathbf{P t}$ & P1 & P2 & $\mathbf{P t}$ & P1 & P2 & Pt \\
\hline 1 & -609.00 & 611.00 & -38.40 & -591.00 & 615.00 & -42.20 & -554.00 & 559.00 & -38.30 \\
\hline 2 & -594.00 & 626.00 & -75.60 & -579.00 & 593.00 & -85.50 & -535.00 & 569.00 & -75.60 \\
\hline 3 & -570.00 & 670.00 & -110.00 & -558.00 & 554.00 & -127.00 & -503.00 & 599.00 & -110.00 \\
\hline 4 & -537.00 & 750.00 & -140.00 & -528.00 & 486.00 & -166.00 & -460.00 & 658.00 & -140.00 \\
\hline 5 & -499.00 & 886.00 & -166.00 & -489.00 & 370.00 & -201.00 & -409.00 & 756.00 & -164.00 \\
\hline 6 & -482.00 & 1070.00 & 146.00 & -445.00 & 118.00 & -121.00 & -349.00 & 856.00 & -118.00 \\
\hline 7 & -492.00 & -1040.00 & -282.00 & -401.00 & -255.00 & -152.00 & -281.00 & -677.00 & -335.00 \\
\hline 8 & -596.00 & -760.00 & 359.00 & -399.00 & -328.00 & 248.00 & -261.00 & -521.00 & -139.00 \\
\hline 9 & -820.00 & -535.00 & 714.00 & -441.00 & -304.00 & 488.00 & -285.00 & -404.00 & -41.30 \\
\hline 10 & -1110.00 & -365.00 & 832.00 & -509.00 & -237.00 & 578.00 & -351.00 & -286.00 & 214.00 \\
\hline 11 & -1410.00 & -250.00 & 691.00 & -579.00 & -163.00 & 505.00 & -430.00 & -205.00 & 278.00 \\
\hline 12 & -333.00 & -161.00 & 311.00 & -634.00 & -102.00 & 328.00 & -523.00 & -147.00 & 310.00 \\
\hline 13 & -447.00 & -98.20 & 224.00 & -665.00 & -52.10 & 236.00 & -598.00 & -96.60 & 224.00 \\
\hline 14 & -558.00 & -51.60 & 143.00 & -676.00 & -10.00 & 150.00 & -643.00 & -54.20 & 143.00 \\
\hline 15 & -616.00 & -16.40 & 68.00 & -671.00 & 24.00 & 71.40 & -664.00 & -20.00 & 67.90 \\
\hline 16 & -637.00 & 10.20 & 0.43 & -654.00 & 50.00 & -0.17 & -665.00 & 6.75 & 0.38 \\
\hline 17 & -631.00 & 29.70 & -59.20 & -626.00 & 68.40 & -63.40 & -647.00 & 26.60 & -59.20 \\
\hline 18 & -606.00 & 43.00 & -110.00 & -589.00 & 79.80 & -117.00 & -616.00 & 40.50 & -110.00 \\
\hline 19 & -566.00 & 51.30 & -152.00 & -546.00 & 85.10 & -162.00 & -572.00 & 49.30 & -152.00 \\
\hline 20 & -516.00 & 55.30 & -186.00 & -497.00 & 85.10 & -197.00 & -519.00 & 53.70 & -186.00 \\
\hline 21 & -458.00 & 55.80 & -210.00 & -445.00 & 80.70 & -223.00 & -460.00 & 54.50 & -210.00 \\
\hline 22 & -396.00 & 53.50 & -225.00 & -389.00 & 73.00 & -239.00 & -397.00 & 52.60 & -225.00 \\
\hline 23 & -331.00 & 49.20 & -231.00 & -334.00 & 63.00 & -246.00 & -332.00 & 48.50 & -231.00 \\
\hline 24 & -267.00 & 43.60 & -229.00 & -278.00 & 51.50 & -244.00 & -268.00 & 43.00 & -229.00 \\
\hline 25 & -206.00 & 37.10 & -219.00 & -225.00 & 39.40 & -233.00 & -206.00 & 36.70 & -219.00 \\
\hline 26 & -149.00 & 30.50 & -202.00 & -175.00 & 27.50 & -215.00 & -149.00 & 30.10 & -202.00 \\
\hline 27 & -99.20 & 24.10 & -179.00 & -130.00 & 16.70 & -190.00 & -99.30 & 23.80 & -179.00 \\
\hline 28 & -57.20 & 18.20 & -150.00 & -89.80 & 7.60 & -160.00 & -57.30 & 18.10 & -151.00 \\
\hline 29 & -25.00 & 13.30 & -117.00 & -56.50 & 0.82 & -124.00 & -25.10 & 13.10 & -117.00 \\
\hline 30 & -3.90 & 8.99 & -80.70 & -30.10 & -3.06 & -85.50 & -3.92 & 8.90 & -80.70 \\
\hline 31 & 4.84 & 5.05 & -41.80 & -11.20 & -3.50 & -44.00 & 4.83 & 5.02 & -41.80 \\
\hline 32 & 0.00 & 0.00 & 0.00 & 0.00 & 0.00 & 0.00 & 0.00 & 0.00 & 0.00 \\
\hline
\end{tabular}

A 2-D static analysis using a Fortran program, which calculated the forces between EB modules by solving for the static equilibrium of each module (see the Tilecal TDR), was used to check the results of the 3-D FE model. In this 2-D static analysis, the loads from the front and back cryostat were distributed over $900 \mathrm{~mm}$ and the lateral support point for the saddle was located at the position calculated in Section 5 Saddle Analysis below. This analysis agreed very closely with the 3-D FE model and a comparison can be seen in Appendix 1. 


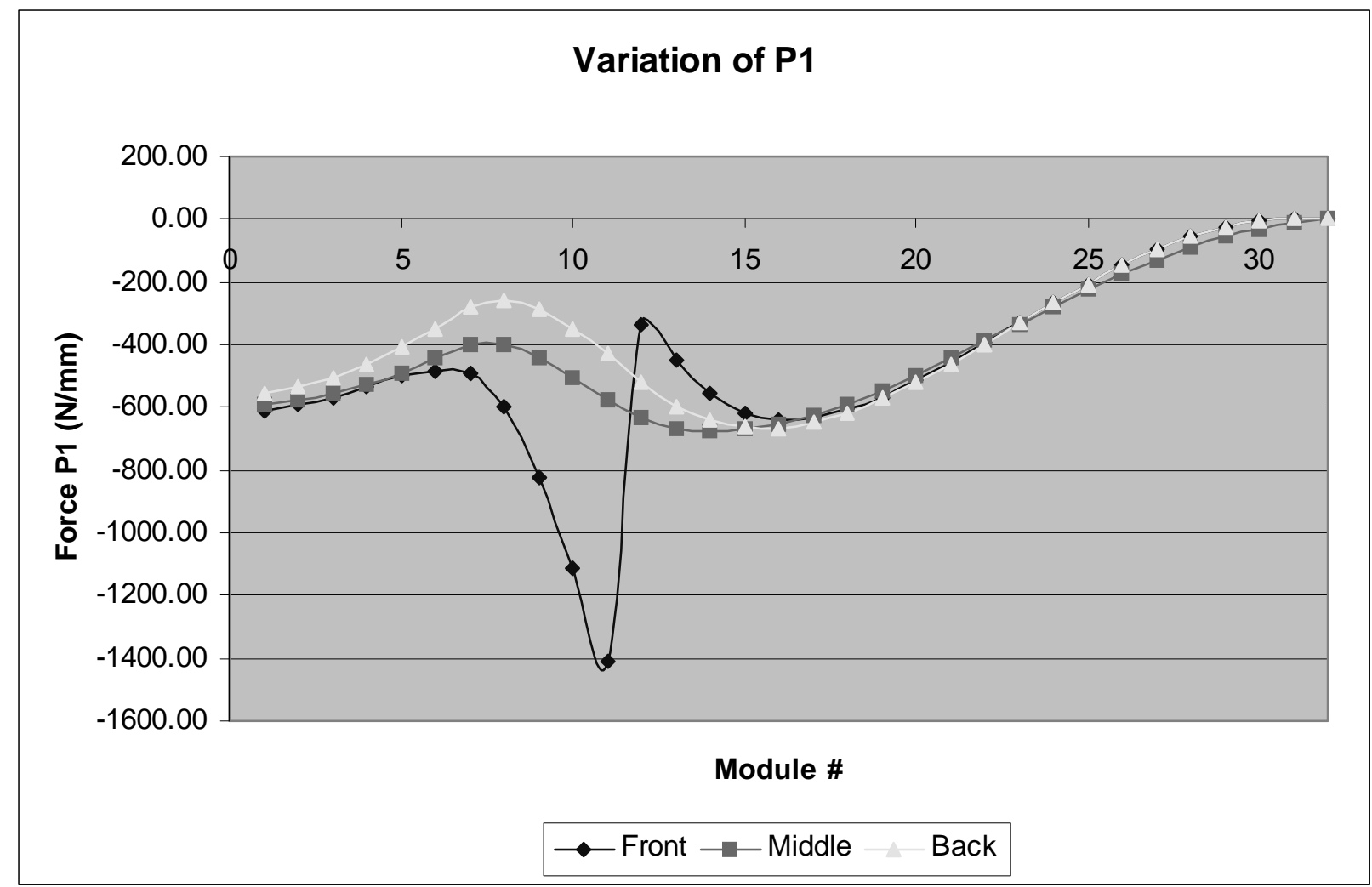

Figure 12. Variation of P1. 


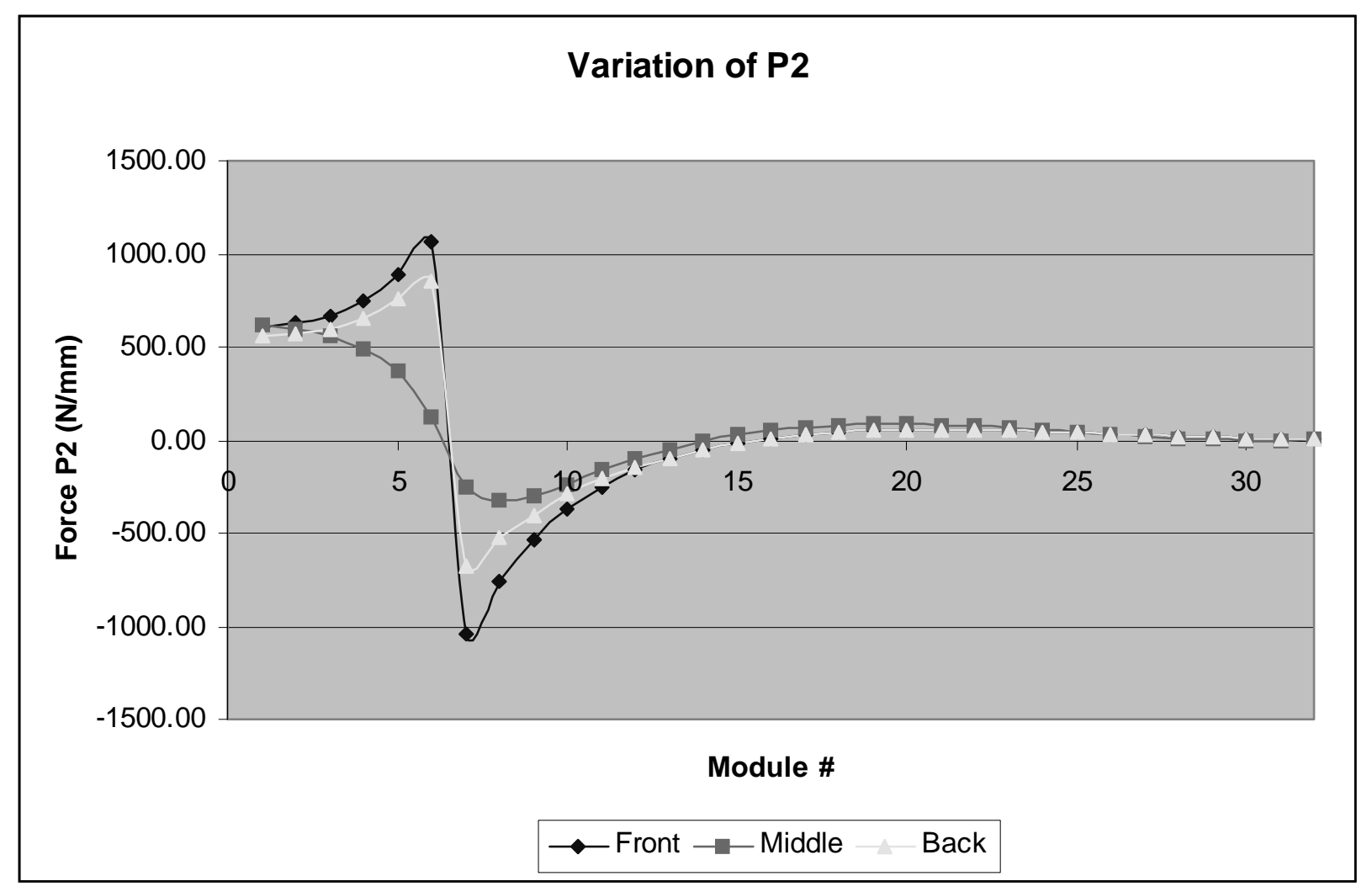

Figure 13. Variation of P2. 


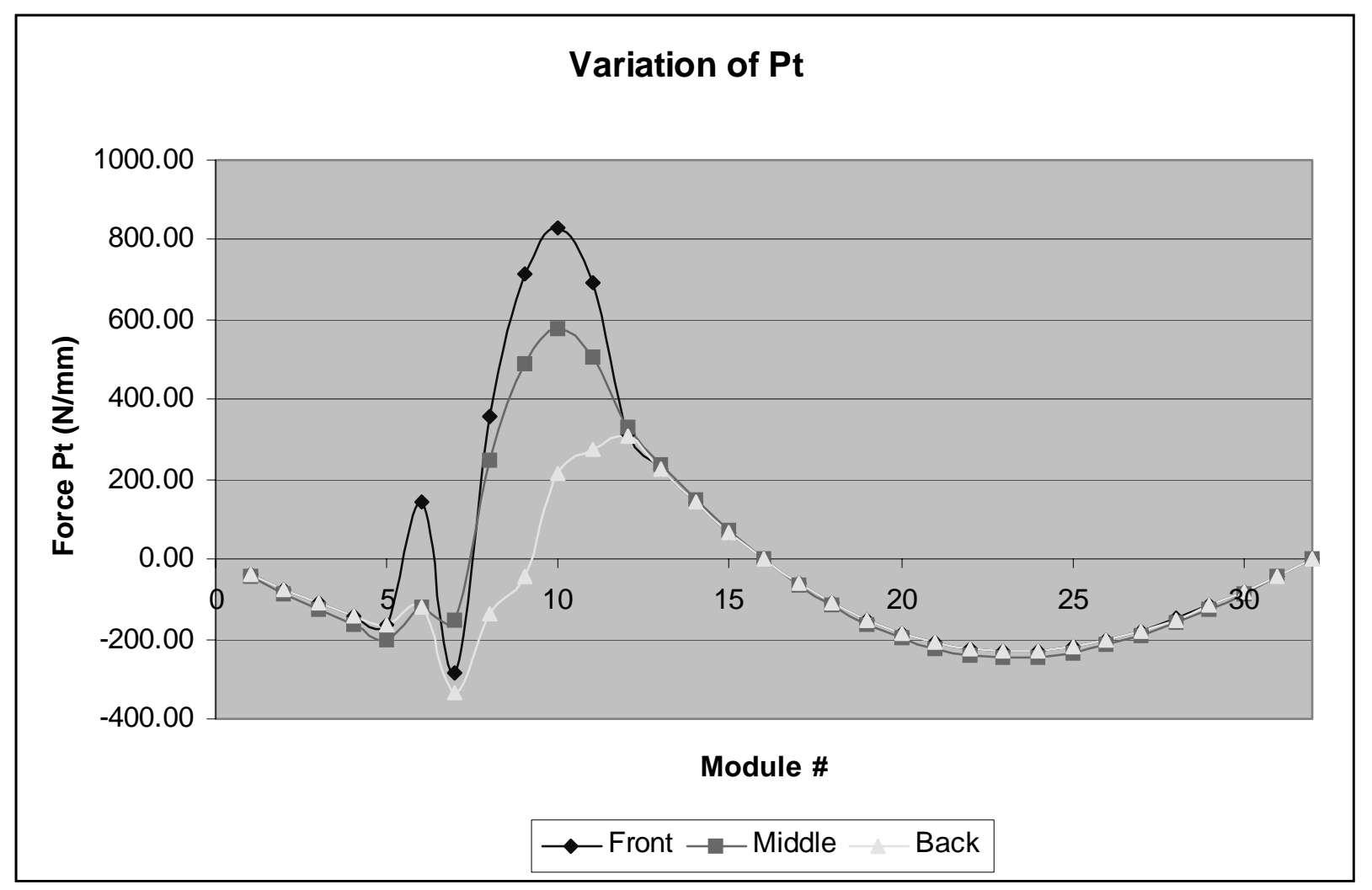

Figure 14. Variation of Pt.

\subsubsection{Static Force Analysis of the Saddles}

The first step in examining the results for the support saddle was to extract from the FE model the forces acting on the saddles from the EB. These forces are listed in Table 2. The loads on the saddle are all in the radial direction except for the forces acting on the key, which are in the circumferential direction. By knowing these forces, it is possible to size correctly the swivel bolts upon which the EB will be resting, to analyze the forces that are acting between each saddle and the support beam tying them together, so that the bolts and welds in this connection can be sized correctly, and to determine the static equilibrium position underneath the support beam of the hydraulic jacks and air pads.

The commercial swivel bolts that were going to be used were load tested and failed at 18 tons. This is less than half of the loads that are expected on some of the bolts. It was anticipated to use $25 \mathrm{~mm}$ diameter bolts with the swivel head on the end. The stresses in the threads and bolts are at an acceptable level, the swivel head itself is not able to support the load. There are two solutions that are currently being examined to solve this problem. First, a custom design swivel head, which is expected to be able to support the calculated loads, is going to be tested. If this custom designed swivel head can support the expected loads, then the design will not have to be further changed. If it cannot, then additional bolts will have to be added in order to distribute the load better.

In Table 2, the radial and key forces are resolved into their X (horizontal), and Y (vertical) components as a first step in order to accomplish these goals. Several things should be noted. First, the force in the $\mathrm{X}$ direction sums to zero for each saddle (Z1 and Z2 for the front saddle, Z3 and Z4 for the back saddle). This is important because the interface between the support beam connecting the saddles 
together and the rails is not designed to carry a lateral load. Each saddle is mounted through a bolted connection to the support structure. Whereas the $\mathrm{X}$ direction forces may sum to zero for each saddle, the individual $\mathrm{X}$ direction forces between the saddles and support beam result in a significant twist of each saddle around the vertical axis. This shows that the bolts used to attach the saddles to the support beam must be sized in order to resist these individual $\mathrm{X}$ direction forces. For example, the bolts on the front saddle must resist approximately 5 tons, and on the back saddle the bolts must resist approximately 16 tons. The analysis to determine the exact size and number of these bolts still must be carried out.

\section{Table 2. Forces Acting on Saddle (Newtons).}

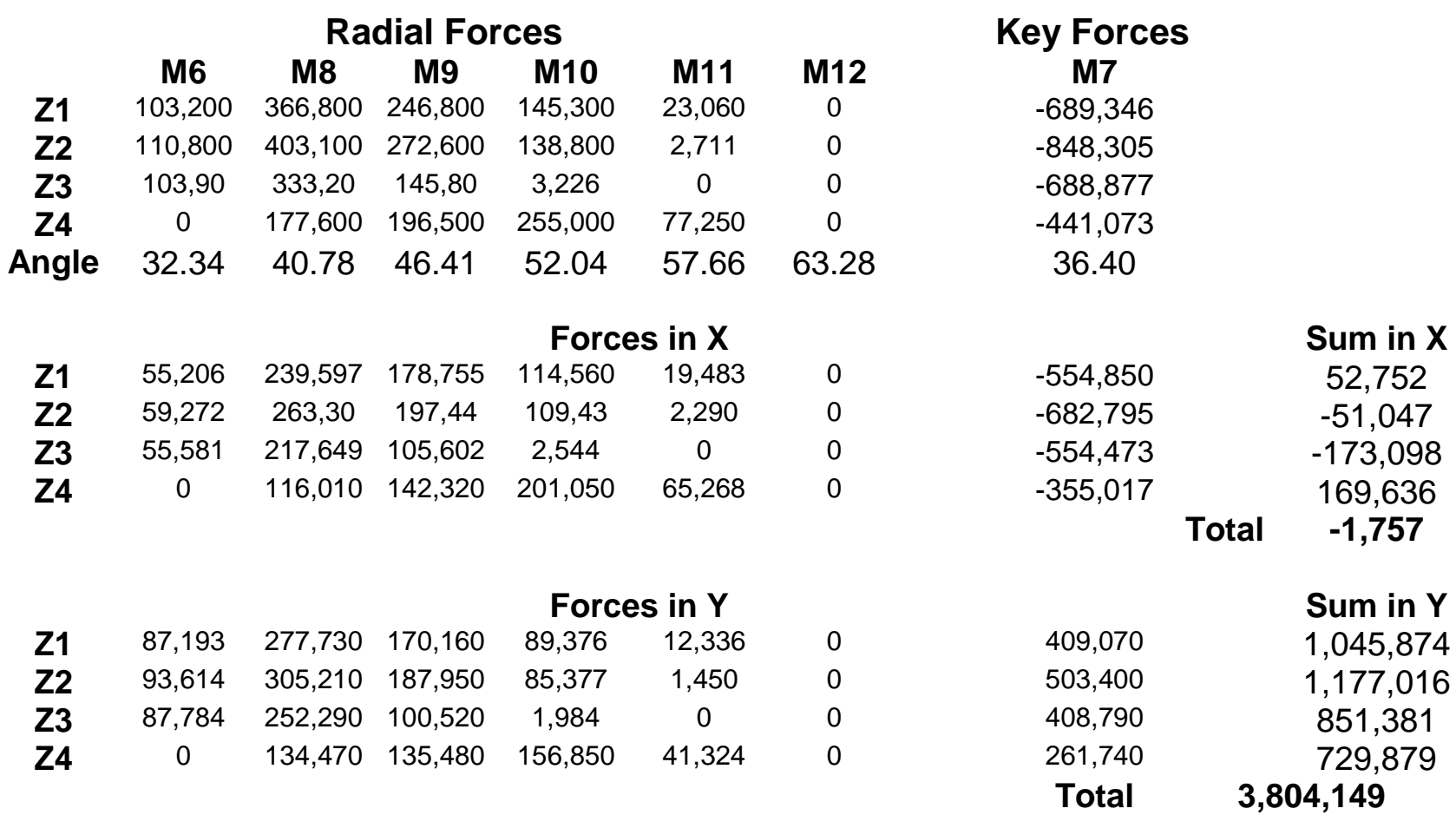

Note: There are two bolts per saddle - Z1 is the Front - Z4 is the Back of the EB. Note: M6 is the swivel bolt at the bottom of the saddle - M12 at the top.

The sum of the forces acting in the Y direction equals the weight of the EB and the Endcap cryostat as expected. By performing a static equilibrium analysis on each saddle, it is possible to determine the lateral position of each vertical force that is being applied to the support beam. Figure 15 shows the location of the vertical force acting from each saddle onto the support beam. Z5 is the vertical force being applied from the back cryostat support onto the support beam. By examining where these forces are being applied laterally to the support beam, it is possible to determine then the position for the location of the hydraulic jacks and air pads underneath the support beam. This analysis shows that these supports should be located $142 \mathrm{~mm}$ from the inside surface of the support beam. An examination of the reaction forces from the FE model itself confirms the location and distribution of the statically calculated forces. 


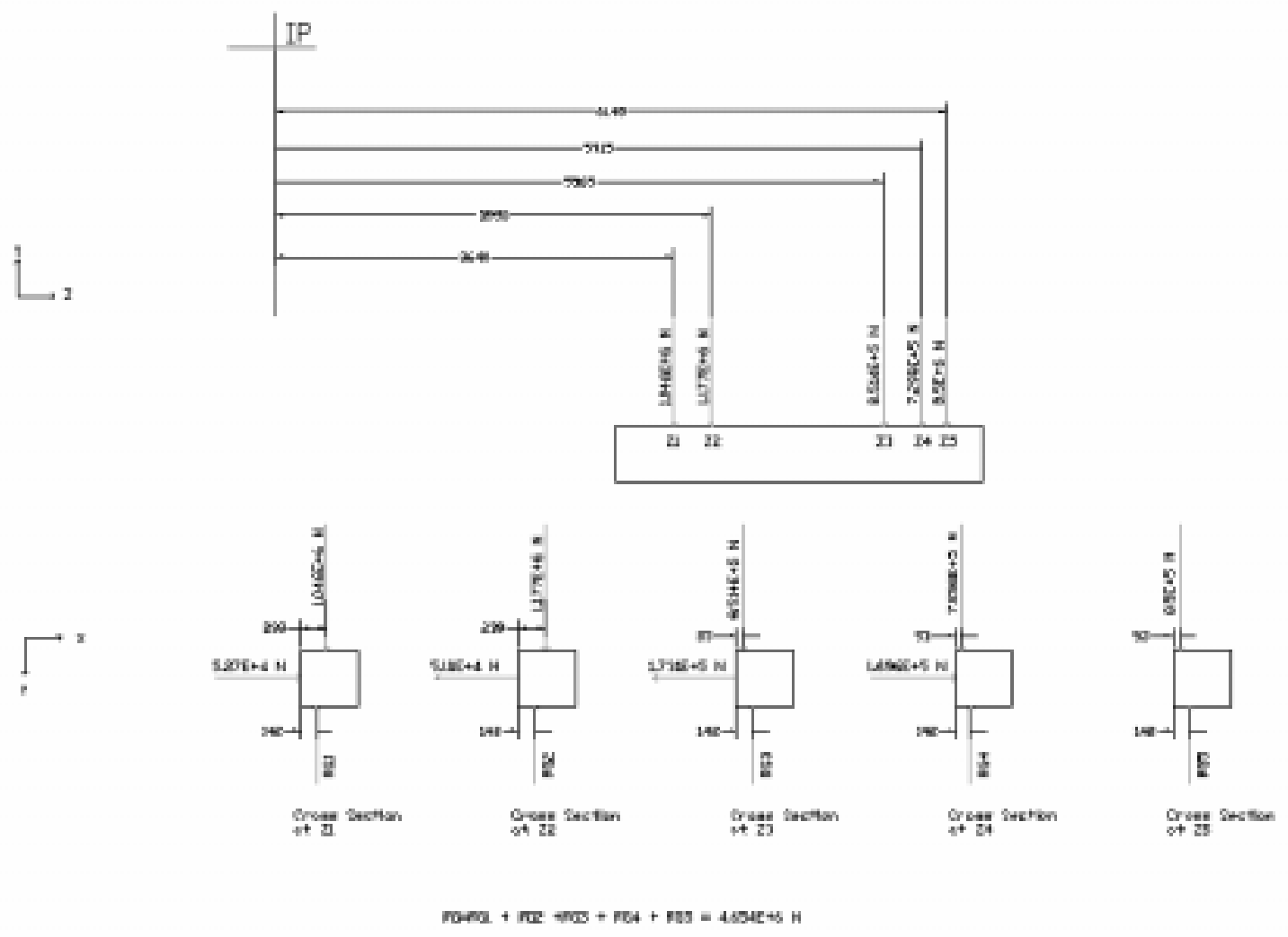

Figure 15. Reaction Forces Acting on the Support Beam.

\subsubsection{Saddle Deflections}

The saddle deflected considerably less than the earlier designs. Table 3 lists the deflections of the saddle at each of the swivel bolts. Figures 16-17 show the deflections of the FE model in the lateral and vertical directions. The design of the saddle has been driven by the requirement to minimize the deflections of the saddle. The deflections of the saddle are at a very minimal level and can be accommodated by the EB. It should be noted that the back saddle is subjected to a small twist due to the loading of the back cryostat support. 
Table 3. Deflection of the Saddle at the Swivel Bolts. (mm)

\begin{tabular}{ccccccc}
\multicolumn{2}{c}{ X Deflections } & & & & & \\
& M6 & M8 & M9 & M10 & M11 & M12 \\
Z1 & 0.10 & 0.04 & 0.18 & 0.41 & 0.69 & 1.00 \\
Z2 & 0.11 & 0.04 & 0.16 & 0.37 & 0.61 & 0.92 \\
Z3 & 0.08 & 0.03 & 0.00 & 0.05 & 0.17 & 0.30 \\
Z4 & 0.08 & -0.06 & -0.09 & -0.09 & 0.00 & 0.16
\end{tabular}

\begin{tabular}{ccccccc}
\multicolumn{2}{c}{ Y Deflections } & & & & & \\
& M6 & M8 & M9 & M10 & M11 & M12 \\
Z1 & -0.30 & -0.13 & -0.21 & -0.38 & -0.56 & -0.74 \\
Z2 & -0.29 & -0.11 & -0.18 & -0.32 & -0.48 & -0.66 \\
Z3 & -0.33 & -0.11 & -0.11 & -0.13 & -0.21 & -0.31 \\
Z4 & -0.37 & -0.16 & -0.10 & -0.09 & -0.14 & -0.23
\end{tabular}

\begin{tabular}{ccccccc}
\multicolumn{2}{c}{ Z Deflections } & & & & & \\
& M6 & M8 & M9 & M10 & M11 & M12 \\
Z1 & 0.00 & 0.00 & 0.00 & 0.00 & -0.08 & -0.12 \\
Z2 & 0.00 & 0.00 & 0.00 & -0.05 & -0.08 & -0.10 \\
Z3 & 0.00 & 0.07 & 0.15 & 0.24 & 0.30 & 0.33 \\
Z4 & 0.00 & 0.07 & 0.15 & 0.24 & 0.30 & 0.32
\end{tabular}

Note: $\mathrm{X}$ is in the lateral direction $-\mathrm{Y}$ is vertical $-\mathrm{Z}$ is in the beam direction. 


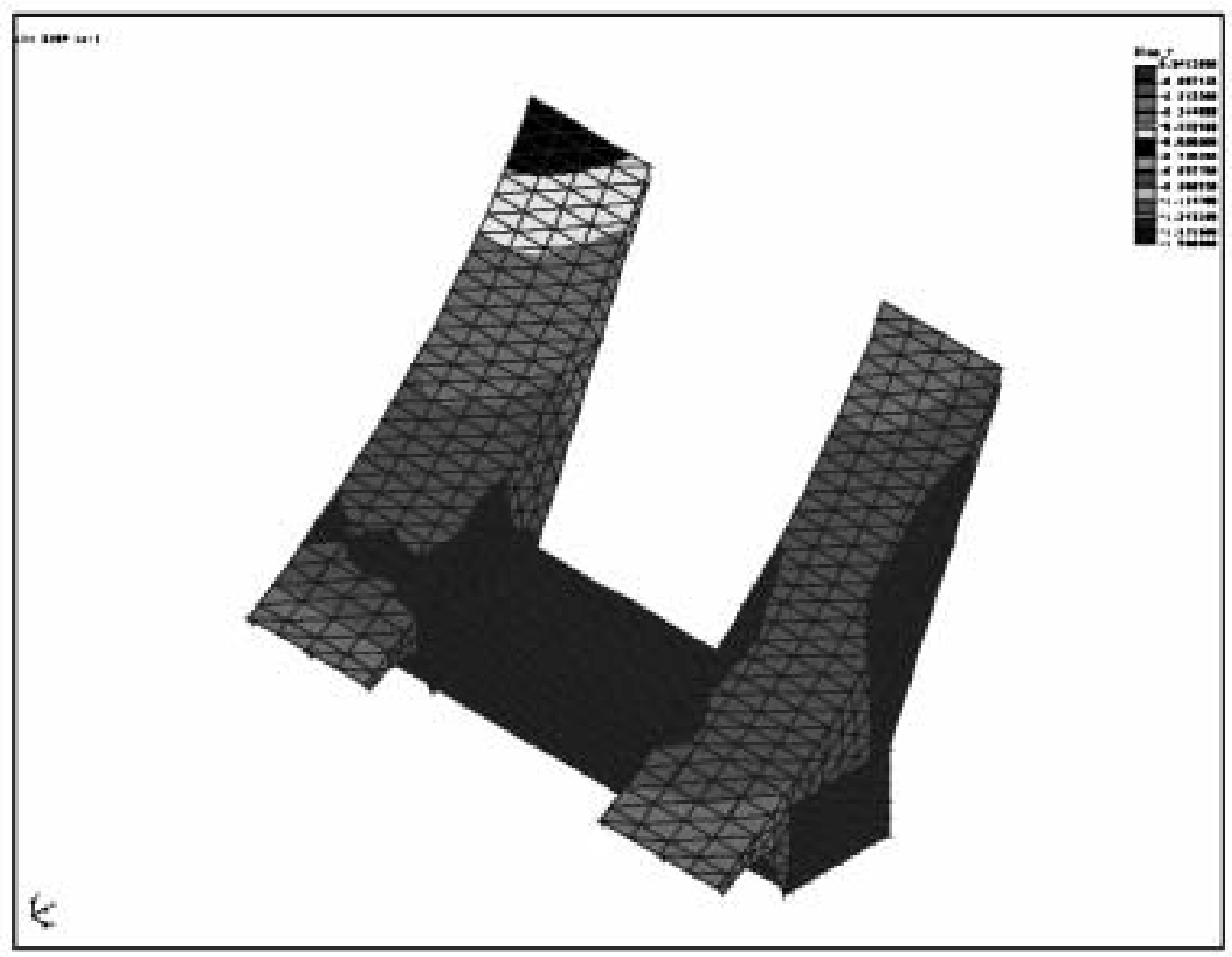

Figure 16. Saddle Deflections in the Vertical (Y) Direction. 


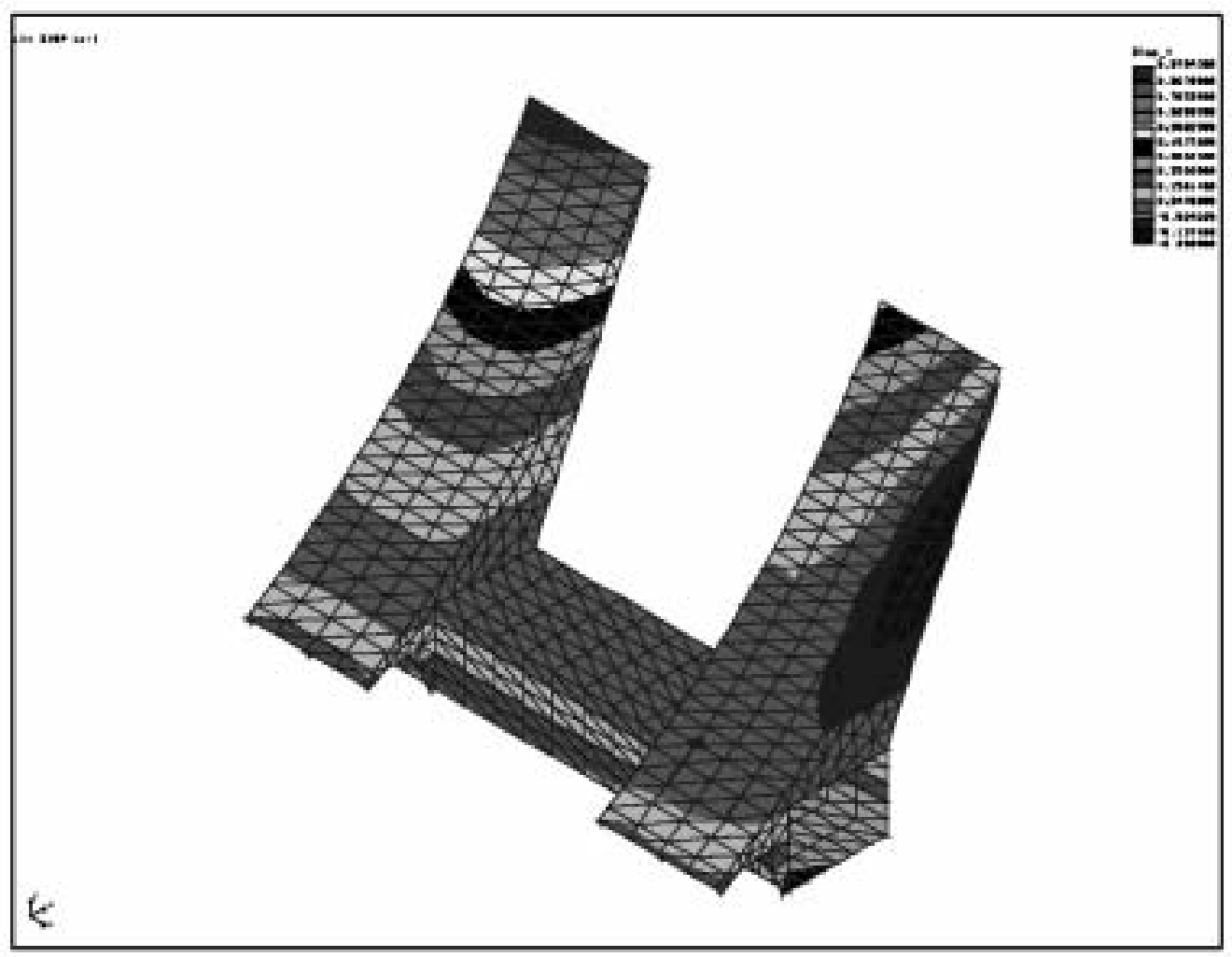

Figure 17. Saddle Deflections in the Horizontal (X) Direction.

\subsubsection{Saddle Stresses}

The stresses in the saddle are small due to the efforts to minimize the deflections of the saddle. The average stresses throughout the saddle and support beam are 25-50 Mpa. Stress concentrations occur at the edges of the gussets where they are welded to the support beam and along the key. However, these stresses only rise to the level of $120-130 \mathrm{Mpa}$, which is still within acceptable limits and are localized. Figure 18 shows the distribution of Von-Mises stress in the saddles and support beam.

This model of the saddle was constructed using plate elements. Therefore, it was not possible to accurately model the key way and the compressive stresses that will arise in that area. However, it is possible to take the values of the calculated load on the key in this region and calculate an approximate compressive stress on the key by dividing the key force by the key area. The key area is

$$
\mathrm{A}=20 \mathrm{~mm} \text { deep } \times 350 \mathrm{~mm} \text { long }=7,000 \mathrm{~mm}^{2} \text {. }
$$

The resulting compressive stress on the key way is: 


\begin{tabular}{|c|c|}
\hline Z position & $\begin{array}{c}\text { Key Bearing Stress } \\
\text { (N/mm2) }\end{array}$ \\
\hline Z1 & -106 \\
\hline$Z 2$ & -131 \\
\hline Z3 & -110 \\
\hline Z4 & -75 \\
\hline
\end{tabular}

The calculated bearing stresses on the key are within acceptable limits.

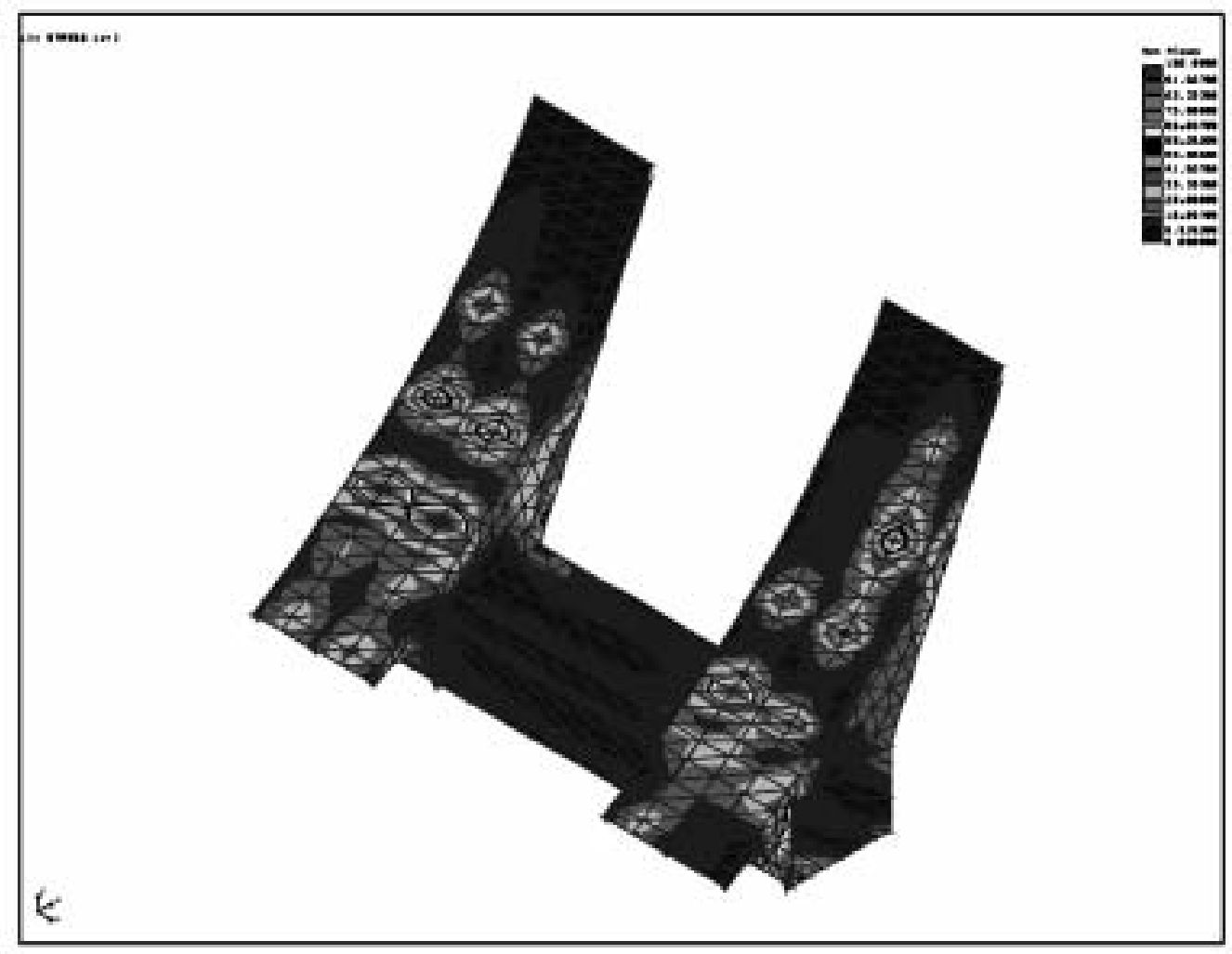

Figure 18. Von-Mises Stresses in Support Saddle.

\subsubsection{Detailed Model of the Saddle}

As a cross check, a more detailed model of the saddles, the support beam, and the back cryostat support was created out of solid elements. The forces calculated in the original FE model with the entire EB modeled were applied to the saddle and the support beam was restrained in only the vertical direction along its edges as in the previous model. This model is shown in Fig. 19. Because the design is still evolving, it was decided not to include the holes in the front plate. In addition, the $25 \mathrm{~mm}$ plates on each saddle were directly merged with nodes on the support beam rather than attempting at this time to model the bolted connection. Finally, the back cryostat support was modeled simply at a solid plate and the cut- 
outs for the drawers in the girder were ignored, the bolted connection between the cryostat support and the saddle was also simplified at this time by simply merging adjacent nodes. The purpose of this analysis was to investigate the performance of the saddle and not this plate. A more detailed analysis of this plate is described in Section 11 below.

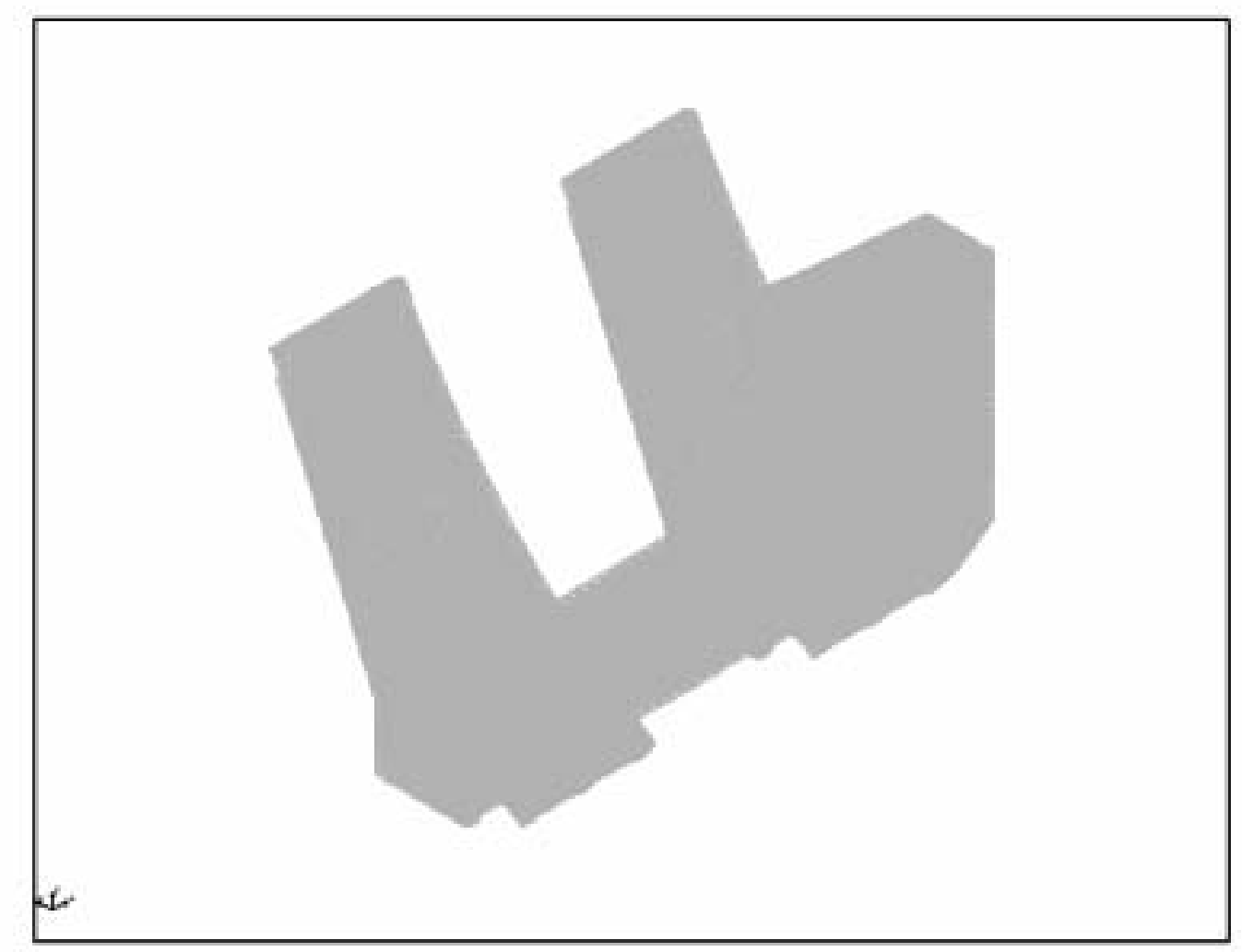

Figure 19a. Isometric View of Saddle Model. 


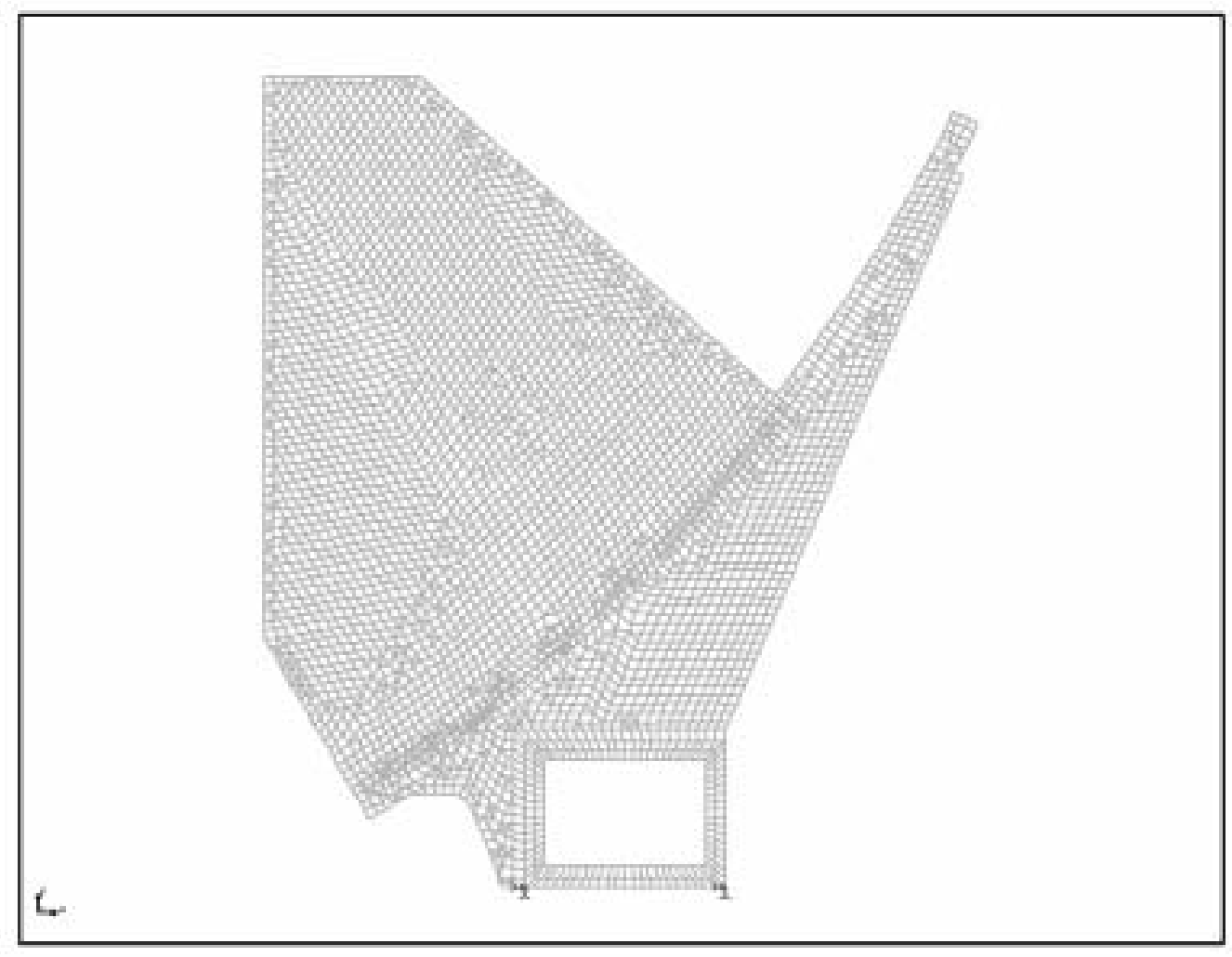

Figure 19b. End View of Saddle Model.

The stresses in this more-detailed model closely matched those in the early model of the entire EB structure. The average stresses remained around 25-50 Mpa with stress concentrations occurring at the points where the gussets are welded to the support plates and in the area of the keyway. These stress concentrations, however, remained in the range of $120-150 \mathrm{Mpa}$. The deflections of saddle in this model also remained similar. The scale of the deflections remained the same, however, there was a discrepancy of .2-.3mm between the results of the two models. Figures 20-22 show the stress and deflection patterns of this model.

Key-way Stresses

In the region of the Key-way, the bearing stresses were varied from 70-110 N/mm2, which is consistent with the stresses calculated from the simpler plate element model. These stresses are all within acceptable limits. 


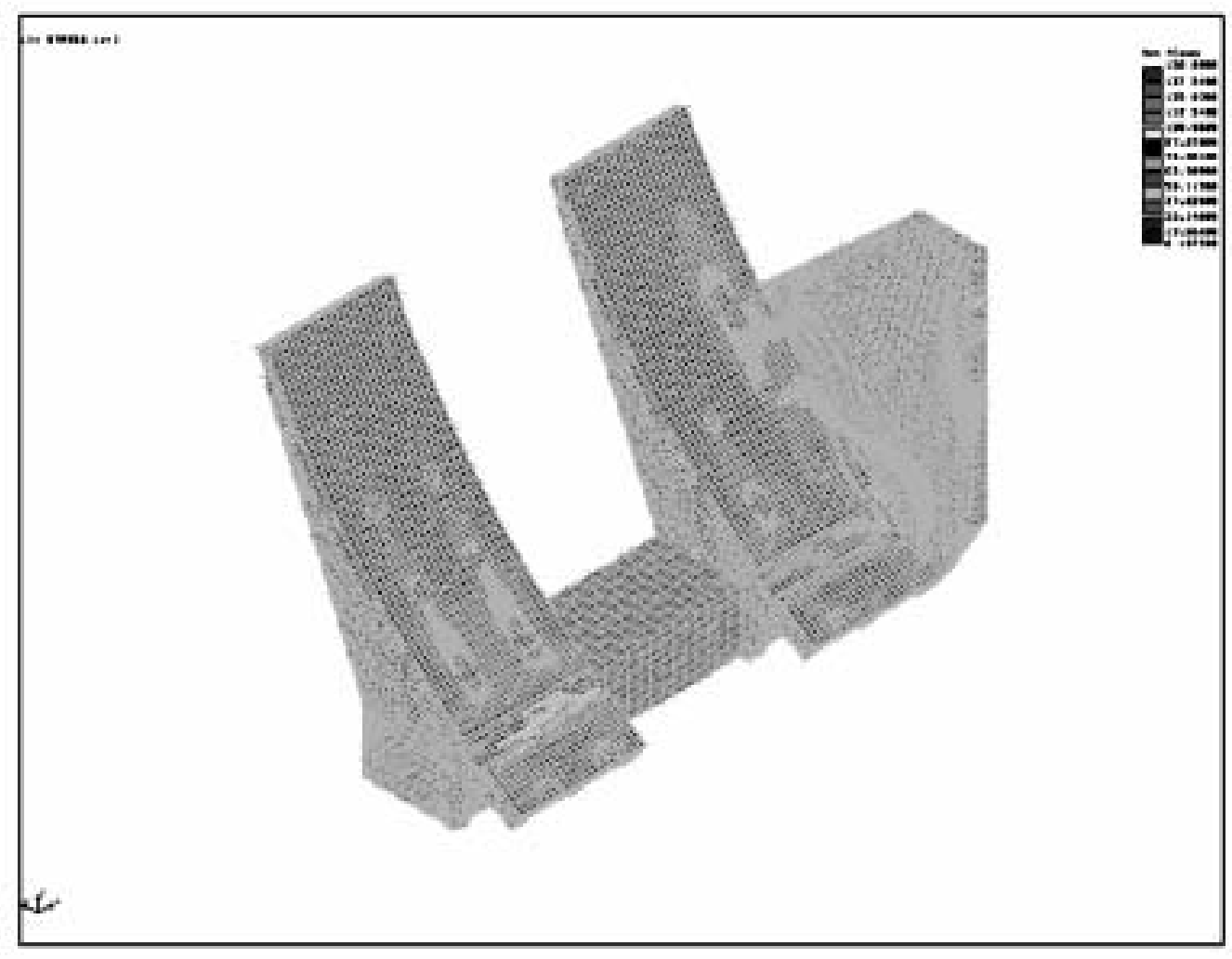

Figure 20. Von Mises Stresses. 


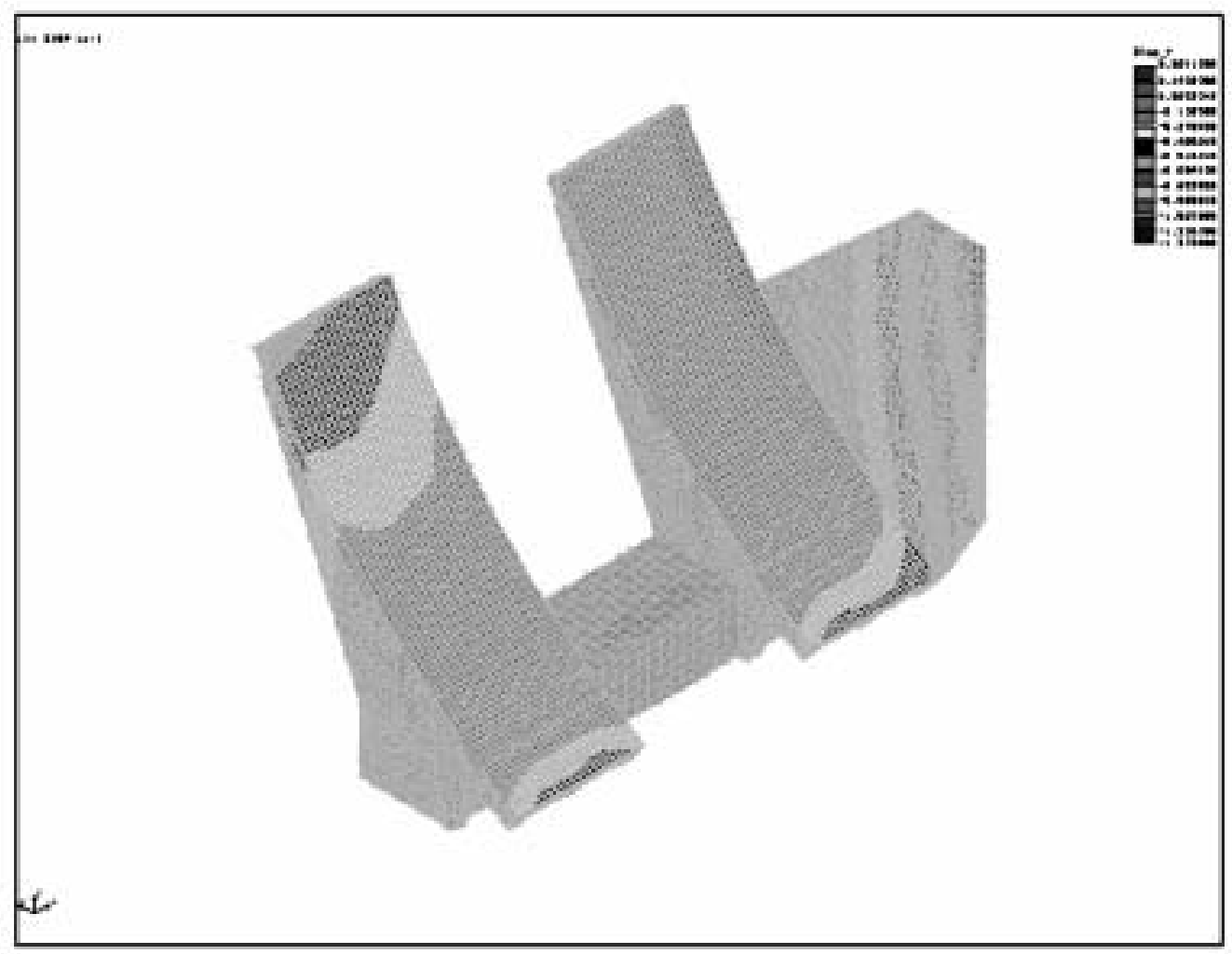

Figure 21. Vertical Deflections. 


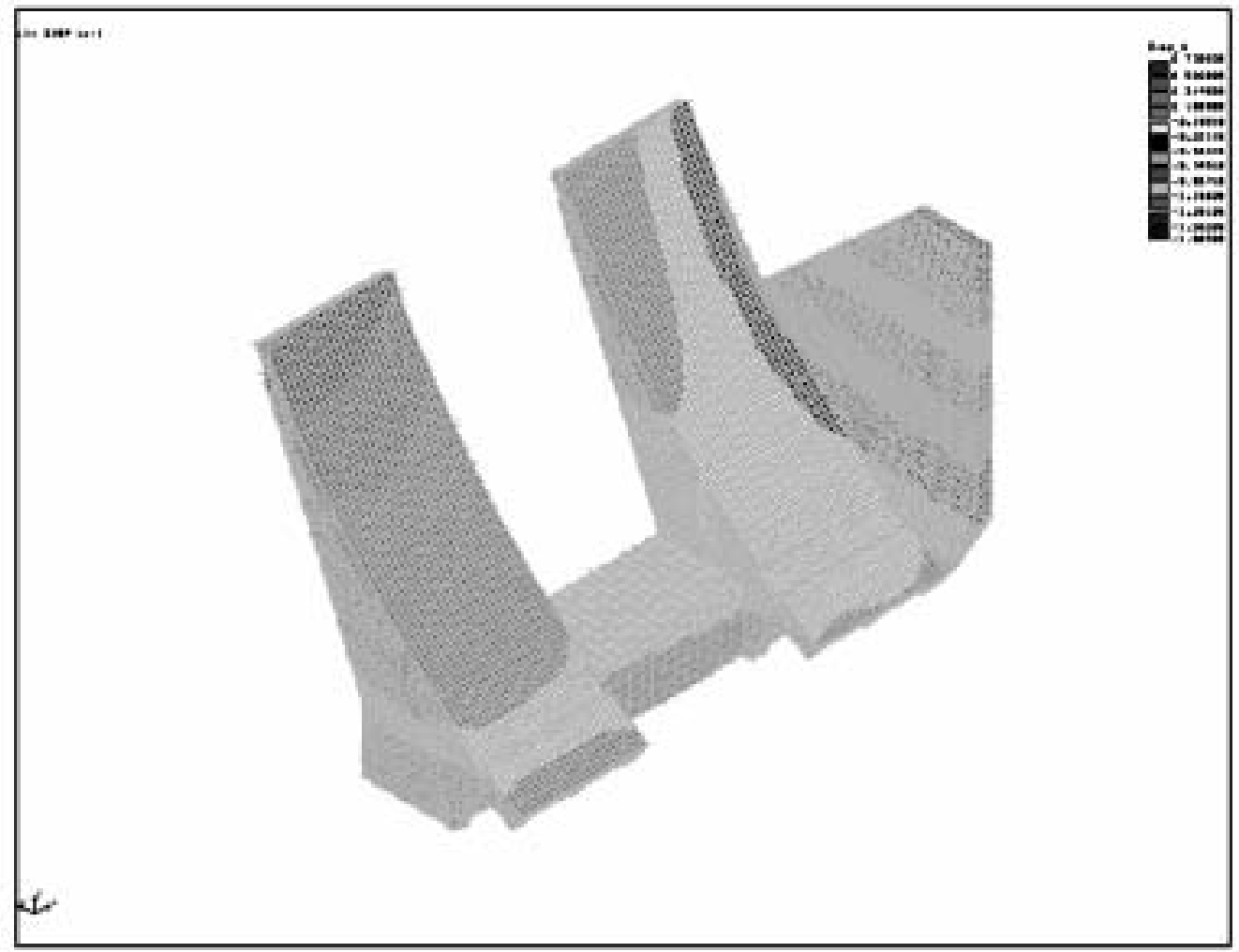

Figure 22. Horizontal Deflections. 


\subsubsection{Swivel Bolt Design}

The EB will be supported by the saddle structure by bearing on a series of swivel bolts. The swivel bolts are comprised of a commercially-purchased nut with a swiveling pad and a M24 grade 12.9 bolt. The M24 bolt is threaded into the front plate and the swivel nut/pad is then threaded onto the end of it (see Fig. 23). Load tests on five of these commercial bolts showed that they failed in compression at 18tons $(176,580 \mathrm{~N})$. The calculations up to this point had been based upon the application of one bolt at each position in Z. However, the calculations described above showed that the radial loads on these swivel bolts exceeded 18 tons (see Table 2). Therefore, it was decided that at each $\mathrm{Z}$ position, 2 swivel bolts will be placed, which doubles the maximum radial load that can be supported to 36 tons $(353,160 \mathrm{~N})$. Only the radial loads at the M8-Z2 and M8-Z3 positions exceed this load. At these two positions, special swivel bolts will have to be fabricated that are capable of supporting the loads at these points. Figure 24 shows a preliminary design of such a special swivel bolt.

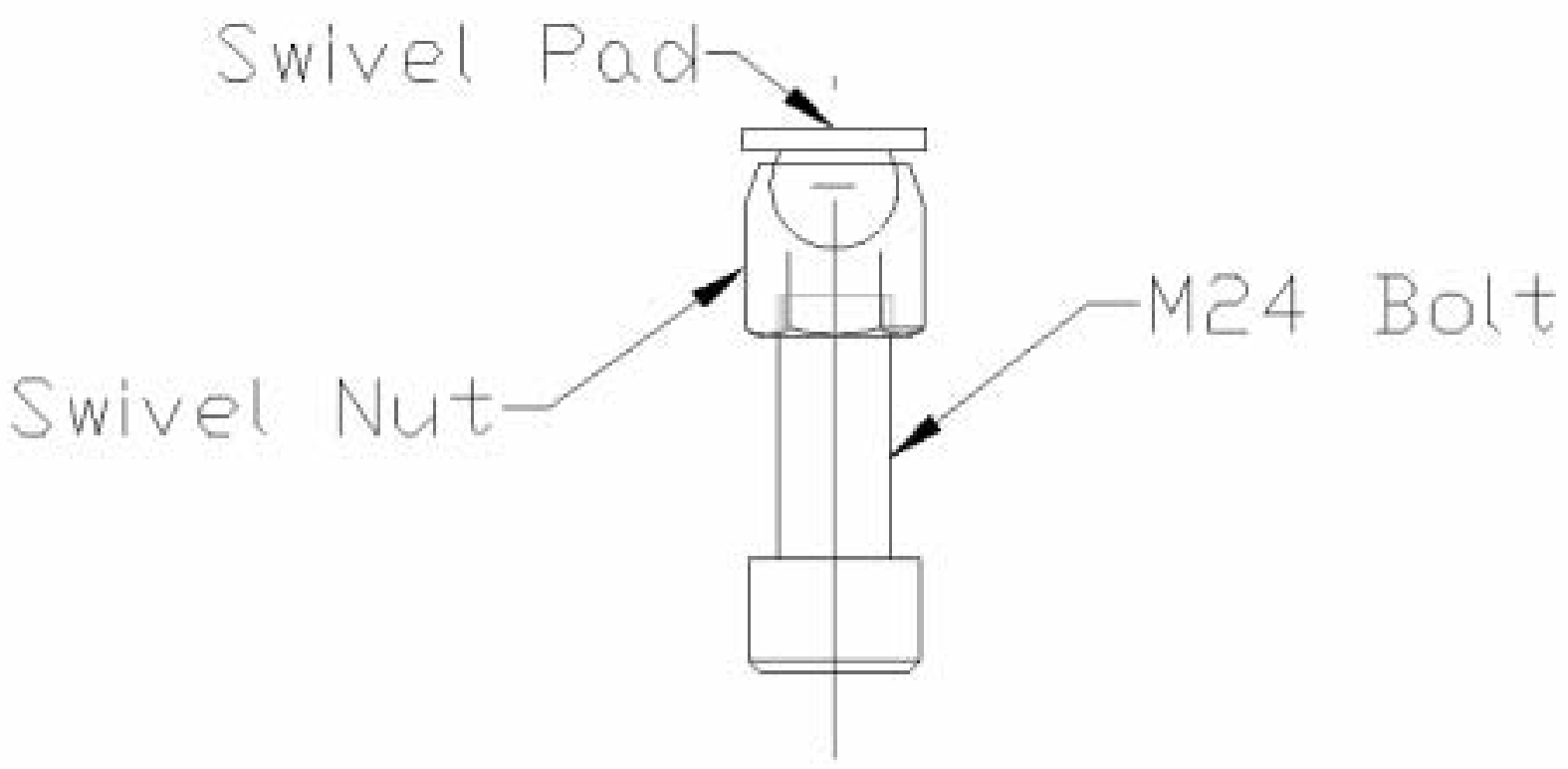

Figure 23. Commercial Swivel Bolt.

The threads in the front plate of the support saddle must also be able to withstand these radial loads without stripping out. Table 4 lists the stresses in the M24 grade 12.9 bolt and the shear stress of the internal in the saddle front plate at each position. All of the stresses are within acceptable levels. 
Table 4. Saddle Swivel Bolts Stress on Bolts and Threads

\begin{tabular}{|c|c|c|c|c|c|c|}
\hline \multicolumn{7}{|c|}{ Swivel Bolt Thread Shear Stresses } \\
\hline & M6 & M8 & M9 & M10 & M11 & M12 \\
\hline Z1 & 58.93 & 191.28 & 125.30 & 71.64 & 10.09 & 0.00 \\
\hline $\mathbf{Z 2}$ & 63.30 & 216.55 & 144.38 & 73.03 & 2.30 & 0.00 \\
\hline Z3 & 52.22 & 175.55 & 86.98 & 12.99 & 0.00 & 0.00 \\
\hline Z4 & 1.07 & 97.20 & 102.04 & 126.74 & 42.62 & 0.00 \\
\hline \multicolumn{7}{|c|}{ Swivel Bolt Normal Stresses } \\
\hline & M6 & M8 & M9 & M10 & M11 & M12 \\
\hline $\mathbf{Z 1}$ & 15.11 & 49.06 & 32.14 & 18.37 & 2.59 & 0.00 \\
\hline Z2 & 16.23 & 55.54 & 37.03 & 18.73 & 0.59 & 0.00 \\
\hline $\mathrm{Z3}$ & 13.39 & 45.02 & 22.31 & 3.33 & 0.00 & 0.00 \\
\hline Z4 & 0.27 & 24.93 & 26.17 & 32.50 & 10.93 & 0.00 \\
\hline \multicolumn{7}{|c|}{ Internal Thread Shear Stresses } \\
\hline & M6 & M8 & M9 & M10 & M11 & M12 \\
\hline Z1 & 15.11 & 49.06 & 32.14 & 18.37 & 2.59 & 0.00 \\
\hline $\mathrm{Z2}$ & 16.23 & 55.54 & 37.03 & 18.73 & 0.59 & 0.00 \\
\hline $\mathrm{Z3}$ & 13.39 & 45.02 & 22.31 & 3.33 & 0.00 & 0.00 \\
\hline Z4 & 0.27 & 24.93 & 26.17 & 32.50 & 10.93 & 0.00 \\
\hline
\end{tabular}




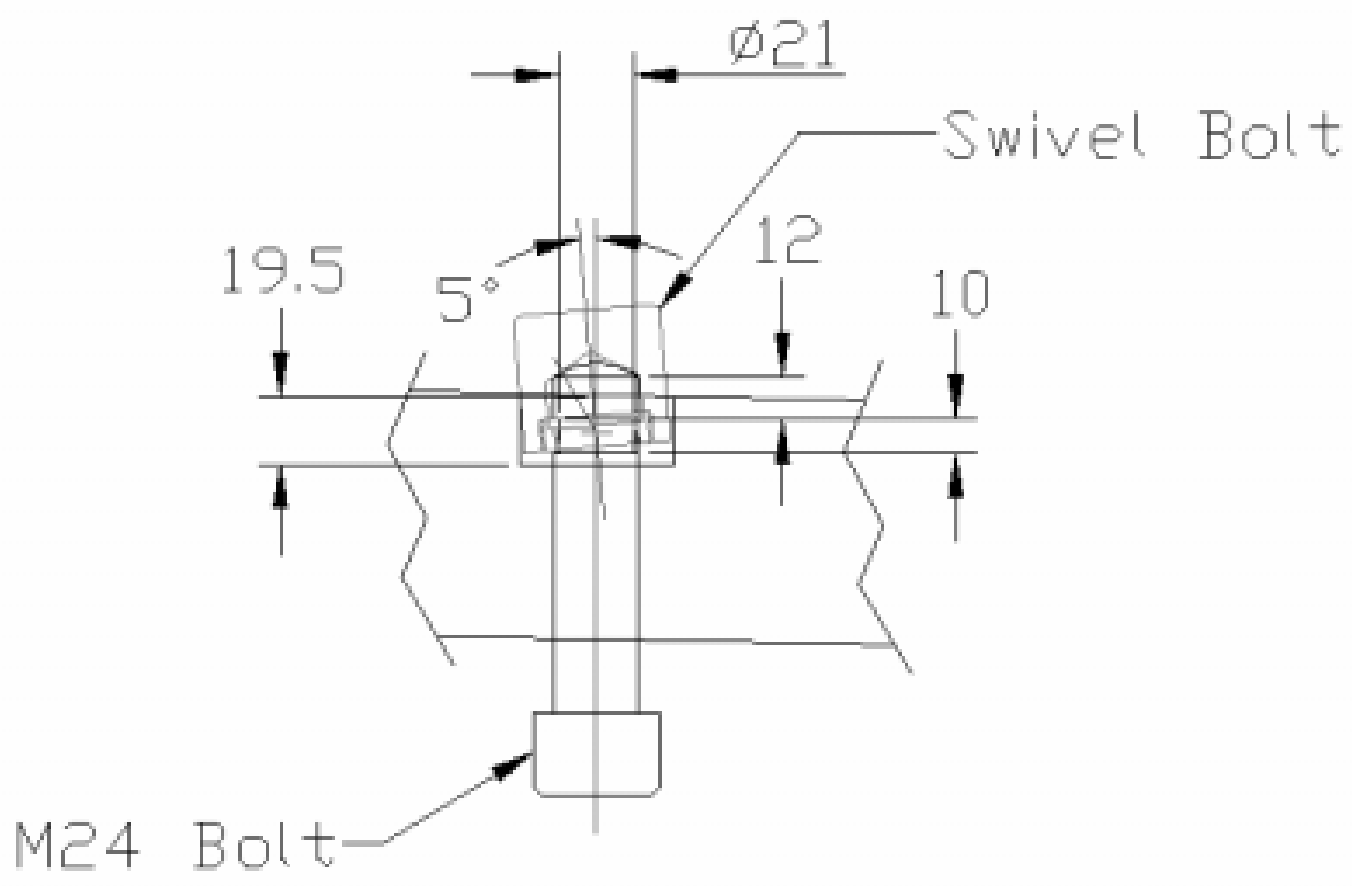

Figure 24. Special Swivel Bolt for High Loads.

\subsection{Seismic Load Conditions}

In Section 2.1 of this paper, the loading on the EB from the seismic conditions were described. A seismic load of $.15 \mathrm{~g}$ was applied to the FE model in the $\mathrm{X}, \mathrm{Y}$, and $\mathrm{Z}$ directions. The loads from the cryostat in the seismic condition were calculated and applied at the appropriate load points on the EB (see Fig. 5a). It was assumed that the front cryostat supports could only support loads from the cryostat in the vertical (Y) direction, whereas the back cryostat supports on the EB could support loads in the X, Y, and Z directions.

In order to isolate the forces from the cryostat in the horizontal plane and to transfer them directly back to the saddle, it was necessary to significantly stiffen the back cryostat support plate. This plate has little stiffness in the $\mathrm{Z}$ direction and, therefore, deflected significantly. Such large $\mathrm{Z}$ deflections would cause the back cryostat support to make contact with the EB. If the back cryostat support contacts the EB, then loads in the $\mathrm{Z}$ direction will be transferred to the modules. A basic design criterion was that no loads should be transferred to the EB modules from the cryostat in either the static or seismic loading conditions. Details of how the back cryostat support was stiffened and the resulting loads can be found in Section 11 below.

The forces between modules changed significantly under the seismic conditions. A table and graph of the P1, P2, and Pt forces between modules can be found in Appendix 3. The values of these forces are still within the design loads for all of the connections within the EB and present no problems. 


\subsubsection{Saddle Forces in Seismic Conditions}

The first step in examining the results for the support saddle was to extract from the FE model the forces acting on the saddles from the EB. These forces are listed in Table 5. The loads on the saddle are all in the radial direction except for the forces acting on the key, which are in the circumferential direction.

In Table 5, the radial and key forces are resolved into their X (horizontal) and Y (vertical) components as a first step in order to accomplish these goals. Several things should be noted. First, the force in the $\mathrm{X}$ direction no longer sums to zero for each saddle (Z1 and Z2 for the front saddle, Z3 and Z4 for the back saddle). The total $\mathrm{X}$ and $\mathrm{Z}$ direction force equals $15 \%$ of the total weight of the cryostat and EB respectively as expected. The interface between the saddle support beam and the rails must be able to support a horizontal force in the $\mathrm{X}$ and $\mathrm{Z}$ direction of this magnitude. In addition, these forces are used to size the bolts and welds of the connection between the saddle and the support beam.

\section{Table 5. Forces Acting on Saddle. (Newtons)}

\begin{tabular}{|c|c|c|c|c|c|c|c|c|c|}
\hline \multicolumn{10}{|c|}{ Left Side of EB } \\
\hline \multicolumn{7}{|c|}{ Radial Forces } & \multicolumn{2}{|c|}{ Key Forces } & \\
\hline & M6 & M8 & M9 & M10 & M11 & M12 & M7 & & \\
\hline $\mathbf{Z 1}$ & 53,460 & 311,900 & 240,900 & 137,000 & 12,390 & 0 & $-522,112$ & & \\
\hline $\mathrm{Z2}$ & 82,310 & 389,900 & 305,500 & 168,200 & 22,750 & 0 & $-865,034$ & & \\
\hline $\mathbf{Z 3}$ & 136,200 & 555,000 & 377,400 & 204,500 & 12,680 & 0 & $-1,218,820$ & & \\
\hline $\mathbf{Z 4}$ & 230,600 & 313,800 & 408,700 & 289,600 & 86,280 & 0 & $-1,002,300$ & & \\
\hline Angle & 32.34 & 40.78 & 46.41 & 52.04 & 57.66 & 63.28 & 36.40 & & \\
\hline \multicolumn{9}{|c|}{ Forces in X } & Sum in $X$ \\
\hline Z1 & 28,598 & 203,736 & 174,482 & 108,016 & 10,468 & 0 & $-420,245$ & & 105,056 \\
\hline $\mathbf{Z 2}$ & 44,031 & 254,686 & 221,271 & 132,616 & 19,221 & 0 & $-696,261$ & & $-24,435$ \\
\hline $\mathbf{Z 3}$ & 72,859 & 362,531 & 273,348 & 161,236 & 10,713 & 0 & $-981,021$ & & $-100,333$ \\
\hline \multirow[t]{3}{*}{$\mathbf{Z 4}$} & 123,358 & 204,977 & 296,018 & 228,332 & 72,897 & 0 & $-806,745$ & & 118,837 \\
\hline & & & & & & & & Total & 99,125 \\
\hline \multirow{2}{*}{\multicolumn{9}{|c|}{ Forces in $Y$}} & \\
\hline & & & & & & & & & Sum in $Y$ \\
\hline $\mathbf{Z 1}$ & 45,168 & 236,164 & 166,099 & 84,270 & 6,628 & 0 & 309,831 & & 848,160 \\
\hline $\mathbf{Z 2}$ & 69,543 & 295,224 & 210,640 & 103,462 & 12,170 & 0 & 513,328 & & $1,204,366$ \\
\hline $\mathbf{Z 3}$ & 115,074 & 420,234 & 260,215 & 125,790 & 6,783 & 0 & 723,271 & & $1,651,366$ \\
\hline \multirow[t]{3}{*}{$\mathbf{Z 4}$} & 194,831 & 237,602 & 281,796 & 178,136 & 46,155 & 0 & 594,784 & & $1,533,304$ \\
\hline & & & & & & & & Total & $5,237,196$ \\
\hline & & & & & & & & & \\
\hline \multicolumn{10}{|c|}{ Right Side of EB } \\
\hline \multirow{2}{*}{\multicolumn{7}{|c|}{ Radial Forces }} & \multicolumn{2}{|l|}{ Key Forces } & \\
\hline & & & & & & & M7 & & \\
\hline $\mathbf{Z 1}$ & 196,300 & 187,600 & 107,400 & 6 & 0 & 0 & $-493,400$ & & \\
\hline $\mathbf{Z 2}$ & 185,300 & 131,800 & 64,350 & 0 & 0 & 0 & $-900,919$ & & \\
\hline $\mathbf{Z 3}$ & 307,500 & 82,630 & 81,880 & 447 & 0 & 0 & $-1,256,700$ & & \\
\hline $\mathbf{Z 4}$ & 125,000 & 620,000 & 358,200 & 96,700 & 0 & 0 & $-948,000$ & & \\
\hline Angle & 32.34 & 40.78 & 46.41 & 52.04 & 57.66 & 63.28 & 36.40 & & \\
\hline \multicolumn{8}{|c|}{ Forces in X } & & Sum in $X$ \\
\hline Z1 & 105.009 & 122.542 & 77.789 & 5 & 0 & 0 & -397.135 & & $-91,789$ \\
\hline $\mathbf{Z 2}$ & 99,125 & 86,093 & 46,608 & 0 & 0 & 0 & $-725,144$ & & $-493,318$ \\
\hline $\mathbf{Z 3}$ & 164,495 & 53,485 & 324 & 0 & 0 & 0 & $-1,011,510$ & & $-793,206$ \\
\hline \multirow[t]{2}{*}{$\mathbf{Z 4}$} & 66,868 & 404,990 & 259,441 & 76,242 & 0 & 0 & $-763,039$ & & 44,502 \\
\hline & & & & & & & & Total & $-1,333,812$ \\
\hline
\end{tabular}




\begin{tabular}{|c|c|c|c|c|c|c|c|c|c|}
\hline \multicolumn{8}{|c|}{ Forces in $Y$} & & Sum in $Y$ \\
\hline Z1 & 165,852 & 142,046 & 74,052 & 4 & 0 & 0 & 292,793 & & 674,746 \\
\hline $\mathbf{Z 2}$ & 156,558 & 99,796 & 44,369 & 0 & 0 & 0 & 534,622 & & 835,345 \\
\hline Z3 & 259,803 & 61,998 & 308 & 0 & 0 & 0 & 745,750 & & $1,067,859$ \\
\hline \multirow[t]{2}{*}{$\mathbf{Z 4}$} & 105,611 & 469,450 & 246,976 & 59,481 & 0 & 0 & 562,561 & & $1,444,080$ \\
\hline & & & & & & & & Total & $4,022,030$ \\
\hline
\end{tabular}

The sum of the forces acting in the $\mathrm{Y}$ direction equals $115 \%$ of the weight of the $\mathrm{EB}$ and the Endcap cryostat as expected.

The support beam was restrained at its outer edges. An examination of the reaction forces at the support beam shows that the vertical reaction force on the left support saddle is centered at $2892.5 \mathrm{~mm}$ from the beam line and on the right saddle it is centered at $2605.7 \mathrm{~mm}$. This indicates, as the earlier calculations of the static case did as well, that the support saddle must be supported across its entire width. Appendix 4 shows how the $\mathrm{X}, \mathrm{Y}$ and $\mathrm{Z}$ reaction forces vary along the length of the support beam.

\subsubsection{Deflections on Seismic Conditions}

Table 6 lists the deflections of the saddle at each of the swivel bolts. The design of the saddle has been driven by the requirement to minimize the deflections of the saddle. The deflections of the saddle are at a very minimal level and can be accommodated by the EB. It should be noted that the back saddle is subjected to a small twist due to the loading of the back cryostat support. Figures 25 and 26 show the deflections for 
Table 6. Deflection of the Saddle at the Swivel Bolts (mm)

\begin{tabular}{|c|c|c|c|c|c|c|}
\hline \multicolumn{7}{|c|}{ Left Side of EB } \\
\hline \multicolumn{7}{|c|}{ X Deflections } \\
\hline & M6 & M8 & M9 & M10 & M11 & M12 \\
\hline Z1 & -0.16 & -0.18 & -0.04 & 0.19 & 0.45 & 0.76 \\
\hline $\mathbf{Z 2}$ & -0.18 & -0.16 & -0.01 & 0.24 & 0.48 & 0.80 \\
\hline Z3 & -0.08 & -0.16 & -0.02 & 0.23 & 0.55 & 0.96 \\
\hline $\mathbf{Z 4}$ & -0.08 & -0.15 & -0.09 & 0.14 & 0.49 & 0.91 \\
\hline \multicolumn{7}{|c|}{ Y Deflections } \\
\hline & M6 & M8 & M9 & M10 & M11 & M12 \\
\hline Z1 & -0.21 & -0.11 & -0.20 & -0.36 & -0.54 & -0.72 \\
\hline $\mathbf{Z 2}$ & -0.23 & -0.11 & -0.18 & -0.35 & -0.53 & -0.71 \\
\hline Z3 & -0.38 & -0.17 & -0.22 & -0.39 & -0.60 & -0.83 \\
\hline $\mathbf{Z 4}$ & -0.38 & -0.25 & -0.27 & -0.45 & -0.68 & -0.92 \\
\hline \multicolumn{7}{|c|}{ Z Deflections } \\
\hline & M6 & M8 & M9 & M10 & M11 & M12 \\
\hline $\mathbf{Z 1}$ & 0.06 & 0.03 & 0.00 & -0.04 & -0.08 & -0.11 \\
\hline $\mathbf{Z 2}$ & 0.06 & -0.01 & -0.01 & -0.04 & -0.08 & -0.12 \\
\hline Z3 & 0.12 & 0.19 & 0.30 & 0.44 & 0.57 & 0.70 \\
\hline $\mathbf{Z 4}$ & 0.13 & 0.18 & 0.29 & 0.44 & 0.57 & 0.70 \\
\hline \multicolumn{7}{|c|}{ Right Side of EB } \\
\hline \multicolumn{7}{|c|}{ X Deflections } \\
\hline & M6 & M8 & M9 & M10 & M11 & M12 \\
\hline $\mathbf{Z 1}$ & 0.73 & 1.05 & 1.00 & 0.94 & 0.89 & 0.84 \\
\hline $\mathbf{Z 2}$ & 0.70 & 1.04 & 1.00 & 0.96 & 0.92 & 0.86 \\
\hline $\mathbf{Z 3}$ & 0.82 & 1.20 & 1.25 & 1.25 & 1.19 & 1.06 \\
\hline $\mathbf{Z 4}$ & 0.89 & 1.27 & 1.50 & 1.40 & 1.30 & 1.19 \\
\hline \multicolumn{7}{|c|}{ Y Deflections } \\
\hline & M6 & M8 & M9 & M10 & M11 & M12 \\
\hline $\mathbf{Z 1}$ & -0.63 & -0.11 & -0.11 & -0.15 & -0.18 & -0.21 \\
\hline $\mathbf{Z 2}$ & -0.65 & -0.09 & -0.08 & -0.11 & -0.13 & -0.16 \\
\hline Z3 & -0.75 & -0.14 & -0.04 & -0.01 & -0.05 & -1.24 \\
\hline $\mathbf{Z 4}$ & -0.75 & -0.25 & 0.00 & -0.04 & -0.12 & -0.20 \\
\hline \multicolumn{7}{|c|}{ Z Deflections } \\
\hline & M6 & M8 & M9 & M10 & M11 & M12 \\
\hline $\mathbf{Z 1}$ & 0.09 & 0.06 & 0.03 & 0.00 & -0.02 & -0.05 \\
\hline $\mathbf{Z 2}$ & 0.09 & 0.05 & 0.02 & 0.00 & -0.02 & -0.05 \\
\hline Z3 & 0.11 & 0.29 & 0.50 & 0.71 & 0.89 & 1.06 \\
\hline $\mathbf{Z 4}$ & 0.12 & 0.30 & 0.50 & 0.70 & 0.90 & 1.06 \\
\hline
\end{tabular}




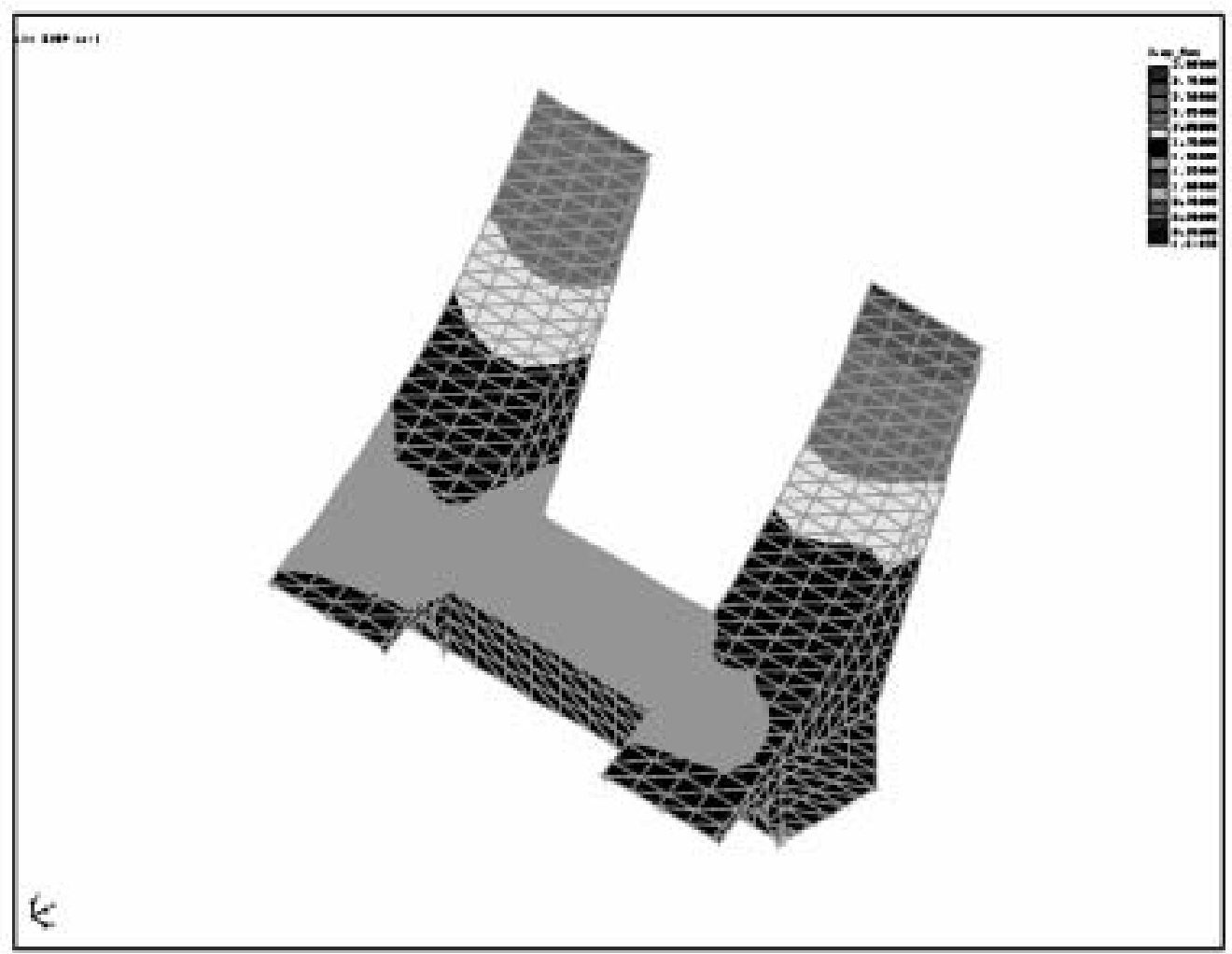

Figure 25. Composite Deflections of Left Saddle. 


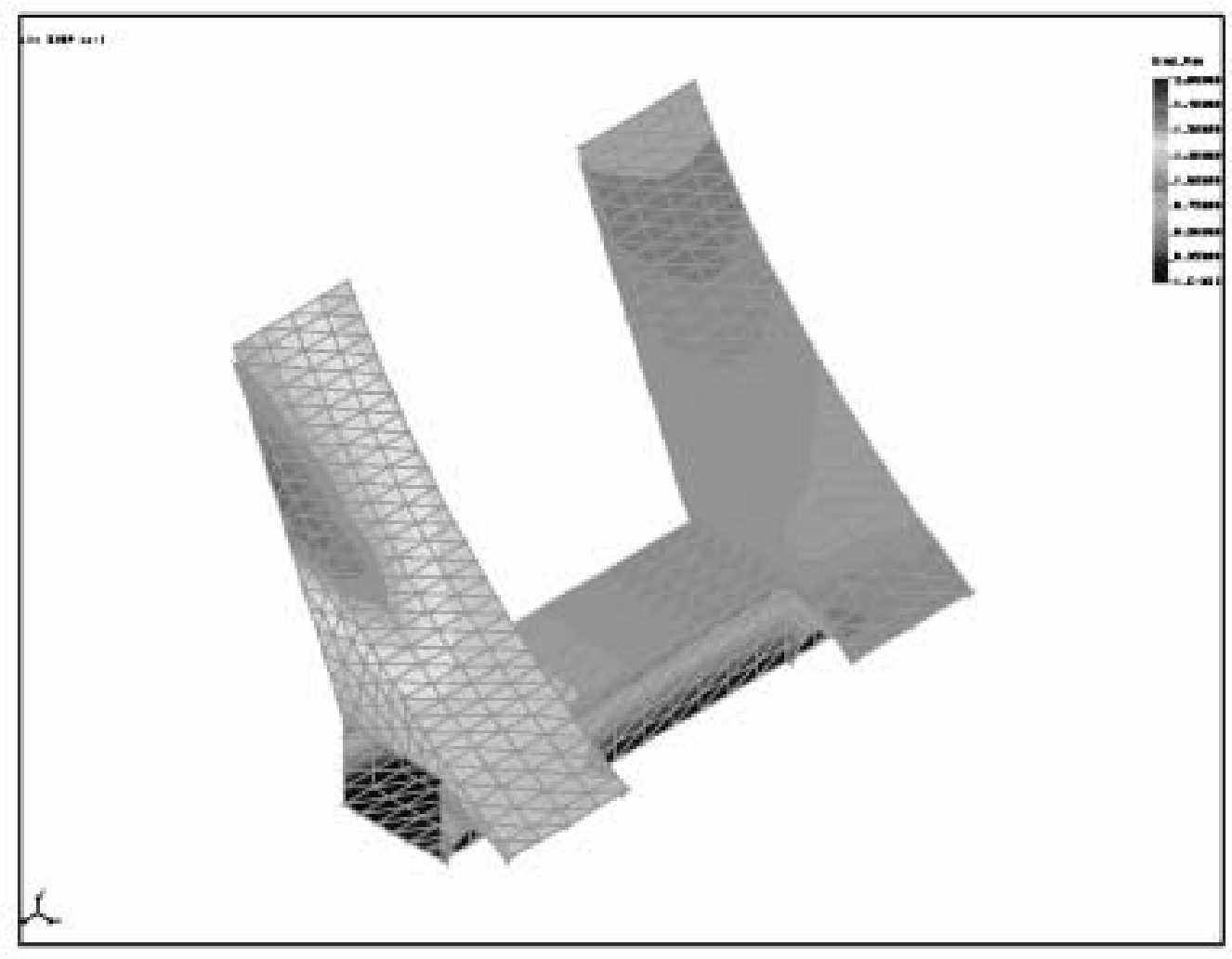

Figure 26. Composite Deflection of Right Saddle.

\subsubsection{Saddle Stresses in Seismic Conditions}

The stresses in the saddle were examined in the full EB model where the saddle and support beam were modeled using shell elements. In this FE model, the average saddle stresses remained low even under the seismic conditions. The general stresses were below $80 \mathrm{~N} / \mathrm{mm} 2$, however, at the point where the stiffening beam on the back cryostat support was attached to the saddle gusset, the stresses rose to $220 \mathrm{~N} / \mathrm{mm} 2$. This stress concentration is due to the location of the stiffening beam on the back cryostat support. In the FE model, a series of beam elements have been included, which have been used to stiffen the back cryostat support plate and the stress concentration is occurring at the point where this line of beam elements is attached to the saddle. In reality, the loads from this beam would be distributed over a much greater area. The Von Mises stresses in the saddles are shown in Figs. 27 and 28. 


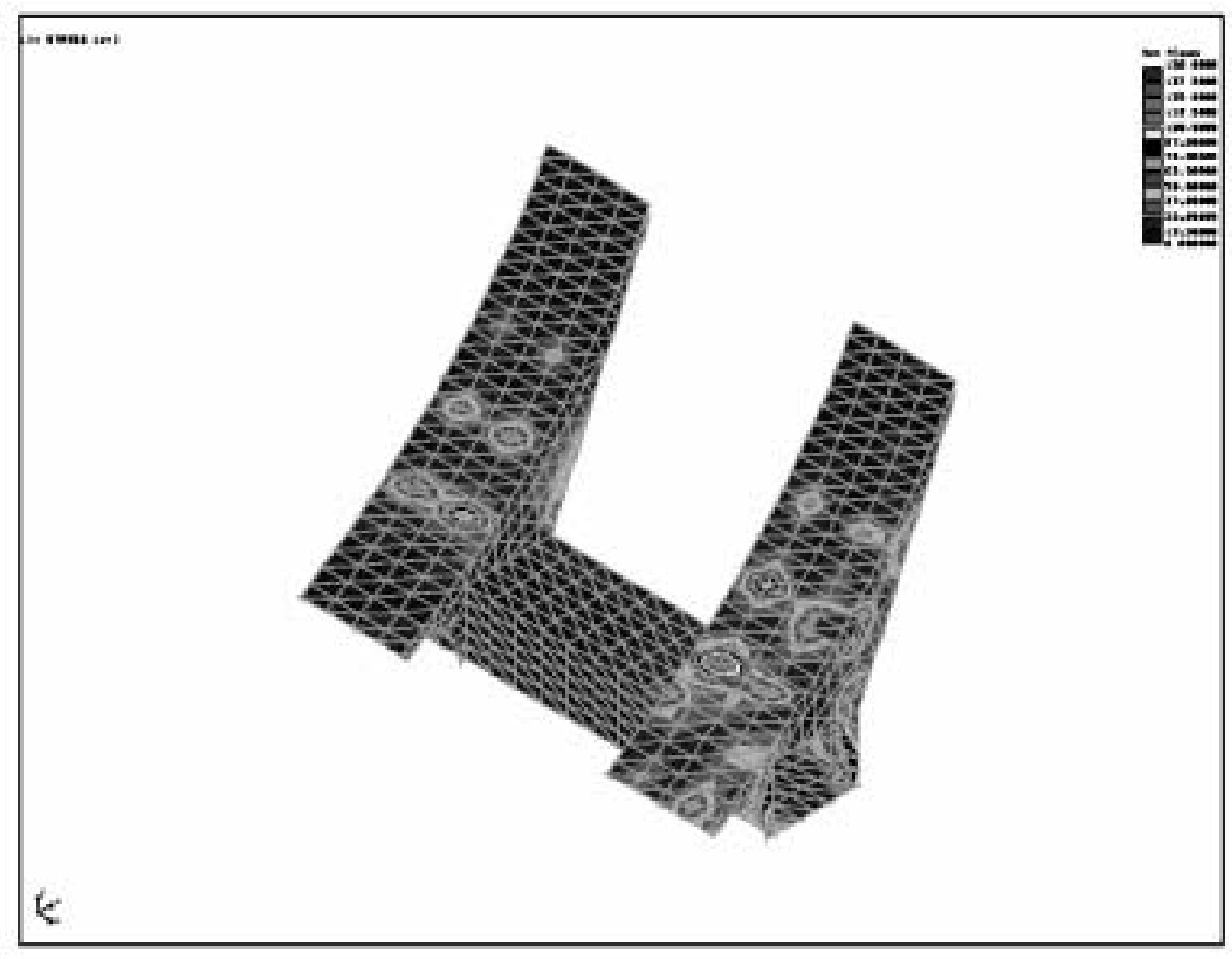

Figure 27. Von Mises Stresses in Left Saddle. 


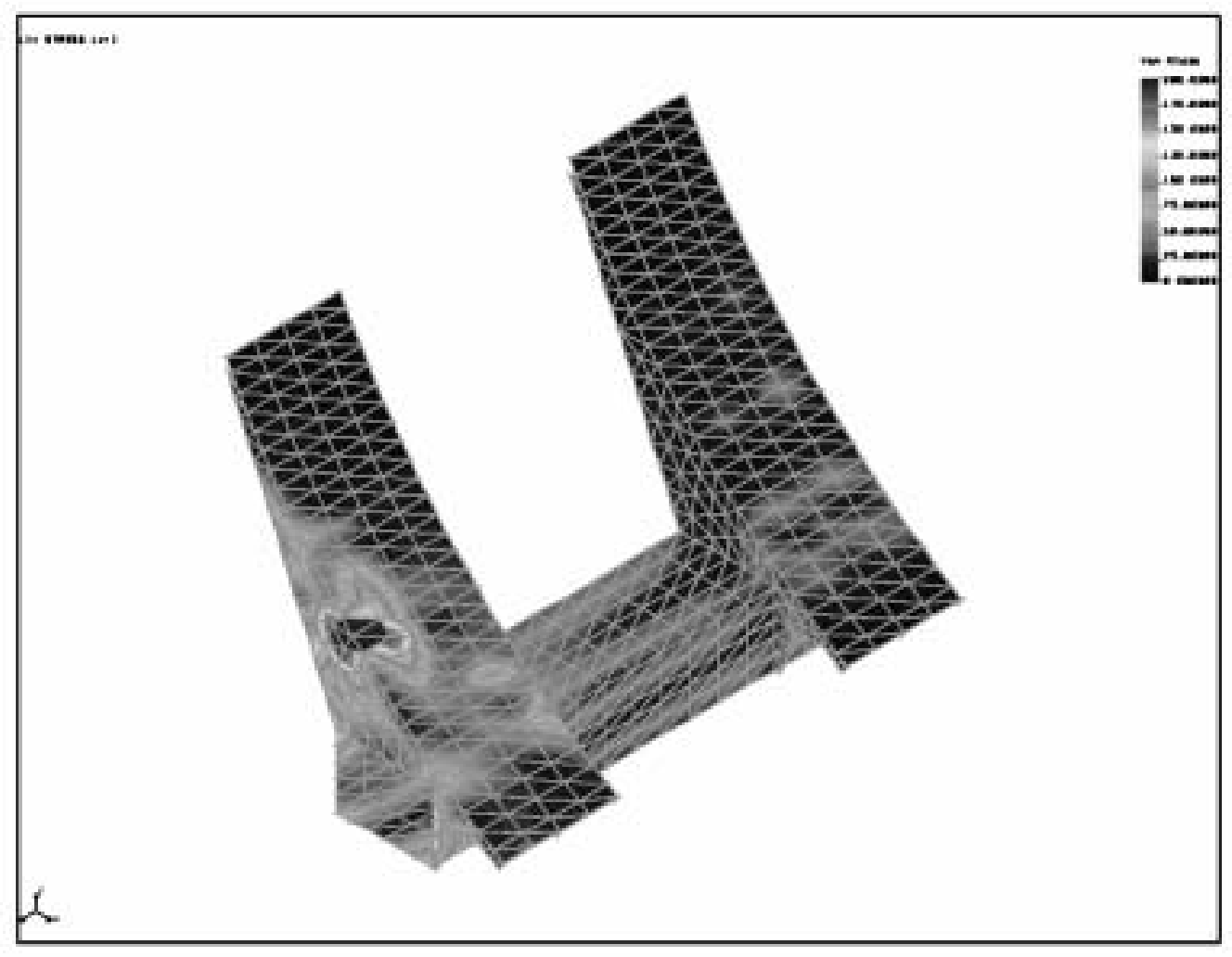

Figure 28. Von Mises Stresses in Right Saddle.

The FE shell element model of the saddle, however, did not model very well the connections between the back cryostat supports, nor did it model the geometry of the keyway. As described earlier, a more detailed FE model was also created using solid elements. The loads on the saddle that had been calculated from the full EB model were applied to this more detailed model of the saddle. In addition, the load from the back cryostat in the seismic condition was applied to the back cryostat support plate. This model showed much higher concentrations of stress using the seismic loading conditions. Whereas the average element Von Mises stress remained in the range of $80 \mathrm{~N} / \mathrm{mm} 2$, significant stress concentrations of 250-300 N/mm 2 were formed along the length of the front plate where the back cryostat support was attached as well, as in the region of the gusset which supported the back cryostat support as shown in Fig. 29. In addition, this model showed very high stresses in the region of the key way of approximately 300 $\mathrm{N} / \mathrm{mm} 2$. The actual bearing stress due to the loading on the key was a maximum of $180 \mathrm{~N} / \mathrm{mm} 2$ on the back saddle, but the stresses in this region increased significantly due to the combination of the bending of the front plate in this region and the reduction of area of the front plate due to the key way. The average bearing stress on the key-way was also calculated using the forces from the simpler plate element model and they are listed below: 


\begin{tabular}{|c|c|c|}
\hline Z position & \multicolumn{2}{|c|}{$\begin{array}{c}\text { Key Bearing Stress } \\
\text { (N/mm2) }\end{array}$} \\
\hline & Left Side & Right Side \\
\hline Z1 & -75 & -70 \\
\hline Z2 & -124 & -129 \\
\hline$Z 3$ & -174 & -180 \\
\hline$Z 4$ & -143 & -134 \\
\hline
\end{tabular}

These calculated stresses correspond well with the stresses that were found in the solid element model of the saddle. These stresses indicate that the bearing stresses on the key exceed the acceptable limit on the yield stress of $120 \mathrm{~N} / \mathrm{mm} 2$.

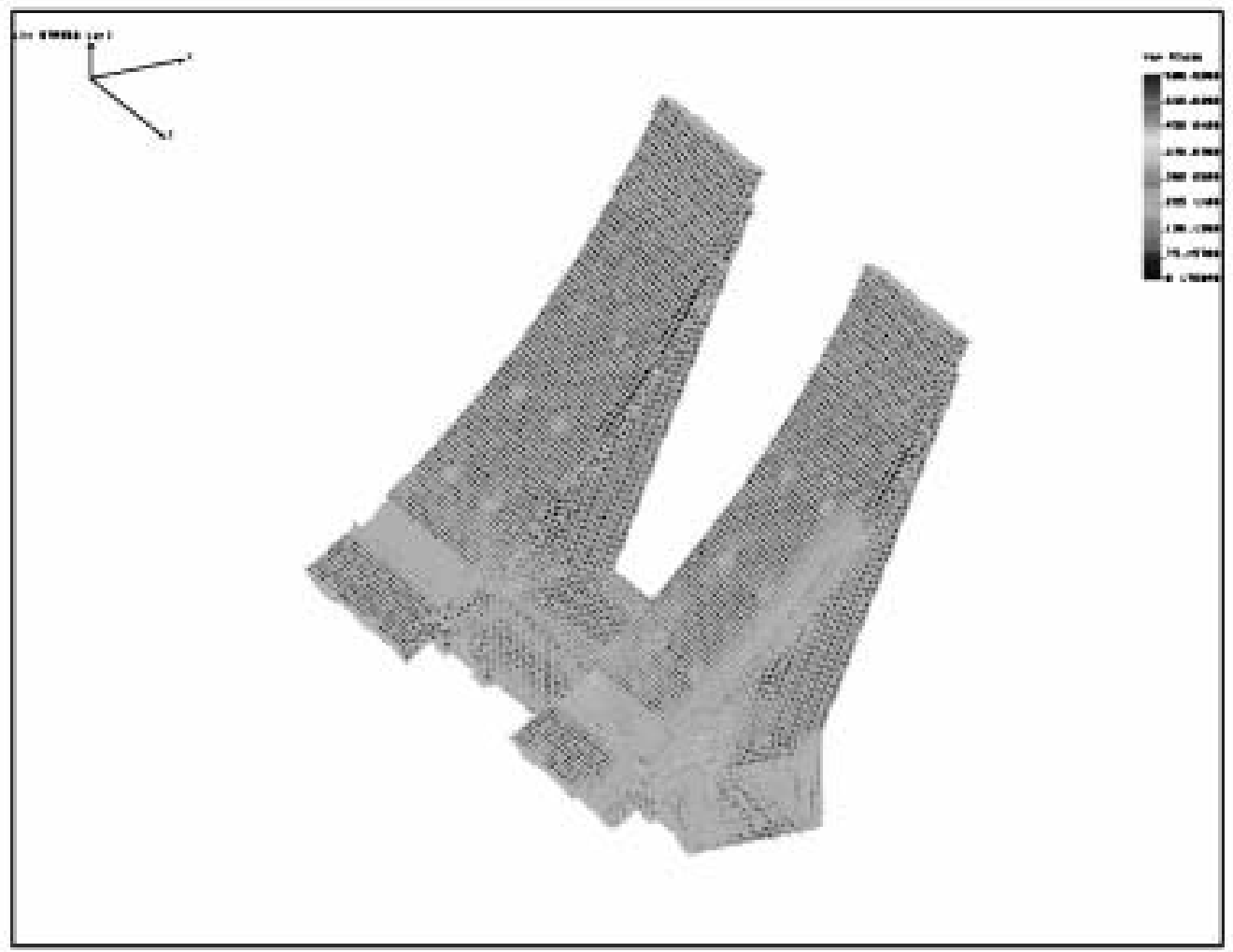

Figure 29. Stresses in FE model using Solid Elements.

\subsubsection{Swivel Bolt Stresses in Seismic Conditions}

The stresses in the swivel bolts in the seismic conditions are shown below: 


\begin{tabular}{|c|c|c|c|c|c|c|}
\hline \multicolumn{7}{|c|}{ Left Side of EB } \\
\hline \multicolumn{7}{|c|}{ Swivel Bolt Thread Stresses } \\
\hline & M6 & M8 & M9 & M10 & M11 & M12 \\
\hline $\mathbf{Z 1}$ & 12.82 & 74.78 & 57.76 & 32.85 & 2.97 & 0.00 \\
\hline $\mathbf{Z 2}$ & 19.73 & 93.48 & 73.25 & 40.33 & 5.45 & 0.00 \\
\hline $\mathbf{Z 3}$ & 32.66 & 133.07 & 90.49 & 49.03 & 3.04 & 0.00 \\
\hline $\mathbf{Z 4}$ & 55.29 & 75.24 & 97.99 & 69.43 & 20.69 & 0.00 \\
\hline \multicolumn{7}{|c|}{ Swivel Bolt Normal Stresses } \\
\hline & M6 & M8 & M9 & M10 & M11 & M12 \\
\hline $\mathbf{Z 1}$ & 6.57 & 38.36 & 29.63 & 16.85 & 1.52 & 0.00 \\
\hline $\mathbf{Z 2}$ & 10.12 & 47.95 & 37.57 & 20.69 & 2.80 & 0.00 \\
\hline $\mathbf{Z 3}$ & 16.75 & 68.26 & 46.41 & 25.15 & 1.56 & 0.00 \\
\hline $\mathbf{Z 4}$ & 28.36 & 38.59 & 50.26 & 35.62 & 10.61 & 0.00 \\
\hline \multicolumn{7}{|c|}{ Internal Thread Stresses in Saddle from Swivel Bolt } \\
\hline & M6 & M8 & M9 & M10 & M11 & M12 \\
\hline $\mathbf{Z 1}$ & 6.57 & 38.36 & 29.63 & 16.85 & 1.52 & 0.00 \\
\hline $\mathbf{Z 2}$ & 10.12 & 47.95 & 37.57 & 20.69 & 2.80 & 0.00 \\
\hline $\mathbf{Z 3}$ & 16.75 & 68.26 & 46.41 & 25.15 & 1.56 & 0.00 \\
\hline $\mathbf{Z 4}$ & 28.36 & 38.59 & 50.26 & 35.62 & 10.61 & 0.00 \\
\hline \multicolumn{7}{|c|}{ Right Side of EB } \\
\hline \multicolumn{7}{|c|}{ Swivel Bolt Thread Stresses } \\
\hline & M6 & M8 & M9 & M10 & M11 & M12 \\
\hline $\mathbf{Z 1}$ & 47.06 & 44.98 & 25.75 & 0.00 & 0.00 & 0.00 \\
\hline $\mathbf{Z 2}$ & 44.43 & 31.60 & 15.43 & 0.00 & 0.00 & 0.00 \\
\hline $\mathbf{Z 3}$ & 73.73 & 19.81 & 19.63 & 0.11 & 0.00 & 0.00 \\
\hline $\mathbf{Z 4}$ & 29.97 & 148.65 & 85.88 & 23.18 & 0.00 & 0.00 \\
\hline \multicolumn{7}{|c|}{ Swivel Bolt Normal Stresses } \\
\hline & M6 & M8 & M9 & M10 & M11 & M12 \\
\hline $\mathbf{Z 1}$ & 24.14 & 23.07 & 13.21 & 0.00 & 0.00 & 0.00 \\
\hline $\mathbf{Z 2}$ & 22.79 & 16.21 & 7.91 & 0.00 & 0.00 & 0.00 \\
\hline $\mathbf{Z 3}$ & 37.82 & 10.16 & 10.07 & 0.06 & 0.00 & 0.00 \\
\hline $\mathbf{Z 4}$ & 15.37 & 76.25 & 44.05 & 11.89 & 0.00 & 0.00 \\
\hline \multicolumn{7}{|c|}{ Thread Stresses in Saddle from Swivel Bolt } \\
\hline & M6 & M8 & M9 & M10 & M11 & M12 \\
\hline $\mathbf{Z 1}$ & 24.14 & 23.07 & 13.21 & 0.00 & 0.00 & 0.00 \\
\hline $\mathbf{Z 2}$ & 22.79 & 16.21 & 7.91 & 0.00 & 0.00 & 0.00 \\
\hline $\mathbf{Z 3}$ & 37.82 & 10.16 & 10.07 & 0.06 & 0.00 & 0.00 \\
\hline Z4 & 15.37 & 76.25 & 44.05 & 11.89 & 0.00 & 0.00 \\
\hline
\end{tabular}

All of the stresses in these bolts are within acceptable limits. However, several of these bolts exceed the 18ton maximum loading of a standard commercial swivel bolt as discussed above. Bolts at the Z4-M8, 
Z4-M9 positions on the right side of the EB and bolts at the Z2-M8, Z3-M8, Z3-M9, and Z4-M9 positions on the left side would have to be replaced with special swivel bolts, which could accommodate the high loads that occur at those positions.

\subsection{Gravity, Magnetic, and Seismic Loading}

The final analysis that was conducted examined the combined loading conditions of gravity, magnetic loading, and seismic loading as described above in Section 2.3. The magnetic force on each module was applied to the center of each module at the outer radius of the girder. The magnetic force was in the positive radial direction. Table 7 lists the magnetic force acting on each module.

Table 7. Magnetic Forces Acting on Modules.

Module \#1 at 12 o'clock position

Angle $=0.0$ at $3 \mathrm{o}^{\prime}$ clock position

\section{Module \# Angle Magnetic}

Force (N)

$\begin{array}{ccc}13 & 22.50 & 2.50 \mathrm{E}+04 \\ 12 & 28.13 & 8.00 \mathrm{E}+04 \\ 11 & 33.75 & 4.00 \mathrm{E}+04 \\ 10 & 39.38 & 1.00 \mathrm{E}+04 \\ 9 & 45.00 & 1.00 \mathrm{E}+04 \\ 8 & 50.63 & 4.00 \mathrm{E}+02 \\ 7 & 56.25 & 8.00 \mathrm{E}+04 \\ 6 & 61.88 & 2.50 \mathrm{E}+04 \\ 5 & 67.50 & 2.50 \mathrm{E}+04 \\ 4 & 73.13 & 8.00 \mathrm{E}+04 \\ 3 & 78.75 & 4.00 \mathrm{E}+04 \\ 2 & 84.38 & 1.00 \mathrm{E}+04 \\ 1 & 90.00 & 1.00 \mathrm{E}+04 \\ 64 & 95.63 & 4.00 \mathrm{E}+02 \\ 63 & 101.25 & 8.00 \mathrm{E}+04 \\ 62 & 106.88 & 2.50 \mathrm{E}+04 \\ 61 & 112.50 & 2.50 \mathrm{E}+04 \\ 60 & 118.13 & 8.00 \mathrm{E}+04 \\ 59 & 123.75 & 4.00 \mathrm{E}+04 \\ 58 & 129.38 & 1.00 \mathrm{E}+04 \\ 57 & 135.00 & 1.00 \mathrm{E}+04 \\ 56 & 140.63 & 4.00 \mathrm{E}+02 \\ 55 & 146.25 & 8.00 \mathrm{E}+04 \\ 54 & 151.88 & 2.50 \mathrm{E}+04 \\ 53 & 157.50 & 2.50 \mathrm{E}+04 \\ 52 & 163.13 & 8.00 \mathrm{E}+04 \\ 51 & 168.75 & 4.00 \mathrm{E}+04 \\ 50 & 174.38 & 1.00 \mathrm{E}+04\end{array}$




$\begin{array}{lll}49 & 180.00 & 1.00 \mathrm{E}+04 \\ 48 & 185.63 & 4.00 \mathrm{E}+02 \\ 47 & 191.25 & 8.00 \mathrm{E}+04 \\ 46 & 196.88 & 2.50 \mathrm{E}+04 \\ 45 & 202.50 & 2.50 \mathrm{E}+04 \\ 44 & 208.13 & 8.00 \mathrm{E}+04 \\ 43 & 213.75 & 4.00 \mathrm{E}+04 \\ 42 & 219.38 & 1.00 \mathrm{E}+04 \\ 41 & 225.00 & 1.00 \mathrm{E}+04 \\ 40 & 230.63 & 4.00 \mathrm{E}+02 \\ 39 & 236.25 & 8.00 \mathrm{E}+04 \\ 38 & 241.88 & 2.50 \mathrm{E}+04 \\ 37 & 247.50 & 2.50 \mathrm{E}+04 \\ 36 & 253.13 & 8.00 \mathrm{E}+04 \\ 35 & 258.75 & 4.00 \mathrm{E}+04 \\ 34 & 264.38 & 1.00 \mathrm{E}+04 \\ 33 & 270.00 & 1.00 \mathrm{E}+04 \\ 32 & 275.63 & 4.00 \mathrm{E}+02 \\ 31 & 281.25 & 8.00 \mathrm{E}+04 \\ 30 & 286.88 & 2.50 \mathrm{E}+04 \\ 29 & 292.50 & 2.50 \mathrm{E}+04 \\ 28 & 298.13 & 8.00 \mathrm{E}+04 \\ 27 & 303.75 & 4.00 \mathrm{E}+04 \\ 26 & 309.38 & 1.00 \mathrm{E}+04 \\ 25 & 315.00 & 1.00 \mathrm{E}+04 \\ 24 & 320.63 & 4.00 \mathrm{E}+02 \\ 23 & 326.25 & 8.00 \mathrm{E}+04 \\ 22 & 331.88 & 2.50 \mathrm{E}+04 \\ 21 & 337.50 & 2.50 \mathrm{E}+04 \\ 20 & 343.13 & 8.00 \mathrm{E}+04 \\ 19 & 348.75 & 4.00 \mathrm{E}+04 \\ 18 & 354.38 & 1.00 \mathrm{E}+04 \\ 17 & 360.00 & 1.00 \mathrm{E}+04 \\ 16 & 365.63 & 4.00 \mathrm{E}+02 \\ 15 & 371.25 & 8.00 \mathrm{E}+04 \\ 14 & 376.88 & 2.50 \mathrm{E}+04\end{array}$

The forces acting between modules are listed in Appendix 5. All of these forces are within the limits of forces used in the design of the connection between modules in the EB.

\subsubsection{Saddle Forces in Gravity, Magnetic, and Seismic Loading}

The forces acting on the saddle swivel bolts were calculated from the FE model and are shown in Table 8. All of the forces are acting in the radial direction except the force on the key, which is acting in 
the circumferential direction. Like the other load cases, the swivel bolts at the top of the saddle are not being loaded. This is due to the rotation of the EB around the key and the saddles cannot deflect enough to keep in contact. On the Right support saddle, a large number of swivel bolts are not loaded because of the seismic load in the $\mathrm{X}$ direction.

Table 8. Forces Acting on the Saddle in the Gravity, Seismic, and Magnetic Load Case.

\begin{tabular}{|c|c|c|c|c|c|c|c|c|c|}
\hline \multicolumn{10}{|c|}{ Left Side of EB } \\
\hline \multicolumn{7}{|c|}{ Radial Forces } & Key & & \\
\hline & M6 & M8 & M9 & M10 & M11 & M12 & M7 & & \\
\hline $\mathbf{Z 1}$ & 92,970 & 398,800 & 292,400 & 163,800 & 13,770 & 0 & $-583,170$ & & \\
\hline $\mathbf{Z 2}$ & 123,000 & 475,000 & 347,200 & 183,900 & 19,560 & 0 & $-966,400$ & & \\
\hline $\mathbf{Z 3}$ & 157,500 & 627,500 & 377,800 & 178,500 & 0 & 0 & $-1,325,000$ & & \\
\hline $\mathbf{Z 4}$ & 214,200 & 384,700 & 500,600 & 408,500 & 135,600 & 0 & $-1,086,400$ & & \\
\hline Angle & 32.34 & 40.78 & 46.41 & 52.04 & 57.66 & 63.28 & 36.40 & & \\
\hline \multicolumn{7}{|c|}{ Forces in $X$} & & & Sum in \\
\hline $\mathbf{Z 1}$ & 49,734 & 260,500 & 211,783 & 129,147 & 11,634 & 0 & $-469,390$ & & 193,407 \\
\hline $\mathbf{Z 2}$ & 65,798 & 310,274 & 251,474 & 144,994 & 16,526 & 0 & $-777,849$ & & 11,217 \\
\hline $\mathbf{Z 3}$ & 84,253 & 409,889 & 273,638 & 140,737 & 0 & 0 & $-1,066,484$ & & $-157,968$ \\
\hline \multirow[t]{2}{*}{$\mathbf{Z 4}$} & 114,585 & 251,290 & 362,581 & 322,078 & 114,567 & 0 & $-874,437$ & & 290,663 \\
\hline & & & & & & & & Total & 337,320 \\
\hline \multicolumn{7}{|c|}{ Forces in $Y$} & & & Sum in $Y$ \\
\hline $\mathbf{Z 1}$ & 78,549 & 301,962 & 201,608 & 100,755 & 7,366 & 0 & 346,064 & & $1,036,305$ \\
\hline $\mathbf{Z 2}$ & 103,921 & 359,659 & 239,392 & 113,119 & 10,463 & 0 & 573,480 & & $1,400,035$ \\
\hline $\mathbf{Z 3}$ & 133,070 & 475,129 & 260,491 & 109,797 & 0 & 0 & 786,280 & & $1,764,767$ \\
\hline \multirow[t]{2}{*}{$\mathbf{Z 4}$} & 180,975 & 291,286 & 345,160 & 251,273 & 72,538 & 0 & 644,690 & & $1,785,923$ \\
\hline & & & & & & & & Total & $5,987,030$ \\
\hline \multicolumn{10}{|c|}{ Right Side of EB } \\
\hline \multicolumn{7}{|c|}{ Radial Forces } & $\begin{array}{c}\text { Key } \\
\text { Forces }\end{array}$ & & \\
\hline & M6 & M8 & M9 & M10 & M11 & M12 & M7 & & \\
\hline Z1 & 0 & 278,500 & 187,800 & 110,600 & 447 & 0 & $-536,300$ & & \\
\hline $\mathbf{Z 2}$ & 0 & 292,200 & 175,100 & 91,400 & 0 & 0 & $-909,300$ & & \\
\hline $\mathbf{Z 3}$ & 0.00 & 439,300 & 205,200 & 91,800 & 0 & 0 & $-1,191,000$ & & \\
\hline $\mathbf{Z 4}$ & 33,320 & 267,000 & 699,700 & 400,900 & 97,340 & 0 & $-859,300$ & & \\
\hline Angle & 32.34 & 40.78 & 46.41 & 52.04 & 57.66 & 63.28 & 36.40 & & \\
\hline \multicolumn{7}{|c|}{ Forces in $X$} & & & Sum in $X$ \\
\hline Z1 & 0 & 181,919 & 136,022 & 87,202 & 378 & 0 & $-431,665$ & & $-26,145$ \\
\hline
\end{tabular}




\begin{tabular}{|c|c|c|c|c|c|c|c|c|c|}
\hline $\mathbf{Z 2}$ & 0 & 190,868 & 126,824 & 72,063 & 0 & 0 & $\mid-731,890$ & & $-342,135$ \\
\hline Z3 & 0 & 286,955 & 148,625 & 72,379 & 0 & 0 & $-958,629$ & & $-450,670$ \\
\hline $\mathbf{Z 4}$ & 17,824 & 174,407 & 506,787 & 316,086 & 82,241 & 0 & $-691,645$ & & 405,700 \\
\hline & & & & & & & & Total & $-413,250$ \\
\hline \multicolumn{7}{|c|}{ Forces in $Y$} & & & Sum in $Y$ \\
\hline Z1 & 0 & 210,874 & 129,487 & 68,031 & 239 & 0 & 318,251 & & 726,882 \\
\hline $\mathbf{Z 2}$ & 0 & 221,247 & 120,730 & 56,221 & 0 & 0 & 539,596 & & 937,794 \\
\hline Z3 & 0 & 69,509 & 141,484 & 56,467 & 0 & 0 & 706,762 & & 974,222 \\
\hline \multirow[t]{2}{*}{$\mathbf{Z 4}$} & 28,152 & 202,166 & 482,438 & 246,598 & 52,071 & 0 & 509,925 & & $1,521,351$ \\
\hline & & & & & & & & Total & $4,160,249$ \\
\hline
\end{tabular}

\subsubsection{Deflections of the Support Saddle in the Gravity, Seismic, and Magnetic Load Conditions}

The deflections of at the swivel bolts are shown in Table 9 below. The swivel bolt deflections remain overall, relatively small, less than $1.0 \mathrm{~mm}$ in all directions. Figures 30 and 31 show the vertical and horizontal deflections of the EB, respectively. These plots show two important phenomenons. First, there is a difference in the vertical deflection between the front and back of the EB of nearly $1.2 \mathrm{~mm}$. The back of the EB is deflecting-1.2mm more than the front at the top of the EB. Second, because the EB is only restrained at one of the support saddles in $\mathrm{Z}$, the other saddle moves in the X direction $1.3 \mathrm{~mm}$. Neither of these deflections is that large over the scale of the entire EB, so these systematic variations along the length of the EB should not be significant. The table below lists the maximum EB deflections at the outer radius that occur at the 12 and 6 o'clock positions.

\begin{tabular}{|c|c|c|c|}
\hline \multirow{2}{*}{$\begin{array}{c}\mathrm{X} \\
\text { Deflections }\end{array}$} & $\begin{array}{c}12 \text { o'clock } \\
\text { position }\end{array}$ & $2.5 \mathrm{~mm}$ & Back \\
\cline { 2 - 4 } & $\begin{array}{c}\text { 6 o'clock } \\
\text { position }\end{array}$ & $1.0 \mathrm{~mm}$ & $0.9 \mathrm{~mm}$ \\
\hline \multirow{2}{*}{$\begin{array}{c}12 \text { o'clock } \\
\text { position }\end{array}$} & $-1.3 \mathrm{~mm}$ & $-2.6 \mathrm{~mm}$ \\
\cline { 2 - 4 } Deflections & $\begin{array}{c}\text { 6 o'clock } \\
\text { position }\end{array}$ & $-0.5 \mathrm{~mm}$ & $-1.2 \mathrm{~mm}$ \\
\hline
\end{tabular}

Table 9.

\begin{tabular}{|c|c|c|c|c|c|c|}
\hline \multicolumn{7}{|c|}{ Deflections at Saddle Swivel Bolts } \\
\hline \multicolumn{7}{|c|}{ Note: $\mathrm{X}$ is in the lateral direction $-\mathrm{Y}$ is vertical $-\mathrm{Z}$ is in the beam direction } \\
\hline \multicolumn{7}{|c|}{ Left Side of EB } \\
\hline \multicolumn{2}{|c|}{ X Deflections } & & & & & \\
\hline & M6 & M8 & M9 & M10 & M11 & M12 \\
\hline $\mathbf{Z 1}$ & 1.19 & 1.15 & 1.32 & 1.50 & 1.80 & 2.20 \\
\hline
\end{tabular}




\begin{tabular}{|c|c|c|c|c|c|c|}
\hline Z2 & 1.20 & 1.10 & 1.30 & 1.50 & 1.80 & 2.20 \\
\hline Z3 & 1.10 & 1.00 & 1.10 & 1.40 & 1.70 & 2.20 \\
\hline $\mathbf{Z 4}$ & 1.10 & 1.00 & 1.00 & 1.20 & 1.60 & 2.00 \\
\hline \multicolumn{7}{|c|}{ Y Deflections } \\
\hline & M6 & M8 & M9 & M10 & M11 & M12 \\
\hline $\mathbf{Z 1}$ & -0.27 & -0.14 & -0.24 & -0.40 & -0.60 & -0.80 \\
\hline $\mathbf{Z 2}$ & -0.30 & -0.10 & -0.20 & -0.40 & -0.60 & -0.80 \\
\hline $\mathbf{Z 3}$ & -0.50 & -0.20 & -0.20 & -0.40 & -0.60 & -0.80 \\
\hline $\mathbf{Z 4}$ & -0.50 & -0.30 & -0.20 & -0.40 & -0.60 & -0.90 \\
\hline \multicolumn{7}{|c|}{ Z Deflections } \\
\hline & M6 & M8 & M9 & M10 & M11 & M12 \\
\hline $\mathbf{Z 1}$ & 0.00 & 0.00 & 0.00 & 0.00 & 0.00 & 0.00 \\
\hline $\mathbf{Z 2}$ & 0.00 & 0.00 & 0.00 & 0.00 & 0.00 & 0.00 \\
\hline $\mathbf{Z 3}$ & 0.00 & 0.20 & 0.30 & 0.50 & 0.60 & 0.80 \\
\hline $\mathbf{Z 4}$ & 0.00 & 0.20 & 0.30 & 0.50 & 0.60 & 0.80 \\
\hline \multicolumn{7}{|c|}{ Right Side of EB } \\
\hline \multicolumn{7}{|c|}{ X Deflections } \\
\hline & M6 & M8 & M9 & M10 & M11 & M12 \\
\hline $\mathbf{Z 1}$ & 0.60 & 0.80 & 0.70 & 0.60 & 0.60 & 0.50 \\
\hline $\mathbf{Z 2}$ & 0.50 & 0.70 & 0.70 & 0.60 & 0.50 & 0.40 \\
\hline $\mathbf{Z 3}$ & 0.50 & 0.80 & 0.70 & 0.70 & 0.60 & 0.30 \\
\hline $\mathbf{Z 4}$ & 0.60 & 0.80 & 1.00 & 0.90 & 0.70 & 0.50 \\
\hline \multicolumn{7}{|c|}{ Y Deflections } \\
\hline & M6 & M8 & M9 & M10 & M11 & M12 \\
\hline $\mathbf{Z 1}$ & -0.50 & -0.10 & -0.10 & -0.20 & -0.20 & -0.30 \\
\hline $\mathbf{Z 2}$ & -0.50 & -0.10 & -0.10 & -0.10 & -0.20 & -0.20 \\
\hline $\mathbf{Z 3}$ & -0.50 & -0.10 & -0.10 & -0.10 & -0.20 & -0.30 \\
\hline $\mathbf{Z 4}$ & -0.60 & -0.20 & -0.10 & -0.20 & -0.30 & -0.40 \\
\hline \multicolumn{7}{|c|}{ Z Deflections } \\
\hline & M6 & M8 & M9 & M10 & M11 & M12 \\
\hline $\mathbf{Z 1}$ & 0.10 & 0.00 & 0.00 & 0.00 & 0.00 & -0.10 \\
\hline Z2 & 0.10 & 0.00 & 0.00 & 0.00 & 0.00 & -0.10 \\
\hline Z3 & 0.10 & 0.20 & 0.40 & 0.60 & 0.80 & 0.90 \\
\hline $\mathbf{Z 4}$ & 0.10 & 0.20 & 0.40 & 0.60 & 0.80 & 0.90 \\
\hline
\end{tabular}




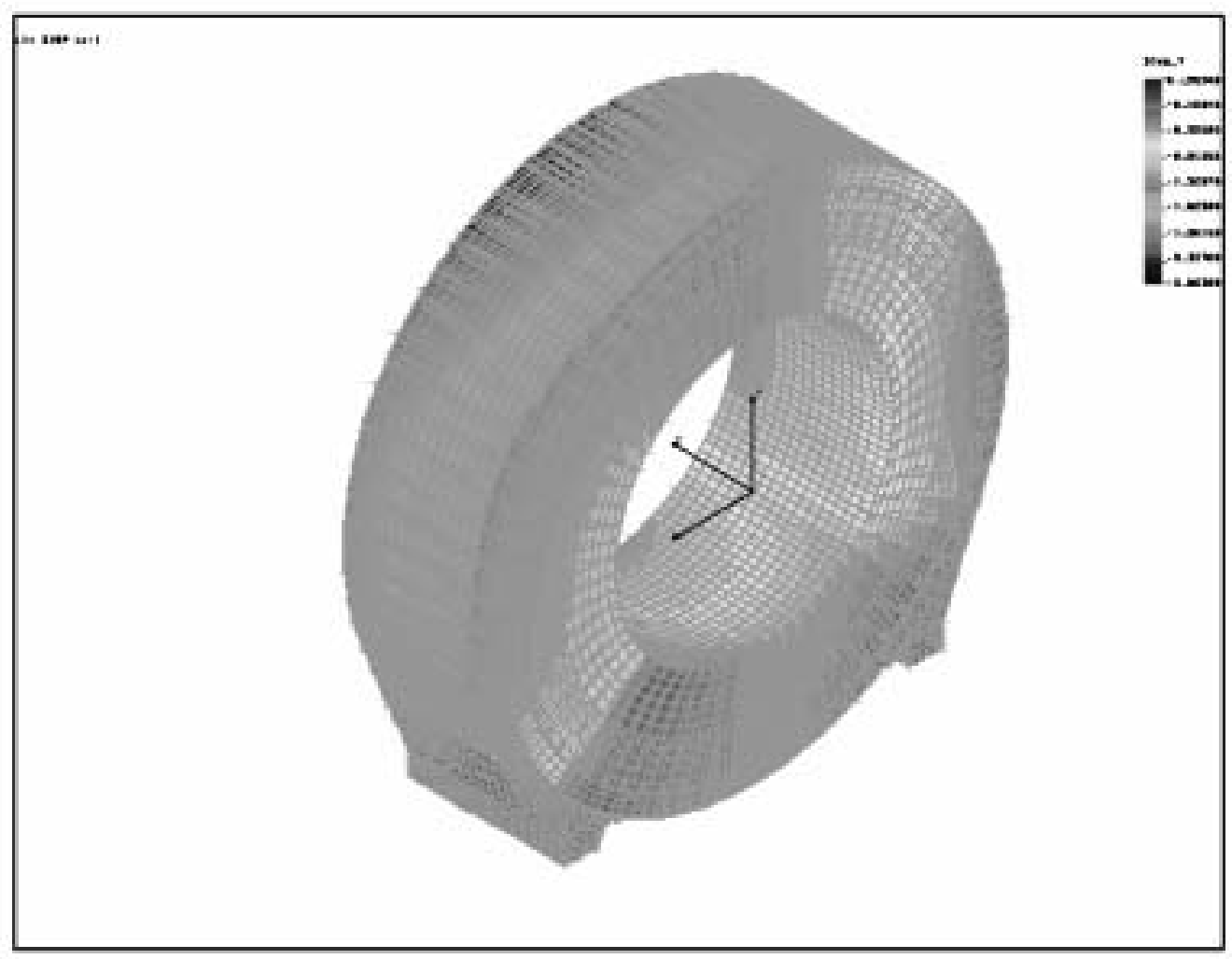

Figure 30. Vertical (Y) Deflections of EB. 


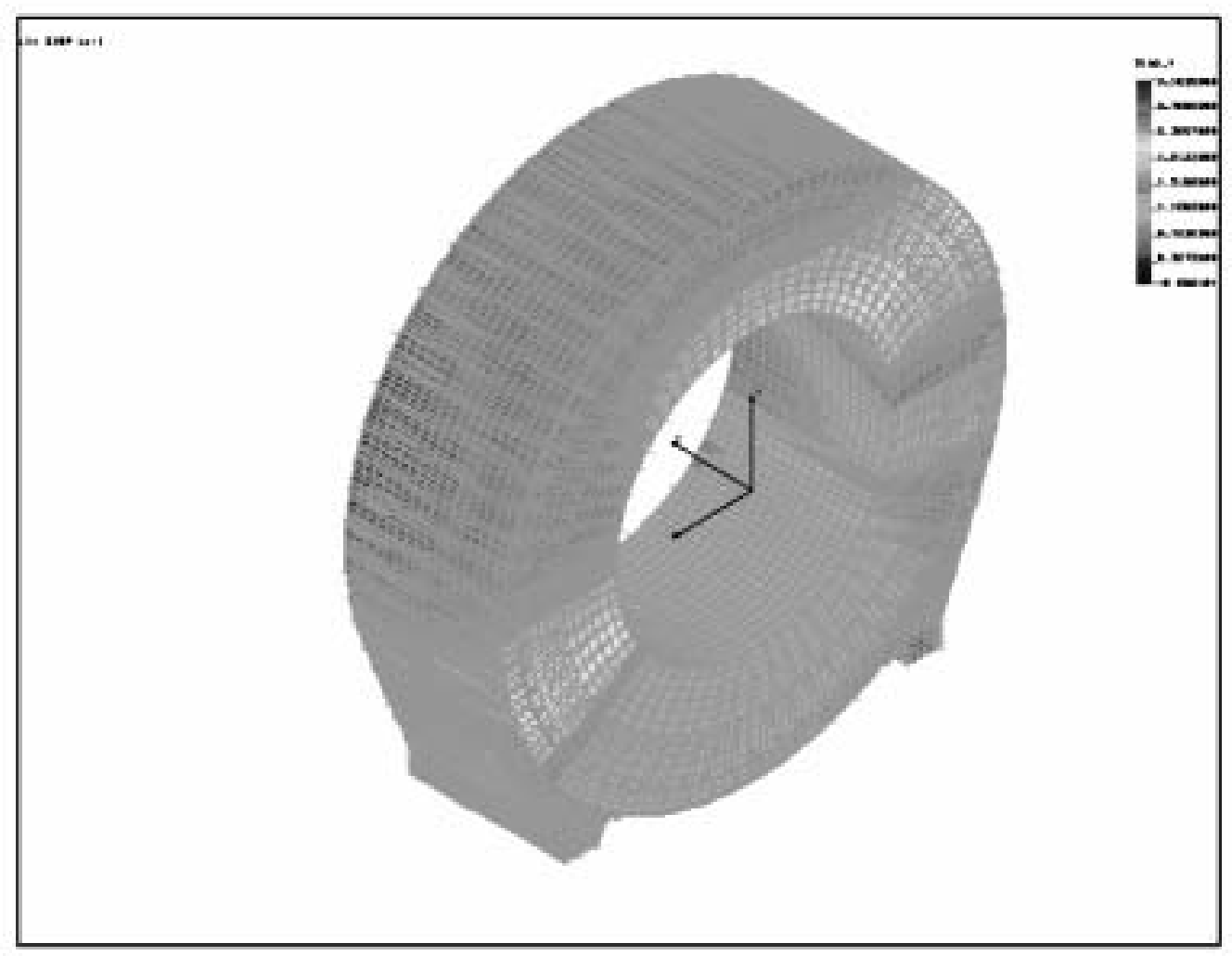

Figure 31. Horizontal (X) Deflection of EB.

\subsubsection{Stresses in the Support Saddle in the Gravity, Seismic, and Magnetic Load Conditions}

The maximum Von Mises stresses are shown in Figs. 32 and 33. As in earlier models, the maximum stresses are occurring along the connection between the back cryostat support plate and the saddle front plate and along the lower part of the gusset below the back cryostat support plate. The average stresses throughout the saddle are approximately $50 \mathrm{~N} / \mathrm{mm} 2$. The stress concentration in the region of the connection between the back cryostat support and the saddle front plate approaches 350 $\mathrm{N} / \mathrm{mm} 2$. However, this stress concentration is due to the location of the stiffening beam on the back cryostat support. In the FE model, a series of beam elements have been included, which have been used to stiffen the back cryostat support plate and the stress concentration is occurring at the point where this line of beam elements is attached to the saddle. In reality, the loads from this beam would be distributed over a much greater area. Therefore, this stress concentration is not seen as a problem. The second stress concentration occurs on the lower part of the gusset below the back cryostat support. The stresses in this region approach $150 \mathrm{~N} / \mathrm{mm} 2$. The design of the saddle has been changed in order to eliminate this stress concentration by adding a stiffening block throughout this area, which will help to transfer the load of the back cryostat support to the support beam. 
The plate element FE model cannot examine the stresses in the key way. In the table below, the calculated bearing stresses in the key way are shown. The bearing stresses in the key way exceed the design target stress of $120 \mathrm{~N} / \mathrm{mm} 2$, but are still below the yield stress of the material.

\begin{tabular}{|c|c|c|}
\hline Z position & \multicolumn{2}{|c|}{$\begin{array}{c}\text { Key Bearing Stress } \\
\text { (N/mm2) }\end{array}$} \\
\hline & Left Side & Right Side \\
\hline$Z 1$ & -83 & -77 \\
\hline$Z 2$ & -138 & -130 \\
\hline$Z 3$ & -189 & -170 \\
\hline$Z 4$ & -155 & -123 \\
\hline
\end{tabular}

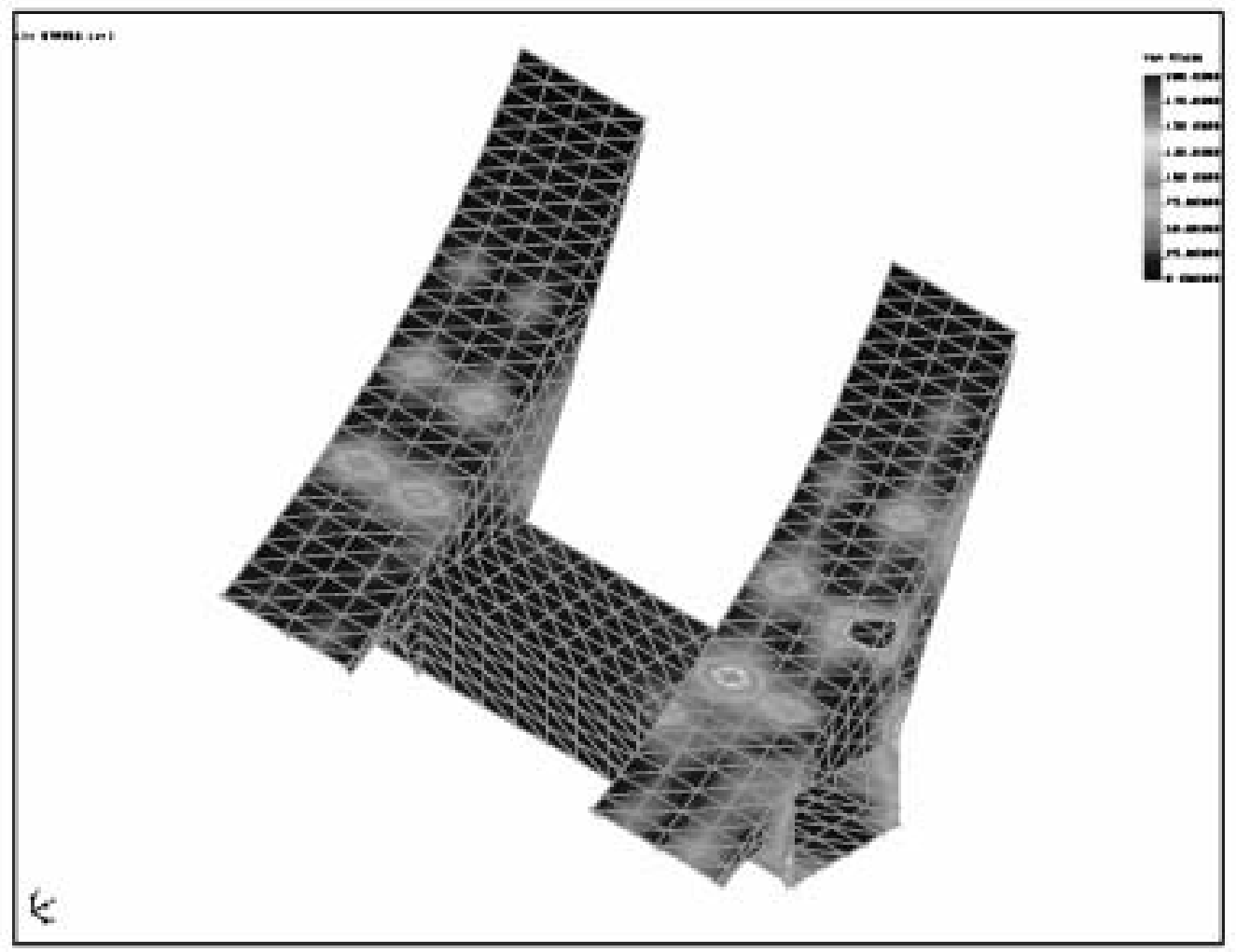

Figure 32. Von Mises Stress in the Saddles under Gravity, Seismic, and Magnetic Loading. 


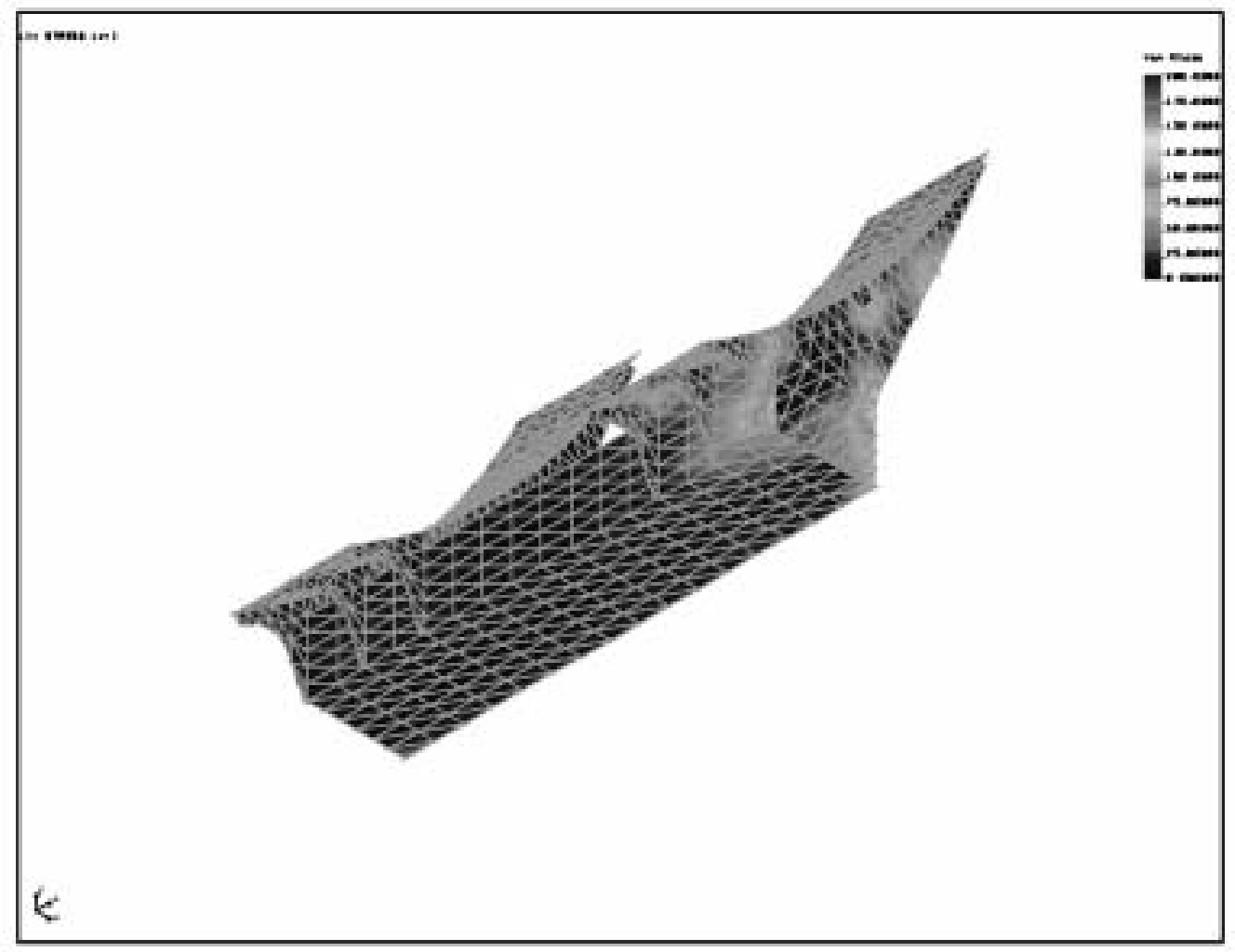

Figure 33. Von Mises Stress in the Saddles under Gravity, Seismic, and Magnetic Loading.

\subsubsection{Swivel Bolt Stresses in the Gravity, Seismic, and Magnetic Load Conditions}

Table 10 lists the normal stresses in the swivel bolts and the shear stresses in the swivel bolt internal and external threads. All of the stresses are within acceptable limits. The limiting factor on the selection of swivel bolts remains the maximum force that the commercial swivel bolt can withstand. As discussed earlier, the largest commercial swivel bolt available has been tested at Argonne and found to be able to withstand only 18 tons. It has been decided that it is necessary to place two swivel bolts at each $\mathrm{Z}$ position in order to obtain a sufficient load-carrying capacity. However, even with 2 swivel bolts, there are several positions on the saddle, which have loads that exceed the combined limiting load of 36 tons. In this analysis, the swivel bolts on the Left Saddle at Z1-M8, Z2-M8, Z2-M9, Z3-M8, Z3-M9, Z4-M8, Z4M9, Z4-M10 and on the Right Saddle at Z3-M8, Z4-M9, and Z4-M10 all have loads that exceed the maximum load-carrying ability of commercially available swivel bolts. As discussed above, special, higher capacity swivel bolts will have to be designed and constructed for these locations. 
Table 10. Stresses in Swivel Bolts and Threads.

\begin{tabular}{|c|c|c|c|c|c|c|}
\hline \multicolumn{7}{|c|}{ Left Side of EB } \\
\hline \multicolumn{7}{|c|}{ Swivel Bolt Thread Stresses } \\
\hline & M6 & M8 & M9 & M10 & M11 & M12 \\
\hline Z1 & 22.29 & 95.62 & 70.11 & 39.27 & 3.30 & 0.00 \\
\hline Z2 & 29.49 & 113.89 & 83.24 & 44.09 & 4.69 & 0.00 \\
\hline Z3 & 37.76 & 150.45 & 90.58 & 42.80 & 0.00 & 0.00 \\
\hline $\mathbf{Z 4}$ & 51.36 & 92.24 & 120.02 & 97.94 & 32.51 & 0.00 \\
\hline \multicolumn{7}{|c|}{ Swivel Bolt Normal Stresses } \\
\hline & M6 & M8 & M9 & M10 & M11 & M12 \\
\hline Z1 & 11.43 & 49.05 & 35.96 & 20.14 & 1.69 & 0.00 \\
\hline Z2 & 15.13 & 58.42 & 42.70 & 22.62 & 2.41 & 0.00 \\
\hline $\mathbf{Z 3}$ & 19.37 & 77.17 & 46.46 & 21.95 & 0.00 & 0.00 \\
\hline Z4 & 26.34 & 47.31 & 61.57 & 50.24 & 16.68 & 0.00 \\
\hline \multicolumn{7}{|c|}{ Thread Stresses in Saddle } \\
\hline & M6 & M8 & M9 & M10 & M11 & M12 \\
\hline Z1 & 11.43 & 49.05 & 35.96 & 20.14 & 1.69 & 0.00 \\
\hline $\mathbf{Z 2}$ & 15.13 & 58.42 & 42.70 & 22.62 & 2.41 & 0.00 \\
\hline Z3 & 19.37 & 77.17 & 46.46 & 21.95 & 0.00 & 0.00 \\
\hline $\mathbf{Z 4}$ & 26.34 & 47.31 & 61.57 & 50.24 & 16.68 & 0.00 \\
\hline & & & & & & \\
\hline \multicolumn{7}{|c|}{ Right Side of EB } \\
\hline \multicolumn{7}{|c|}{ Swivel Bolt Thread Stresses } \\
\hline & M6 & M8 & M9 & M10 & M11 & M12 \\
\hline Z1 & 0.00 & 66.77 & 45.03 & 26.52 & 0.11 & 0.00 \\
\hline Z2 & 0.00 & 70.06 & 41.98 & 21.91 & 0.00 & 0.00 \\
\hline $\mathbf{Z 3}$ & 0.00 & 105.33 & 49.20 & 22.01 & 0.00 & 0.00 \\
\hline $\mathbf{Z 4}$ & 7.99 & 64.02 & 167.76 & 96.12 & 23.34 & 0.00 \\
\hline \multicolumn{7}{|c|}{ Swivel Bolt Normal Stresses } \\
\hline & M6 & M8 & M9 & M10 & M11 & M12 \\
\hline $\mathbf{Z 1}$ & 0.00 & 34.25 & 23.10 & 13.60 & 0.05 & 0.00 \\
\hline $\mathbf{Z 2}$ & 0.00 & 35.94 & 21.53 & 11.24 & 0.00 & 0.00 \\
\hline $\mathbf{Z 3}$ & 0.00 & 54.03 & 25.24 & 11.29 & 0.00 & 0.00 \\
\hline $\mathbf{Z 4}$ & 4.10 & 32.84 & 86.05 & 49.30 & 11.97 & 0.00 \\
\hline
\end{tabular}




\begin{tabular}{|c|c|c|c|c|c|c|}
\hline \multicolumn{7}{|c|}{ Thread Stresses in Saddle from Swivel Bolt } \\
\hline & M6 & M8 & M9 & M10 & M11 & M12 \\
\hline Z1 & 0.00 & 34.25 & 23.10 & 13.60 & 0.05 & 0.00 \\
\hline Z2 & 0.00 & 35.94 & 21.53 & 11.24 & 0.00 & 0.00 \\
\hline Z3 & 0.00 & 54.03 & 25.24 & 11.29 & 0.00 & 0.00 \\
\hline Z4 & 4.10 & 32.84 & 86.05 & 49.30 & 11.97 & 0.00 \\
\hline
\end{tabular}

\subsection{Back Cryostat Support}

The rear of the cryostat is supported by two identical plates attached to the saddle support. The two plates are located symmetrically about the $\mathrm{Y}$-axis with one of the plates shown in Fig. 34. In addition to the gravity load, these two plates must completely withstand seismic loads applied to the cryostat C.G. in all directions. The design of the Back Cryostat Plate has been iterated through various analysis and redesign. The details of these designs and subsequent analysis are reported in the following. In all cases, the analysis includes simplified hand calculations and multiple FEA models to give confidence to the results. The design goal is to limit Von Mises stress to below $130 \mathrm{Mpa}$ and shear stresses below 90MPa. In particular, the following areas are examined in all cases:

1. Plate stresses.

2. Shear stress in threads at plate/saddle connection (internal and external)

3. Stresses in stiffener beams.

4. Stresses at key.

Section 3.1 details the initial design of the plate (Fig. 34) and analyzes static gravity loads in the Ydirection. The design is found to be acceptable in the static case in all areas except in the region of the key. A preliminary study into the Seismic loading is discussed in Section 3.2 with the application of a static Z-direction force with magnitude 15\% the total weight of the cryostat applied through the cryostat C.G. It is shown there that both excessive stress and deflections occur in the plate requiring the addition

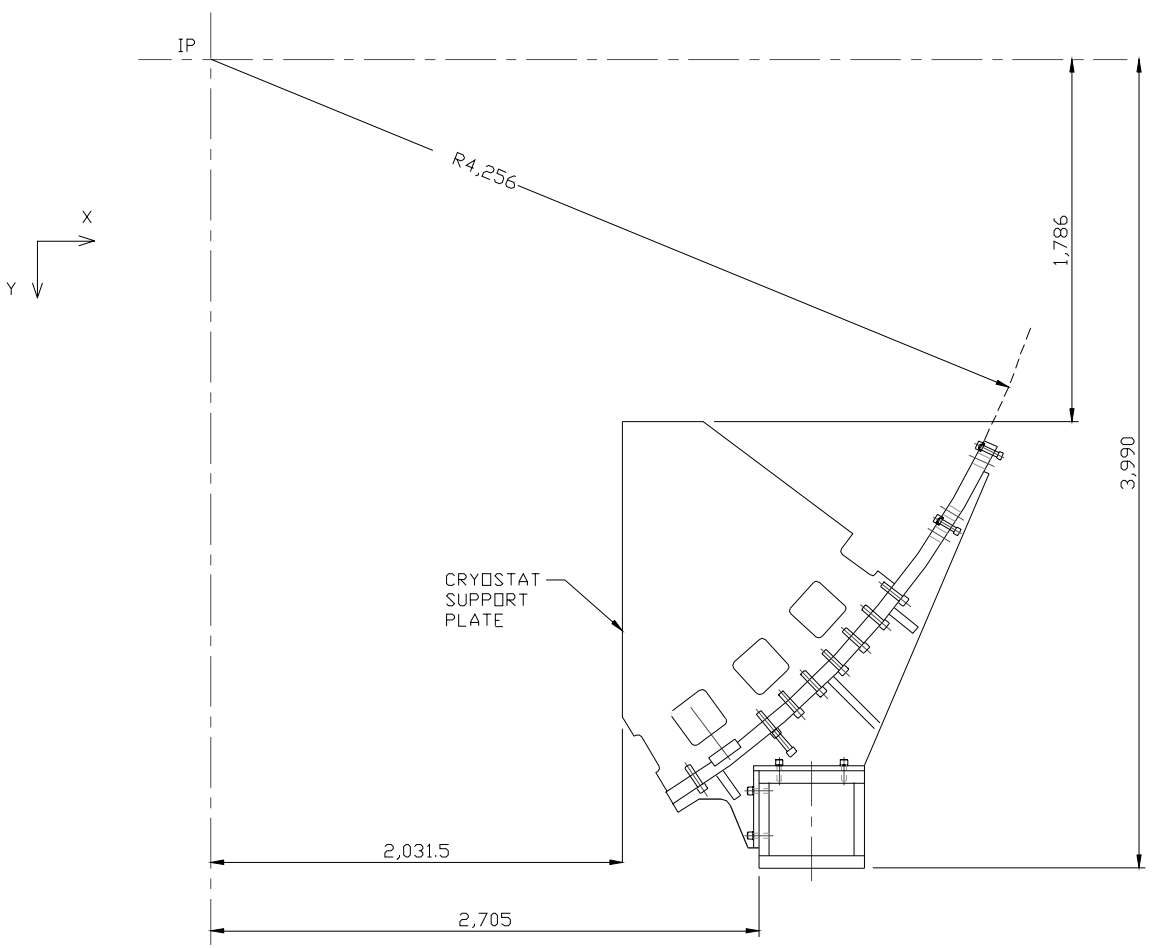


of stiffener beams to reduce deflections and transfer the reaction moment. This first redesign is described in Section 3.3. This redesign includes the addition of the stiffener beams and an enlarged key in the plate. The addition of the stiffener beam also required a reduction in the plate/saddle connection bolts. The static case was analyzed again and with satisfactory results. Section 3.4 expands the seismic loading from that described in Section 3.2 by determining the resultant reaction forces on the cryostat plate when the $15 \%$ weight load is applied simultaneously through the cryostat C.G. in all three axes. It is seen that the seismic load in X-direction produces a large moment that adds to the Z-direction reaction force on the plate. The various combinations of seismic load cases are reduced to 6 load cases of reaction forces to be applied to the cryostat support plate. The analysis of these seismic load cases applied to the stiffened cryostat plate is presented in Section 3.5. This detailed analysis of the combined seismic loading finds stresses in excess of the design limits in many areas. Additionally, the plate deflects $8 \mathrm{~mm}$ in the Z-direction exceeding the available clearance between the extended barrels. In reviews of this design, it was found that the stiffener beams were located in space reserved for electric boxes and that these could not be relocated. Further design alternatives are described in Section 3.6. These designs include a single stiffener alone and with one and two additional shorter beams to help in transferring the reaction to the saddle support. This analysis is done with loads only in the Z-direction and strives to determine the maximum allowable Z-load based on the limiting stress values.

\subsection{Initial Design Analysis for the Static Case}

The initial cryostat plate analysis includes both static hand calculations and FEA modeling. The goals of the analysis are to evaluate the forces on the bolts, bolt threads in the plate, key, and to identify areas of high stress within the plate. It was found for the static case that the loading on the threads in the steel plate is in the acceptable limit. However, it is found that the stress in the plate at the key is higher than desired and this is identified as a point of further design iteration.

Table 11. Cryostat Support Plate - Angle of Bolts and Key.

\begin{tabular}{|c|c|c|c|c|c|c|c|c|c|}
\hline Bolt \# & 1 & Key & 2 & 3 & 4 & 5 & 6 & 7 & 8 \\
\hline $\begin{array}{c}\text { Angle } \\
\text { degrees }\end{array}$ & 34 & 37.6 & 40 & 42 & 44 & 46 & 48 & 50 & 52 \\
\hline
\end{tabular}




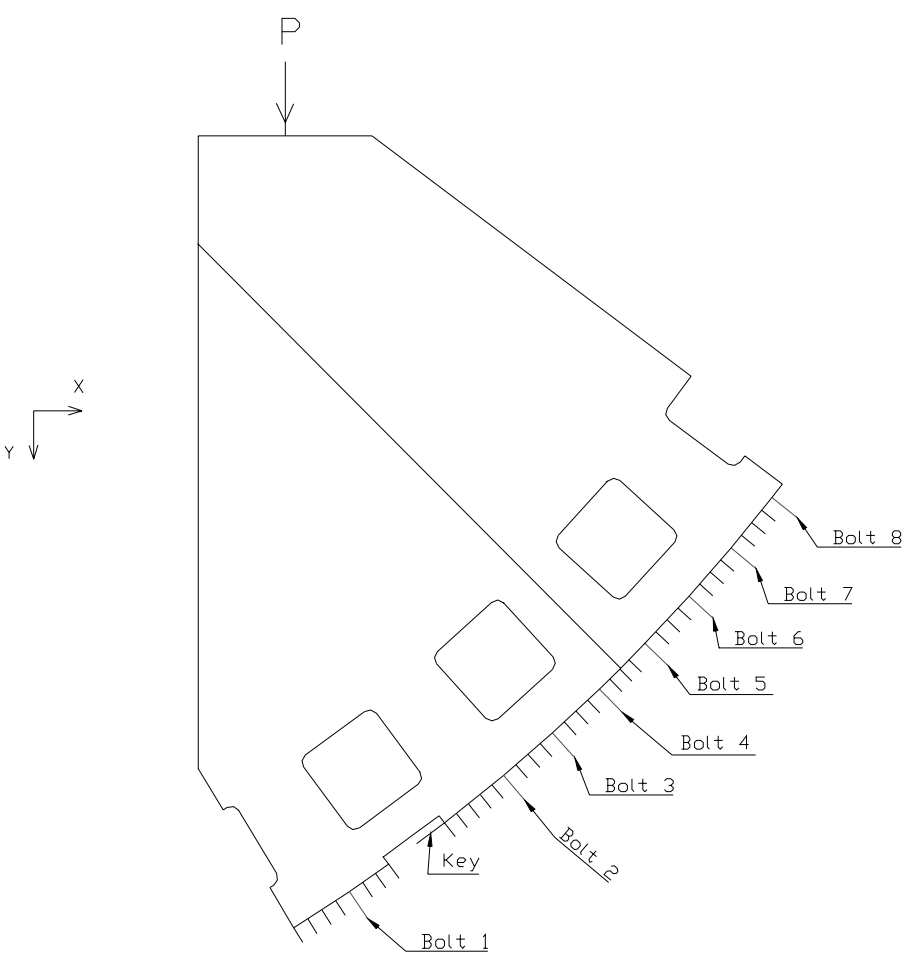

Figure 35. Cryostat Plate and Model Showing Bolt Labels.

\subsubsection{Hand Calculation (Initial Static)}

An initial hand calculation of the reaction forces on the cryostat plate was performed using only two bolts and the key. The free-body diagram is shown in Fig. 36.

Assumptions:

1. Load of the cryostat is $\mathrm{P}=8.5 \mathrm{e} 5 \mathrm{~N}$ and treated as a point load $(\mathrm{P})$.

2. $\mathrm{P}$ is applied to the center of the top portion of the plate at a distance of $2232 \mathrm{~mm}$ from the IP along the $\mathrm{x}$-axis.

3. The only reaction forces are from bolts 1 and 5 and the key.

4. The bolt forces are applied radially through the IP and the key forces are applied tangentially to the IP only. That is, no shear is handled by the bolts.

Summing moments about IP,

$$
\begin{aligned}
\Sigma \mathrm{M}_{\mathrm{IP}}: & -\mathrm{F}_{\mathrm{k}} \mathrm{r}_{\mathrm{k}}+\mathrm{Pr}_{\mathrm{p}}=0 \\
& -\mathrm{F}_{\mathrm{k}}(4256 \mathrm{~mm})+(8.5 \mathrm{e} 5 \mathrm{~N})(2232 \mathrm{~mm})=0 \\
& \mathrm{~F}_{\mathrm{k}}=4.458 \mathrm{e} 5 \mathrm{~N} \\
\Sigma \mathrm{Fx}: & -\mathrm{F}_{1} \sin \mathrm{Y}_{1}-\mathrm{F}_{5} \sin \mathrm{Y}_{5}+\mathrm{F}_{\mathrm{k}} \cos \mathrm{Y}_{\mathrm{k}}=0
\end{aligned}
$$




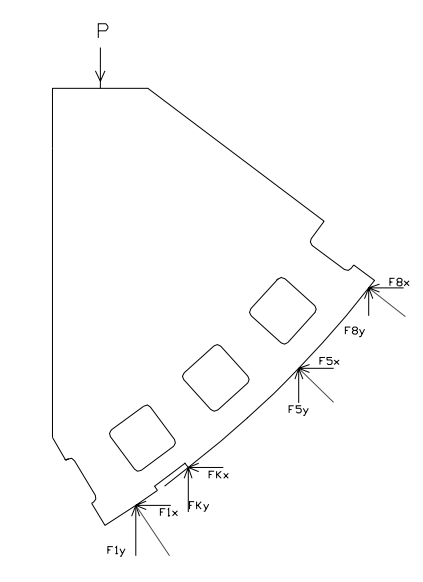

Figure 36. Free Body Diagram of Static Calculation.

$\Sigma \mathrm{Fy}: \quad-\mathrm{F}_{1} \cos \mathrm{Y}_{1}-\mathrm{F}_{5} \cos \mathrm{Y}_{5}-\mathrm{F}_{\mathrm{k}} \sin \mathrm{Y}_{\mathrm{k}}+\mathrm{P}=0$

Substituting $\mathrm{Y}_{1}=348, \mathrm{Y}_{5}=468, \mathrm{Y}_{\mathrm{k}}=37.648, \mathrm{P}=8.5 \mathrm{e} 5 \mathrm{~N}$, and $\mathrm{F}_{\mathrm{k}}=4.458 \mathrm{e} 5 \mathrm{~N}$ into Eqs. (2) and (3) yields:

$$
\begin{aligned}
& F_{1}=-8.196 e 5 \mathrm{~N} \\
& F_{5}=-1.464 \mathrm{e} 5 \mathrm{~N}
\end{aligned}
$$

\subsubsection{FEA Model (Initial Static)}

Using the 2D model shown in Fig. 35, an FEA model was created. The area of the plate was meshed as 3-node triangular thin shell elements with thickness of $70 \mathrm{~mm}$. Average element size is $40 \mathrm{~mm}$. The eight bolts and key were meshed as 3-D truss elements. Additionally, gap elements were added along the outer radius to represent the compressive reaction force provided by the saddle supports. Three types of analysis were performed on the model. In all cases, the load $\mathrm{P}=8.5 \mathrm{e} 5 \mathrm{~N}$ is applied equally over the center 5 nodes on the top of the plate (evenly around the small, vertical mark at the top of the drawing). Buckling analysis was not performed.

Case 1. Bolts 1, 5, and the key only are constrained to zero translation in all directions. The purpose of this analysis is to compare with the hand calculation.

Case 2. All eight bolts and the key are constrained to have zero displacement in all directions. 
Case 3. All eight bolts and the key are constrained to have zero displacement in all directions. Additionally, gap elements are placed at each node along the outer radius of the plate to model the effect of the saddle support.

\subsubsection{Bolt Forces and Stresses (Initial Static)}

Table 12 shows the reaction forces at the bolts for the both the hand calculation and the FEA models. There is close agreement between the hand calculation and Case 1. This is required (though not sufficient) to confirm the validity of the model. However, this is not a realistic loading situation as the remaining bolts will share in the load carrying, as will the saddle distribute the compressive forces. In comparing with Cases 2 and 3, it is seen that the bolt 5 force reduces by an order of magnitude when additional bolts are considered, as should be expected with the additional constraints. In comparing the loads between Cases 2 and 3, a further reduction is seen in the bolt forces, which is due to the different distribution of the compressive forces through the gap elements. Table 9 shows a comparison of the forces for Cases 2 and 3, as well as showing a summed total in Case 3 for the bolt and any nearby, active gap elements. There is relatively good agreement in bolts 1-4. Due to the geometry of loading, the force flow generally follows a path vertically from the load application to the support. In viewing Fig. 36, it can be seen that in Case 2, bolt 1 provides the left-most compressive force. In Case 3, however, where the gap elements are utilized, this left-most point is moved over to significantly alter the tensile forces needed in bolts 5-8. To verify this, a ninth bolt was added in the place where the left-most gap element is in Case 3 . As expected, this bolt took a large share of the compression and the forces on bolts 7 and $8(7.66 \mathrm{e}+4 \mathrm{~N}$ and $1.25 \mathrm{e}+8 \mathrm{~N}$, respectively) were much closer to the values of Case 3 . 
Table 12. Comparison of Reaction Forces Between Hand Calculations and FE Model.

\begin{tabular}{|c|c|c|c|c|c|c|c|}
\hline Bolt & $\begin{array}{c}\text { GAP } \\
\text { ELEMENT }\end{array}$ & $\begin{array}{c}\text { TRUSS } \\
\text { ELEMENT }\end{array}$ & $\begin{array}{c}\text { Hand } \\
\text { Calc. [N] }\end{array}$ & $\begin{array}{c}\text { Case } 1 \\
{[\mathrm{~N}]}\end{array}$ & $\begin{array}{c}\text { Case } 2 \\
{[\mathrm{~N}]}\end{array}$ & $\begin{array}{c}\text { Case } 3 \\
{[\mathrm{~N}]}\end{array}$ & $\begin{array}{c}\text { Case } 3 \\
\text { Gap+Truss } \\
{[N]}\end{array}$ \\
\hline & 1900 & & & & & $-4.43 \mathrm{E}+04$ & \\
\hline & 1901 & & & & & $-1.39 E+05$ & \\
\hline & 1902 & & & & & $-1.44 \mathrm{E}+05$ & \\
\hline & 1903 & & & & & & \\
\hline & 1904 & & & & & $-1.38 E+05$ & \\
\hline & 1905 & & & & & & \\
\hline & 1906 & & & & & $-3.66 \mathrm{E}+04$ & \\
\hline \multirow[t]{6}{*}{1} & & 1891 & $-8.20 E+05$ & $-8.28 \mathrm{E}+05$ & $-5.04 E+05$ & $-3.64 E+03$ & $-5.05 E+05$ \\
\hline & 1907 & & & & & $-2.52 E+05$ & \\
\hline & 1908 & & & & & & \\
\hline & 1909 & & & & & & \\
\hline & 1910 & & & & & & \\
\hline & 1911 & & & & & $-6.25 E+04$ & \\
\hline \multirow[t]{4}{*}{2} & & 1893 & & & $-2.40 \mathrm{E}+05$ & 3.99E+03 & $-3.10 \mathrm{E}+05$ \\
\hline & 1912 & & & & & & \\
\hline & 1913 & & & & & & \\
\hline & 1914 & & & & & & \\
\hline \multirow[t]{4}{*}{3} & & 1894 & & & $-1.41 E+05$ & $2.94 \mathrm{E}+03$ & $2.94 \mathrm{E}+03$ \\
\hline & 1915 & & & & & & \\
\hline & 1916 & & & & & $-1.24 \mathrm{E}+04$ & \\
\hline & 1917 & & & & & $-7.50 E+02$ & \\
\hline \multirow[t]{4}{*}{4} & & 1895 & & & $-1.08 E+05$ & 4.13E+03 & $-1.11 \mathrm{E}+05$ \\
\hline & 1918 & & & & & $-1.75 E+04$ & \\
\hline & 1919 & & & & & $-8.45 E+04$ & \\
\hline & 1920 & & & & & & \\
\hline \multirow[t]{4}{*}{5} & & 1896 & $1.46 \mathrm{E}+05$ & $1.43 E+05$ & $-1.57 E+04$ & $4.11 \mathrm{E}+04$ & $4.11 \mathrm{E}+04$ \\
\hline & 1921 & & & & & & \\
\hline & 1922 & & & & & & \\
\hline & 1923 & & & & & & \\
\hline \multirow[t]{4}{*}{6} & & 1897 & & & $2.39 E+04$ & $3.30 \mathrm{E}+04$ & $3.30 \mathrm{E}+04$ \\
\hline & 1924 & & & & & & \\
\hline & 1925 & & & & & & \\
\hline & 1926 & & & & & & \\
\hline \multirow[t]{4}{*}{7} & & 1898 & & & $1.16 \mathrm{E}+05$ & $7.15 E+04$ & $7.15 E+04$ \\
\hline & 1927 & & & & & & \\
\hline & 1928 & & & & & & \\
\hline & 1929 & & & & & & \\
\hline 8 & & 1899 & & & $1.91 \mathrm{E}+05$ & $9.61 \mathrm{E}+04$ & $9.61 \mathrm{E}+04$ \\
\hline Key & & 1892 & $-4.46 \mathrm{E}+05$ & $-4.54 \mathrm{E}+05$ & $-4.45 \mathrm{E}+05$ & $-4.48 \mathrm{E}+05$ & $-4.48 \mathrm{E}+05$ \\
\hline
\end{tabular}

Table 10 compares the calculated stress in the bolt cross section and the thread stress in the cryostat plate. While the bolt stresses are considerably higher, this is relatively easily resolved with high strength bolts. The bolts examined in this analysis are M24x3 bolts (minor diameter $=20.7 \mathrm{~mm}$ ). In calculating the thread stress, the following formula was used:

$$
\tau 5 \mathrm{~F} /(\pi \mathrm{d}(0.75 \mathrm{t}))
$$

where $\mathrm{d}$ is the major diameter of the bolt, $\mathrm{t}$ is the thread length (here $1.5 \mathrm{~d}$ is used). 
M24 x 3 bolt

Cross section Area $=\pi(20.7 \mathrm{~mm} / 2)^{2}=336 \mathrm{~mm}^{2}$

Thread Area $=(3.1415)(24 \mathrm{~mm})(1.5 * 24 \mathrm{~mm})(0.75)=2036 \mathrm{~mm}^{2}$

In looking at the thread stresses, only bolt 8 in Case 2 is excessive and will require a high strength bolt. In Case 3, this stress is considerably lower and in a reasonable range. It is reasonable to believe that Case 3 is the more realistic model, where the compressive contact forces along the saddle help lower the tensile forces in the extreme bolts (5-8). The stresses found in the bolts from simple analysis are within the range of high-strength bolts. More detailed analysis taking into account preload should be done after maximum forces are determined from the earthquake studies.

Table 11. Bolt Stresses (in Pa).

\begin{tabular}{|c|c|c|c|c|c|c|c|c|}
\hline Bolt & $\begin{array}{c}\text { Hand Calc. } \\
\text { Bolt } \\
\text { Stress } \\
{[\mathrm{Pa}]}\end{array}$ & $\begin{array}{c}\text { Thread } \\
\text { Stress } \\
{[\mathrm{Pa}]}\end{array}$ & $\begin{array}{l}\text { Case } 1 \\
\text { Bolt } \\
\text { Stress } \\
{[\mathrm{Pa}]}\end{array}$ & $\begin{array}{c}\text { Thread } \\
\text { Stress } \\
{[\mathrm{Pa}]}\end{array}$ & $\begin{array}{c}\text { Case } 2 \\
\text { Bolt } \\
\text { Stress } \\
{[\mathrm{Pa}]}\end{array}$ & $\begin{array}{c}\text { Thread } \\
\text { Stress } \\
{[\mathrm{Pa}]}\end{array}$ & \begin{tabular}{|} 
Case 3 \\
Bolt \\
Stress \\
{$[\mathrm{Pa}]$}
\end{tabular} & $\begin{array}{c}\text { Thread } \\
\text { Stress } \\
{[\mathrm{Pa}]}\end{array}$ \\
\hline 1 & $-2.44 E+09$ & $-4.03 E+08$ & $-2.47 E+09$ & $-4.07 E+08$ & $-1.50 E+09$ & $-2.48 \mathrm{E}+08$ & $-1.08 \mathrm{E}+07$ & $-1.79 \mathrm{E}+06$ \\
\hline 2 & & & & & $-7.14 \mathrm{E}+08$ & $-1.18 E+08$ & $1.19 \mathrm{E}+07$ & $1.96 \mathrm{E}+06$ \\
\hline 3 & & & & & $-4.18 E+08$ & $-6.90 E+07$ & $8.75 E+06$ & $1.44 \mathrm{E}+06$ \\
\hline 4 & & & & & $-3.21 E+08$ & $-5.29 E+07$ & $1.23 \mathrm{E}+07$ & $2.03 E+06$ \\
\hline 5 & $4.36 \mathrm{E}+08$ & $7.19 E+07$ & $4.27 E+08$ & $7.04 \mathrm{E}+07$ & $-4.68 E+07$ & $-7.73 \mathrm{E}+06$ & $1.22 \mathrm{E}+08$ & $2.02 E+07$ \\
\hline 6 & & & & & $7.12 \mathrm{E}+07$ & $1.18 \mathrm{E}+07$ & $9.82 \mathrm{E}+07$ & $1.62 \mathrm{E}+07$ \\
\hline 7 & & & & & $3.44 \mathrm{E}+08$ & $5.68 \mathrm{E}+07$ & $2.13 E+08$ & $3.51 E+07$ \\
\hline 8 & & & & & $5.69 \mathrm{E}+08$ & $9.39 E+07$ & $2.86 E+08$ & $4.72 E+07$ \\
\hline
\end{tabular}



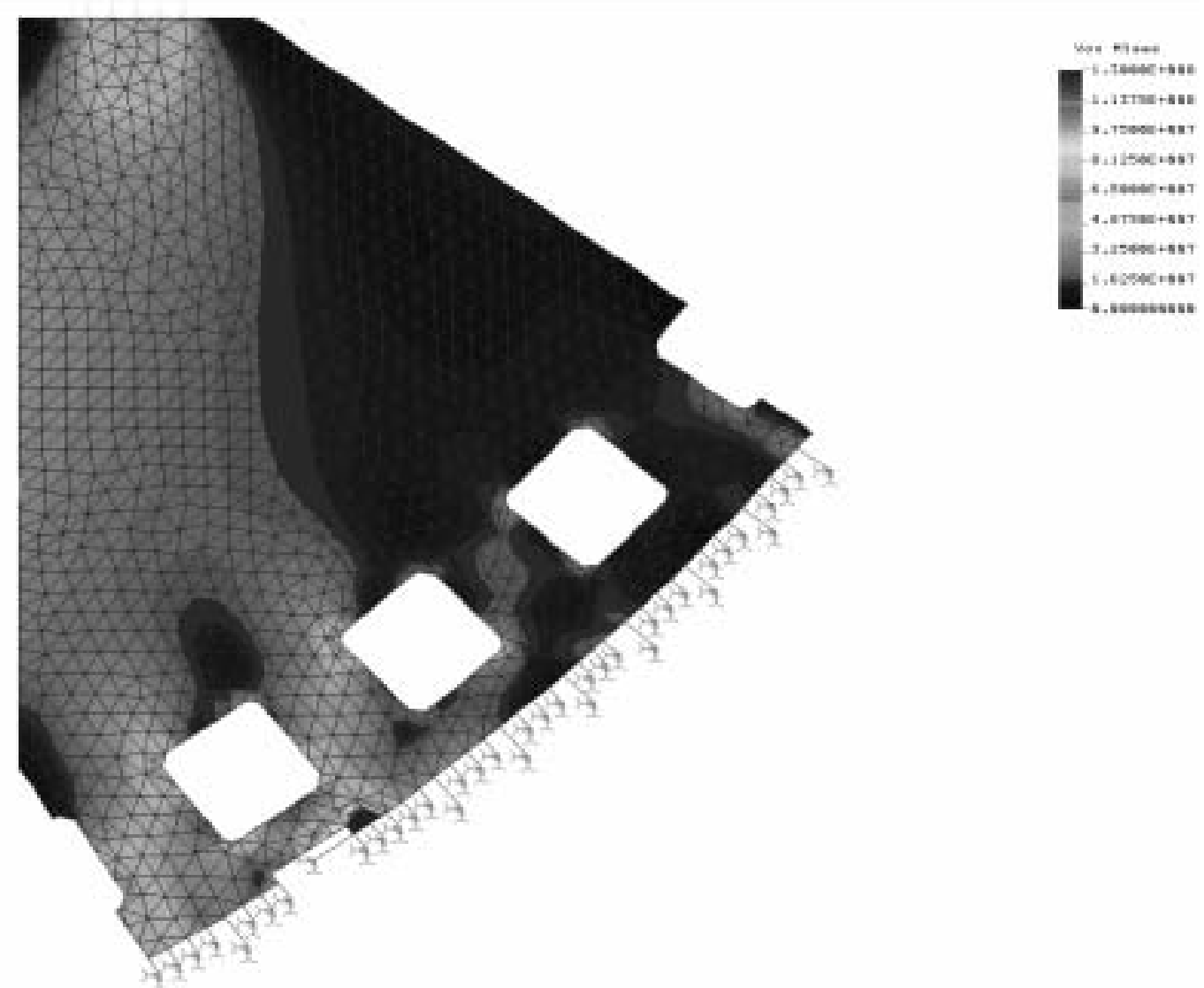

Figure 37. Von Mises Stress Plot of Case 3 (8 bolts plus gap elements).

\subsubsection{Plate Stresses (Initial Static)}

For the key forces, both the hand calculation and the three, FEA cases have good agreement, which gives considerable confidence in the value. In the direction of the applied force, the bearing face of the key has dimension $20 \mathrm{~mm} \times 70 \mathrm{~mm}$ (square) or an area of $A_{k}=1400 \mathrm{~mm}^{2}$. Using the value for the key force $\mathrm{F}_{\mathrm{k}}=4.46 \mathrm{e}+5 \mathrm{~N}$ and assuming uniform distribution over the face,

$$
\sigma_{k}=F_{k} / A_{k}=(4.46 e+5 N) /\left(1400 \mathrm{~mm}^{2}\right)=318 \mathrm{MPa} \text {. }
$$

This stress exceeds the yield stress of stainless steels.

Figure 37 shows a plot of the Von Mises stress for Case 3. The effective stress is below 80MPa for all of the plate except at the location of the key. At the point of contact, the Von Mises stress has a value of $265 \mathrm{Mpa}$. This value is in excess of the design limit of $130 \mathrm{MPa}$. The solution is to make the key greater depth and thereby increase the bearing area for both the plate and the key. This design change and subsequent analysis is discussed in Section 3.3. 


\subsection{Preliminary Seismic Loading Analysis}

A preliminary investigation was done in examining the effect of seismic forces. The analysis focused mainly on the Z-direction forces, as the bending stresses and deflection caused by this direction are expected to be considerably more significant than the $\mathrm{X}$ - and $\mathrm{Y}$ - directions. Two forms of analysis were done, a simple FEA model using 2-D beam elements and 3-D analysis using the same model described in Section 3.1.2. Both models show good agreement and indicate that maximum deflections in the $\mathrm{Z}$ direction of the unstiffened plate are on the order of $40 \mathrm{~mm}$ with stresses due to bending greatly exceeding yield. Additionally, the reaction moment needed at the plate/saddle interface is large.

A static load equivalent to $15 \%$ of the vertical load applied through the cryostat C.G. is used to represent the seismic load condition as determined by CERN TC. The two, back cryostat plates are intended to completely withstand the full lateral force in Z. Using the force due to the full weight of the cryostat, $2.646 \mathrm{kN}, 15 \%$ of this value is $396.9 \mathrm{kN}$. Sharing this load equally across the two support plates gives a seismic force in the $\mathrm{Z}$-direction $\mathrm{F}_{\mathrm{EQZ}}=198.4 \mathrm{kN}$.

As a first pass approximation, the support plate was modeled as a cantilevered, tapered beam made of four beam elements. Each element had an area amount of an approximate value of the plate area segment it represented. The cut-outs in the plate were not considered in the value for the area. The load $\mathrm{F}_{\mathrm{EQZ}}$ was applied laterally to the beam. The total tip deflection was $31 \mathrm{~mm}$. The reaction moment at the base of the beam was $2.98 \mathrm{e} 5 \mathrm{Nm}$. These results are listed in Appendix 2.

Similarly, the FEA model using shell elements (described above) had the load $\mathrm{F}_{\mathrm{EQZ}}$ applied in the same position as the static load in the analysis above, but directed in the Z-direction. The plate was constrained in all DOF at the 8 bolts. The maximum deflection in the $\mathrm{Z}$ direction was $42 \mathrm{~mm}$ with the 


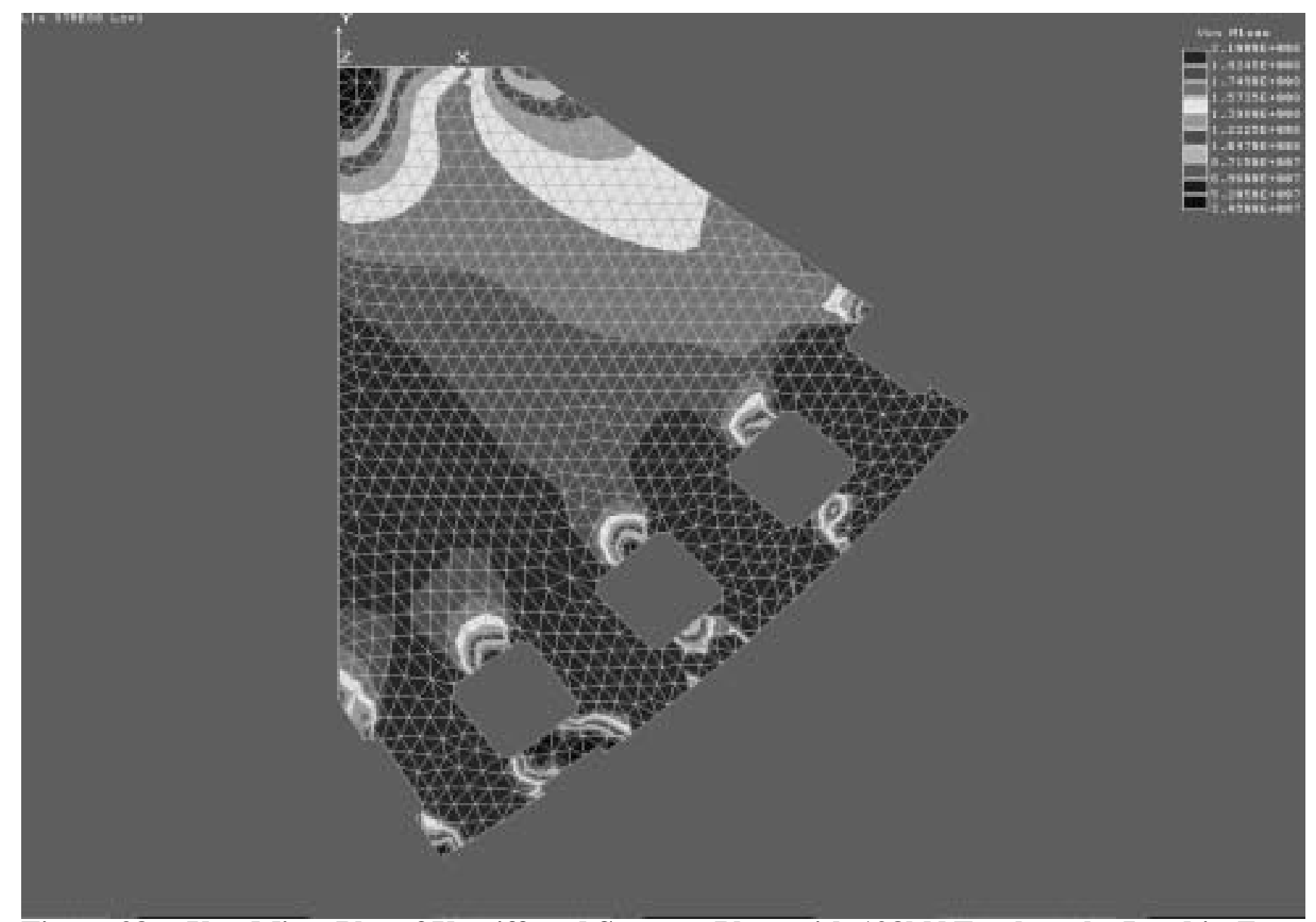

Figure 38. Von Mises Plot of Unstiffened Support Plate with 198kN Earthquake Load in Z direction.

sum of the moment reaction at the bolts equaling $2.773 \mathrm{e} 5 \mathrm{Nm}$. The deflections and reaction show good agreement between the beam and shell models. It is expected that the beam model has less deflection, as the cut-outs are not accounted for. These reduce the area considerably in an area subjected to high stress. The reactions calculated from the two methods are close, considering that the bolts as restraints offer varying moment arms that are difficult to account for in the simple beam model.

Figure 38 shows a Von Mises stress plot of plate under the earthquake load. The effective stress exceeds the yield in much of the lower portion of the plate and takes on values above 400MPa in the areas between the cut-outs. It is clear from this that the cryostat plate requires stiffening. A solution to stiffening the plate is to attach a beam to the plate in the form of a rib. Based on size and space limitations, a custom-shaped beam is specified to handle the bending moment. Figure 39 shows the location and dimensions of the proposed beam. The simple beam FEA model discussed above was modified to include the increased inertia brought on by the beam and, using the same loads as previously, the deflection at the tip is now reduced to an acceptable $0.9 \mathrm{~mm}$. This serves as a good first approximation, although it remains to incorporate this beam into the $3 \mathrm{D}$ shell model to verify this value.

Further analysis of the seismic loading is discussed in Section 3.5. It is shown that the load for the Z-direction increases significantly when simultaneous, seismic loading in the $\mathrm{X}$ and $\mathrm{Y}$ directions are considered. Using the same approach outlined here, the stiffener beam is resized and an additional one is added. This is the basis of the redesign that is discussed in Section 3.3. 


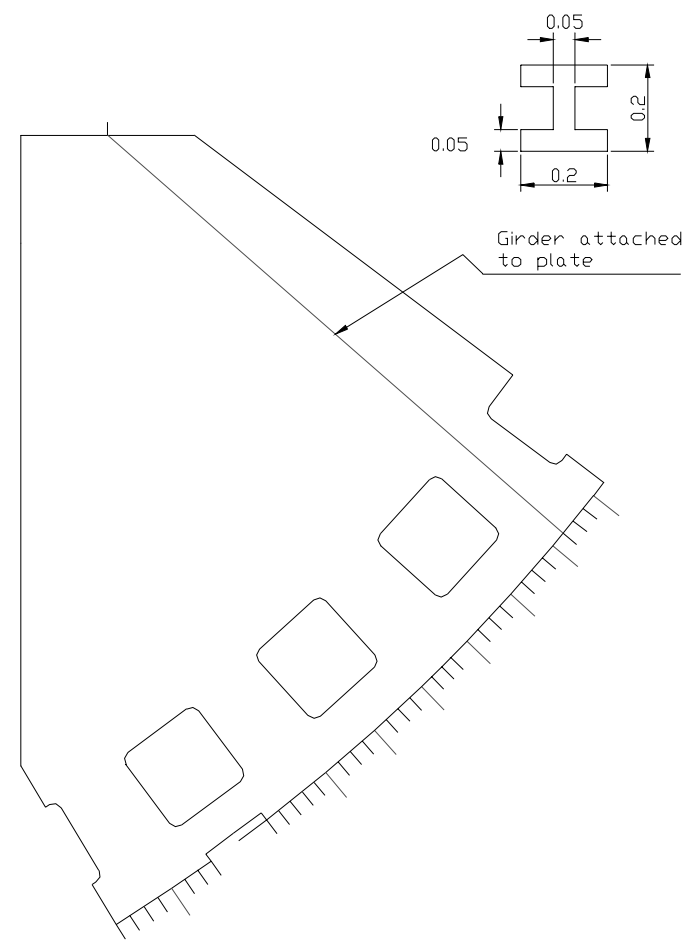

Figure 39. Location and Shape of Proposed Stiffener Beam Attached to Plate. 


\subsection{Redesign and Static Analysis of Cryostat Plate Incorporating Stiffener Beams}

\subsubsection{Cryostat Plate with Stiffener Beams}

The preliminary analysis of Section 3.2 shows that earthquake loading in the Z-direction caused excessive plate deflection $(>40 \mathrm{~mm})$ and created a large reaction moment at the base of the cryostat plate. Figure 40 shows the revised design of one of the symmetric, back cryostat supports with two stiffener beams attached. The two stiffener beams were added to both reduce the plate deflection and provide a reasonable means for transferring the reaction moment to the saddle support. Due to the location of the beams, the bolt pattern for attaching the plate to the saddle had to be altered and the number of bolts was reduced from 8 to 5, as can be seen in Figs. 40 and 41. This resulted in the need to perform the static analysis again with the new model.

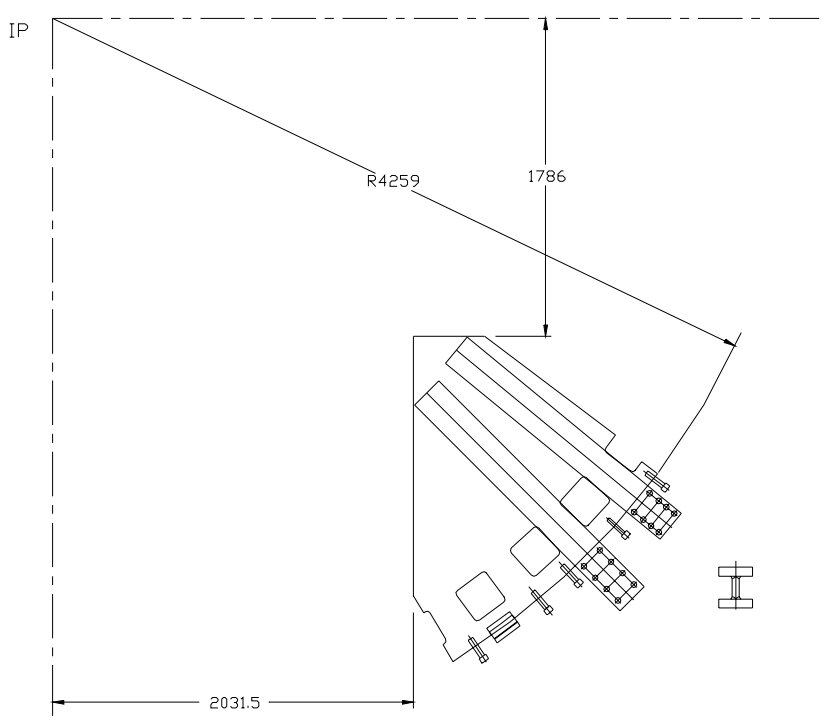

Figure 40. Back Cryostat Support Plate with Stiffening Beams. 


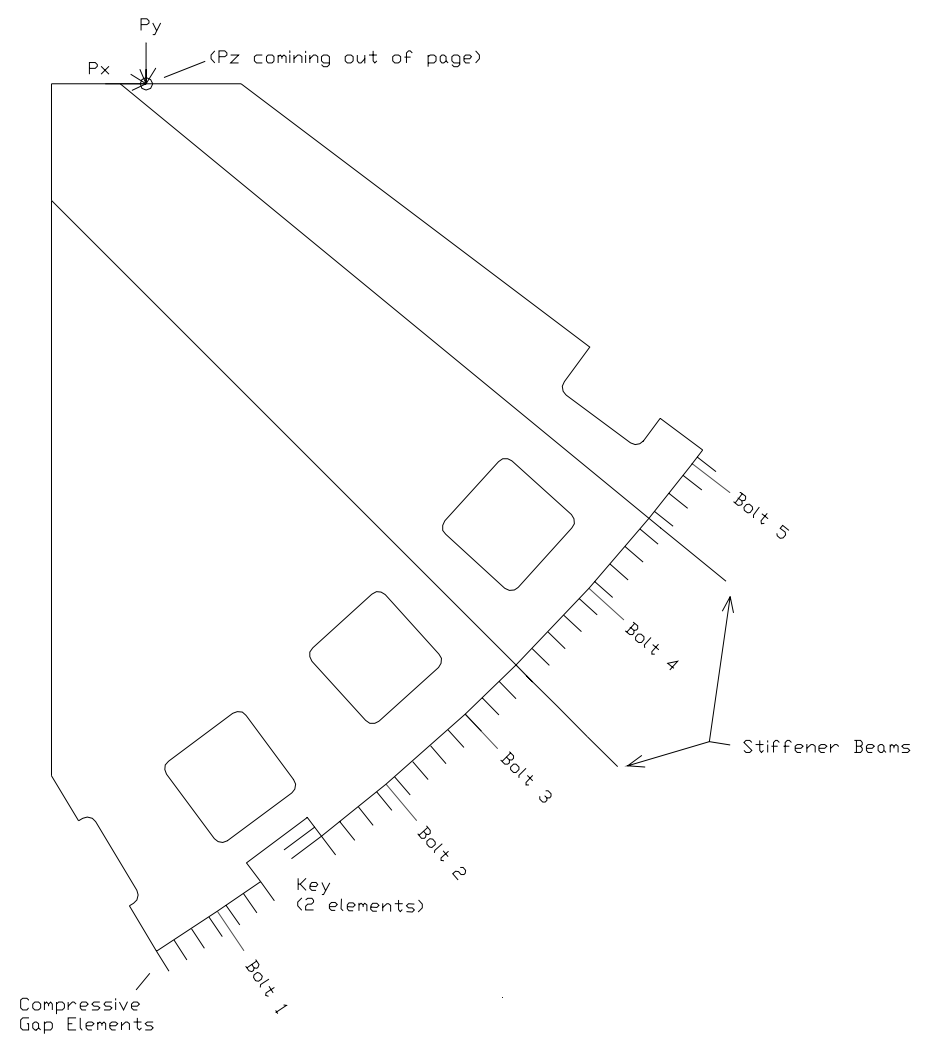

Figure 41. Redesigned Cryostat Plate Model Showing Bolt Locations.

Table 14. Bolt and Key Locations from IP in Theta.

\begin{tabular}{|c|c|c|c|c|c|c|}
\hline Bolt\# & $\mathbf{1}$ & Key & $\mathbf{2}$ & $\mathbf{3}$ & $\mathbf{4}$ & $\mathbf{5}$ \\
\hline Angle (deg) & 34 & 37.64 & 40 & 43 & 48 & 52.6 \\
\hline
\end{tabular}

\subsubsection{Static Load Case and Bolt Analysis}

Before discussing the seismic loading, we first reexamine the new model for the static gravity load. As was done in Section 3.1, we compare a simple hand calculation with the FEA model. A simple static calculation is performed using Eqs. (1)-(3) in Section 3.1.1 with similar assumptions:

1. Load of the cryostat is $\mathrm{P}=8.5 \mathrm{e} 5 \mathrm{~N}$ and treated as a point load $(\mathrm{P})$.

2. $\mathrm{P}$ is applied to the top, center portion of the plate at a distance of $2232 \mathrm{~mm}$ from the IP along the $\mathrm{x}$-axis.

3. The only reaction forces are from the two bolts used in the calculation and the key.

4. The bolt forces are radial loads through the IP and the key forces are applied tangentially to the IP only. That is, there is no shear load handled by the bolts.

In this case we substitute bolt 4 for bolt 5 . Substituting $P=8.5 e+5 \mathrm{~N}, \mathrm{r}_{\mathrm{K}}=4256 \mathrm{~mm}, \mathrm{r}_{\mathrm{p}}=2232 \mathrm{~mm}$, $v_{1}=348, v_{K}=37.68, v_{4}=488$ into Eqs. (1)-(3) of Section 11, we find: 
Static Case A

$$
\mathrm{F}_{1}=-7.985 \mathrm{e} 5 \mathrm{~N} \quad \mathrm{~F}_{4}=1.258 \mathrm{e} 5 \mathrm{~N} \quad \mathrm{~F}_{\mathrm{K}}=-4.458 \mathrm{e} 5 \mathrm{~N}
$$

Static Case B

If the same calculation is repeated for bolt 5 , substituting $v_{5}=52.6$, we find:

$$
\mathrm{F}_{1}=-7.668 \mathrm{e} 5 \mathrm{~N} \quad \mathrm{~F}_{5}=9.544 \mathrm{e} 4 \mathrm{~N} \quad \mathrm{~F}_{\mathrm{K}}=-4.458 \mathrm{e} 5 \mathrm{~N}
$$

Using the 2-D model shown in Fig. 41, an FEA model was created. The area of the plate was meshed as 3 -node triangular thin shell elements with thickness of $70 \mathrm{~mm}$. Average element size was reduced from $40 \mathrm{~mm}$ in the previous model to $25 \mathrm{~mm}$. The five bolts and key were meshed as 3-D truss elements. The key was meshed as two separate elements. Again, gap elements were added along the outer radius to represent the compressive reaction force provided by the saddle supports. Two types of analysis were performed on the model. In both cases, the load $\mathrm{P}=8.5 \mathrm{e} 5 \mathrm{~N}$ is applied equally over the center 6 nodes on the top center of the plate. Buckling analysis was not performed.

\section{Static Case C}

Bolts 1, 4, and the key only are constrained to zero translation in all directions. The purpose of this analysis is to compare with the hand calculation.

\section{Static Case D}

All eight bolts and the key are constrained to have zero displacement in all directions.

Additionally, gap elements are placed at each node along the outer radius of the plate to model the effect of the saddle support.

\section{Static Case E}

Similar to Case D, but with gap and key elements moved from corner. This analysis is mainly to understand stresses at the key and is described further in Section 3.3.3. 


\begin{tabular}{|c|c|c|c|c|c|c|}
\hline NODE & Fx & Fy & $\mathbf{F z}$ & Mx & My & Mz \\
\hline 2708 & $3.56 \mathrm{E}+05$ & $2.69 \mathrm{E}+05$ & $0.00 \mathrm{E}+00$ & & --------- & --------- \\
\hline 2711 & $-1.44 \mathrm{E}+03$ & $2.14 \mathrm{E}+03$ & $0.00 \mathrm{E}+00$ & & & \\
\hline 2713 & $4.72 \mathrm{E}+03$ & $-5.62 E+03$ & $0.00 \mathrm{E}+00$ & & & \\
\hline 2715 & $3.31 E+03$ & $-3.55 E+03$ & $0.00 \mathrm{E}+00$ & ---------- & & \\
\hline 2717 & $3.96 \mathrm{E}+04$ & $-3.57 E+04$ & $0.00 \mathrm{E}+00$ & ---------- & ---------- & -----.-. \\
\hline 2719 & $7.53 \mathrm{E}+04$ & $-5.76 E+04$ & $0.00 \mathrm{E}+00$ & -- & ---------- & --- \\
\hline 2737 & $-2.69 E+04$ & $4.31 \mathrm{E}+04$ & ---------- & & ---------- & \\
\hline 2739 & $-7.86 \mathrm{E}+04$ & $1.23 \mathrm{E}+05$ & & & & \\
\hline 2741 & $-6.56 \mathrm{E}+04$ & $1.01 \mathrm{E}+05$ & --------- & & & \\
\hline 2743 & $-4.99 E+04$ & $7.47 \mathrm{E}+04$ & --------- & ---------- & & \\
\hline 2745 & $-2.97 E+04$ & $4.35 E+04$ & ---------- & ---------- & --------- & ---- \\
\hline 2747 & $-1.48 \mathrm{E}+04$ & $2.13 \mathrm{E}+04$ & ---------- & ---------- & ---------- & ---------- \\
\hline 2749 & $-3.92 E+03$ & $5.50 \mathrm{E}+03$ & ---------- & ---------- & ---------- & ---------- \\
\hline 2750 & $-2.05 E+05$ & $2.66 \mathrm{E}+05$ & --------- & ---------- & ---------- & ---------- \\
\hline 2752 & $-2.58 E+03$ & $3.27 \mathrm{E}+03$ & ---------- & ---------- & ---------- & ---------- \\
\hline Total & $-1.00 \mathrm{E}+00$ & $8.50 \mathrm{E}+05$ & $0.00 \mathrm{E}+00$ & $0.00 E+00$ & $0.00 E+00$ & $0.00 E+00$ \\
\hline
\end{tabular}

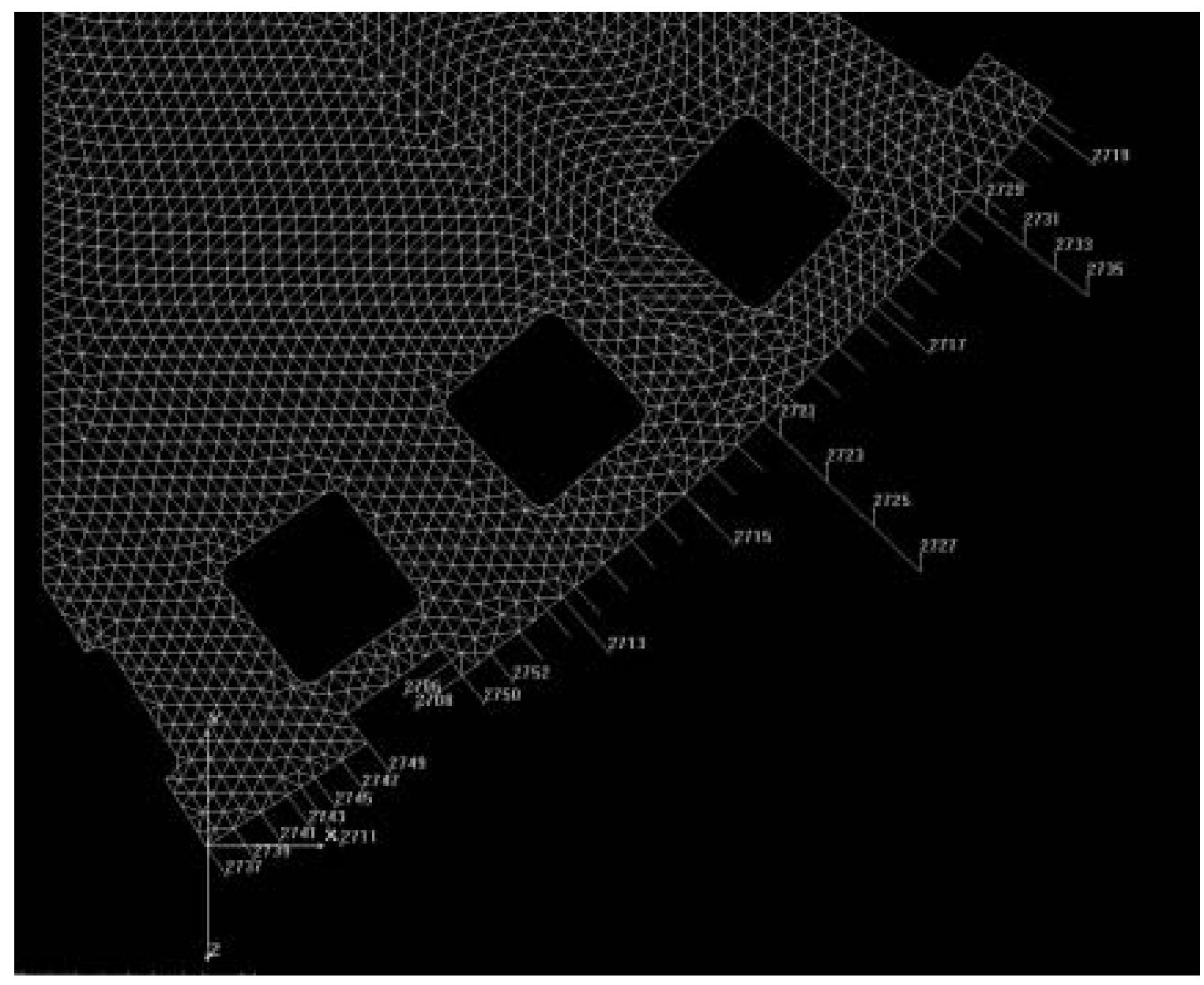

Figure 42. Identification of nodes for reaction force interpretation. 
A summary of the reaction forces is listed in Table 15 and the corresponding nodes are identified in Fig. 42. This serves as a check that the reaction forces are summing up to the applied loads as they do. A comparison of values for the hand calculations and FEA models is given in Table 16. Cases A and C are designed to compare to the similar calculations shown in Table 12. The slight difference in values is accounted for by the slightly differing locations of Bolt 5 in the model of Section 3.1 and bolt 4 of the current model. Cases A and $\mathrm{C}$ show excellent agreement. However, a more realistic loading situation exists when the compressive reaction of the saddle is considered. This is achieved through the gap elements used in Case D. Bolt stresses are shown in Table 17 and compare reasonably with those shown in Table 13 for the 8 bolt case. Table 17 shows the bolt and thread stresses for the static load case. The stresses are well within range and below the design limit of 90MPa. Figure 40 shows the Von Mises stress for the static load case.

Table 16. Comparison of Hand Calculation and FEA Models for Several Static Load Cases.

\begin{tabular}{|c|c|c|c|c|c|c|c|c|}
\hline & \multicolumn{2}{|c|}{ HAND CALC } & \multicolumn{3}{|c|}{ FEA MODEL } & \multirow[b]{2}{*}{$\begin{array}{c}\text { SUM GAP } \\
\text { AND BOLTS } \\
{[N]}\end{array}$} \\
\hline $\begin{array}{r}\text { BOLT } \\
\text { NUMBER }\end{array}$ & $\begin{array}{c}\text { TRUSS } \\
\text { ELEMENT }\end{array}$ & $\begin{array}{c}\text { ACTIVE } \\
\text { GAP } \\
\text { ELEMENTS }\end{array}$ & $\begin{array}{c}\text { FORCE } \\
{[\mathrm{N}]} \\
\text { CASE A }\end{array}$ & $\begin{array}{c}\text { FORCE } \\
{[\mathrm{N}]} \\
\text { CASE B }\end{array}$ & $\begin{array}{l}\text { FORCE } \\
{[\mathrm{N}]} \\
\text { CASE C }\end{array}$ & $\begin{array}{c}\text { FORCE } \\
\text { (bolts) } \\
{[\mathrm{N}]}\end{array}$ & $\begin{array}{c}\text { FORCE } \\
\text { (gaps) } \\
{[\mathrm{N}]} \\
\text { CASE D }\end{array}$ & \\
\hline 1 & 4753 & $\begin{array}{l}766 \\
4767 \\
4768 \\
4769 \\
4770 \\
4771 \\
4772\end{array}$ & $-7.99 \mathrm{E}+05$ & $-7.67 E+05$ & $-8.01 E+05$ & $-2.58 E+03$ & $\begin{array}{c}-50830 \\
-146200 \\
-120100 \\
-89830 \\
-52690 \\
-25910 \\
-6751\end{array}$ & \\
\hline 2 & 4754 & $\begin{array}{l}4773 \\
4774\end{array}$ & & & & $7.34 \mathrm{E}+03$ & $\begin{array}{c}-335900 \\
-4161\end{array}$ & $-8.28 E+05$ \\
\hline 3 & 4755 & & & & & $4.85 E+03$ & & \\
\hline 4 & 4756 & & $1.26 \mathrm{E}+05$ & & $1.24 \mathrm{E}+05$ & $5.33 E+04$ & & \\
\hline 5 & 4757 & & & $9.54 \mathrm{E}+04$ & & $9.48 E+04$ & & $1.53 \mathrm{E}+05$ \\
\hline KEY & 4752 & & $-4.46 \mathrm{E}+05$ & $-4.46 \mathrm{E}+05$ & $-4.46 \mathrm{E}+05$ & $-4.46 \mathrm{E}+05$ & & $-4.46 \mathrm{E}+05$ \\
\hline
\end{tabular}

Table 17. Bolt and Thread Stresses For Static Load Case D.

\begin{tabular}{|c|c|c|c|c|}
\hline \multirow[b]{2}{*}{ Element } & \multirow[b]{2}{*}{$\begin{array}{l}\text { Bolt } \\
\text { Force } \\
{[\mathrm{N}]}\end{array}$} & \multicolumn{2}{|c|}{ BOLT STRESSES } & \multirow[b]{2}{*}{$\begin{array}{l}\text { PLATE } \\
\text { Int. thread } \\
\text { Stripping } \\
\text { Stress } \\
\text { [Mpa] }\end{array}$} \\
\hline & & $\begin{array}{l}\text { Axial } \\
\text { Bolt } \\
\text { Stress } \\
\text { [Mpa] }\end{array}$ & \begin{tabular}{|l|} 
Ext. thread \\
Stripping \\
Stress \\
[Mpa]
\end{tabular} & \\
\hline 4753 & $-2.58 \mathrm{E}+03$ & -8 & -1.8 & -1.3 \\
\hline 4754 & $7.34 \mathrm{E}+03$ & 23 & 5.2 & 3.6 \\
\hline 4755 & $4.85 \mathrm{E}+03$ & 16 & 3.4 & 2.4 \\
\hline 4756 & $5.33 E+04$ & 170 & 37.9 & 26.2 \\
\hline 4757 & $9.48 \mathrm{E}+04$ & 303 & 67.4 & 46.6 \\
\hline
\end{tabular}




\subsubsection{Plate Stresses and Key Area Analysis}

The stresses for the plate are also well below the design limit of $130 \mathrm{MPa}$ in all areas except the key. Comparing the results with those of Section 3.1.4 (Fig. 37), good agreement is shown between the models.

The FEA model determines a maximum Von Mises stress of 356MPa at the point of contact between the key and the plate. The question is whether this high stress concentration in the key area is due to the geometry and the restraint in the model, or is it real. The model uses a single truss element to represent the key, thereby producing a large point load at the two nodes near the key. Similarly a compressive gap element is located at the same corner node of the key. This force is quantified and identified in Table 16 and Fig. 44, respectively. Figure 44 shows the key area in greater detail and Fig. 45 shows the same area in terms of element stresses. These figures show that the stress is not only concentrated at the core, but that it also drops off steeply a short distance from the key. Note that the average element size in this case is $25 \mathrm{~mm}$. If these stress concentrations are real, the material in the corner would yield and strain until the remaining surface area started carrying a higher share of the load. This is not unlike a contact stress problem. Solving this analytically is not simple, as the standard developed contact stress formulas generally involve at least one curved surface, such as Hertz contact problems.

To take a simplified approach at understanding the stresses, we reduce the corner of the key to a square that is $25 \mathrm{~mm}$ square (with depth of $70 \mathrm{~mm}$ ) starting from the corner node that is acted upon by elements 4752 and 4773 (Fig. 44). We will assume that the force acting on the corner node is evenly distributed over the face of the cube. Recalling that the plate is $70 \mathrm{~mm}$ thick, and using the values for the key force, $\mathrm{F}_{\mathrm{K}}$ (element 4752), and the saddle compressive gap force, $\mathrm{F}_{\mathrm{G}}$, we determine the average stresses on each face, $\sigma_{\mathrm{K}}$ and $\sigma_{\mathrm{G}}$ :

$$
\begin{gathered}
A_{25}=25 \mathrm{~mm} \times 70 \mathrm{~mm}=1750 \mathrm{~mm}^{2} \\
\sigma_{K}=\frac{F_{K}}{A_{25}}=\frac{-4.44 \mathrm{e} 5 \mathrm{~N}}{1750 \mathrm{~mm}^{2}}=-254 \mathrm{MPa} \\
\sigma_{G}=\frac{F_{G}}{A_{25}}=\frac{-3.359 e 5 \mathrm{~N}}{1750 \mathrm{~mm}^{2}}=-192 \mathrm{MPa}
\end{gathered}
$$

If we assume further that $\sigma_{\mathrm{K}}$ and $\sigma_{\mathrm{G}}$ are the only stresses and that no shear stresses are present, then these stresses are principle. We then use the equation for principle stresses to determine the Von Mises stress, $\sigma_{\mathrm{E}}$, substituting $\sigma_{\mathrm{K}}$ and $\sigma_{\mathrm{G}}$ for $\sigma_{1}$ and $\sigma_{2}$.

$$
\sigma_{E}=\sqrt{\sigma_{1}^{2}+\sigma_{2}^{2}-\sigma_{1} \sigma_{2}}=\sqrt{(-254 M p a)^{2}+(-192 M P a)^{2}-(-254 M P a)(-192 M p a)}=230 M P a
$$

This value compares well with the stresses shown when looking at the element stress in Fig. 45. However, this concentrates the total load to a smaller area than is available and is not realistic. The same calculation as above is extended to $50 \mathrm{~mm}$ square area. Performing similar calculations as above, with 
$\mathrm{A}_{50}=3500 \mathrm{~mm}^{2}, \sigma_{\mathrm{K}}=-127 \mathrm{MPa}, \sigma_{\mathrm{G}}=-96 \mathrm{MPa}$, we get $\sigma_{\mathrm{E}}=114 \mathrm{MPa}$. This value is below the design limit of $130 \mathrm{MPa}$, but is based on the same assumptions of uniform stress distribution and the stress being principle. It is more likely that the highest stresses are between these two values.

It should also be mentioned that the inside corner of the key produces a stress concentration. Because of the design, the entire tangential load along the bottom curve of the plate is compressive at the bearing face of the key. A more typical evaluation of stress concentrations, such as the one due the inside corner, would be the result of tensile loads traveling through the area above the key and below the first cut-out. Although some load does follow this path in transferring the Y direction load to the saddle and bolts, there is not a large tensile force to speak of and, in fact, this material would not be needed if only tangential loads were being dealt with. The FEA model for Case D gives values of stress on the order of $110 \mathrm{MPa}$ in this region.

Viewing Figs. 44 and 45, active gaps can be seen at the corner of the key at the same location as the single truss element representing the key. To understand the nature of the stress distribution in that area, the truss element and gap element acting on the corner point were removed and run in a new analysis (Case E). Additionally, the truss element representing the key acts on the middle portion of the key (refer to Fig. 41 where the key is shown as two elements). Figures 46 and 47 show the node and element Von Mises stress at the key for the static loading Case E with the modification at the corner. Note that the scale is lower in Fig. 46 than in Fig. 45.

The above analysis has calculated the stresses near or over the design limit of 130MPa, depending on the assumption you choose to follow. While it is reasonable to believe that the values that are less than the design limit are correct, there are several assumptions made that are difficult to prove. These lower stress values are dependent upon these assumptions. Also, looking ahead to the added seismic loads that increase the force in the key area, there is good justification in seeking to further reduce the stress in this region of the plate. This can be done by increasing the plate thickness in the key area. 


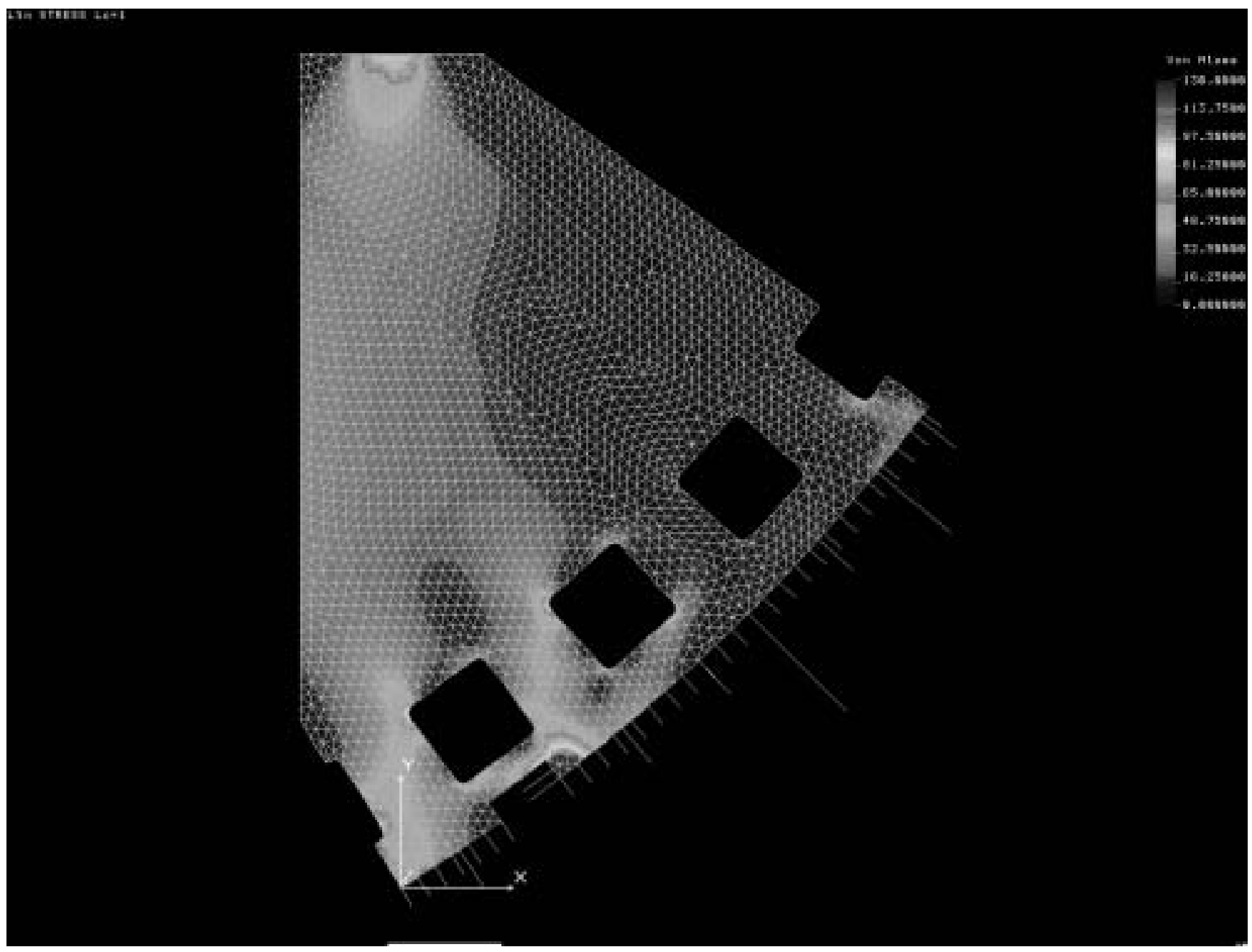

Figure 43. Von Mises Stress Plot of Static Loading Case D (Saddle Bolts and Gaps active). 


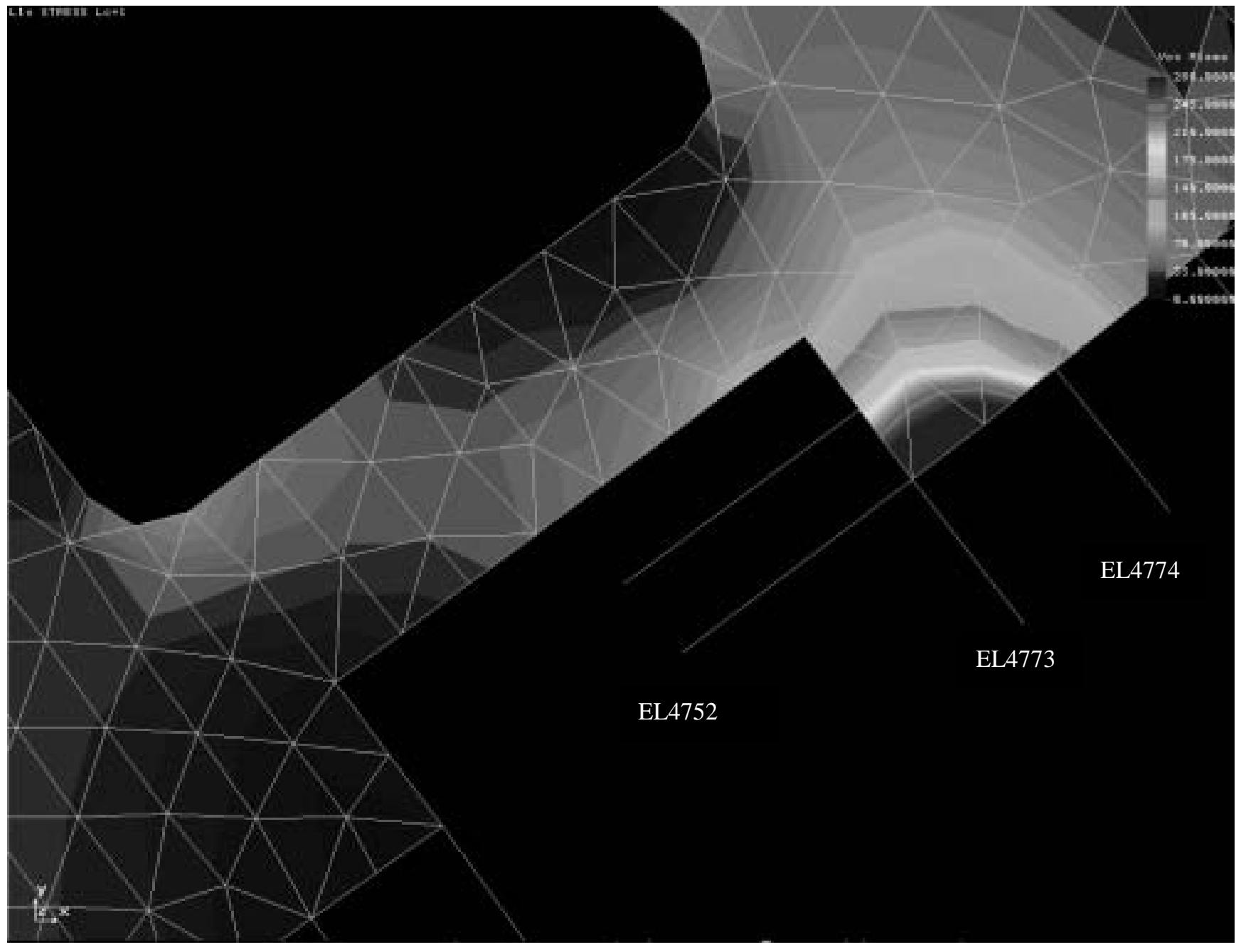

Figure 44. Enlarged View of Key Area for Static Loading Case D (Saddle Bolts and Gaps active). 


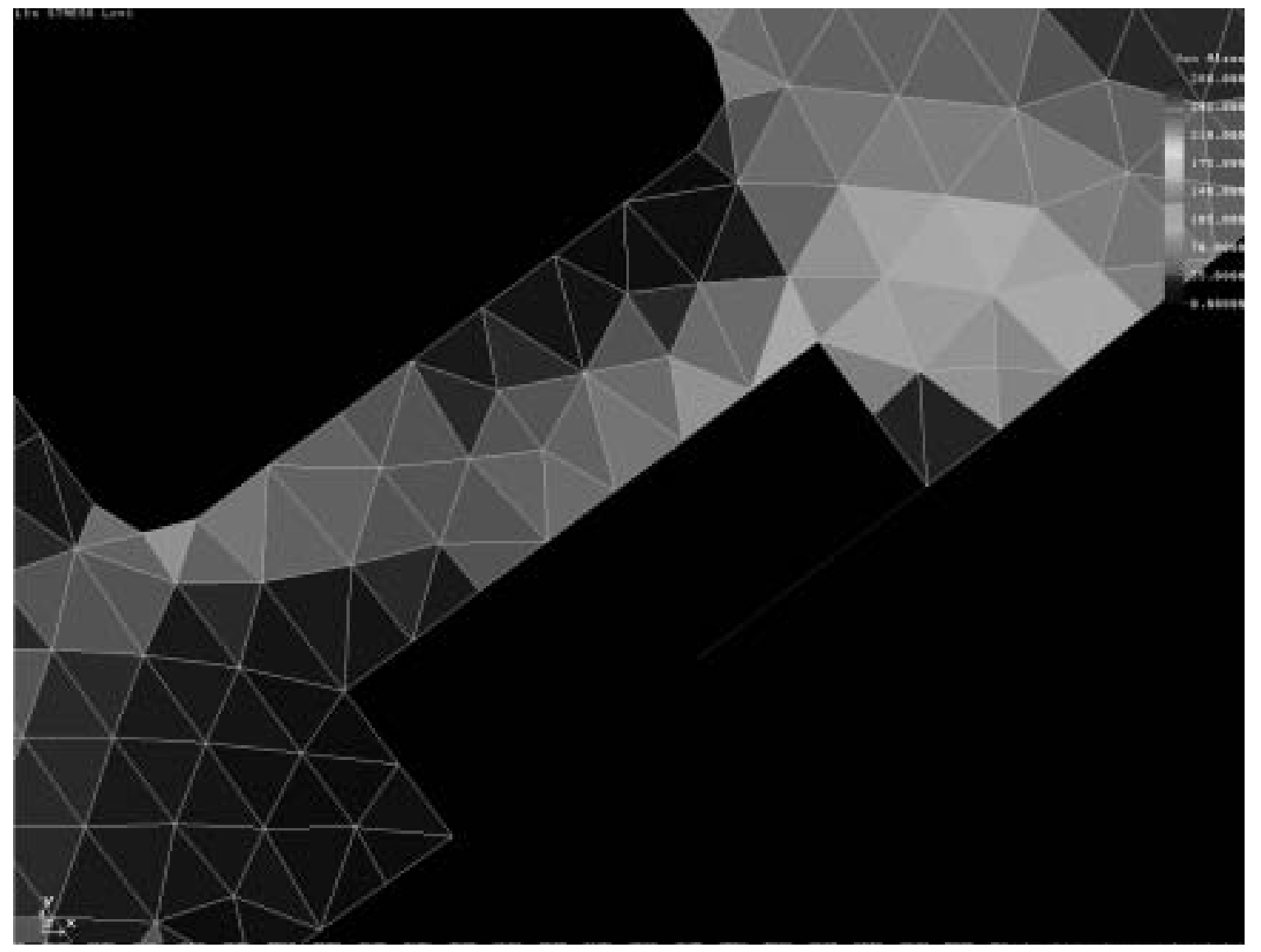

Figure 45. Enlarged View of Key Area for Static Loading Case D. (Saddle bolts and gaps active) Von Mises Stress. 


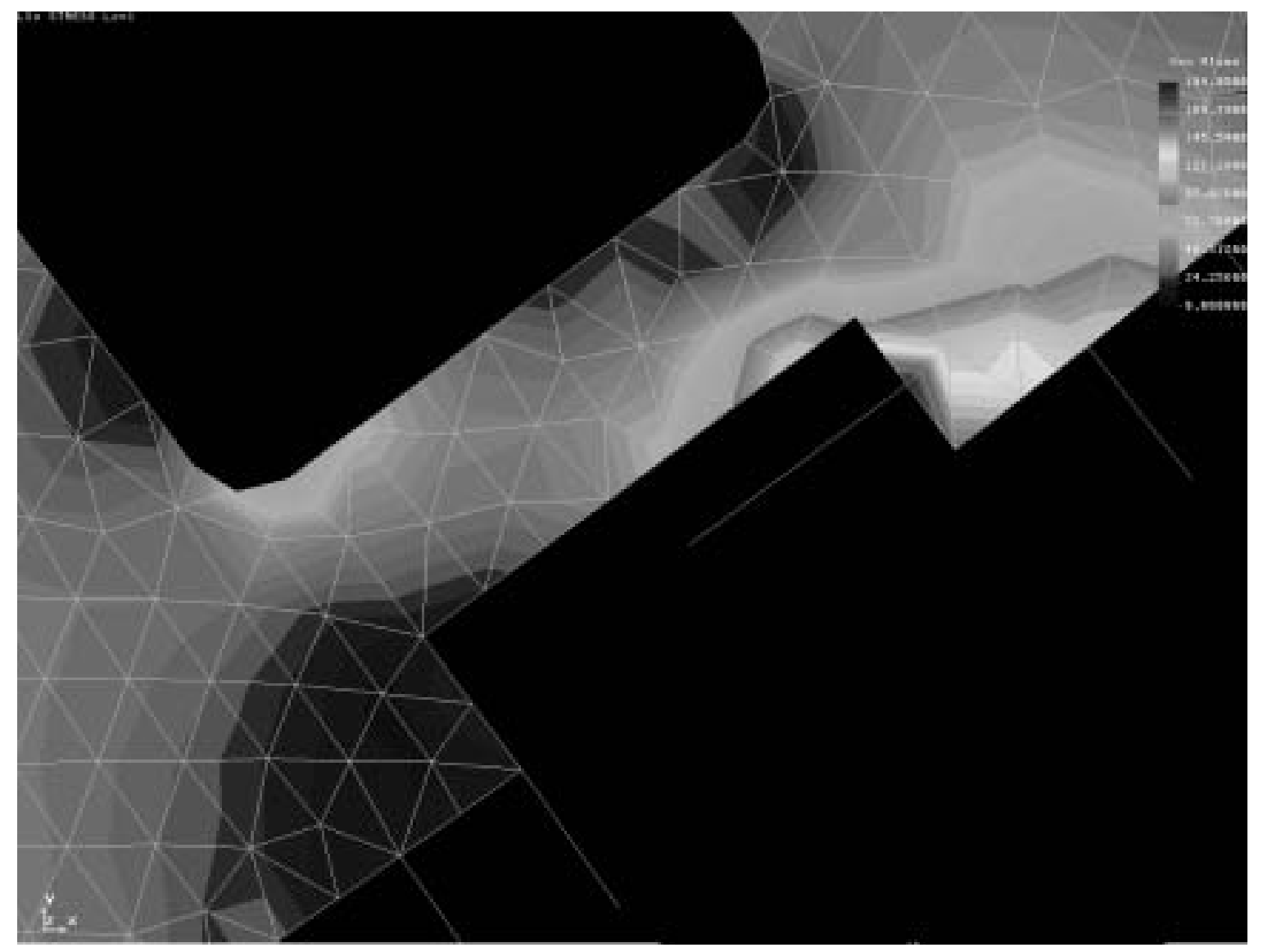

Figure 46. Static Load Case $\mathbf{E}$ with gap and truss elements removed from corner (Von Mises Stress). 


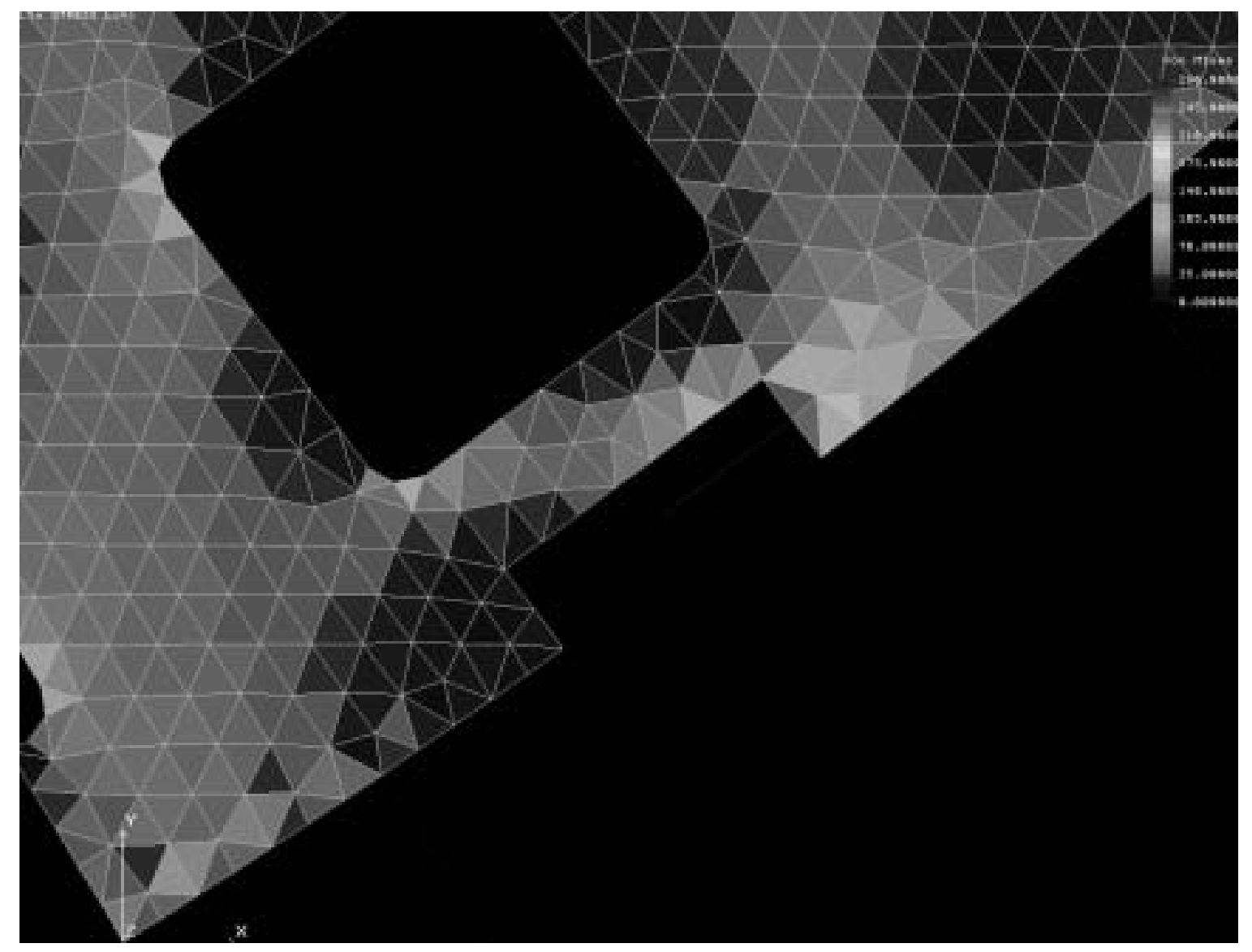

Figure 47. Static Load Case E. Von Mises Stress with elements removed from corner.

\subsubsection{Deflections of Plate for Static Case}

$\mathrm{U}_{\mathrm{Y}}$ and $\mathrm{U}_{\mathrm{X}}$ Displacements for the static load case $\mathrm{D}$ are shown in Fig. 48 and 49. The maximum $\mathrm{x}$ deflection, $\mathrm{U}_{\mathrm{X}}=0.53 \mathrm{~mm}$, is at the right side of the top of the plate (when looking at the figures), whereas the maximum y deflection, $\mathrm{Uy}=0.44 \mathrm{~mm}$, is at the top left side of the plate. The maximum resultant displacement, $U_{R}=0.68 \mathrm{~mm}$, is located near the top center of the plate. 


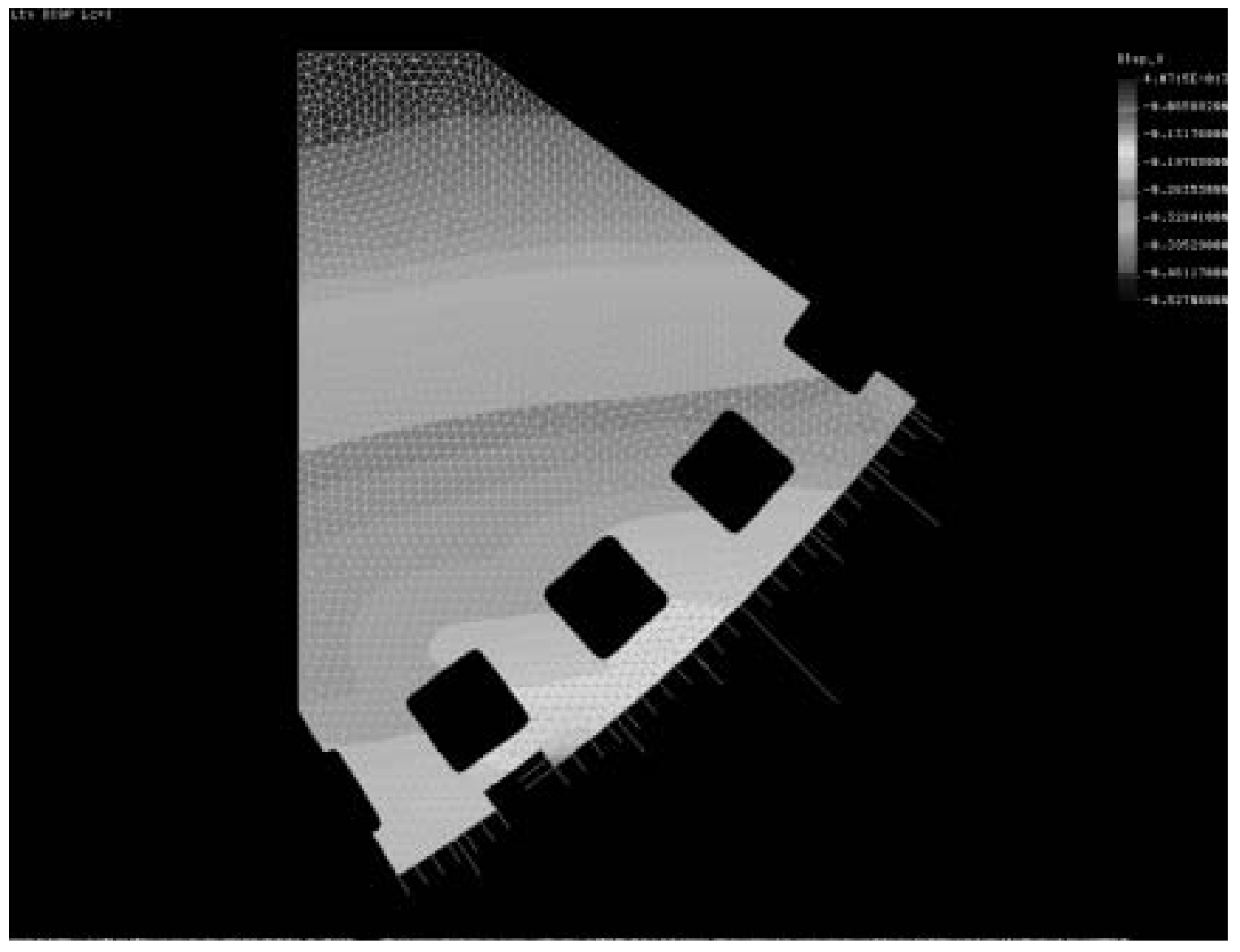

Figure 48. Static Load Case $D-U_{X}$ deflection. 


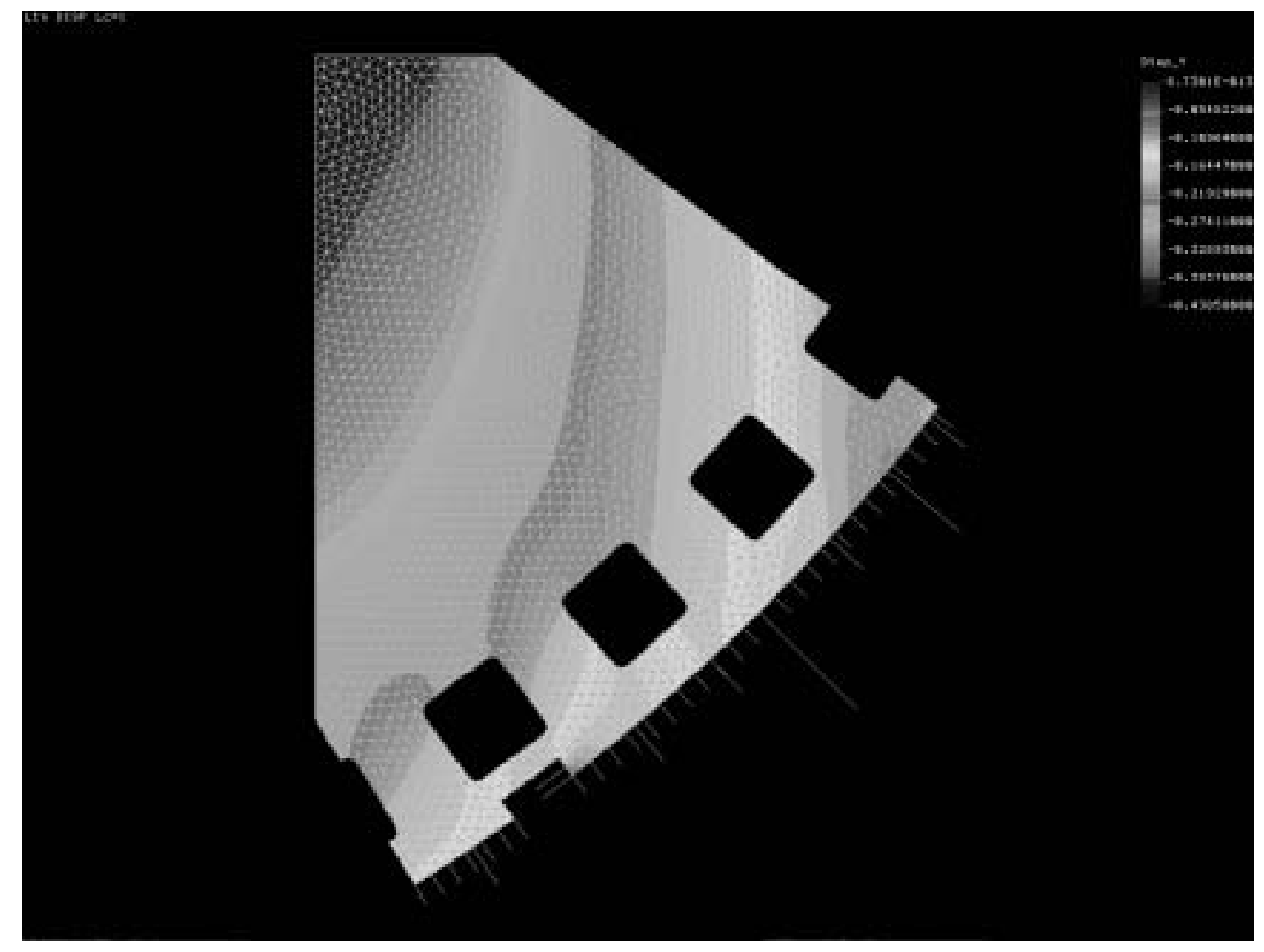

Figure 49. Static Load Case $D-U_{Y}$ Deflection.

\subsection{Determination of Seismic Loads}

The equivalent seismic load is considered $15 \%$ of the static gravity load (weight) applied through the center of mass (per CERN TC). The cryostat has mass 270 tons and is supported at four points, two in the front and two in the back. The front two supports act as simple supports designed only to provide support in the Y-direction (neglecting the effect of friction). The back support consists of two of the Back Cryostat Support Plates shown in Fig. 40. Figure 50 shows a schematic representation of the support locations and associated forces with respect to the cryostat center of mass. This same point also serves as the application point of the seismic loads. Note that points 1 and 2 are the locations of the Back cryostat support plates. As there are 8 unknown forces, the solution of the reaction forces is statically indeterminate. Accurate determination of these forces is only possible when the cryostat stiffness is taken into account. However, this has not been modeled for the present study. Instead an approximation is made by using two resultant $\mathrm{F}_{\mathrm{Y}}$ forces in place of the $\mathrm{F}_{\mathrm{Y} 1}-\mathrm{F}_{\mathrm{Y} 4}$ and choosing location for this force approximately between the support locations. In this way, the problem can be solved by statics. After the effective force is found, it is resolved back into the $\mathrm{F}_{\mathrm{Y}_{1}}-\mathrm{F}_{\mathrm{Y} 4}$ using assumptions about symmetry. 


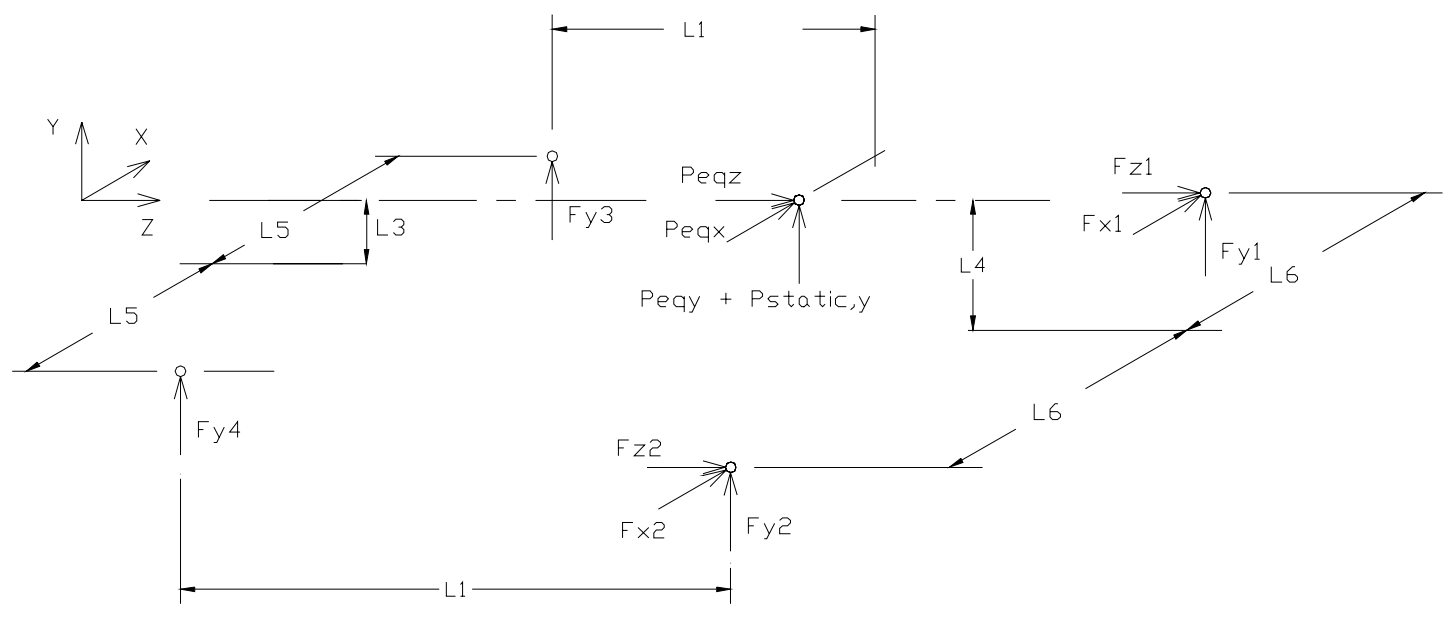

$\begin{array}{ll}\mathrm{L} 1=2222 & \mathrm{P}_{\mathrm{STATIC}, \mathrm{Y}}=-270 \text { tons } \quad \text { (static gravity load of cryostat) } \\ \mathrm{L} 2=1270 & \mathrm{P}_{\mathrm{EQX}}=\text { seismic load in } \mathrm{X} \text {-direction } \\ \mathrm{L} 3=810 & \mathrm{P}_{\mathrm{EQY}}=\text { seismic load in y-direction } \\ \mathrm{L} 4=1786 & \mathrm{P}_{\mathrm{EQZ}}=\text { seismic load in z-direction } \\ \mathrm{L} 5=2197 & \end{array}$

(dimensions in $\mathrm{mm}$ )

Figure 50. Cryostat Reaction Diagram.

Because the direction of an earthquake is not known, it is conservative to perform analysis by simultaneously applying the seismic loads in the X, Y, and Z direction. As each force can change sign, there are 8 possible permutations of the seismic loading. The analysis was run for each of these eight cases. Table 18 details the load orientations and the resulting reaction forces. Each case results in two load sets, which are of primary concern. These are labeled A and B for each load set and correspond to the reaction produced at each of the two back cryostat plates. It is seen then that the 8 load cases produce 16 different load combinations for the cryostat plates that must be analyzed in the current design. After further examination of the 16 load cases, it is seen that there are six load combinations that can properly represent the entire set based on the magnitude and direction of the forces. Table 19 shows these sets of forces. Note the sign change as the reactions become the load for the back cryostat support. 
Table 18. Cryostat Back Support Reaction Forces Due to Seismic Loading (Force in Metric Tons).

\begin{tabular}{|c|c|c|c|c|}
\hline & Fx & Fy & $\mathbf{F z}$ & \\
\hline Case A & \multicolumn{3}{|c|}{ Peqx,-Pstatic-Peqy,Peqz } & Set \\
\hline 1 & -20.25 & 105.97 & -28.89 & $1 \mathrm{~A}$ \\
\hline 2 & -20.25 & 86.26 & -11.61 & $2 A$ \\
\hline Case B & \multicolumn{4}{|c|}{ Peqx,-Pstatic-Peqy,-Peqz } \\
\hline 1 & -20.25 & 91.21 & 11.61 & $1 \mathrm{~B}$ \\
\hline 2 & -20.25 & 71.5 & 28.89 & $2 \mathrm{~B}$ \\
\hline Case C & \multicolumn{4}{|c|}{-Peqx,-Pstatic-Peqy,Peqz } \\
\hline 1 & 20.25 & 86.26 & -11.61 & $1 \mathrm{C}$ \\
\hline 2 & 20.25 & 105.97 & -28.89 & $2 \mathrm{C}$ \\
\hline Case D & \multicolumn{4}{|c|}{-Peqx,-Pstatic-Peqy,-Peqz } \\
\hline 1 & 20.25 & 71.5 & 28.89 & 1D \\
\hline 2 & 20.25 & 91.21 & 11.61 & 2D \\
\hline Case E & \multicolumn{4}{|c|}{ Peqx,-Pstatic+Peqy,Peqz } \\
\hline 1 & -20.25 & 82.82 & -28.89 & $1 \mathrm{E}$ \\
\hline 2 & -20.25 & 63.11 & -11.61 & $2 \mathrm{E}$ \\
\hline Case F & \multicolumn{4}{|c|}{ PeqX,-Pstatic $+P e q y,-P e q z$} \\
\hline 1 & -20.25 & 68.06 & 11.61 & $1 F$ \\
\hline 2 & -20.25 & 48.35 & 28.89 & $2 \mathrm{~F}$ \\
\hline Case $\mathrm{G}$ & \multicolumn{4}{|c|}{-Peqx,-Pstatic + Peqy, Peqz } \\
\hline 1 & 20.25 & 63.11 & -11.61 & $1 \mathrm{G}$ \\
\hline 2 & 20.25 & 82.82 & -28.89 & $2 \mathrm{G}$ \\
\hline Case $\mathrm{H}$ & \multicolumn{4}{|c|}{- Peqx,- Pstatic + Peqy,, Peqz } \\
\hline 1 & 20.25 & 48.35 & 28.89 & $1 \mathrm{H}$ \\
\hline 2 & 20.25 & 68.06 & 11.61 & $2 \mathrm{H}$ \\
\hline
\end{tabular}

Table 19. Reduced set of reaction forces applied to FEA Model (loads in metric tons).

\begin{tabular}{|c|c|c|c|c|}
\hline \multicolumn{4}{|c|}{ FEA Model Loads } & \multirow[b]{2}{*}{$\begin{array}{c}\text { Reaction } \\
\text { Set }\end{array}$} \\
\hline $\begin{array}{l}\text { Load } \\
\text { Case }\end{array}$ & Peqx & Peqy & Peqz & \\
\hline 1 & -20.3 & -106.0 & 28.9 & $2 \mathrm{C}$ \\
\hline 2 & 20.3 & -106.0 & 28.9 & $1 \mathrm{~A}$ \\
\hline 3 & -20.3 & -71.5 & -28.9 & $1 \mathrm{D}$ \\
\hline 4 & 20.3 & -71.5 & -28.9 & $2 B$ \\
\hline 5 & -20.3 & -91.2 & -11.6 & 2D \\
\hline 6 & 20.3 & -91.2 & -11.6 & $1 \mathrm{~B}$ \\
\hline
\end{tabular}



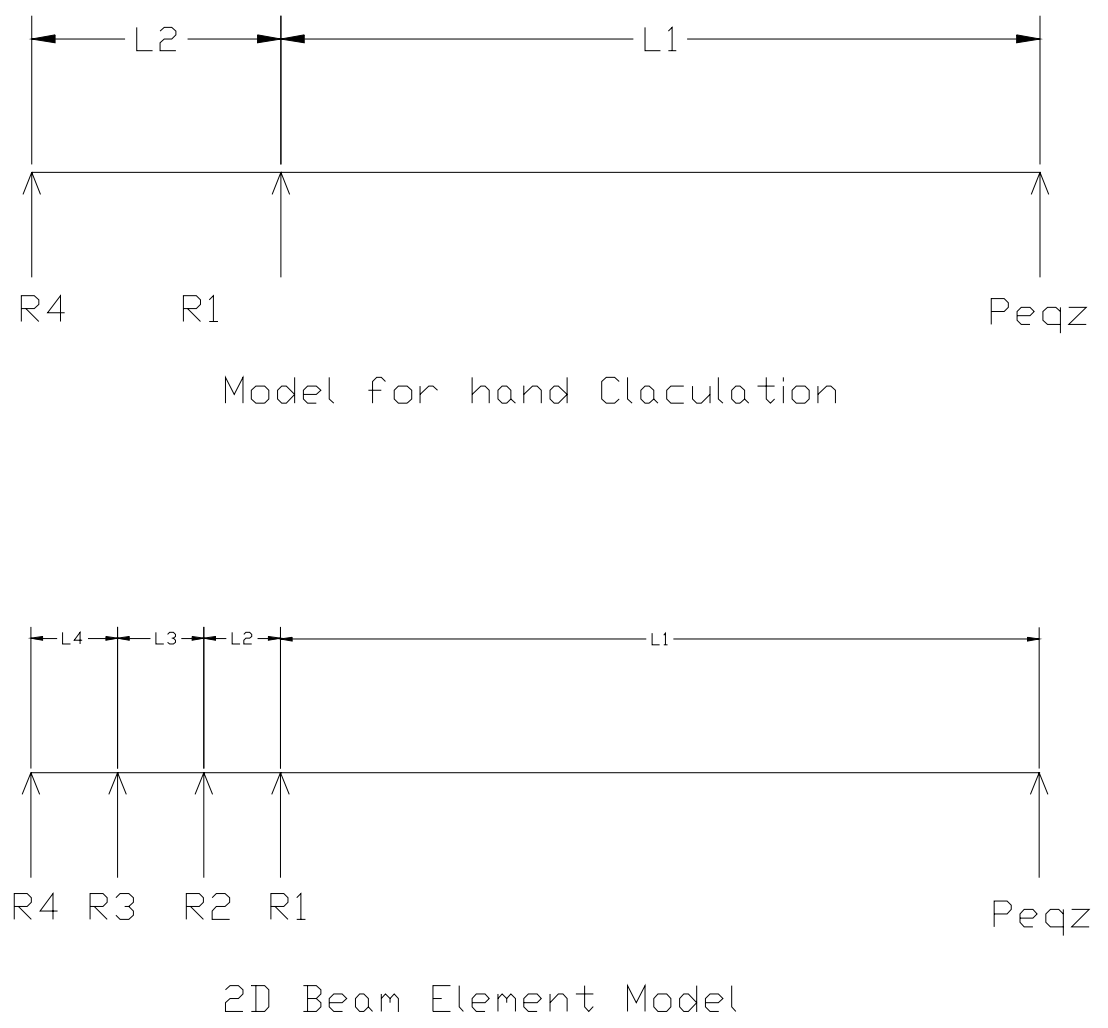

Figure 51. Diagrams for Hand Calculation and FEA using 2D Beam Elements.

\subsection{Seismic Loads Applied to Cryostat Plate With Two Full Length Stiffeners}

\subsubsection{Hand Calculations and Beam 2D Approximations}

In order to get a feel for the bolt forces due to $\mathrm{P}_{\mathrm{EQZ}}$, a simplified hand calculation was performed. Referring to Fig. 51, we get:

$$
\begin{aligned}
& \sum F_{Z}: P_{E Q Z}-R_{1}-R_{4}=0 \\
& \sum M_{X}:-P_{E Q Z}\left(l_{1}+l_{2}\right)+R_{1} l_{2}=0 \\
& \Rightarrow \\
& R_{1}=\frac{P_{E Q Z}\left(l_{1}+l_{2}\right)}{l_{2}} \\
& R_{4}=P_{E Q Z}-R_{1}
\end{aligned}
$$

Using $\mathrm{L} 1=1444 \mathrm{~mm}, \mathrm{~L} 2=210 \mathrm{~mm}$, and assuming the two stiffener beams share the load equally, $(0.5) \mathrm{P}_{\mathrm{EQZ}}=(0.5) 28.9$ tons $=1.416 \mathrm{e} 5 \mathrm{~N}$, we get:

$$
\mathrm{R} 1=1.12 \mathrm{e} 6 \mathrm{~N}
$$




$$
\mathrm{R} 4=-9.73 \mathrm{e} 5 \mathrm{~N}
$$

To take into account the addition of two more bolt locations, as well as the compressive reaction where the beam will mount to the saddle, we made an FEA model using 2D beam elements. Note that the beam elements from node 1 to node 11 in Fig. 52 are on the plate and use the inertia value $\mathrm{I}_{\text {TTP }}$ given in Table 12, whereas the remaining beams elements from node 11-19 use the value $\mathrm{I}_{\mathrm{TT}}$. The 4 bolts are represented as truss elements and compressive gap elements with cross sectional area representative of 2 M30 bolts. Table 20 lists the bolt forces and compares them with the hand calculation. It is expected that the bolt forces are reduced when additional bolts are added so that these results appear consistent when compared with the hand calculations. The deflections are shown in Table 21. These will be referred to later when the deflections are considered from the full FEA analysis. It is noted that there is $0.56 \mathrm{~mm}$ deflection at bolt 1. The FEA model does not include bolt preload and this deflection should be avoided with proper preload on the bolt. The elongation of bolt 1 in this model therefore accounts for $3.5 \mathrm{~mm}$ of the deflection at the tip. The maximum beam stress was $145 \mathrm{MPa}$ and found as expected right at the connection to bolt 1 near node 13. Finally, it should be understood that the assumption that the beams carry equal portions of the load is not likely valid. It does, however, serve as a reference point to confirming the more detailed FEA model to follow.

Table 20. Comparison of Bolt Forces Between Hand and Simple FEA Model.

\begin{tabular}{l|l|l|l|l|l} 
& & $\mathrm{R} 1$ & $\mathrm{R} 2$ & $\mathrm{R} 3$ & $\mathrm{R} 4$ \\
\hline Hand Calculation & Bolt & $1.12 \mathrm{E}+06$ & & & $-9.73 \mathrm{E}+05$ \\
\hline Beam2D FEA & $\begin{array}{l}\text { Gap } \\
\text { Bolt }\end{array}$ & $9.07 \mathrm{E}+05$ & $5.24 \mathrm{E}+05$ & $2.50 \mathrm{E}+05$ & $-1.54 \mathrm{E}+06$ \\
& & &
\end{tabular}

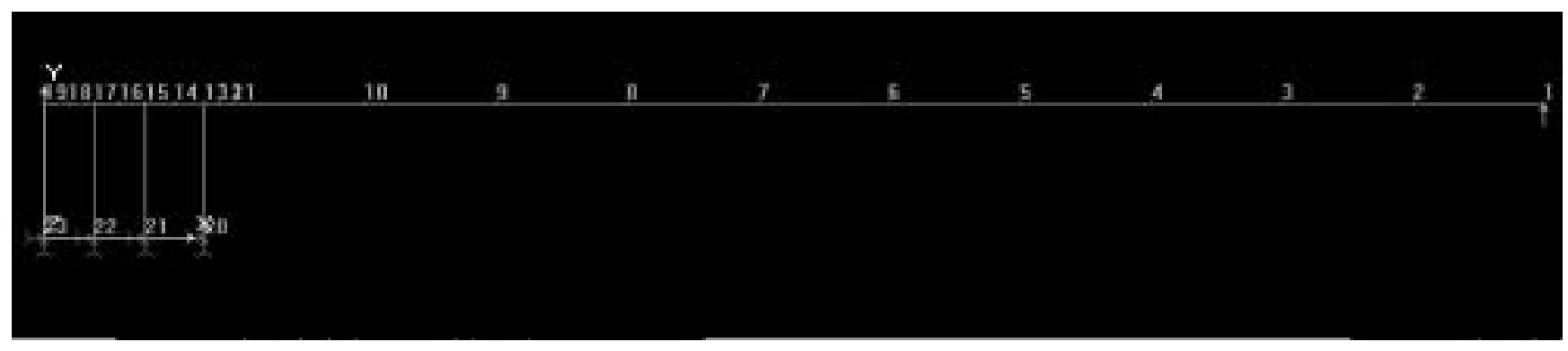

Figure 52. Node Diagram for Beam2D FEA Model. 
Table 21. Displacements of the Beam 2D FEA Model.

\begin{tabular}{|c|c|}
\hline NODE & w \\
\hline 1 & 9.94 \\
2 & 8.88 \\
3 & 7.81 \\
4 & 6.77 \\
5 & 5.76 \\
6 & 4.77 \\
7 & 3.84 \\
8 & 2.95 \\
9 & 2.13 \\
10 & 1.37 \\
11 & 0.69 \\
12 & 0.62 \\
13 & 0.56 \\
14 & 0.44 \\
15 & 0.32 \\
16 & 0.24 \\
17 & 0.15 \\
18 & 0.08 \\
19 & 0.00 \\
20 & 0.00 \\
21 & 0.00 \\
22 & 0.00 \\
23 & 0.00 \\
\hline
\end{tabular}

\subsubsection{FEA Shell Model for Seismic Load Cases}

Before discussing the more detailed analysis of the earthquake loads, a few more comments should be made about the FEA model. As discussed previously, two curves are included in the model to represent the stiffener beams added to the plate for stiffness in the Z-direction. These curves were meshed with 3D beam elements with the nodes merged to the shell elements in the plate. Figure 54 shows the meshed model rotated about the $\mathrm{Y}$-axis to reveal the elements that connect the stiffener beam to the saddle. These elements are actually a truss element and compressive gap element merged to the same nodes. The truss elements have area equal to 2 M30 bolts as each stiffener is actually connected through 4 pairs or 8 bolts. Figure 55 shows a cross section of the beam on the cryostat plate. Table 24 lists the beam constants. The beam elements that are meshed in the plate with the shell elements have the value $\mathrm{I}_{\text {TTP }}$ as the value of the moment of inertia about the T-axis $\left(\mathrm{I}_{\mathrm{TT}}\right)$ to take in the fact that the beam is offset from the plate-bending axis. $\mathrm{I}_{\text {TTP }}$ is calculated by including the section of the cryostat plate under the beam that is the same width of the beam. This width is chosen as it corresponds to the width at the cut-outs. The beam is then treated as a built-up beam with the centroid of the plate section and the beam was redetermined and found to shift down $52 \mathrm{~mm}$ from the centroid of the beam alone. $\mathrm{I}_{\text {TTP }}$ then became the inertia of the beam only taken about the new centroid keeping in mind that the plate contribution should be seen from the shell elements that already exist. The beam elements off of the plate at the saddle connection do not have this effect and use the value $\mathrm{I}_{\mathrm{TT}}$ listed in Table 24 . 
Table 22 lists the sum of the reaction forces for the Seismic Load Case 1. In comparing with the applied loads listed in Table 19, it can be seen that the forces balance, serving as one check of the validity of the FEA model.

\begin{tabular}{|c|c|c|c|c|c|c|}
\hline NODE & Fx & Fy & Fz & Mx & My & Mz \\
\hline 2706 & $2.97 \mathrm{E}+05$ & $2.20 \mathrm{E}+05$ & $0.00 \mathrm{E}+00$ & -- & & \\
\hline 2708 & $2.09 \mathrm{E}+05$ & $1.58 \mathrm{E}+05$ & $0.00 \mathrm{E}+00$ & ---------- & ---------- & \\
\hline 2711 & $-2.34 E+03$ & $3.47 \mathrm{E}+03$ & $0.00 \mathrm{E}+00$ & ---------- & ---------- & \\
\hline 2713 & $1.88 \mathrm{E}+04$ & $-2.24 \mathrm{E}+04$ & $0.00 \mathrm{E}+00$ & ---------- & ---------- & \\
\hline 2715 & $3.78 \mathrm{E}+04$ & $-4.05 E+04$ & $0.00 \mathrm{E}+00$ & ---------- & & \\
\hline 2717 & $1.21 \mathrm{E}+05$ & $-1.09 E+05$ & $0.00 \mathrm{E}+00$ & & & \\
\hline 2719 & $1.92 \mathrm{E}+05$ & $-1.47 \mathrm{E}+05$ & $0.00 \mathrm{E}+00$ & & & \\
\hline 2721 & $2.35 E+00$ & $2.99 \mathrm{E}+02$ & $-5.23 E+05$ & & & \\
\hline 2723 & $-4.86 E-01$ & $-1.62 E-01$ & $-2.52 E+05$ & & & \\
\hline 2725 & $1.88 \mathrm{E}-01$ & $-4.70 \mathrm{E}-01$ & $-9.76 E+04$ & & & \\
\hline 2727 & $3.84 E+00$ & $-1.10 E+00$ & $8.53 E+05$ & & & \\
\hline 2729 & $-4.52 E+01$ & $-4.65 E+00$ & $-1.03 E+06$ & & & \\
\hline 2731 & $-1.69 E+01$ & $-2.58 E+00$ & $-5.73 E+05$ & & & \\
\hline 2733 & $-4.10 E+00$ & $-1.20 E+00$ & $-2.66 E+05$ & ---------- & & \\
\hline 2735 & $0.00 \mathrm{E}+00$ & $7.23 \mathrm{E}+00$ & $1.61 \mathrm{E}+06$ & ---------- & --------- & \\
\hline 2737 & $-4.61 E+04$ & $7.40 \mathrm{E}+04$ & ---------- & ---------- & ---------- & \\
\hline 2739 & $-1.34 \mathrm{E}+05$ & $2.10 \mathrm{E}+05$ & ---------- & --------- & --------- & ------- \\
\hline 2741 & $-1.11 \mathrm{E}+05$ & $1.70 \mathrm{E}+05$ & --------- & & & \\
\hline 2743 & $-8.24 E+04$ & $1.24 \mathrm{E}+05$ & & & & \\
\hline 2745 & $-4.71 E+04$ & $6.90 \mathrm{E}+04$ & ---------- & & & \\
\hline 2747 & $-2.17 E+04$ & $3.12 E+04$ & --------- & --------- & & \\
\hline 2749 & $-5.66 E+03$ & $7.94 \mathrm{E}+03$ & & ---------- & & \\
\hline 2750 & $-1.81 E+05$ & $2.35 E+05$ & & ---------- & --------- & \\
\hline 2752 & $-4.43 E+04$ & $5.61 \mathrm{E}+04$ & ---------- & ---------- & ---------- & --------. \\
\hline Total & 1.99E+05 & $1.04 \mathrm{E}+06$ & $-2.84 E+05$ & $0.00 E+00$ & $0.00 E+00$ & $0.00 E+00$ \\
\hline
\end{tabular}




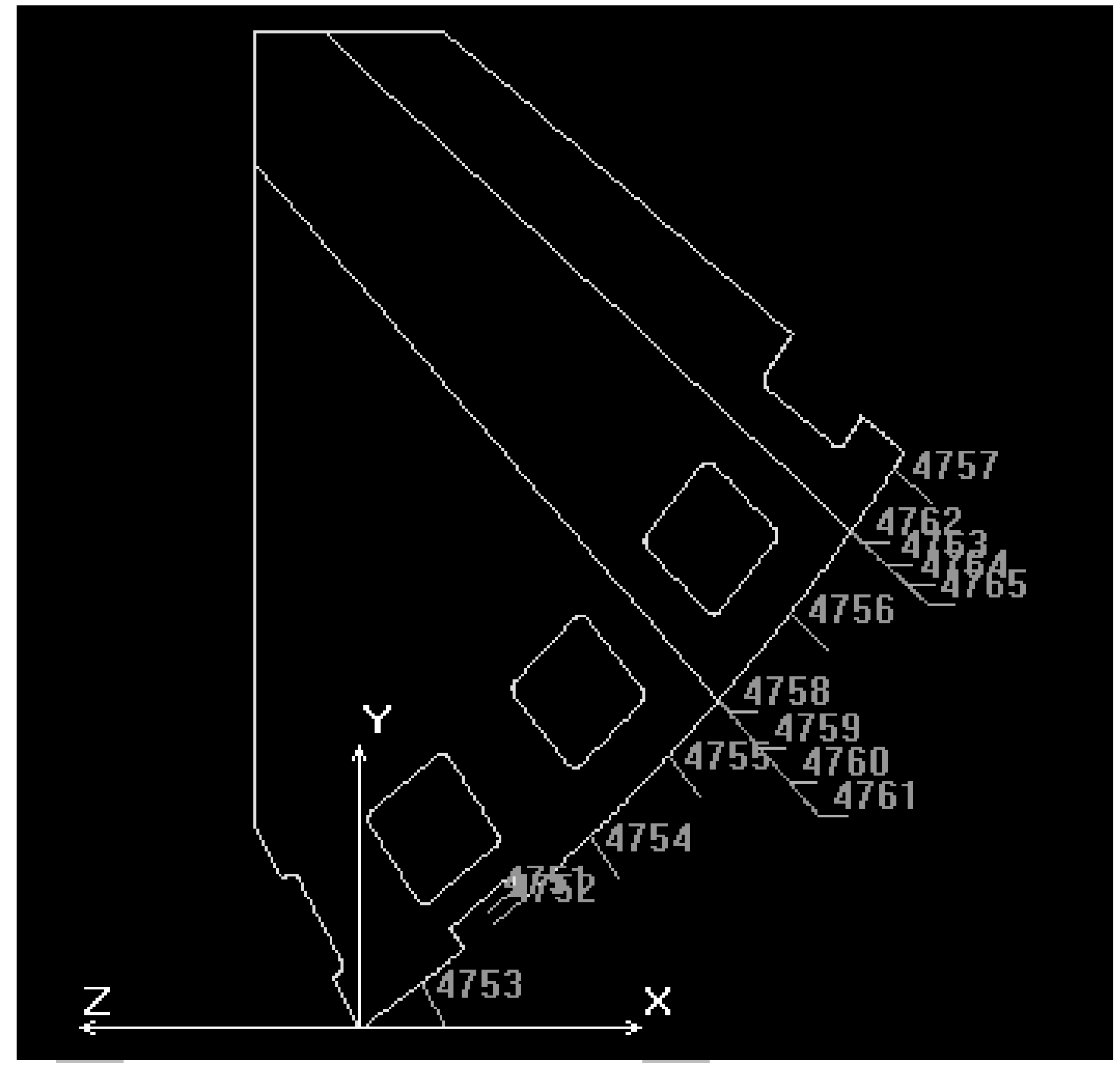

Figure 53. Bolt and Key Element Numbering. 


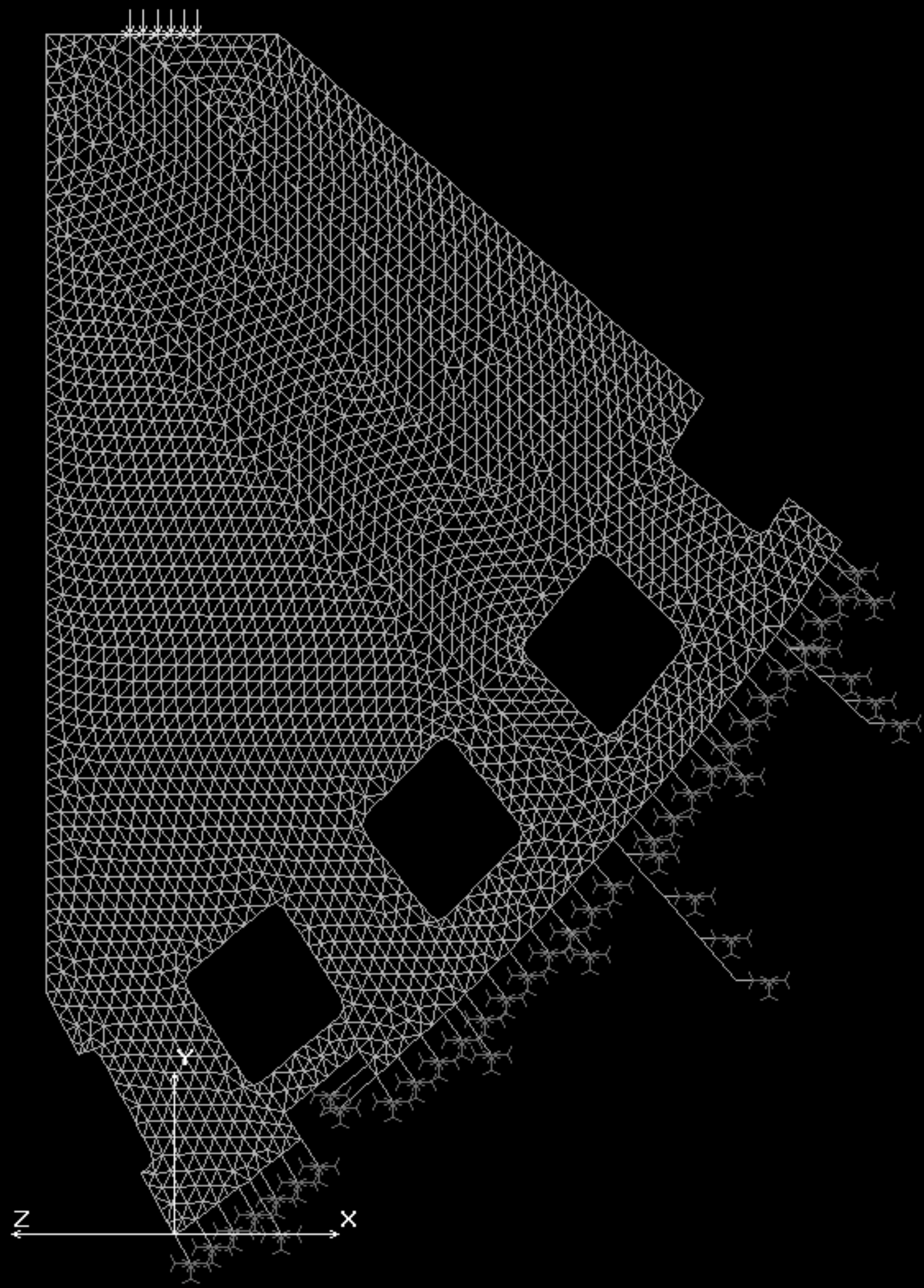

Figure 54. Finite Element Mesh of Back Cryostat Support Plate Rotated to Show Stiffener Bolts. 


\subsubsection{Analysis of Bolt Forces and Stresses - (Seismic)}

Tables 25 and 26 list the bolt and thread stresses for the six seismic load cases described above and listed in Table 19. Figures 41 and 53 show the bolt and element numbering. In the following formula for the thread stripping stress for the threaded area, $\tau_{\text {INT }}$ (where it is assumed that the engaged thread length is equal to 1.5 times the diameter),

$$
\tau_{I N T}=\frac{F}{n \pi d(0.75 t)}=\frac{F}{n \pi d\left(\frac{3}{4} \frac{3}{2} d\right)}=\frac{8 F}{9 n \pi d^{2}}
$$

$\mathrm{n}=$ number of bolts and $\mathrm{d}=$ minor diameter of bolt or major diameter of internal thread.

If we define the thread stress area $A_{T}=\frac{9}{8} n \pi d^{2}$, we can rewrite Eq. (4) as

$$
\tau_{I N T}=\frac{F}{A_{T}}
$$

Table 23. Thread Stress Area for Bolted Connections.

\begin{tabular}{|l|c|c|}
\hline & $\mathbf{A}_{\mathbf{T}}$ (Internal Thread) & $\mathbf{A}_{\mathbf{T}}$ (External Thread) \\
\hline two (2) M30x3.5 bolts & 6362 & 4527 \\
\hline using one (1) M24x3 bolt & 2036 & 1407 \\
\hline
\end{tabular}

Examining the bolt stresses in Tables 25 and 26, we see that the highest axial stress is $877 \mathrm{MPa}$ in one of the stiffener bolts. Grade 10.9 bolts have a minimum tensile strength of $1000 \mathrm{Mpa}$. and should be used for all the bolted connections for the cryostat plate. In the support plate connection, we see that the axial stresses in bolt 5 reaches $669 \mathrm{MPa}$. The stress on the internal threads at these locations is more of a concern. The internal thread stress on bolt 5 of the support plate connection reaches $119 \mathrm{MPa}$ which is above the design limit of $90 \mathrm{MPa}$ in shear. Additionally, excessive internal stresses are seen on several of the stiffener beam bolts that thread into the saddle. These stresses are as high as $162 \mathrm{MPa}$. Threaded inserts will be investigated as a possible solution to increase the thread area at the saddle connection. 


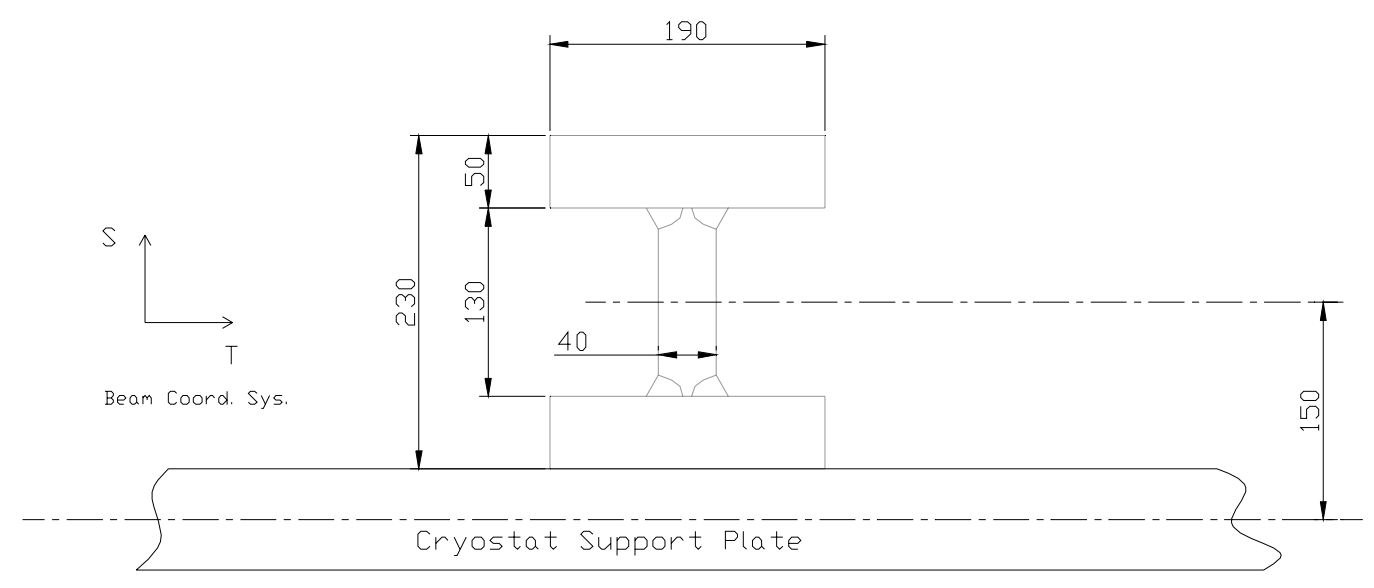

Figure 55. Drawing of Stiffener Beam Cross Section.

Table 24. Beam Constants for Stiffener Beam.

\begin{tabular}{|l|l|}
\hline$A_{\text {BEAM }}$ & $2.42 \mathrm{e} 4 \mathrm{~mm}^{2}$ \\
\hline $\mathrm{I}_{\mathrm{TT}}$ ( Off Plate) & $1.652 \mathrm{e} 8 \mathrm{~mm}^{2}$ \\
\hline $\mathrm{I}_{\mathrm{SS}}$ & $5.785 \mathrm{e} 7 \mathrm{~mm}^{2}$ \\
\hline $\mathrm{K}$ & $1.967 \mathrm{e} 7 \mathrm{~mm}^{2}$ \\
\hline $\mathrm{d}$ & $150 \mathrm{~mm}$ \\
\hline $\mathrm{I}_{\mathrm{TTP}}$ (On Plate) & $2.332 \mathrm{e} 8 \mathrm{~mm}^{2}$ \\
\hline
\end{tabular}


Table 25. Bolt and Thread Stresses for Seismic Load Cases (1-3).

\section{Stiffener Beam Connection at Saddle}

LOAD CASE 1

\begin{tabular}{|c|c|c|c|c|}
\hline \multirow[b]{2}{*}{ Element } & \multirow[b]{2}{*}{\begin{tabular}{|l} 
Bolt \\
Force \\
{$[\mathrm{N}]$}
\end{tabular}} & \multicolumn{2}{|c|}{ BOLT STRESSES } & \multirow[b]{2}{*}{\begin{tabular}{|l|} 
SADDLE \\
Int. thread \\
Stripping \\
Stress \\
[Mpa] \\
\end{tabular}} \\
\hline & & \begin{tabular}{|l|} 
Axial \\
Bolt \\
Stress \\
[Mpa]
\end{tabular} & $\begin{array}{l}\text { Ext. thread } \\
\text { Stripping } \\
\text { Stress } \\
{[\mathrm{Mpa}]}\end{array}$ & \\
\hline 4758 & $5.23 \mathrm{E}+05$ & 454 & 115.5 & 82.2 \\
\hline 4759 & $2.52 E+05$ & 219 & 55.7 & 39.7 \\
\hline 4760 & $9.76 \mathrm{E}+04$ & 85 & 21.6 & 15.3 \\
\hline 4761 & $-2.80 \mathrm{E}-10$ & 0 & 0.0 & 0.0 \\
\hline 4762 & $1.03 E+06$ & 877 & 228.3 & 162.5 \\
\hline 4763 & $5.73 E+05$ & 486 & 126.5 & 90.0 \\
\hline 4764 & $2.66 \mathrm{E}+05$ & 226 & 58.8 & 41.8 \\
\hline 4765 & $-2.66 \mathrm{E}-10$ & 0 & 0.0 & 0.0 \\
\hline
\end{tabular}

LOAD CASE 2

\begin{tabular}{|c|c|c|c|c|}
\hline \multirow[b]{2}{*}{ Element } & \multirow[b]{2}{*}{\begin{tabular}{|l} 
Bolt \\
Force \\
{$[\mathrm{N}]$}
\end{tabular}} & \multicolumn{2}{|c|}{ BOLT STRESSES } & SADDLE \\
\hline & & \begin{tabular}{|l|} 
Axial \\
Bolt \\
Stress \\
[Mpa]
\end{tabular} & $\begin{array}{l}\text { Ext. thread } \\
\text { Stripping } \\
\text { Stress } \\
\text { [Mpa] } \\
\end{array}$ & $\begin{array}{l}\text { Int. thread } \\
\text { Stripping } \\
\text { Stress } \\
\text { [Mpa] }\end{array}$ \\
\hline 4758 & $5.23 \mathrm{E}+05$ & 454 & 115.5 & 82.2 \\
\hline 4759 & $2.52 E+05$ & 219 & 55.7 & 39.7 \\
\hline 4760 & $9.75 E+04$ & 85 & 21.5 & 15.3 \\
\hline 4761 & $-5.31 E-10$ & 0 & 0.0 & 0.0 \\
\hline 4762 & $1.03 E+06$ & 877 & 228.3 & 162.5 \\
\hline 4763 & $5.73 E+05$ & 486 & 126.5 & 90.0 \\
\hline 4764 & $2.66 E+05$ & 226 & 58.8 & 41.8 \\
\hline 4765 & $-9.46 \mathrm{E}-10$ & 0 & 0.0 & 0.0 \\
\hline
\end{tabular}

\section{LOAD CASE 3}

\begin{tabular}{|r|l|l|l|l|}
\hline \multirow{2}{*}{ Element } & \multicolumn{3}{|l|}{ BOLT STRESSES } & SADDLE \\
\cline { 3 - 6 } & \multirow{2}{*}{$\begin{array}{l}\text { Bolt } \\
\text { Force } \\
{[\mathrm{N}]}\end{array}$} & $\begin{array}{l}\text { Axial } \\
\text { Bolt } \\
\text { Stress } \\
{[\mathrm{Mpa}]}\end{array}$ & $\begin{array}{l}\text { Ext. thread } \\
\text { Stripping } \\
\text { Stress } \\
{[\mathrm{Mpa}]}\end{array}$ & $\begin{array}{l}\text { Int. thread } \\
\text { Stripping } \\
\text { Stress } \\
{[\mathrm{Mpa}]}\end{array}$ \\
\hline 4758 & $-7.89 \mathrm{E}-10$ & 0 & 0.0 & 0.0 \\
4759 & $1.64 \mathrm{E}+05$ & 140 & 36.3 & 25.8 \\
4760 & $2.86 \mathrm{E}+05$ & 244 & 63.3 & 45.0 \\
4761 & $4.18 \mathrm{E}+05$ & 357 & 92.3 & 65.7 \\
4762 & $-1.23 \mathrm{E}-09$ & 0 & 0.0 & 0.0 \\
4763 & $2.94 \mathrm{E}+05$ & 253 & 64.9 & 46.2 \\
4764 & $5.33 \mathrm{E}+05$ & 458 & 117.7 & 83.8 \\
4765 & $8.01 \mathrm{E}+05$ & 688 & 176.9 & 125.9 \\
\hline
\end{tabular}

Support Plate Connection

\begin{tabular}{|c|c|c|c|c|}
\hline \multirow[b]{2}{*}{ Element } & \multirow[b]{2}{*}{\begin{tabular}{|l} 
Bolt \\
Force \\
{$[\mathrm{N}]$}
\end{tabular}} & \multicolumn{2}{|c|}{ BOLT STRESSES } & \multirow[b]{2}{*}{\begin{tabular}{|l} 
PLATE \\
Int. thread \\
Stripping \\
Stress \\
[Mpa]
\end{tabular}} \\
\hline & & \begin{tabular}{|l|} 
Axial \\
Bolt \\
Stress \\
[Mpa]
\end{tabular} & $\begin{array}{l}\text { Ext. threac } \\
\text { Stripping } \\
\text { Stress } \\
\text { [Mpa] }\end{array}$ & \\
\hline 4753 & $-4.19 E+03$ & -12 & -3.0 & -2.1 \\
\hline 4754 & $2.92 E+04$ & 87 & 20.8 & 14.3 \\
\hline 4755 & $5.54 \mathrm{E}+04$ & 165 & 39.4 & 27.2 \\
\hline 4756 & $1.63 E+05$ & 484 & 115.8 & 80.0 \\
\hline 4757 & $2.41 \mathrm{E}+05$ & 717 & 171.5 & 118.5 \\
\hline
\end{tabular}

\begin{tabular}{|c|c|c|c|c|c|}
\hline \multirow[b]{2}{*}{ Element } & \multirow[b]{2}{*}{$\begin{array}{l}\text { Bolt } \\
\text { Force } \\
{[\mathrm{N}]}\end{array}$} & \multicolumn{3}{|c|}{ BOLT STRESSES } & \multirow{2}{*}{\begin{tabular}{|l} 
PLATE \\
Int. thread \\
Stripping \\
Stress \\
[Mpa]
\end{tabular}} \\
\hline & & $\begin{array}{l}\text { Axial } \\
\text { Bolt } \\
\text { Stress } \\
\text { [Mpa] }\end{array}$ & & $\begin{array}{l}\text { Ext. thread } \\
\text { Stripping } \\
\text { Stress } \\
\text { [Mpa] }\end{array}$ & \\
\hline 4753 & $-2.09 E+03$ & & -6 & -1.5 & -1.0 \\
\hline 4754 & $1.58 \mathrm{E}+03$ & & 5 & 1.1 & 0.8 \\
\hline 4755 & $-5.49 E+00$ & & 0 & 0.0 & 0.0 \\
\hline 4756 & $6.23 E+03$ & & 19 & 4.4 & 3.1 \\
\hline 4757 & $3.23 E+04$ & & 96 & 22.9 & 15.8 \\
\hline
\end{tabular}


Table 26. Bolt and Thread Stresses for Seismic Load Cases (4-6).

\section{Stiffener Beam Connection at Saddle}

LOAD CASE 4

\begin{tabular}{|c|c|c|c|c|}
\hline \multirow[b]{2}{*}{ Element } & \multirow[b]{2}{*}{$\begin{array}{l}\text { Bolt } \\
\text { Force } \\
{[\mathrm{N}]}\end{array}$} & \multicolumn{2}{|c|}{ BOLT STRESSES } & \multirow{2}{*}{\begin{tabular}{|l|} 
SADDLE \\
Int. thread \\
Stripping \\
Stress \\
[Mpa] \\
\end{tabular}} \\
\hline & & \begin{tabular}{|l|} 
Axial \\
Bolt \\
Stress \\
[Mpa] \\
\end{tabular} & $\begin{array}{l}\text { Ext. thread } \\
\text { Stripping } \\
\text { Stress } \\
\text { [Mpa] }\end{array}$ & \\
\hline 4758 & $-8.11 \mathrm{E}-10$ & 0 & 0.0 & 0.0 \\
\hline 4759 & $1.64 \mathrm{E}+05$ & 140 & 36.3 & 25.8 \\
\hline 4760 & $2.86 \mathrm{E}+05$ & 244 & 63.2 & 45.0 \\
\hline 4761 & $4.18 E+05$ & 357 & 92.3 & 65.7 \\
\hline 4762 & $-1.49 E-09$ & 0 & 0.0 & 0.0 \\
\hline 4763 & $2.94 \mathrm{E}+05$ & 253 & 64.9 & 46.2 \\
\hline 4764 & $5.33 E+05$ & 458 & 117.7 & 83.8 \\
\hline 4765 & $8.01 E+05$ & 688 & 176.9 & 125.9 \\
\hline
\end{tabular}

LOAD CASE 5

\begin{tabular}{|c|c|c|c|c|}
\hline \multirow[b]{2}{*}{ Element } & \multirow[b]{2}{*}{$\begin{array}{l}\text { Bolt } \\
\text { Force } \\
{[\mathrm{N}]}\end{array}$} & \multicolumn{2}{|c|}{ BOLT STRESSES } & \multirow{2}{*}{\begin{tabular}{|l|} 
SADDLE \\
Int. thread \\
Stripping \\
Stress \\
[Mpa]
\end{tabular}} \\
\hline & & \begin{tabular}{|l|} 
Axial \\
Bolt \\
Stress \\
[Mpa]
\end{tabular} & $\begin{array}{l}\text { Ext. thread } \\
\text { Stripping } \\
\text { Stress } \\
\text { [Mpa] }\end{array}$ & \\
\hline 4758 & $-4.33 \mathrm{E}-10$ & 0 & 0.0 & 0.0 \\
\hline 4759 & $6.60 \mathrm{E}+04$ & 56 & 14.6 & 10.4 \\
\hline 4760 & $1.15 E+05$ & 98 & 25.4 & 18.1 \\
\hline 4761 & $1.68 \mathrm{E}+05$ & 143 & 37.1 & 26.4 \\
\hline 4762 & $-6.40 \mathrm{E}-10$ & 0 & 0.0 & 0.0 \\
\hline 4763 & $1.18 \mathrm{E}+05$ & 101 & 26.1 & 18.6 \\
\hline 4764 & $2.14 \mathrm{E}+05$ & 184 & 47.3 & 33.7 \\
\hline 4765 & $3.22 \mathrm{E}+05$ & 277 & 71.1 & 50.6 \\
\hline
\end{tabular}

LOAD CASE 6

\begin{tabular}{|c|c|c|c|c|}
\hline \multirow[b]{2}{*}{ Element } & \multirow[b]{2}{*}{$\begin{array}{l}\text { Bolt } \\
\text { Force } \\
{[\mathrm{N}]}\end{array}$} & \multicolumn{2}{|c|}{ BOLT STRESSES } & \multirow[b]{2}{*}{$\begin{array}{l}\text { SADDLE } \\
\text { Int. thread } \\
\text { Stripping } \\
\text { Stress } \\
\text { [Mpa] }\end{array}$} \\
\hline & & \begin{tabular}{|l|} 
Axial \\
Bolt \\
Stress \\
[Mpa]
\end{tabular} & $\begin{array}{l}\text { Ext. thread } \\
\text { Stripping } \\
\text { Stress } \\
\text { [Mpa] }\end{array}$ & \\
\hline 4758 & $-3.75 \mathrm{E}-10$ & 0 & 0.0 & 0.0 \\
\hline 4759 & $6.60 \mathrm{E}+04$ & 56 & 14.6 & 10.4 \\
\hline 4760 & $1.15 \mathrm{E}+05$ & 98 & 25.4 & 18.1 \\
\hline 4761 & $1.68 \mathrm{E}+05$ & 143 & 37.1 & 26.4 \\
\hline 4762 & $-2.19 E-10$ & 0 & 0.0 & 0.0 \\
\hline 4763 & $1.18 E+05$ & 101 & 26.1 & 18.6 \\
\hline 4764 & $2.14 \mathrm{E}+05$ & 184 & 47.3 & 33.7 \\
\hline 4765 & $3.22 E+05$ & 277 & 71.1 & 50.6 \\
\hline
\end{tabular}

Support Plate Connection

\begin{tabular}{|c|c|c|c|c|}
\hline \multirow[b]{2}{*}{ Element } & \multirow[b]{2}{*}{$\begin{array}{l}\text { Bolt } \\
\text { Force } \\
{[\mathrm{N}]}\end{array}$} & \multicolumn{2}{|c|}{ BOLT STRESSES } & \multirow[b]{2}{*}{\begin{tabular}{|l} 
PLATE \\
Int. thread \\
Stripping \\
Stress \\
[Mpa]
\end{tabular}} \\
\hline & & \begin{tabular}{|l|} 
Axial \\
Bolt \\
Stress \\
[Mpa]
\end{tabular} & \begin{tabular}{|l|} 
Ext. thread \\
Stripping \\
Stress \\
[Mpa]
\end{tabular} & \\
\hline 4753 & $-1.13 \mathrm{E}+03$ & -3 & -0.8 & -0.6 \\
\hline 4754 & $7.34 \mathrm{E}+02$ & 2 & 0.5 & 0.4 \\
\hline 4755 & $-3.46 \mathrm{E}+00$ & 0 & 0.0 & 0.0 \\
\hline 4756 & $-1.14 \mathrm{E}+02$ & 0 & -0.1 & -0.1 \\
\hline 4757 & $7.76 \mathrm{E}+03$ & 23 & 5.5 & 3.8 \\
\hline
\end{tabular}

\begin{tabular}{|c|c|c|c|c|}
\hline \multirow[b]{2}{*}{ Element } & \multirow[b]{2}{*}{$\begin{array}{l}\text { Bolt } \\
\text { Force } \\
{[\mathrm{N}]}\end{array}$} & \multicolumn{2}{|c|}{ BOLT STRESSES } & \multirow[b]{2}{*}{\begin{tabular}{|l} 
PLATE \\
Int. thread \\
Stripping \\
Stress \\
[Mpa]
\end{tabular}} \\
\hline & & \begin{tabular}{|l} 
Axial \\
Bolt \\
Stress \\
[Mpa] \\
\end{tabular} & $\begin{array}{l}\text { Ext. thread } \\
\text { Stripping } \\
\text { Stress } \\
\text { [Mpa] }\end{array}$ & \\
\hline 4753 & $-3.74 \mathrm{E}+03$ & -11 & -2.7 & -1.8 \\
\hline 4754 & $2.84 \mathrm{E}+04$ & 84 & 20.1 & 13.9 \\
\hline 4755 & $5.48 \mathrm{E}+04$ & 163 & 38.9 & 26.9 \\
\hline 4756 & $1.54 \mathrm{E}+05$ & 458 & 109.5 & 75.7 \\
\hline 4757 & $2.25 E+05$ & 669 & 160.0 & 110.6 \\
\hline
\end{tabular}

\subsubsection{Stress on Stiffener Beam Elements (Seismic Case)}

Figure 56 shows the plot identifying the beam elements for the stiffener beam portion that is off of the cryostat support plate. As discussed previously, this section has a smaller moment of inertia as it is not aided by the cryostat plate. This section is also the area of the greatest moment and is therefore an area where we must carefully examine the stresses.

Table 27 lists the bending moment about the T-axis and the extreme fiber stress due to that moment. Only Cases 1-4 are shown as Cases 5 and 6 are considerably lower stress due to the lower Z- 
force. It is seen that the fiber stress exceeds the $130 \mathrm{MPa}$ design limit to a near $150 \mathrm{MPa}$ in elements 4733-4735 in load Cases 1 and 2 and near $160 \mathrm{MPa}$ in load Cases 3 and 4. This is still below the yield and may constitute a sufficient safety factor considering that this does not occur for the static case. These stresses correspond well with the simplified Beam $2 \mathrm{~d}$ model that determined stresses of $145 \mathrm{MPa}$.

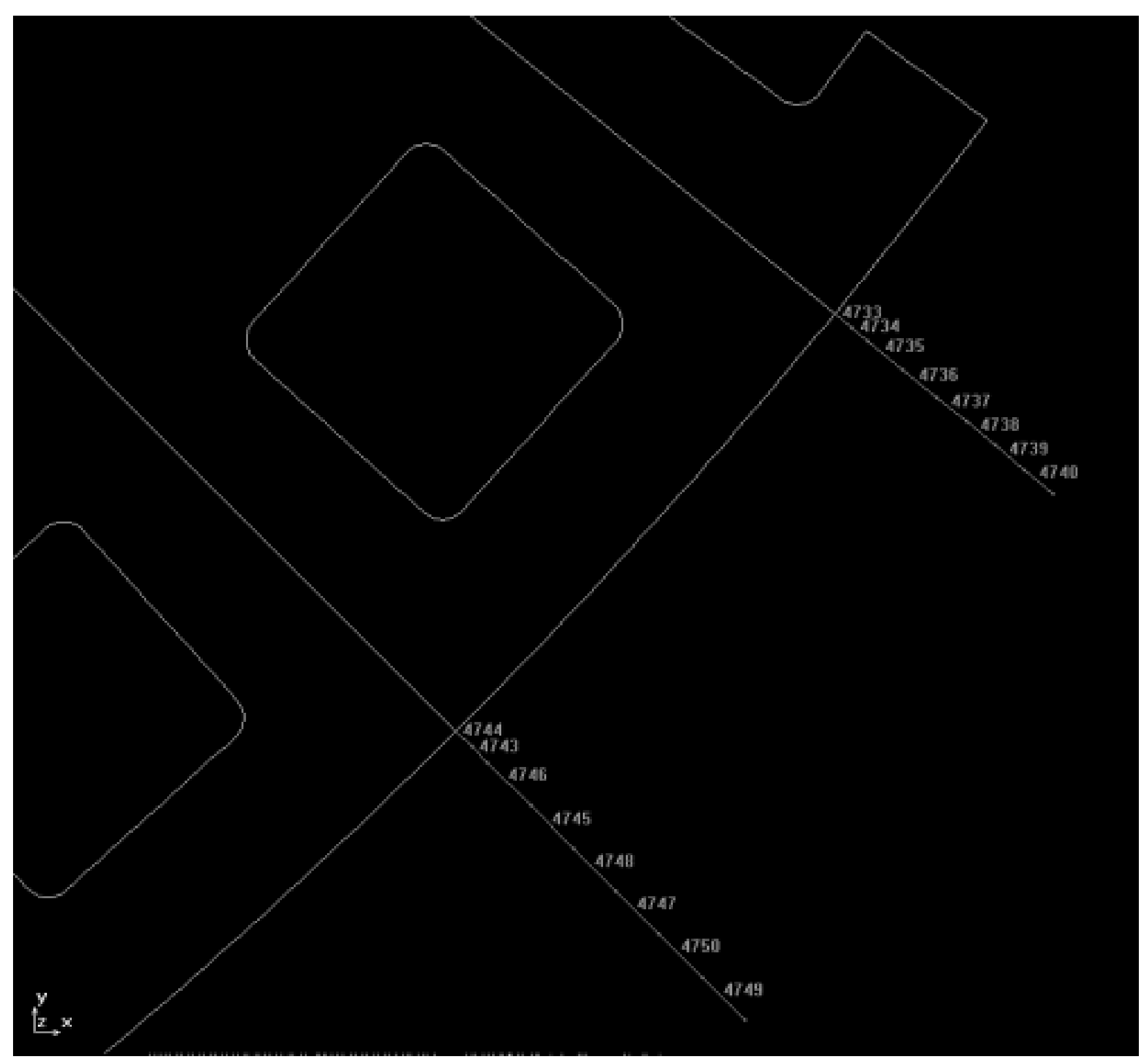

Figure 56. Identification of Beam Elements at Saddle Connection. 
Table 27. Beam Element Moments and Max. Fiber stress about T-axis.

\begin{tabular}{|c|c|c|c|c|c|c|c|}
\hline & ELEMENT & NODE 1 & NODE 2 & $\begin{array}{c}\text { Mt (node 1) } \\
{[\mathrm{N} / \mathrm{mm}]}\end{array}$ & $\begin{array}{c}\text { Mt (node 2) } \\
{[\mathrm{N} / \mathrm{mm}]}\end{array}$ & $\begin{array}{c}\text { Max. fiber } \\
\text { stress (node1) } \\
{[\text { Mpa] }}\end{array}$ & $\begin{array}{c}\text { Max. fiber } \\
\text { stress (node1) } \\
\text { [Mpa] }\end{array}$ \\
\hline \multirow[t]{17}{*}{ Load Case } & 1 & & & & & & \\
\hline & 4733 & 1457 & 2681 & $-2.08 E+08$ & $2.12 \mathrm{E}+08$ & 145 & 148 \\
\hline & 4734 & 2681 & 2682 & $-2.12 E+08$ & $2.16 \mathrm{E}+08$ & 148 & 150 \\
\hline & 4735 & 2682 & 2684 & $-2.16 E+08$ & $1.91 \mathrm{E}+08$ & 150 & 133 \\
\hline & 4736 & 2684 & 2685 & $-1.91 E+08$ & $1.65 E+08$ & 133 & 115 \\
\hline & 4737 & 2685 & 2687 & $-1.65 E+08$ & $1.28 \mathrm{E}+08$ & 115 & 89 \\
\hline & 4738 & 2687 & 2688 & $-1.28 E+08$ & $9.01 \mathrm{E}+07$ & 89 & 63 \\
\hline & 4739 & 2688 & 2690 & $-9.01 E+07$ & $4.50 \mathrm{E}+07$ & 63 & 31 \\
\hline & 4740 & 2690 & 2691 & $-4.50 E+07$ & $-8.80 \mathrm{E}-08$ & 31 & 0 \\
\hline & 4743 & 2695 & 2696 & $-1.90 E+08$ & $1.90 \mathrm{E}+08$ & 132 & 132 \\
\hline & 4744 & 2696 & 118 & $-1.90 E+08$ & $1.89 \mathrm{E}+08$ & 132 & 132 \\
\hline & 4745 & 2698 & 2699 & $-1.45 E+08$ & $1.67 \mathrm{E}+08$ & 101 & 117 \\
\hline & 4746 & 2699 & 2695 & $-1.67 E+08$ & $1.90 \mathrm{E}+08$ & 117 & 132 \\
\hline & 4747 & 2701 & 2702 & $-7.68 E+07$ & $1.11 \mathrm{E}+08$ & 53 & 77 \\
\hline & 4748 & 2702 & 2698 & $-1.11 E+08$ & $1.45 \mathrm{E}+08$ & 77 & 101 \\
\hline & 4749 & 2704 & 2705 & 9.66E-09 & $3.84 \mathrm{E}+07$ & 0 & 27 \\
\hline & 4750 & 2705 & 2701 & $-3.84 E+07$ & $7.68 \mathrm{E}+07$ & 27 & 53 \\
\hline \multirow[t]{17}{*}{ Load Case } & 2 & & & & & & \\
\hline & 4733 & 1457 & 2681 & $-2.08 E+08$ & $2.12 \mathrm{E}+08$ & 145 & 148 \\
\hline & 4734 & 2681 & 2682 & $-2.12 E+08$ & $2.16 \mathrm{E}+08$ & 148 & 150 \\
\hline & 4735 & 2682 & 2684 & $-2.16 E+08$ & $1.91 \mathrm{E}+08$ & 150 & 133 \\
\hline & 4736 & 2684 & 2685 & $-1.91 E+08$ & $1.65 \mathrm{E}+08$ & 133 & 115 \\
\hline & 4737 & 2685 & 2687 & $-1.65 E+08$ & $1.28 \mathrm{E}+08$ & 115 & 89 \\
\hline & 4738 & 2687 & 2688 & $-1.28 E+08$ & $9.01 \mathrm{E}+07$ & 89 & 63 \\
\hline & 4739 & 2688 & 2690 & $-9.01 E+07$ & $4.50 \mathrm{E}+07$ & 63 & 31 \\
\hline & 4740 & 2690 & 2691 & $-4.50 E+07$ & $6.44 \mathrm{E}-07$ & 31 & 0 \\
\hline & 4743 & 2695 & 2696 & $-1.90 E+08$ & $1.90 \mathrm{E}+08$ & 132 & 132 \\
\hline & 4744 & 2696 & 118 & $-1.90 E+08$ & $1.89 \mathrm{E}+08$ & 132 & 132 \\
\hline & 4745 & 2698 & 2699 & $-1.45 E+08$ & $1.67 \mathrm{E}+08$ & 101 & 117 \\
\hline & 4746 & 2699 & 2695 & $-1.67 E+08$ & $1.90 \mathrm{E}+08$ & 117 & 132 \\
\hline & 4747 & 2701 & 2702 & $-7.68 E+07$ & $1.11 \mathrm{E}+08$ & 53 & 77 \\
\hline & 4748 & 2702 & 2698 & $-1.11 E+08$ & $1.45 E+08$ & 77 & 101 \\
\hline & 4749 & 2704 & 2705 & $1.81 \mathrm{E}-07$ & $3.84 \mathrm{E}+07$ & 0 & 27 \\
\hline & 4750 & 2705 & 2701 & $-3.84 E+07$ & $7.68 \mathrm{E}+07$ & 27 & 53 \\
\hline \multirow[t]{17}{*}{ Load Case } & 3 & & & & & & \\
\hline & 4733 & 1457 & 2681 & $2.18 \mathrm{E}+08$ & $-2.23 E+08$ & -152 & -155 \\
\hline & 4734 & 2681 & 2682 & $2.23 E+08$ & $-2.27 E+08$ & -155 & -158 \\
\hline & 4735 & 2682 & 2684 & $2.27 \mathrm{E}+08$ & $-1.73 E+08$ & -158 & -121 \\
\hline & 4736 & 2684 & 2685 & $1.73 E+08$ & $-1.20 E+08$ & -121 & -83 \\
\hline & 4737 & 2685 & 2687 & $1.20 \mathrm{E}+08$ & $-8.22 E+07$ & -83 & -57 \\
\hline & 4738 & 2687 & 2688 & $8.22 E+07$ & $-4.48 E+07$ & -57 & -31 \\
\hline & 4739 & 2688 & 2690 & $4.48 \mathrm{E}+07$ & $-2.24 \mathrm{E}+07$ & -31 & -16 \\
\hline & 4740 & 2690 & 2691 & $2.24 \mathrm{E}+07$ & $-3.97 E-07$ & -16 & 0 \\
\hline & 4743 & 2695 & 2696 & $1.79 E+08$ & $-1.79 E+08$ & -125 & -125 \\
\hline & 4744 & 2696 & 118 & $1.79 E+08$ & $-1.79 E+08$ & -125 & -124 \\
\hline & 4745 & 2698 & 2699 & $1.01 \mathrm{E}+08$ & $-1.40 E+08$ & -70 & -98 \\
\hline & 4746 & 2699 & 2695 & $1.40 \mathrm{E}+08$ & $-1.79 E+08$ & -98 & -125 \\
\hline & 4747 & 2701 & 2702 & $3.76 \mathrm{E}+07$ & $-6.93 E+07$ & -26 & -48 \\
\hline & 4748 & 2702 & 2698 & $6.93 E+07$ & $-1.01 \mathrm{E}+08$ & -48 & -70 \\
\hline & 4749 & 2704 & 2705 & $1.32 \mathrm{E}-07$ & $-1.88 E+07$ & 0 & -13 \\
\hline & 4750 & 2705 & 2701 & $1.88 \mathrm{E}+07$ & $-3.76 E+07$ & -13 & -26 \\
\hline \multirow[t]{17}{*}{ Load Case } & 4 & & & & & & \\
\hline & 4733 & 1457 & 2681 & $2.18 \mathrm{E}+08$ & $-2.23 E+08$ & -152 & -155 \\
\hline & 4734 & 2681 & 2682 & $2.23 E+08$ & $-2.27 E+08$ & -155 & -158 \\
\hline & 4735 & 2682 & 2684 & $2.27 E+08$ & $-1.73 E+08$ & -158 & -121 \\
\hline & 4736 & 2684 & 2685 & $1.73 E+08$ & $-1.20 E+08$ & -121 & -83 \\
\hline & 4737 & 2685 & 2687 & $1.20 \mathrm{E}+08$ & $-8.22 E+07$ & -83 & -57 \\
\hline & 4738 & 2687 & 2688 & $8.22 \mathrm{E}+07$ & $-4.48 E+07$ & -57 & -31 \\
\hline & 4739 & 2688 & 2690 & $4.48 \mathrm{E}+07$ & $-2.24 E+07$ & -31 & -16 \\
\hline & 4740 & 2690 & 2691 & $2.24 \mathrm{E}+07$ & $-2.19 E-08$ & -16 & 0 \\
\hline & 4743 & 2695 & 2696 & $1.79 \mathrm{E}+08$ & $-1.79 E+08$ & -125 & -125 \\
\hline & 4744 & 2696 & 118 & $1.79 E+08$ & $-1.79 E+08$ & -125 & -124 \\
\hline & 4745 & 2698 & 2699 & $1.01 \mathrm{E}+08$ & $-1.40 E+08$ & -70 & -98 \\
\hline & 4746 & 2699 & 2695 & $1.40 \mathrm{E}+08$ & $-1.79 E+08$ & -98 & -125 \\
\hline & 4747 & 2701 & 2702 & $3.76 \mathrm{E}+07$ & $-6.93 E+07$ & -26 & -48 \\
\hline & 4748 & 2702 & 2698 & $6.93 E+07$ & $-1.01 \mathrm{E}+08$ & -48 & -70 \\
\hline & 4749 & 2704 & 2705 & $1.59 \mathrm{E}-07$ & $-1.88 E+07$ & 0 & -13 \\
\hline & 4750 & 2705 & 2701 & $1.88 \mathrm{E}+07$ & $-3.76 E+07$ & -13 & -26 \\
\hline \multirow[t]{3}{*}{ Load Case } & 5 & & & & & & \\
\hline & 4733 & 1457 & 2681 & $8.78 \mathrm{E}+07$ & $-8.95 E+07$ & -61 & -62 \\
\hline & 4734 & 2681 & 2682 & $8.95 \mathrm{E}+07$ & $-9.12 E+07$ & -62 & -63 \\
\hline
\end{tabular}




\subsubsection{Plate Stresses (Seismic)}

Figure 57 shows the Von Mises stress for seismic load Case 1. This is representative of the worst loading of all six cases. The plot shows several small regions of stress higher than the design limit (>130 $\mathrm{MPa}$ ). There are local stress concentrations near the cut-outs that reach $180 \mathrm{MPa}$. These areas are not a concern as the high stress regions are small and in the event yielding occurred, it would only be local.

A larger stress concentration occurs at the top of the plate near the point of loading and coinciding with the beam location. The high effective stress (as high as 220MPa) in this area is dominated by bending stresses. These stresses are the result of the load Seismic load in the Z-direction being transferred from the point of application to the stiffener beam. By making very simple assumptions, hand calculations can confirm that these stresses are reasonable, depending on the point of application distance from the beam. It is, however, the design intent of the stiffener beams to carry the entire Z-direction seismic load. A simple modification to properly transfer the load to the stiffener beam exists. As discussed previously, the load was arbitrarily applied in the center of the back cryostat support for this analysis, as more detailed knowledge is not available at this time. The proper transferring of the load should be reexamined after more complete load information is available.

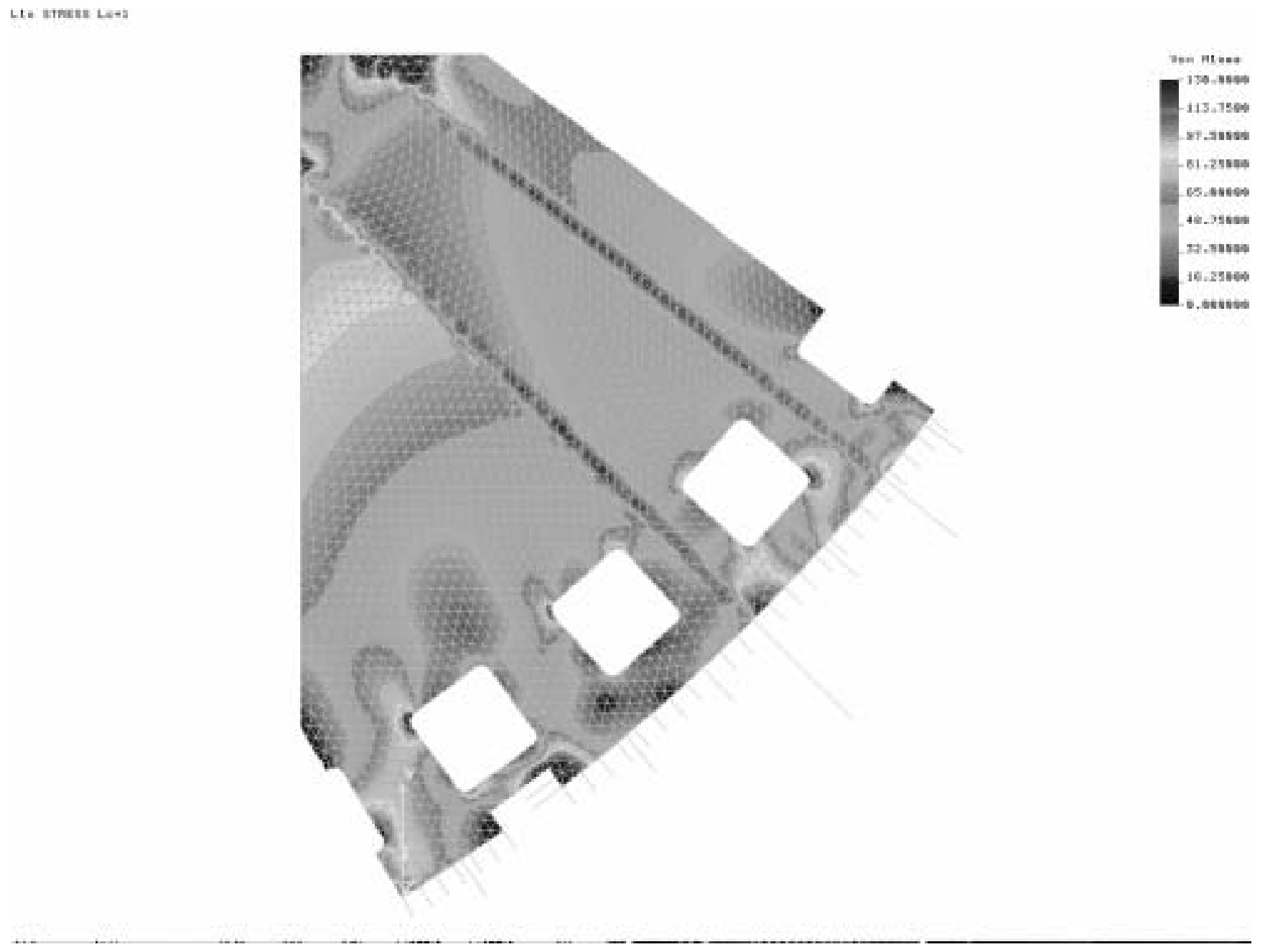

Figure 57. Von Mises Stress for Seismic Load Case 1. 
Table 28. Forces [N] on Key Elements for Seismic Load Cases.

\begin{tabular}{c|cc|c} 
& $\begin{array}{c}\text { Key } \\
\text { Elem. } \\
\mathbf{4 7 5 1}\end{array}$ & $\begin{array}{c}\text { Key } \\
\text { Elem. } \\
\mathbf{4 7 5 2}\end{array}$ & $\begin{array}{c}\text { Sum } \\
\text { of both } \\
\text { keys }\end{array}$ \\
\hline $\mathbf{1}$ & $-3.69 \mathrm{E}+05$ & $-2.62 \mathrm{E}+05$ & $-6.31 \mathrm{E}+05$ \\
$\mathbf{2}$ & $-2.69 \mathrm{E}+05$ & $-1.95 \mathrm{E}+05$ & $-4.64 \mathrm{E}+05$ \\
$\mathbf{3}$ & $-2.66 \mathrm{E}+05$ & $-1.87 \mathrm{E}+05$ & $-4.53 \mathrm{E}+05$ \\
$\mathbf{4}$ & $-1.66 \mathrm{E}+05$ & $-1.20 \mathrm{E}+05$ & $-2.86 \mathrm{E}+05$ \\
$\mathbf{5}$ & $-3.25 \mathrm{E}+05$ & $-2.29 \mathrm{E}+05$ & $-5.55 \mathrm{E}+05$ \\
$\mathbf{6}$ & $-2.25 \mathrm{E}+05$ & $-1.63 \mathrm{E}+05$ & $-3.87 \mathrm{E}+05$
\end{tabular}

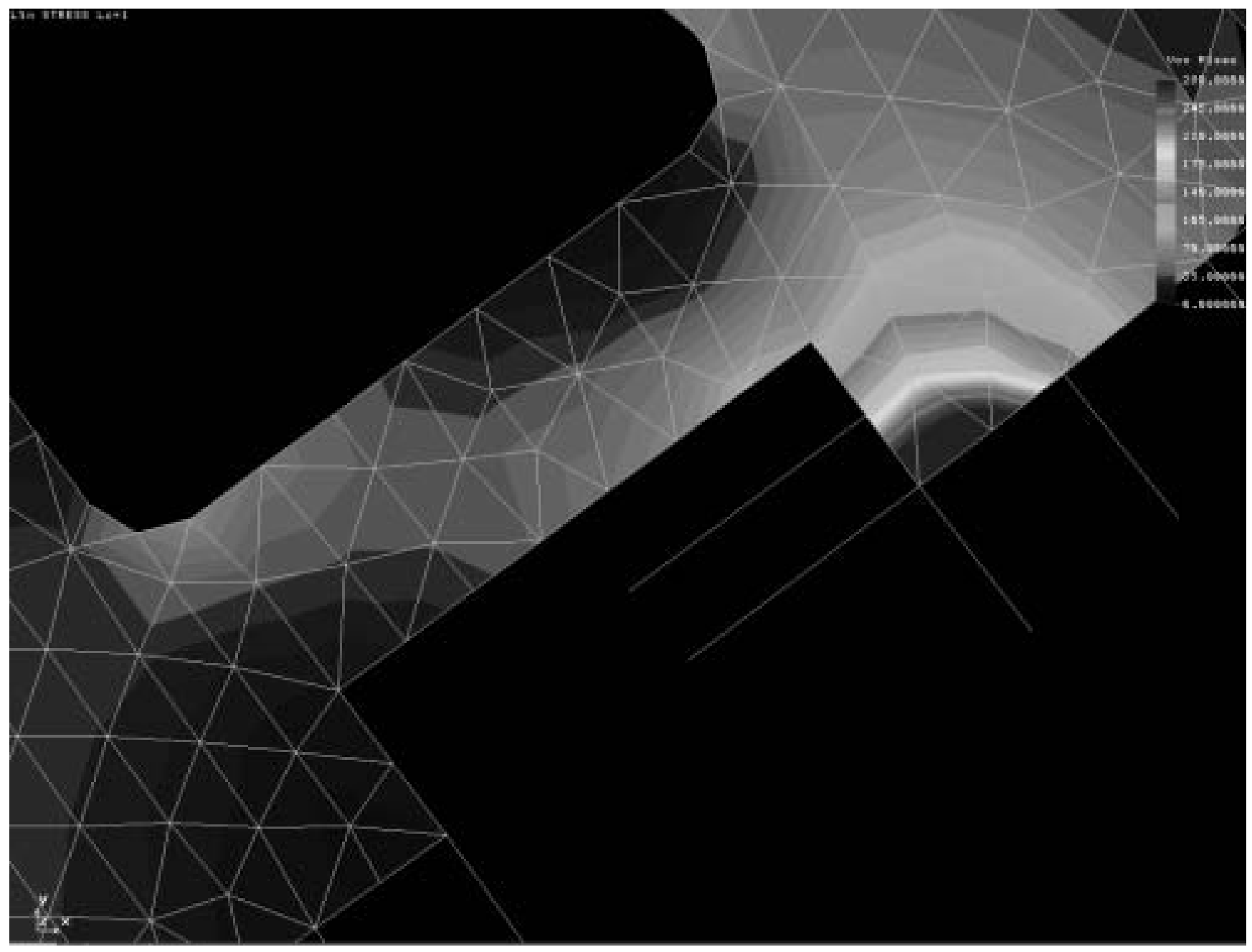

Figure 58. Von Mises Stress for Seismic Load Case 1 (enlarged at Key ). Scale max. 280MPa.

Similar to the static case discussed in Section 3.3.3, the only area of large stress (>130 MPa) is in the area of the key. The Von Mises stress in this area reaches a high value of $282 \mathrm{MPa}$. The key depth in the plate is $50 \mathrm{~mm}$. The effective stress is seen to quickly drop off as we move away to $200 \mathrm{MPa}$. The element mesh in the area of the key is relatively coarse as compared to the key dimension. The model 
uses two truss elements and therefore the forces are concentrated over two nodes. In reality, this force will be distributed more over the area.

The discussion of the nature of the stresses in the key region presented in Section 3.3.3 applies equally well here. Using a similar analysis, as done in Section 3.3.3, we analytically determine the stresses. If we assume the forces act uniformly over a $25 \mathrm{~mm}$ square area starting at the corner, we have $\mathrm{A}_{25}=1750 \mathrm{~mm}^{2}, \sigma_{\mathrm{K}}=-148 \mathrm{MPa}$ (using element 4752, Case 1, Table 28), $\sigma_{\mathrm{G}}=-170 \mathrm{MPa}$ (using the single gap force acting on the same corner), and, $\sigma_{\mathrm{E}}=164 \mathrm{MPa}$. If we assume the forces act uniformly over a $50 \mathrm{~mm}$ square area, we have $\mathrm{A}_{50}=3500 \mathrm{~mm}^{2}, \sigma_{\mathrm{K}}=-180 \mathrm{MPa}$ (using the summed key force from Case 1, Table 28), $\sigma_{\mathrm{G}}=-105 \mathrm{MPa}$ (using the sum of the first two gap elements at the corner for the same load case), and, $\sigma_{\mathrm{E}}=156 \mathrm{MPa}$. Because the extra key helps distribute the load in this model, we see closer values between these two values than for those found in Section 3.3.3. However, in both cases the stresses are over the 130MPa design limit. As was mentioned in Section 3.3.3, a further modification to reduce the stress in the key area will be needed.

\subsubsection{PLATE DEFLECTIONS FOR SEISMIC CASE}

Figure 59 shows the deflections in the Z-direction for load Case 1 and Table 29 lists the maximum and minimum values. Figure 60 shows the location of the nodes listed in Table 29. For clarity, nodes $2312-2318$ are left out, but are distributed evenly between nodes 2311 and 2319. The maximum deflection is equal to $8.3 \mathrm{~mm}$ and is located at the point of load application. Since the Z-direction (w) displacement is driven by the force in the Z-direction, load Cases 1-4 are found to have similar deflections, except for a change in sign as appropriate. Deflections for load Case 5 and 6 are more on the order of $2.5 \mathrm{~mm}$ at the top of the plate. Deflections in the X-direction $(\mathrm{u})$ are near $1 \mathrm{~mm}$ at the top and $0.6 \mathrm{~mm}$ for load Cases 1-4, where this is a result of the plate bending.

To speak in general terms, it is instructive to consider the load Case 1, which is equal to the worst case ignoring change in direction. Preloading of the bolts is not considered, so bolt elongation is adding to the tip deflection similar to the Beam2D case described above. Referring to Fig. 60, node 2682 deflects $0.4 \mathrm{~mm}$ in $\mathrm{z}$. This deflection adds $3 \mathrm{~mm}$ to the tip deflection that should be eliminated with proper bolt preload.

The loading in the Z-direction also causes the plate to bend in such a way that the unrestrained bottom left corner (when viewing Fig. 59) deflects almost 2.3-2.7mm (node 73) opposite the direction of the tip deflection in Cases 1-4. This deflection is larger than the bolt clearance and will in reality be constrained by the bolts. This FEA model did not include a Z-direction constraint. Further analysis is needed to determine the shear load that will be placed on the bolts if they are to stop this deflection. Analysis will also be done to determine if a pin can be placed to constrain this deflection. 


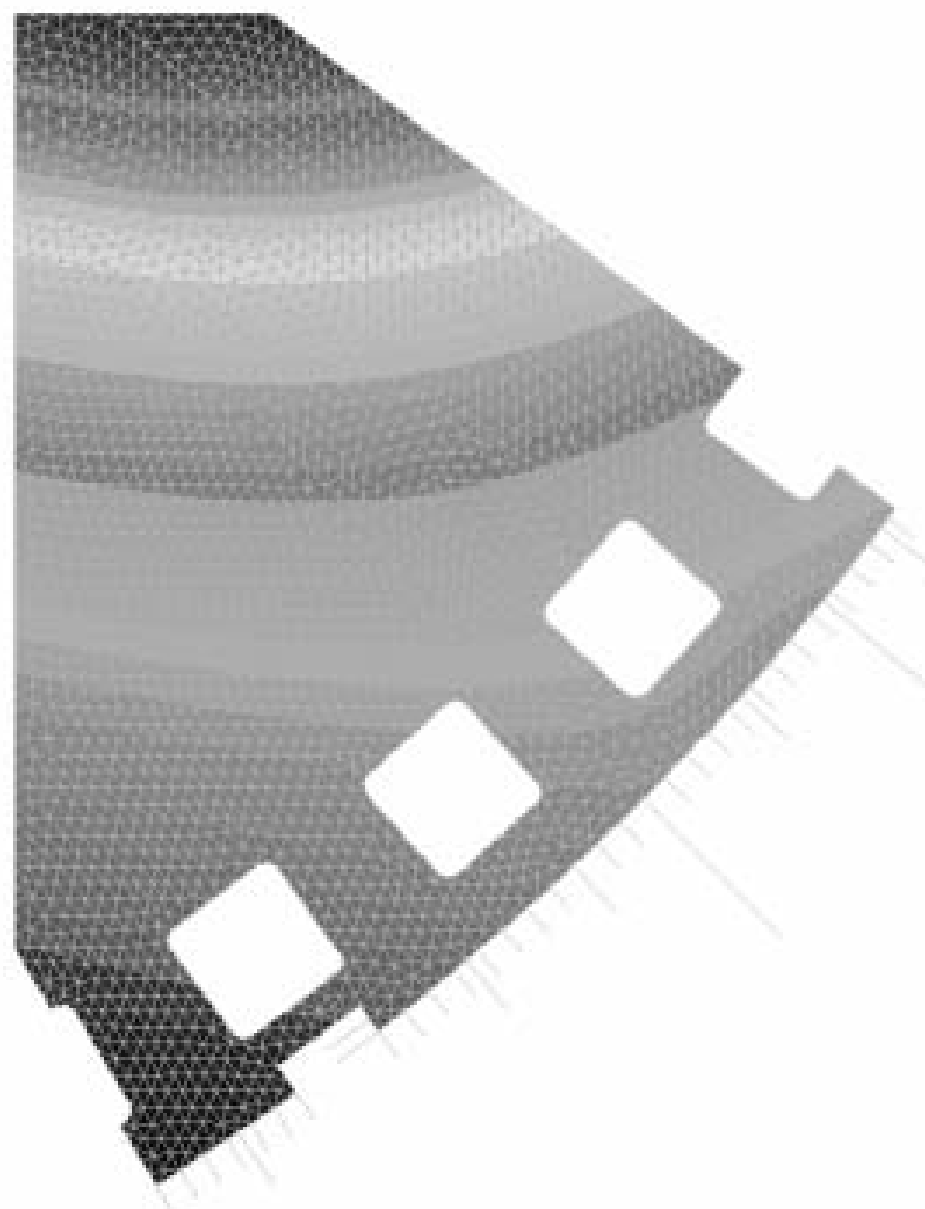

Figure 59. UZ-deflection for Seismic Load Case 1. 
Table 29. Maximum/Minimum Displacements for Seismic Load Cases.

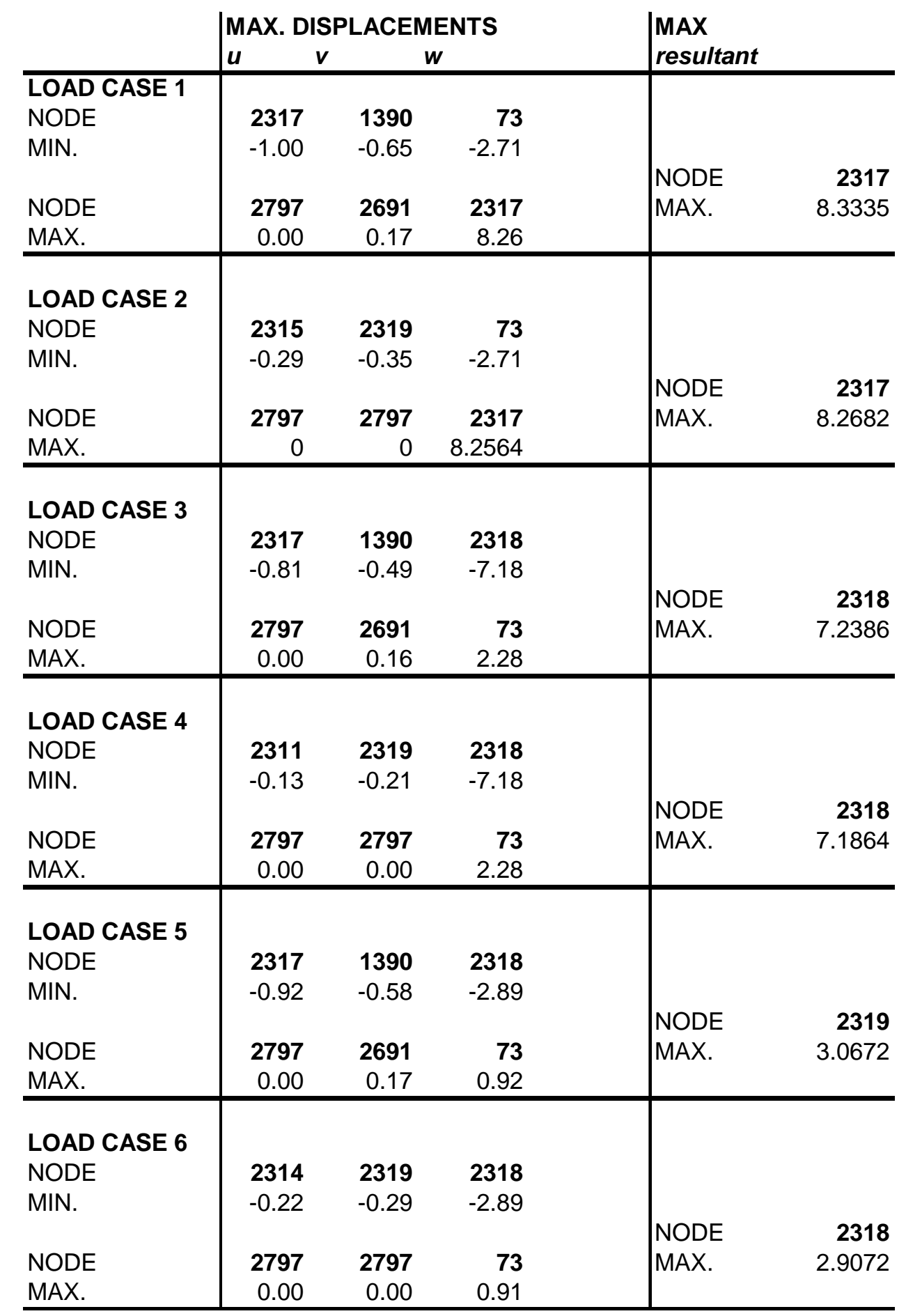




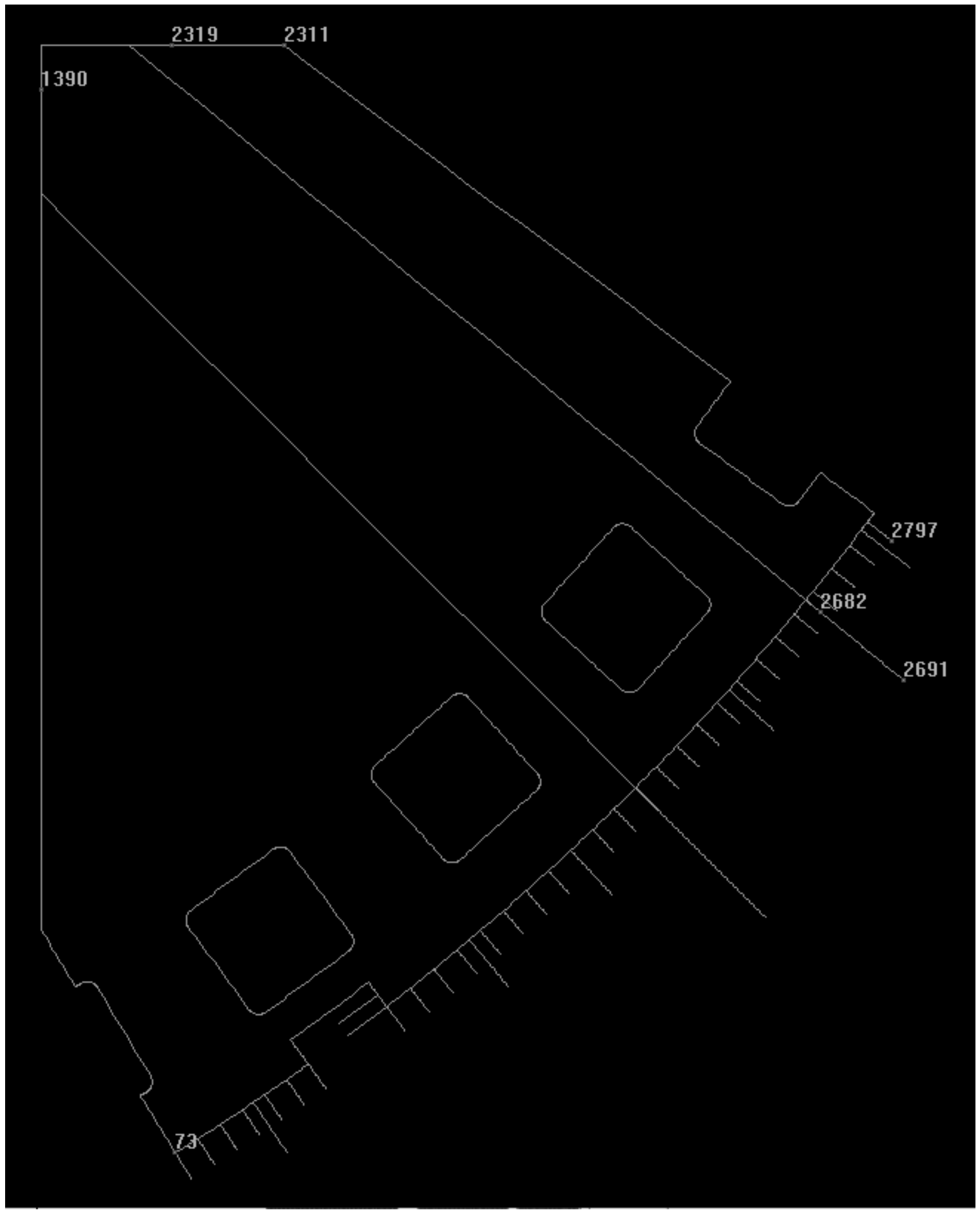

Figure 60. Location of Nodes with Maximum Deflection. 


\subsection{Further Redesign}

The analysis of Section 3.5 for the design presented in Section 3.3 revealed high stresses in multiple areas. These stresses were due mainly to the reaction force in Z-direction that is developed by the seismic loading in both the $\mathrm{Z}$ and $\mathrm{X}$ directions. This is discussed in Section 3.4. Redesign to eliminate these high stresses is complicated by space conflicts in the area of the stiffener beams. Electrical boxes for the cryostat occupy the region of the lower stiffener beam in the region of the plate above the cut-outs. For this reason, CERN TC requested that the plate be evaluated with different stiffener options. Additionally, CERN TC stated that the loading for the seismic analysis should consist of only the static gravity load in the $\mathrm{Y}$ direction combined with the $12 \%(1.59 \mathrm{e} 5 \mathrm{~N})$ of the gravity load applied through the cryostat C.G. in the $\mathrm{Z}$ direction only. To evaluate different options, three alternatives (Cases E, F, and $\mathrm{K}$ ), were briefly analyzed to determine the maximum capacity for Z-loading. In Cases E and F, the static gravity load was applied and the $\mathrm{Z}$ load was varied until the limiting values of 90Mpa and $120 \mathrm{MPa}$ were arrived at. In Case K, the first load case used the limiting value of $90 \mathrm{MPa}$, whereas the second load case was that load equivalent to the $12 \%$ load discussed above.

\subsubsection{Seismic Case E (Single Stiffener Beam)}

The same FEA model discussed previously in Sections 3.3 and 3.5 was used as a starting point for this new case. The beam elements that represented the lower stiffener beam were deleted. An additional Z-direction restraint was added to the node at the top of bolt 1 to prevent rotation of the plate. If this method is to be pursued further, the torsion of the beam will have to be better understood. Two load cases were set-up corresponding to the load requirements described in the introduction. The results are briefly summarized in Table 30.

Table 30. Summary of Analysis of Seismic Case E.

\begin{tabular}{|lll|}
\hline & LOAD CASE 1 & LOAD CASE 2 \\
Fy & $8.5 \mathrm{e} 5 \mathrm{~N}$ & $8.5 \mathrm{e} 5 \mathrm{~N}$ \\
Fz & $8.987 \mathrm{e} 4 \mathrm{~N}$ & $1.198 \mathrm{e} 5 \mathrm{~N}$ \\
max Uz Deflection & $5.2 \mathrm{~mm}$ & $6.89 \mathrm{~mm}$ \\
Max Fiber Stress in Beam & $90 \mathrm{MPa}$ & $120 \mathrm{MPA}$ \\
$\begin{array}{l}\text { Largest Int. Thread Stress } \\
\text { on Saddle }\end{array}$ & & \\
$\begin{array}{l}\text { Reaction in Z-direction } \\
\text { at bolt 1 }\end{array}$ & $90 \mathrm{MPa}$ & $120 \mathrm{MPa}$ \\
\hline
\end{tabular}

\subsubsection{Seismic Case F (Shortened Lower Stiffener Beam)}

In the second option, a similar model was evaluated as in 3.6.1. In this case, however, only the lower stiffener beam elements above the cut-outs on the plate were removed, leaving a shortened, lower stiffener beam. It was hoped that this would help in transferring the moment to the saddle. Note that the bolt $1 \mathrm{Z}$-direction restraint, as described in Section 3.6.1, is not needed. However, similar to that discussed in Section 3.5.6, the lower, left edge of the plate deflects $2.5 \mathrm{~mm}$ in the opposite direction of the $5.2 \mathrm{~mm}$ that the tip deflects in Case 1, and $3.3 \mathrm{~mm}$ for load Case 2. The results are listed in Table 31 . 
Table 31. Summary of Analysis for Seismic Case F.

\begin{tabular}{|lll|}
\hline & LOAD CASE 1 & LOAD CASE 2 \\
Fy & $8.5 \mathrm{e} 5 \mathrm{~N}$ & $8.5 \mathrm{e} 5 \mathrm{~N}$ \\
$\mathrm{Fz}$ & $1.26 \mathrm{e} 5 \mathrm{~N}$ & $1.69 \mathrm{e} 5 \mathrm{~N}$ \\
max Uz Deflection & $5.2 \mathrm{~mm}$ & $6.95 \mathrm{~mm}$ \\
Max Fiber Stress in Beam & $90 \mathrm{MPa}$ & $120 \mathrm{MPA}$ \\
Largest Beam Bolt Force & $5.979 \mathrm{e} 5 \mathrm{~N}$ & $7.99 \mathrm{e} 5 \mathrm{~N}$ \\
Largest Int. Thread Stress & & \\
on Saddle & $94 \mathrm{MPa}$ & $126 \mathrm{MPa}$ \\
\hline
\end{tabular}

Figure 65 shows the Von Mises tress for the file Seismic Case F for the second load case. The stresses on the plate in the region above the shortened stiffener beam reach just above 130MPa and averages near 140-150MPa. This stress propagates from the point where the lower stiffener beam ends. In reality, this beam is as wide as the space between the cut-outs and, it would be expected that a less intense stress distribution should occur in that region. To examine that, an improved FEA model was developed where the stiffener beams are actually model-using shell elements. The details and results of this analysis are given further in Section 7. There, in the citing of Fig. 66, it can be seen that the stresses are much lower in this same area.

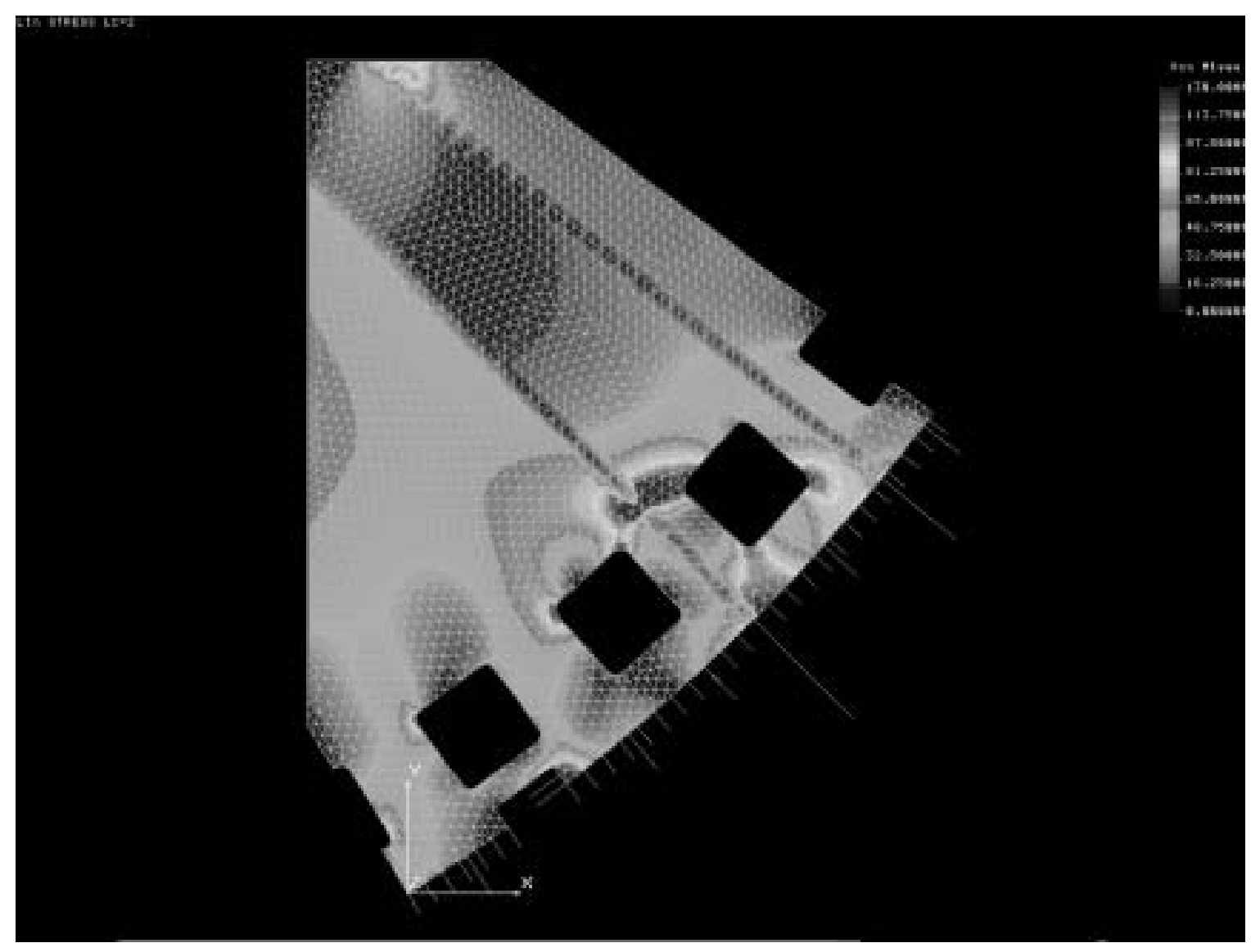

Figure 61. Von Mises Stress for Seismic Case F, Load Case 2. 


\subsubsection{Seismic Case K (Two Shortened, Lower Stiffener Beam)}

The third option evaluated was to add an additional, short, stiffener beam between the first and second cut-out. Because this stiffener interferes with bolt 2 , this bolt is relocated closer to bolt 3 . Figure 62 shows the location of the stiffener beams and the new bolt 2 . In this case the load for load Case 2 was chosen to be the maximum seismic load (12\% of gravity load applied in Z-direction through Cryostat $\mathrm{CM})$. It is seen in Table 32 that the additional short stiffener beam aids in reducing the deflection and stress even further. Figure 63 shows the Von Mises stress for the load Case 2. As was the case for seismic Case F (discussed in Section 3.6.2), there is an area of high stress in the plate at the top end of the middle stiffener beam. The stress in that area is near $140 \mathrm{MPa}$ with high points near $160 \mathrm{MPa}$. For the same reasons discussed in Section 3.6.2, these stresses are likely high due to the point loading of the beam elements. As the true beam is considerably wider, a better distribution should be expected. This is seen to be true in Section 3.7.2 where shells are used to model the beam. The comparison of the stresses found between the seismic Case F and seismic Case F-Shell are analogous to this model. An equivalent shell beam model of this seismic Case $\mathrm{K}$ is to be carried out where it is expected that these high stresses will also dissipate.

Table 32. Summary of Analysis for Seismic Case K.

\begin{tabular}{|lll|}
\cline { 2 - 3 } \multicolumn{1}{c|}{} & LOAD CASE 1 & LOAD CASE 2 \\
\hline Fy & $8.5 \mathrm{e} 5 \mathrm{~N}$ & $8.5 \mathrm{e} 5 \mathrm{~N}$ \\
Fz & $1.36 \mathrm{e} 5 \mathrm{~N}$ & $1.59 \mathrm{e} 5$ \\
max Uz Deflection & $5.2 \mathrm{~mm}$ & $6.03 \mathrm{~mm}$ \\
Max Fiber Stress in Beam & $90 \mathrm{MPa}$ & $104 \mathrm{MPA}$ \\
Largest Beam Bolt Force & $5.71 \mathrm{e} 5 \mathrm{~N}$ & $6.67 \mathrm{e} 5 \mathrm{~N}$ \\
Largest Int. Thread Stress & & \\
on Saddle & $90 \mathrm{MPa}$ & $105 \mathrm{MPa}$ \\
& & \\
\hline
\end{tabular}




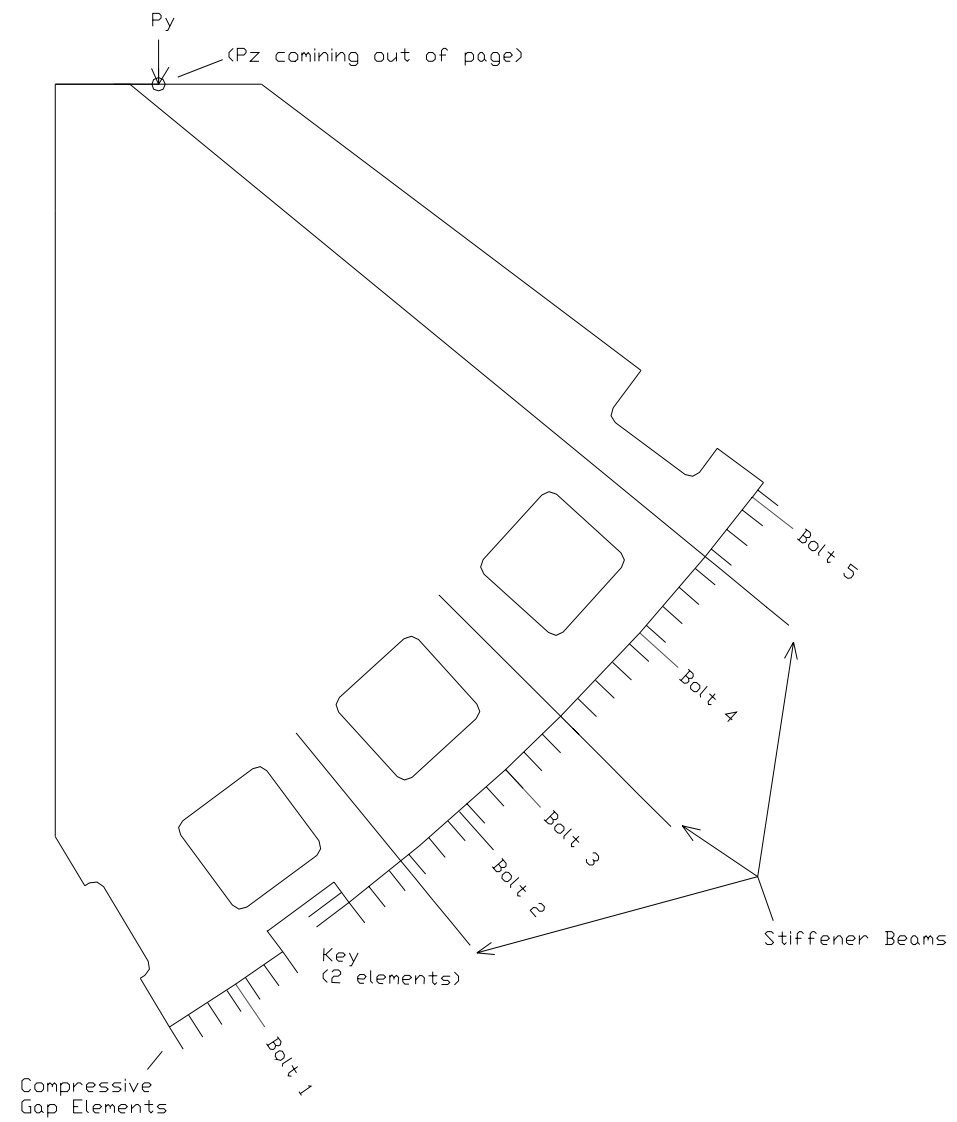

Figure 62. FEA Model Used for Seismic Case K. 

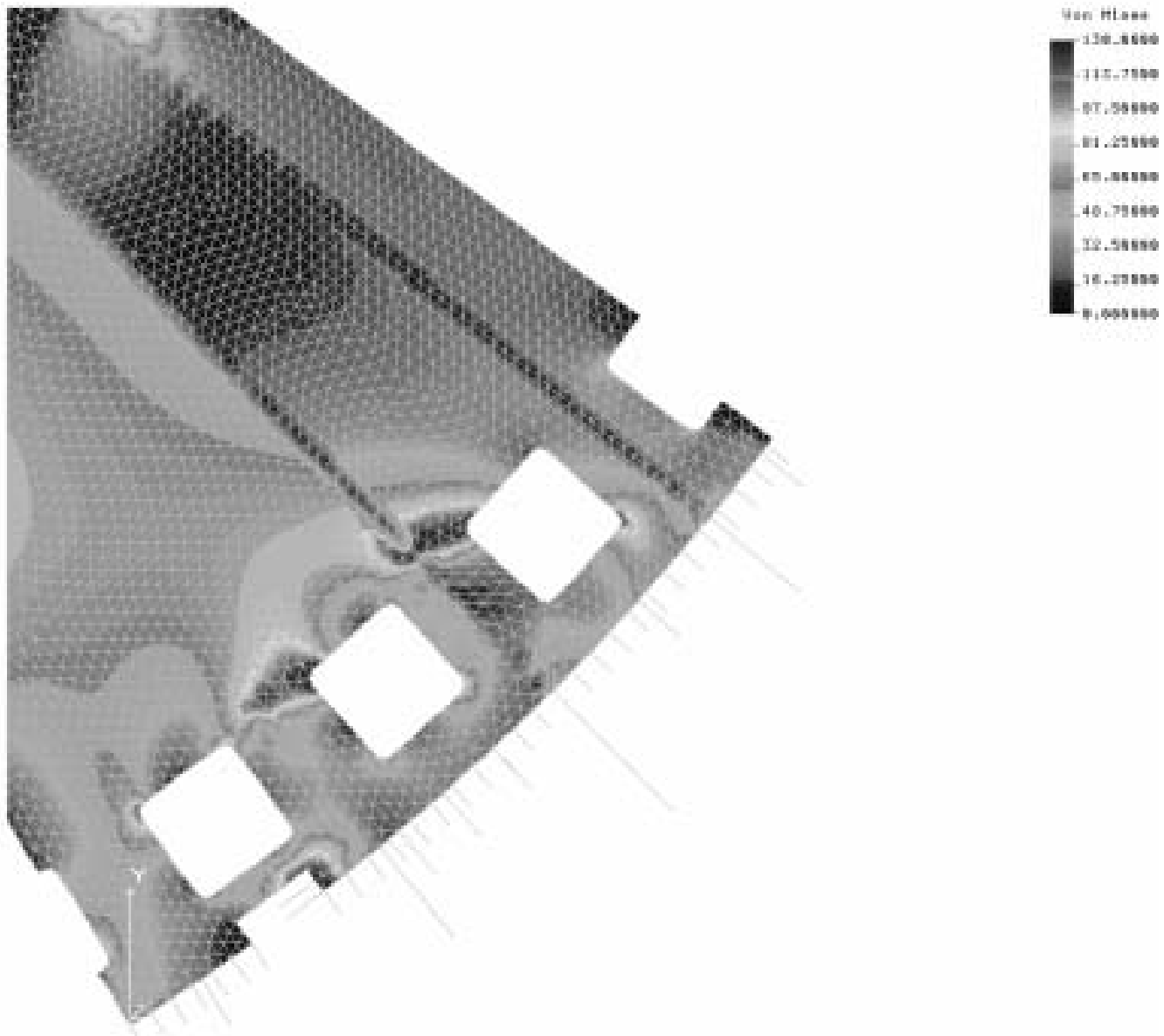

Figure 63. Von Mises Stress (top) for Seismic Case K, Load Case 2. 


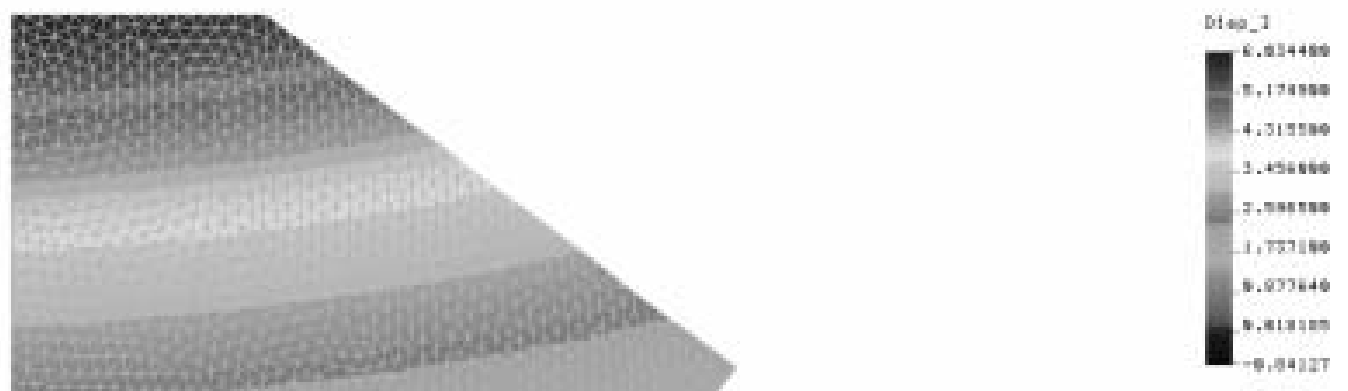

Figure 64. Uz Deflection for Seismic Case K - Load Case 2.

\subsection{FEA Model Using Shell Elements for Stiffener Beam}

As a further iteration of the FEA modeling, a model was developed where the stiffener beams were modeled using shell elements instead of the Beam3D elements. To approximate the geometry of the Ibeam stiffeners, 2D surfaces were created in the geometry of the flanges and web, meshed with 3-node thin shells, and nodes merged along the joint between the flanges and web. The flanges were spaced apart at the distance of the mid-planes. Referring to Fig. 55, the mid-plane distance is $180 \mathrm{~mm}$. The flanges and web were meshed with shell elements of $50 \mathrm{~mm}$ and $40 \mathrm{~mm}$ thickness, respectively, following the I-beam geometry. Because the web must connect to the shells, which are located at the mid-plane distance, the web is actually $50 \mathrm{~mm}$ taller than it should be. It is easy to show that this additional material increases the inertia by only a trivial amount and, therefore, this effect is neglected. The cryostat support plate is the similar 2D geometry used previously and is again meshed with 70mm thick, 3-node thin shell elements. By similar argument as for the beam flanges, the spacing between the plate and the bottom flange of the beam should be determined by the mid-plane distances. Again referring to Fig. 55, this distance is 60mm. To form the connection between the beams and the plate, rigid coupling constraints are used at several nodes along each side of the bottom flange. This is a realistic modeling, as the welding also will be intermittent and on the edges only. This constraint method does not yield the connective force, which 
would be useful in sizing the welds for this assembly. In the future, these constraints will be substituted with beam elements to capture the weld forces. Figure 65 shows one such model made in this fashion.

\subsubsection{Seismic Case F-Shell}

The FEA model for the seismic Case F-shell duplicates the design of seismic Case F discussed in Section 3.6.2. The purpose here is to improve and verify the analysis. Figure 65 shows the mesh of the model showing the two stiffener beams with the lower beam shortened, as was described for seismic Case F. One difference is that the gap elements along the curved bottom edge of the cryostat support plate are not modeled here. However, as this analysis was mainly concerned with the Z-direction loading, this is not significant. 


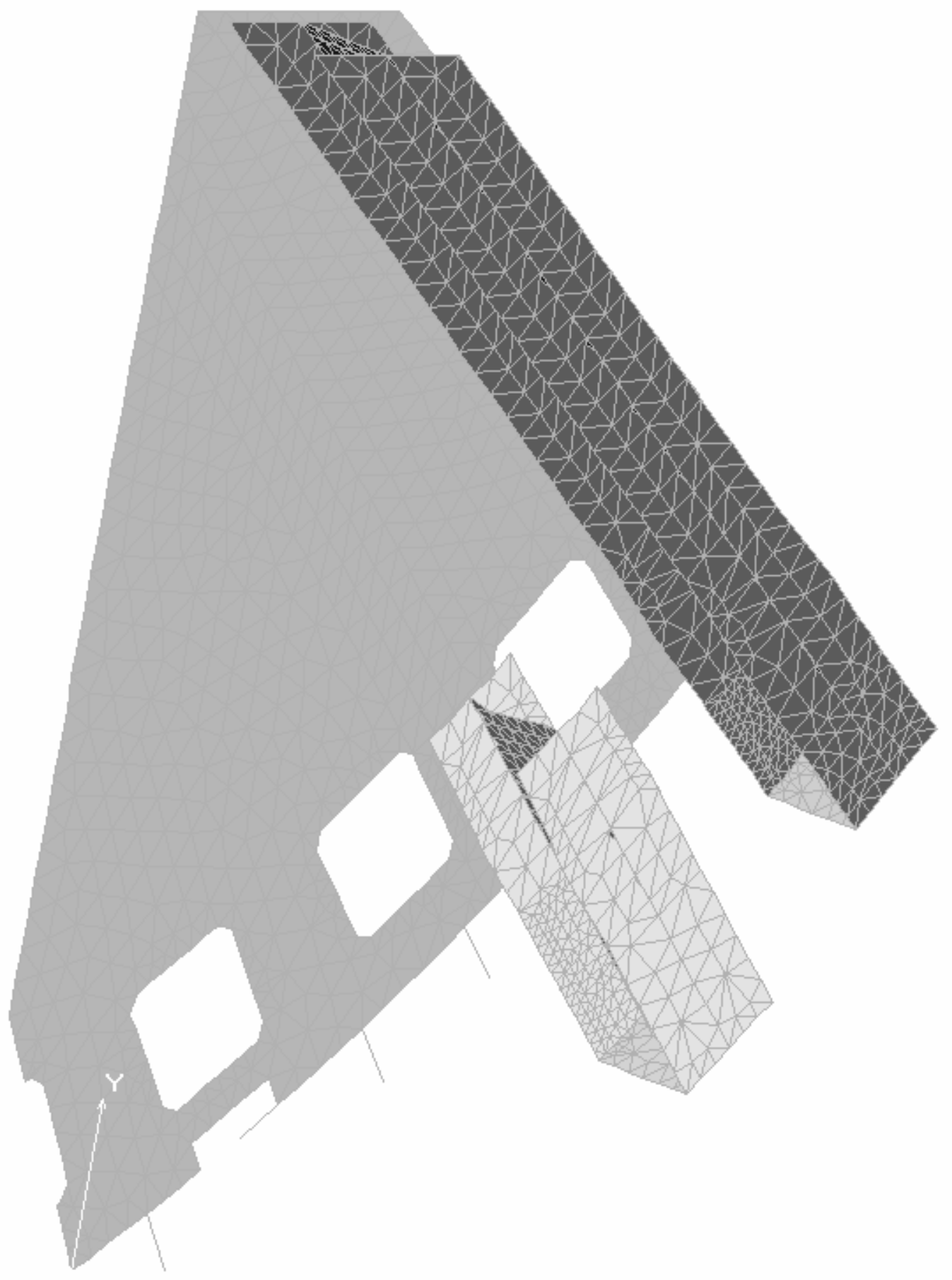

Figure 65. FEA Model for Using Shell Elements to Represent Stiffener Beam; Seismic Case F-Shell. 


\subsubsection{Analysis of Seismic F-Shell}

Figure 68 shows a close-up of the stiffener beams where they mount to the saddle. It is seen there that the full beam reaches stresses on the order of $130 \mathrm{MPa}$ on the top flange. This is in good agreement with the 120MPa max. determined for the seismic Case F in Sect. 3.6.2. The shell modelling of the beam offers more information about the loading. The 3D geometry allows a more accurate description of the bolted connection. The truss elements that represent the stiffener beam bolts are connected to the bottom flange precisely where they are design to be placed. In viewing Fig. 68, it is seen that large stresses exist at the bolting points on the bottom flanges. These stresses are the result of bending stresses in the flanges and are different than the fiber stresses. The 2-dimension beam elements (although they have 3D motion) did not have the capability to determine this. Seeing this in an early analysis of the shell prompted the addition of a plate along the back of the I-beam to help in transferring the load from the bottom flange to the top. This addition did reduce the stress considerably on this bottom flange, but it is clear that a similar rib or some other means of stress reduction will be needed at the front of the bolt pattern.

In Fig. 67, the beams are not shown to get a clear view of the plate stresses. In particular, we want to examine the area of concern seen in Section 3.6.2, the region of the plate at the end of the short stiffener beam. It is seen here that the stress is greatly reduced in this area, which is due to the larger distribution of the reaction between the plate and the stiffener beam.

Again, it is worth noting that there are the same high stresses in the key area similar to those discussed in other models. The important point to note is that the stresses are increased (on the order of 25\%) as compared to the static case, due to additional stress caused by bending. This is lower than the stresses found in the seismic analysis of Section 3.5, where combined seismic loads in all three directions create larger forces. However, this increase in stress above the already questionable static case (Section 3.3.2) adds further justification to the adding of material in the area of the key. 

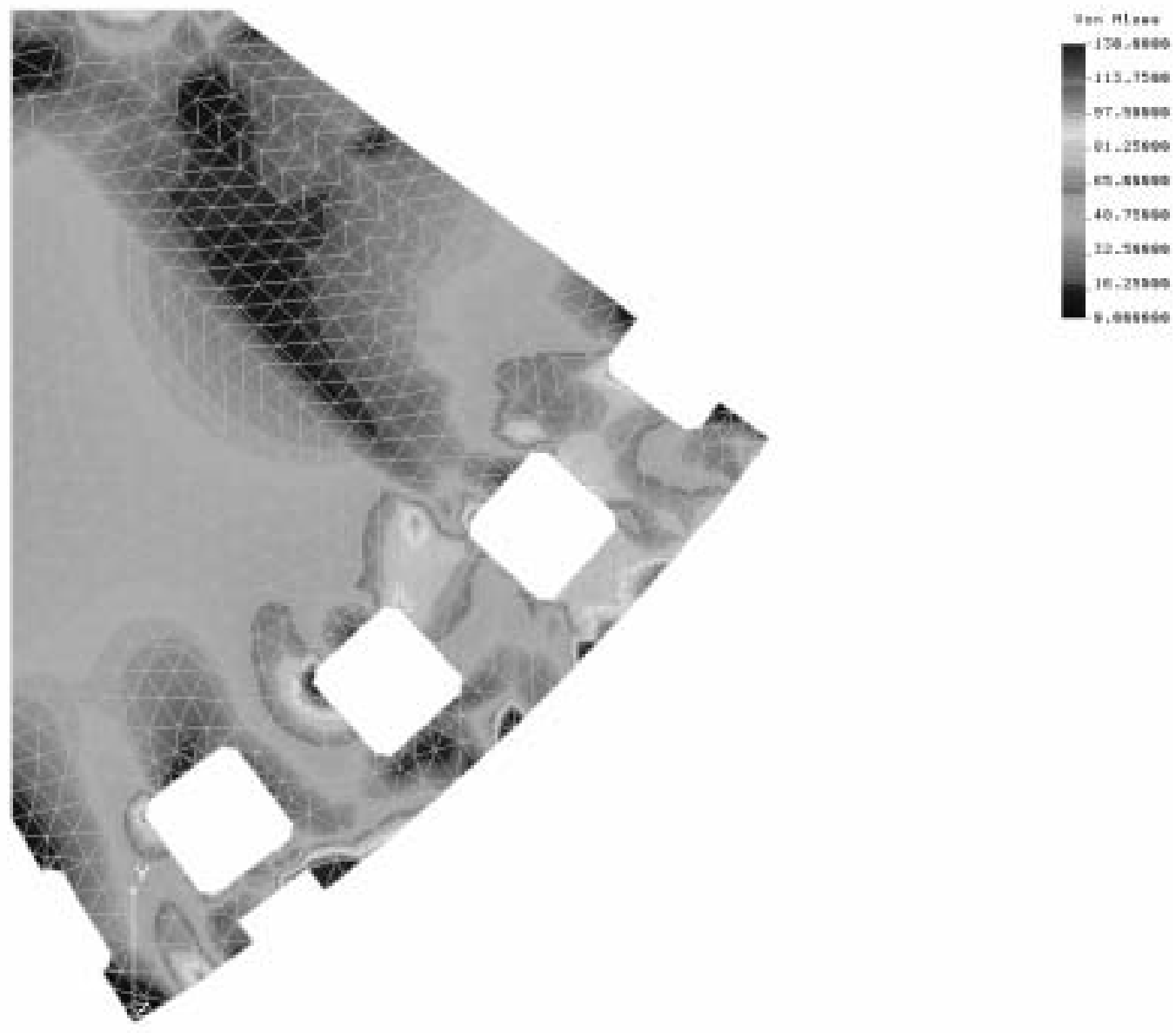

Figure 66. Von Mises Stress on Plate (top of shell elements) for Seismic Case F-Shell; Beams not shown. 


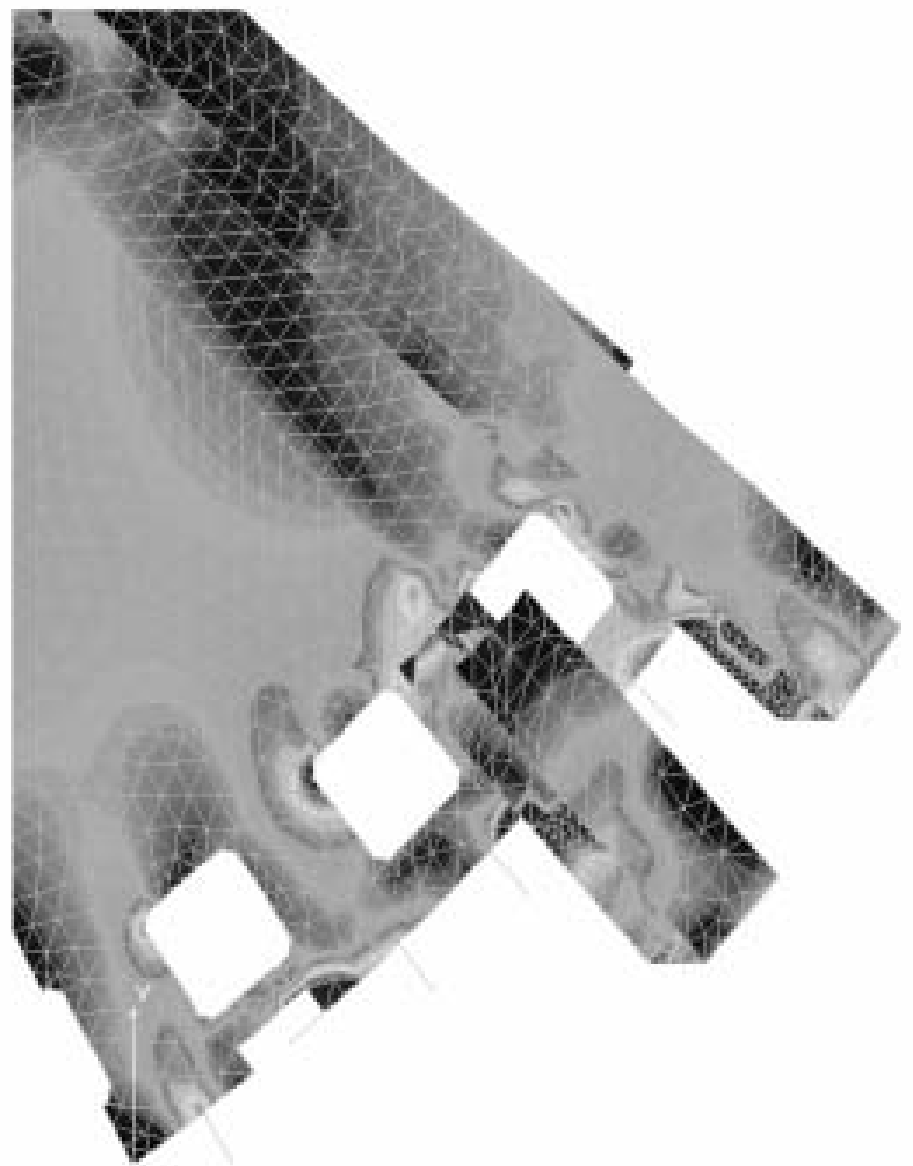

Figure 67. Von Mises Stress (Top) for Seismic Case F-Shell. 


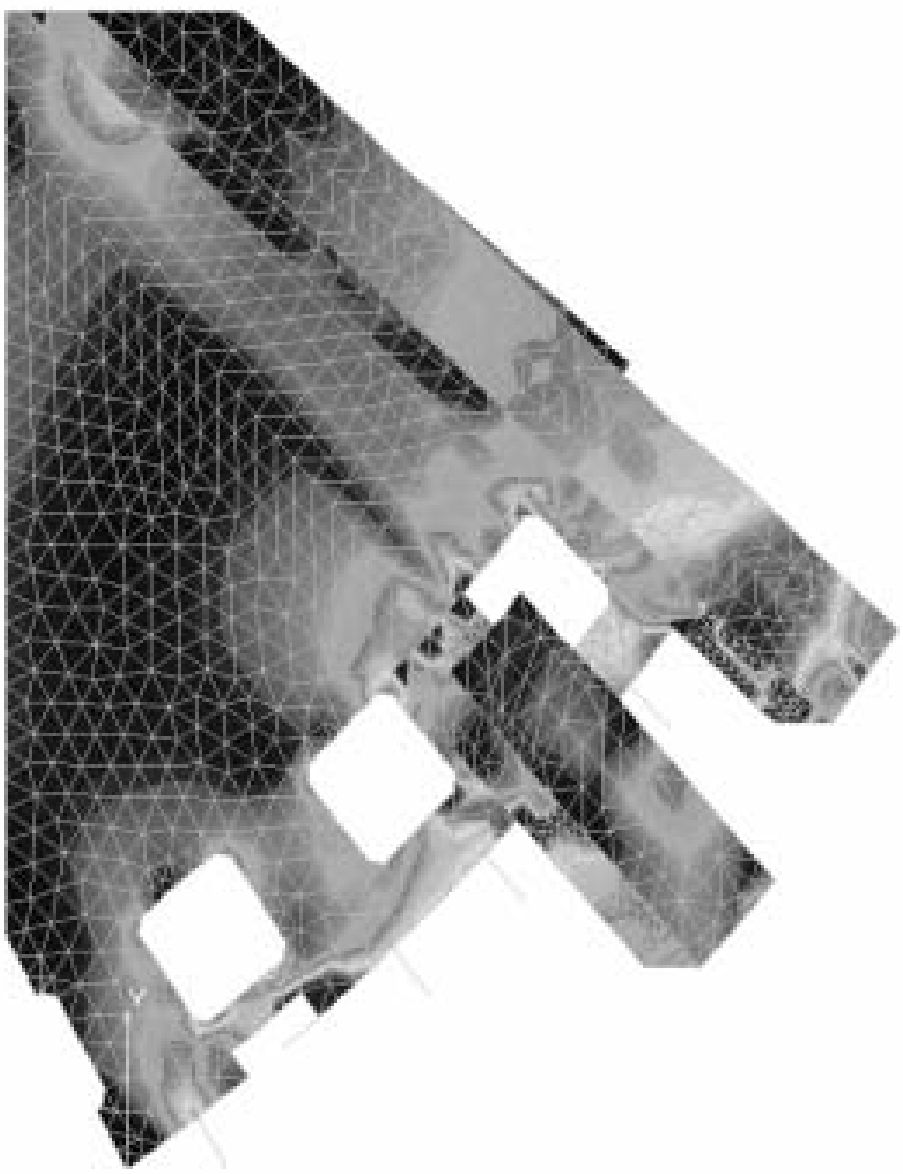

Non nats

Tiss.bats

167, Tws

3) , $5000 \mathrm{n}$

ul.sent

57, 90018

at, 15ess

$32.560 \mathrm{se}$

14. 370as

4.30095

Figure 68. Von Mises Stress (Bottom) for Seismic Case F-Shell. 


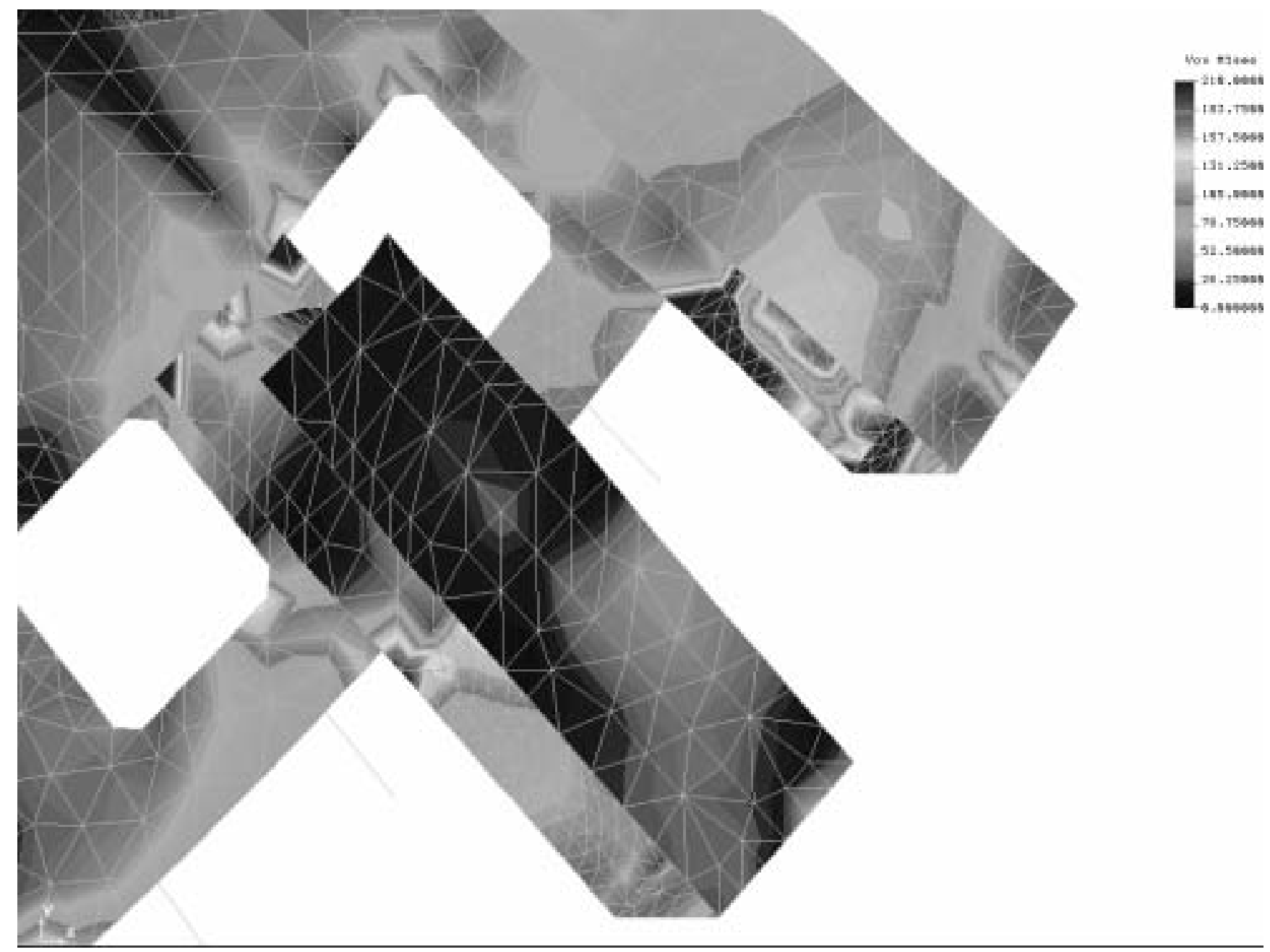

Figure 69. Von Mises Stress (Bottom) for Seismic Case F-Shell Enlarged with Scale Change (210MPa max).

\section{CONCLUSIONS}

An extensive analysis of the EB and its support structure has been carried out. This analysis has shown that the current design of the EB support saddle has stresses and deflections that are within acceptable limits under normal static loading conditions. In addition, an extensive structural analysis was carried out on the back cryostat support plate. In both of these analyses, several models were analyzed and compared with hand calculations.

\subsection{EB Support Saddle}

A FE model of the EB was created which was supported by a simplified model of the support saddles. The purpose of this was to take into account the stiffness of the EB in order to most accurately calculate the loads acting on the support saddle.

For this analysis, it was assumed that the Left side of the EB was restrained in the X, Y, and Z directions along the outer edges of the support beam and, on the right side the support beam, was 
restrained at its outer edges in only the $\mathrm{Y}$ and $\mathrm{Z}$ directions. Further, the load of the cryostat on the EB was assumed to be only in the vertical direction at the front. The back cryostat supports were assumed to be able to support forces in the $\mathrm{Y}$ and $\mathrm{Z}$ direction and only the left support could also support a force in the $\mathrm{X}$ direction. Using the restraints, the weight of the cryostat, and the location of the C.G., the loads from the cryostat onto the EB were calculated using statics. It should be noted that a very severe seismic condition was assumed and that simultaneous loading of $.15 \mathrm{~g}$ would occur in the $\mathrm{X}, \mathrm{Y}$, and $\mathrm{Z}$ directions.

The deflections in all of the loading conditions were small, less than $1.0 \mathrm{~mm}$ in all of the cases at the saddles. As expected, the maximum deflections occurred at the top of the saddles.

The stresses in the static case were small, on average no more than 50Mpa throughout the support saddles. Stress concentrations occurred at corners and at the point where the saddle gussets were attached to the support beam, however, these did not exceed 130Mpa. In addition, the stresses in the key-way on the saddle were also within acceptable limits. However, in the seismic condition, the stresses rose considerably. The average stresses rose to approximately $80 \mathrm{Mpa}$, but severe stress concentrations occurred at the corners, which were in the range of 220Mpa. It would be expected that local yielding would occur in these areas under seismic conditions. In addition, the key stresses rose to an average of approximately 220Mpa with stress concentrations occurring in the corners of close to 300Mpa. In the combined loading case of gravity, seismic, and magnetic, the average stresses also remained low, approximately $50 \mathrm{~N} / \mathrm{mm} 2$. However, there were stress concentrations along the connection between the back cryostat support and along the lower part of the gusset directly below the back cryostat support. The gusset stress concentration will be eliminated by a design change, in which a stiffening block will be added to this region. The stress concentration at the joint between the back cryostat support and the saddle front plate is a result of the modeling technique and a more refined model will show that it is much lower. Finally, the bearing stresses in the key way were quite large, approximately $160 \mathrm{~N} / \mathrm{mm} 2$ on average. While exceeding the design stress for yield, this stress is still below the yield stress of the material.

The initial plan had called for the use of one swivel bolt at each position in Z. However, load tests on commercial swivel bolts showed that these can withstand up to 18tons which was less than the calculated loads. Therefore, in the final design two bolts will be located symmetrically around each $\mathrm{Z}$ position. Even in the case of using two bolts there are several individual bolts at each position which exceed the maximum load of the commercial bolts. Therefore, specially constructed swivel bolts will have to be used in these regions.

In the current design of the $\mathrm{EB}$, there is no method of transferring Z-direction loading from an earthquake from module to module except by friction at the bolted connections. This friction load approaches $7.5 \%(15 \% / 2)$ of the total weight of the detector in the region of the support saddle. A further calculation needs to be done to check that a sufficient friction force exists to withstand this load. In addition, there is not currently a method of transferring a Z-direction load from the EB to the support saddles. Design work of the special link plates at the saddle key is currently occurring, so that these will be capable of transferring the Z-direction loading from the EB to the support saddle.

\subsection{Back Cryostat Support}

An extensive, detailed analysis of the back cryostat support plate has been carried out. This plate was analyzed using several different FE methods and hand calculations, which come to close agreement and, therefore, give confidence in the analysis. The design of the back cryostat support is driven by the requirements of the seismic loading condition. The initial addition of two, I-beam stiffeners is solely driven by the need to reduce the stresses and deflections under seismic conditions. 
Under normal static loading conditions, the stresses in the plate and the bolts remain well within acceptable limits. The stress in the area of the key-way was a driving factor in the design of the back cryostat support in the static case. The depth of the key had to be increased significantly in order to reduce the bearing stresses in this region. Although reduced from original studies, it is determined that the stresses should still be reduced in this area as an added margin of safety. However, under seismic conditions, the stresses and deflections increase significantly. First, the maximum fiber stress in the stiffening beam approach 160Mpa at the joint between the cryostat plate and the saddle. Second, the stresses in the plate itself remain on average within acceptable limits; however, stress concentrations of up to $180 \mathrm{Mpa}$ occur. Third, the stress in the key region increases significantly to an average of $180 \mathrm{Mpa}$ with stress concentrations of up to $282 \mathrm{Mpa}$. Local yielding can be expected in this region under the seismic conditions that were assumed. Finally, the greatest concern in the seismic conditions are the thread shear stress in the bolts that (a) hold the back cryostat support plate and (b) attach the stiffening beams to the saddle. These thread shear stresses approach 162Mpa in the worst case, which is well above the acceptable limits. A potential solution that will be examined is the use of thread inserts, which can provide greater strength.

The maximum deflection at the top of the back cryostat support is a little more than $8 \mathrm{~mm}$ in the $\mathrm{Z}$ direction. This poses a potential problem because there is only a $3 \mathrm{~mm}$ clearance between the cryostat support plate and the end plate of the EB.

These added stiffener beams of the redesign were found to interfere with electrical boxes for the cryostat. Rather than move these boxes, it was decided by CERN TC that alternate methods of stiffening should be evaluated and with a lower seismic loading. The seismic loading requirement was reduced to the single addition of a Z-direction load of $12 \%$ the cryostat weight applied through the cryostat C.G. Several options were evaluated and it was found that leaving the top stiffener beam and adding two shorter beams are enough to reduce stress to the acceptable level. The deflection for this case is still at $6 \mathrm{~mm}$.

A preliminary analysis was done using shell elements for the beam. This model should be extended to describe the last version of design with the additional, two, short stiffeners. The high stresses observed in the bottom flanges of these beams at the connection points should be evaluated and reduced. The additional support material needed in the key area must also be analyzed.

\subsection{Further Work}

The following detailed analysis should be carried out to complete the analysis of the EB support saddles.

1. A detailed solid element model of the saddles and the support beam should be constructed which has detailed features of the design included. Such a model would include:

- Access holes in the front plate for the link element bolts

- A detailed model of the back cryostat support plate.

- A detailed model of the deeper key in the region of the back cryostat support plate.

- The modeling of the bolted connection between each saddle and the support beam.

- A more realistic method of restraining the support beam.

2. The final design of the swivel bolts has to be resolved. 
3. The exact load points and method of securing the cryostat to the back supports need to be worked out. The design of the jacks at the front of the cryostat needs to be finalized and the exact method of restraining the cryostat at the back needs to be finalized.

4. The method of transferring and supporting the Z-direction loading that results from an earthquake needs to be examined in detail. The Z-direction force will be transferred within the EB through friction at the OR. The exact friction load needs to be calculated and the integrated Z-load needs to be calculated.

5. The high-bearing stresses at the key way in the seismic and magnetic loading cases need to be examined again and a determination must be made whether or not the stresses are acceptable.

6. The loads of the cryostat onto the EB and the cryostat support points under the seismic load conditions need to be examined and confirmed by someone in the cryostat group.

7. Higher-strength swivel bolts need to be designed.

8. The support beam between the saddles needs to be designed and integrated with the air pad system and the saddles. 


\section{Appendix 1}

Comparison of Static Analysis and FE Analysis for the Forces Between Modules

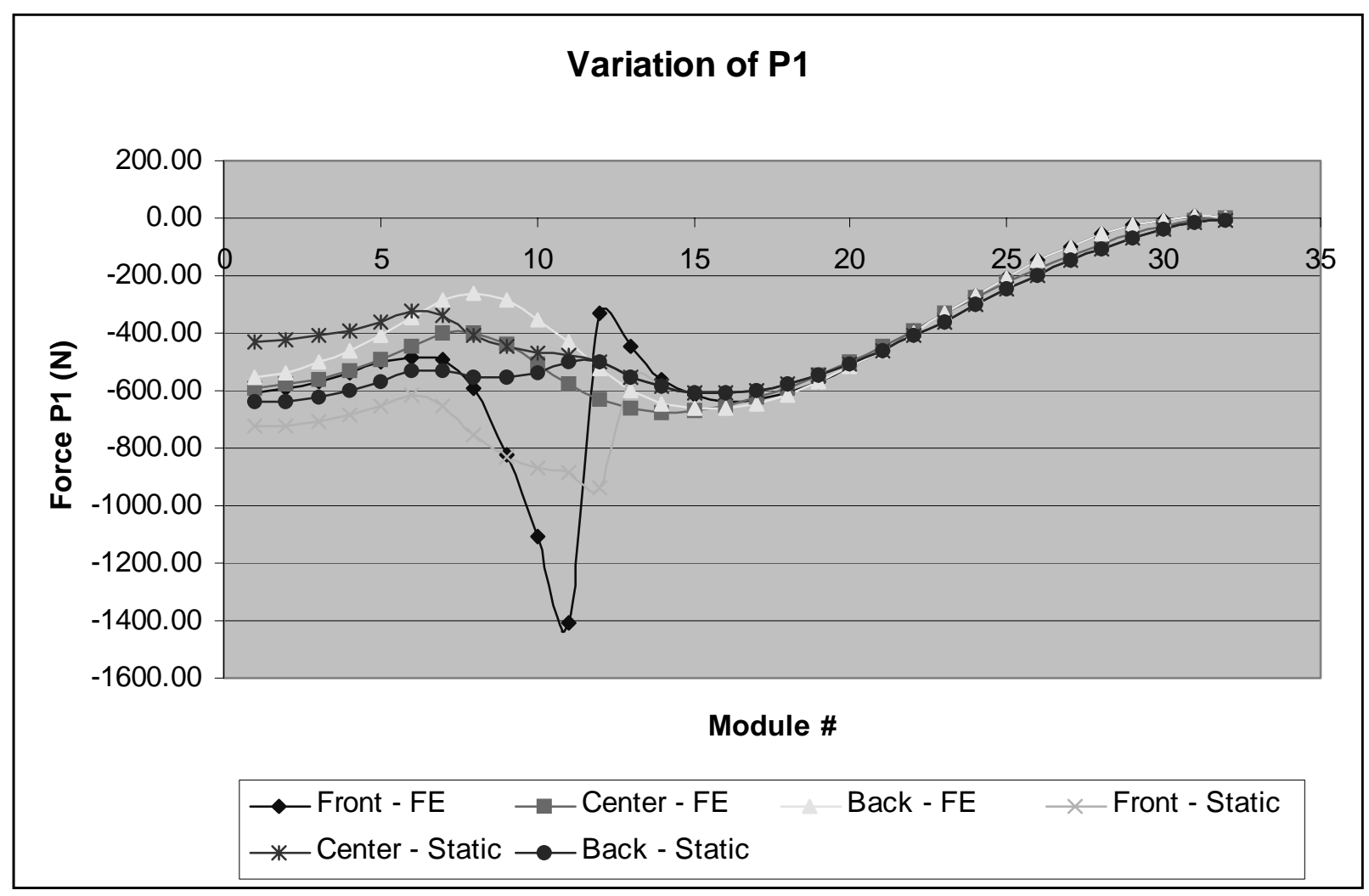



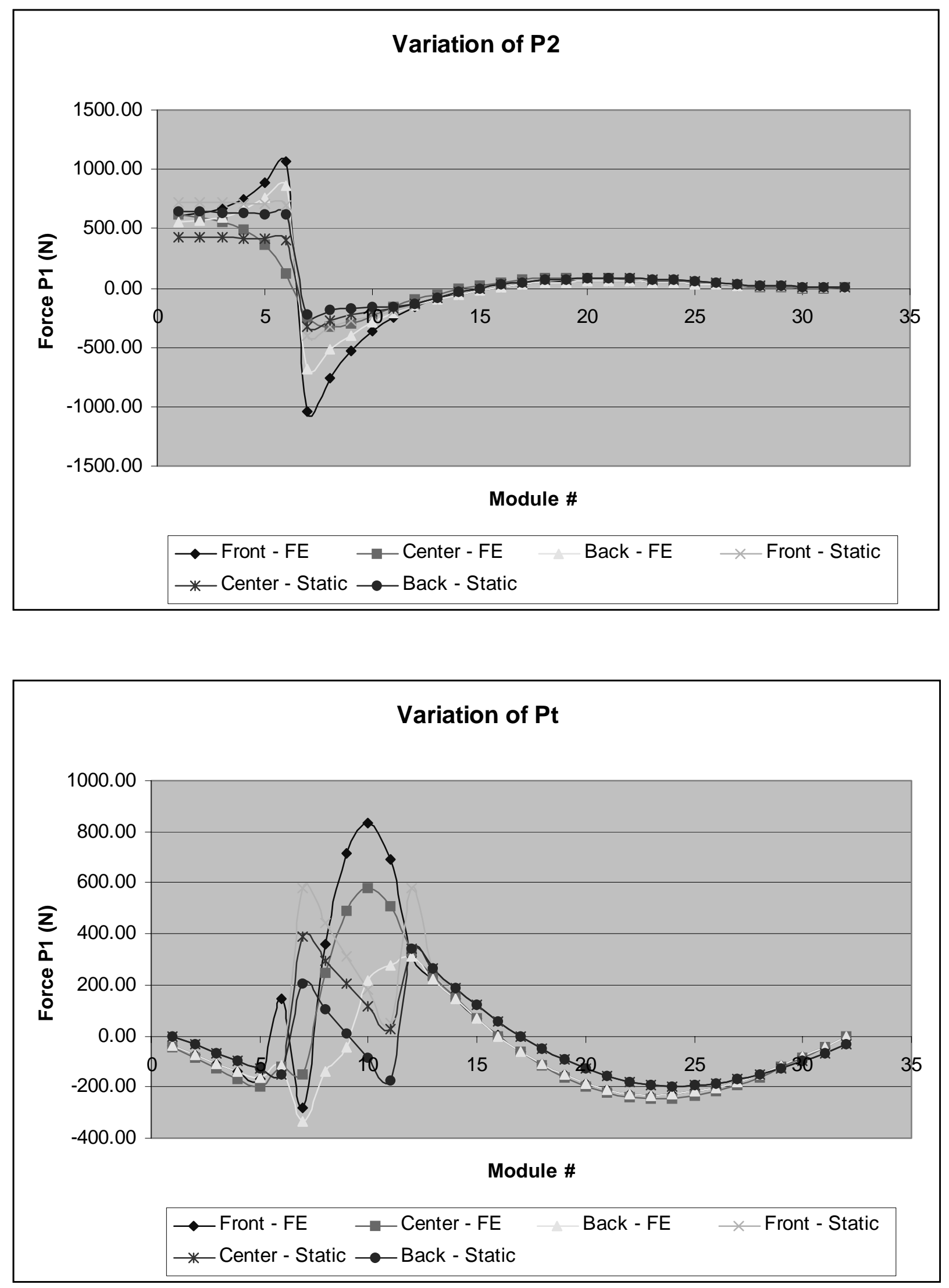


\section{Appendix 2}

\section{Tapered Beam Model of Earthquake Loading on Back Cryostat Support}

PLANE FRAME ANALYSIS--INPUT DATA

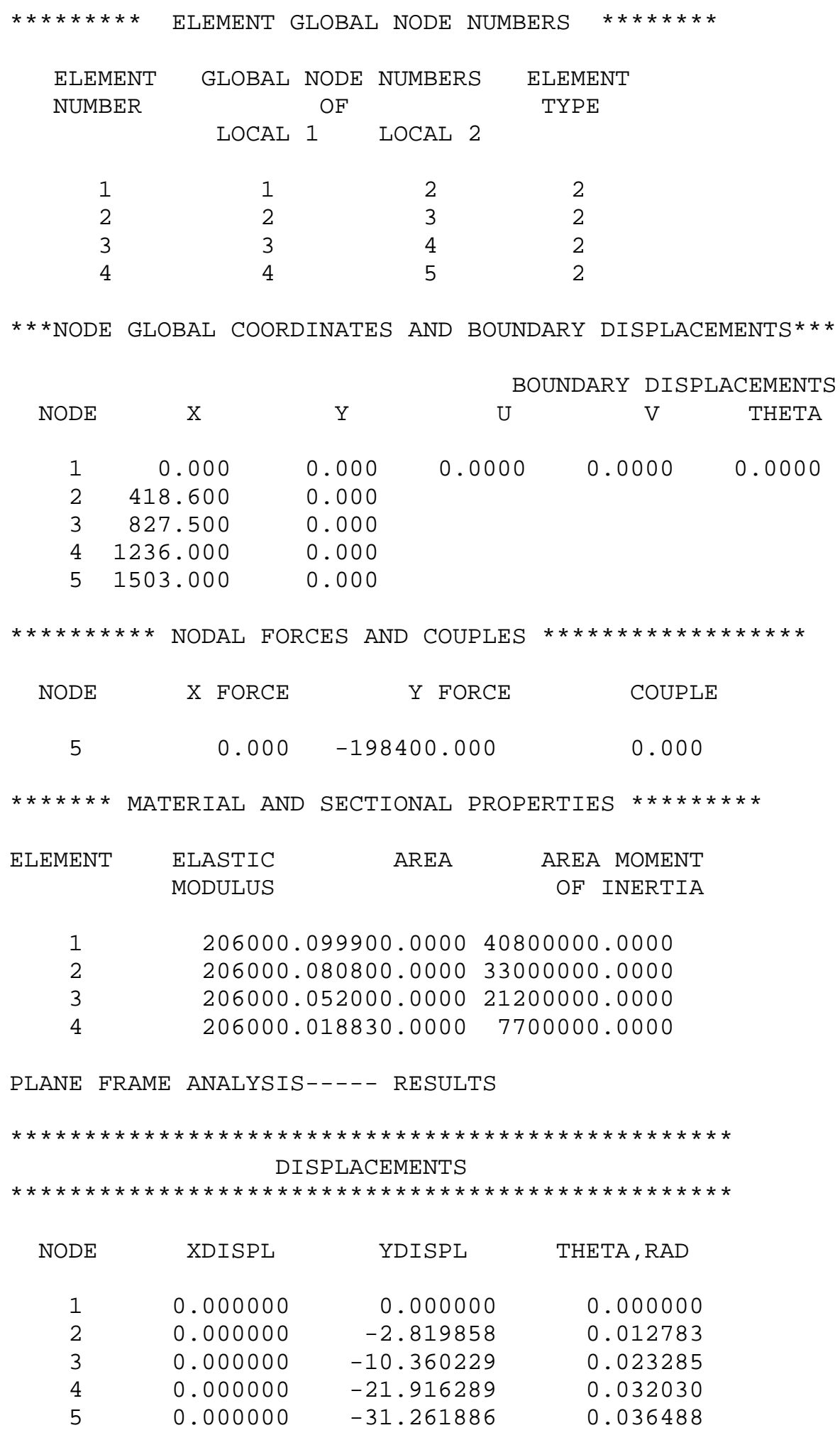

\begin{tabular}{|c|c|c|c|}
\hline \multicolumn{4}{|c|}{ DISPLACEMENTS } \\
\hline NODE & XDISPL & YDISPL & THETA, RAD \\
\hline 1 & 0.000000 & 0.000000 & 0.000000 \\
\hline 2 & 0.000000 & -2.819858 & 0.012783 \\
\hline 3 & 0.000000 & -10.360229 & 0.023285 \\
\hline 4 & 0.000000 & -21.916289 & 0.032030 \\
\hline 5 & 0.000000 & -31.261886 & 0.036488 \\
\hline
\end{tabular}


ELEMENT NODE FORCES

\begin{tabular}{|c|c|c|c|c|c|}
\hline \multicolumn{6}{|c|}{--NOTE-NODE NUMBERS ARE GLOBAL, LISTED } \\
\hline ELEMENT & NODE & AXIAL & LOAD & SHEAR LOAD & COUPLE \\
\hline 1 & 2 & & 0.0 & -198400.0 & 215144959.9 \\
\hline 2 & 2 & & 0.0 & 198400.0 & -215144959.9 \\
\hline 2 & 3 & & 0.0 & -198400.0 & 134019200.0 \\
\hline 3 & 3 & & 0.0 & 198400.0 & -134019200.0 \\
\hline 3 & 4 & & 0.0 & -198400.0 & 52972800.0 \\
\hline 4 & 4 & & 0.0 & 198400.0 & -52972800.0 \\
\hline
\end{tabular}

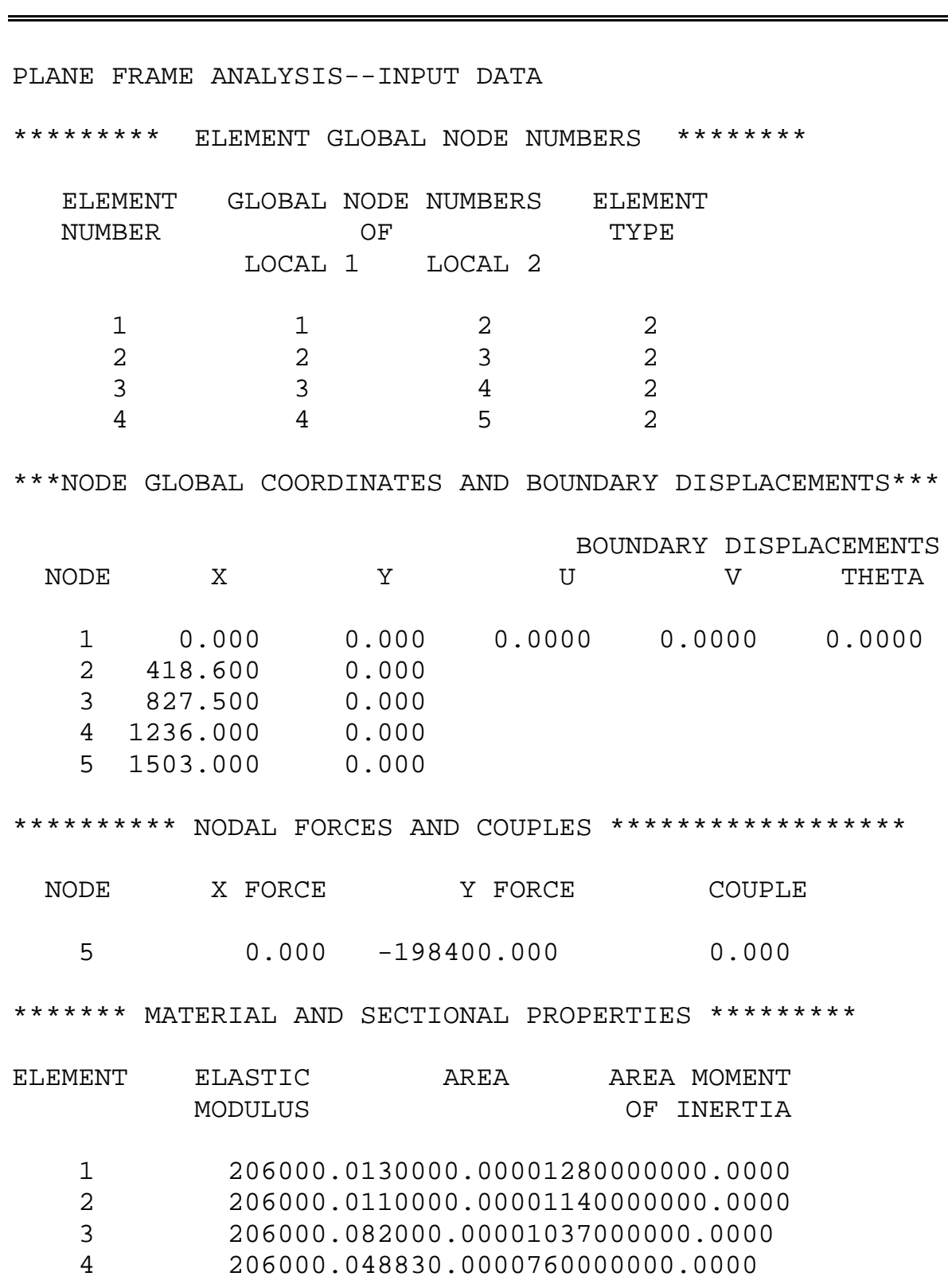




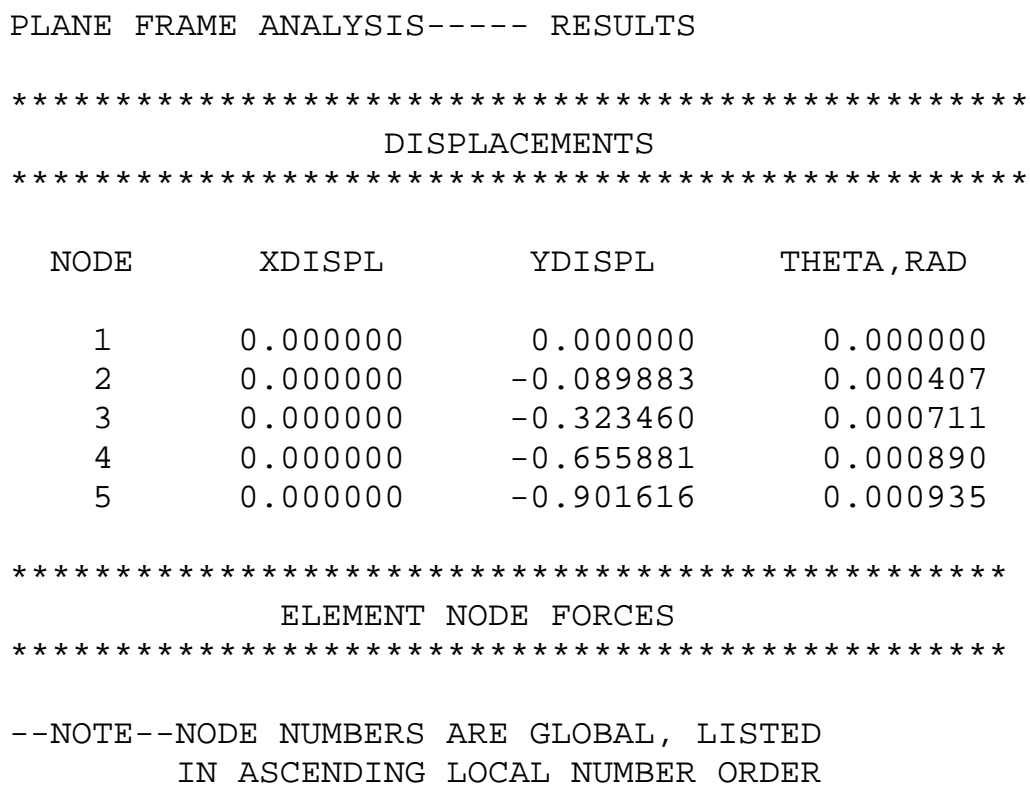

\begin{tabular}{|c|c|c|c|c|}
\hline ELEMENT & NODE & AXIAL LOAD & SHEAR LOAD & COUPLE \\
\hline 1 & 1 & 0.0 & 198400.0 & -298195199.7 \\
\hline 1 & 2 & 0.0 & -198400.0 & 215144959.8 \\
\hline 2 & 2 & 0.0 & 198400.0 & -215144959.8 \\
\hline 2 & 3 & 0.0 & -198400.0 & 134019199.9 \\
\hline 3 & 3 & 0.0 & 198400.0 & -134019199.9 \\
\hline 3 & 4 & 0.0 & -198400.0 & 52972800.0 \\
\hline 4 & 4 & 0.0 & 198400.0 & -52972800.0 \\
\hline 4 & 5 & 0.0 & -198400.0 & -0.0 \\
\hline
\end{tabular}




\section{Appendix 3}

\section{Forces Between Modules in Seismic Load Case}

Variation of Forces Between Modules

Seismic Loading of .15g in the $\mathrm{X}, \mathrm{Y}$, and $\mathrm{Z}$ directions

\begin{tabular}{|c|c|c|c|c|c|c|c|c|c|}
\hline & & & & & & & & & \\
\hline & & Front & & & Middle & & & Back & \\
\hline Module & P1 & P2 & $\mathbf{P t}$ & P1 & P2 & $\mathbf{P t}$ & P1 & P2 & Pt \\
\hline 1 & -142.00 & 585.00 & -208.00 & -423.00 & 739.00 & -273.00 & -561.00 & 759.00 & -296.00 \\
\hline 2 & -70.70 & 596.00 & -195.00 & -370.00 & 676.00 & -285.00 & -494.00 & 774.00 & -325.00 \\
\hline 3 & 10.60 & 638.00 & -178.00 & -314.00 & 594.00 & -296.00 & -424.00 & 817.00 & -350.00 \\
\hline 4 & 99.90 & 731.00 & -155.00 & -254.00 & 479.00 & -305.00 & -354.00 & 905.00 & -370.00 \\
\hline 5 & 193.00 & 900.00 & -127.00 & -188.00 & 302.00 & -309.00 & -290.00 & $1,060.00$ & -388.00 \\
\hline 6 & 285.00 & $1,130.00$ & -34.00 & -123.00 & -65.50 & -167.00 & -274.00 & $1,340.00$ & 130.00 \\
\hline 7 & 319.00 & -543.00 & -272.00 & -59.60 & -586.00 & -186.00 & -276.00 & $-1,920.00$ & -399.00 \\
\hline 8 & 202.00 & -508.00 & 188.00 & -54.20 & -689.00 & 280.00 & -293.00 & $-1,470.00$ & -24.50 \\
\hline 9 & -56.80 & -426.00 & 482.00 & -123.00 & -658.00 & 651.00 & -420.00 & $-1,100.00$ & 505.00 \\
\hline 10 & -405.00 & -350.00 & 621.00 & -237.00 & -568.00 & 810.00 & -621.00 & -825.00 & 866.00 \\
\hline 11 & -803.00 & -300.00 & 541.00 & -357.00 & -467.00 & 735.00 & -807.00 & -629.00 & 853.00 \\
\hline 12 & 693.00 & -254.00 & 126.00 & -459.00 & -381.00 & 516.00 & -974.00 & -481.00 & 841.00 \\
\hline 13 & 479.00 & -222.00 & 113.00 & -530.00 & -307.00 & 415.00 & $-1,090.00$ & -358.00 & 664.00 \\
\hline 14 & 247.00 & -195.00 & 97.50 & -575.00 & -242.00 & 319.00 & $-1,150.00$ & -257.00 & 498.00 \\
\hline 15 & 74.70 & -172.00 & 79.50 & -601.00 & -184.00 & 228.00 & $-1,170.00$ & -177.00 & 345.00 \\
\hline 16 & -56.00 & -150.00 & 60.00 & -610.00 & -136.00 & 144.00 & $-1,150.00$ & -112.00 & 205.00 \\
\hline 17 & -157.00 & -131.00 & 40.20 & -604.00 & -96.70 & 68.20 & $-1,090.00$ & -61.30 & 81.70 \\
\hline 18 & -234.00 & -114.00 & 20.60 & -587.00 & -65.50 & 0.44 & $-1,020.00$ & -22.10 & -26.00 \\
\hline 19 & -292.00 & -100.00 & 2.05 & -560.00 & -41.70 & -58.00 & -918.00 & 7.41 & -117.00 \\
\hline 20 & -334.00 & -89.40 & -15.00 & -525.00 & -24.60 & -107.00 & -805.00 & 29.00 & -192.00 \\
\hline 21 & -363.00 & -80.90 & -29.90 & -483.00 & -13.20 & -146.00 & -681.00 & 43.80 & -250.00 \\
\hline 22 & -380.00 & -74.20 & -42.20 & -435.00 & -6.57 & -175.00 & -552.00 & 53.40 & -291.00 \\
\hline 23 & -388.00 & -70.20 & -51.80 & -384.00 & -3.70 & -193.00 & -420.00 & 58.70 & -317.00 \\
\hline 24 & -389.00 & -66.80 & -58.20 & -332.00 & -3.58 & -202.00 & -290.00 & 60.70 & -327.00 \\
\hline 25 & -384.00 & -64.80 & -61.40 & -280.00 & -5.27 & -202.00 & -164.00 & 60.20 & -322.00 \\
\hline 26 & -377.00 & -62.80 & -61.40 & -230.00 & -7.86 & -193.00 & -46.20 & 57.70 & -304.00 \\
\hline 27 & -368.00 & -60.30 & -58.10 & -185.00 & -10.50 & -175.00 & 61.10 & 54.00 & -275.00 \\
\hline 28 & -360.00 & -56.60 & -51.90 & -144.00 & -12.40 & -151.00 & 156.00 & 49.20 & -234.00 \\
\hline 29 & -354.00 & -50.70 & -42.80 & -111.00 & -13.00 & -120.00 & 237.00 & 43.00 & -185.00 \\
\hline 30 & -353.00 & -41.30 & -31.30 & -85.50 & -11.50 & -84.10 & 303.00 & 34.80 & -128.00 \\
\hline 31 & -359.00 & -26.30 & -17.60 & -69.20 & -7.41 & -44.20 & 354.00 & 22.30 & -67.20 \\
\hline 32 & -352.00 & -20.70 & -17.10 & -66.20 & 3.40 & -44.20 & 363.00 & 27.40 & -66.80 \\
\hline 33 & -339.00 & -30.00 & -34.70 & -80.00 & 9.58 & -88.10 & 320.00 & 44.90 & -132.00 \\
\hline
\end{tabular}




\begin{tabular}{|c|c|c|c|c|c|c|c|c|c|}
\hline 34 & -334.00 & -33.40 & -52.60 & -104.00 & 18.70 & -131.00 & 261.00 & 58.40 & -195.00 \\
\hline 35 & -336.00 & -32.90 & -70.30 & -138.00 & 30.50 & -170.00 & 185.00 & 70.10 & -253.00 \\
\hline 36 & -344.00 & -29.50 & -87.30 & -181.00 & 44.70 & -207.00 & 92.20 & 81.10 & -305.00 \\
\hline 37 & -355.00 & -24.20 & -103.00 & -232.00 & 60.60 & -238.00 & -16.40 & 92.10 & -348.00 \\
\hline 38 & -369.00 & -17.40 & -118.00 & -290.00 & 77.80 & -263.00 & -139.00 & 102.00 & -381.00 \\
\hline 39 & -384.00 & -9.87 & -130.00 & -355.00 & 95.70 & -280.00 & -274.00 & 111.00 & -402.00 \\
\hline 40 & -398.00 & -1.95 & -141.00 & -423.00 & 113.00 & -290.00 & -419.00 & 120.00 & -409.00 \\
\hline 41 & -410.00 & 5.70 & -149.00 & -494.00 & 129.00 & -290.00 & -569.00 & 125.00 & -402.00 \\
\hline 42 & -419.00 & 12.80 & -154.00 & -566.00 & 143.00 & -281.00 & -723.00 & 128.00 & -380.00 \\
\hline 43 & -421.00 & 18.80 & -157.00 & -637.00 & 155.00 & -261.00 & -876.00 & 126.00 & -341.00 \\
\hline 44 & -415.00 & 23.50 & -158.00 & -705.00 & 162.00 & -232.00 & $-1,020.00$ & 119.00 & -284.00 \\
\hline 45 & -399.00 & 26.60 & -156.00 & -768.00 & 164.00 & -191.00 & $-1,160.00$ & 105.00 & -211.00 \\
\hline 46 & -368.00 & 28.10 & -152.00 & -825.00 & 160.00 & -140.00 & $-1,280.00$ & 81.20 & -120.00 \\
\hline 47 & -319.00 & 28.00 & -146.00 & -874.00 & 150.00 & -79.20 & $-1,390.00$ & 46.90 & -10.60 \\
\hline 48 & -246.00 & 26.50 & -138.00 & -911.00 & 131.00 & -8.19 & $-1,460.00$ & -0.50 & 116.00 \\
\hline 49 & -136.00 & 23.50 & -130.00 & -933.00 & 105.00 & 71.90 & $-1,510.00$ & -64.80 & 259.00 \\
\hline 50 & 29.90 & 18.20 & -121.00 & -936.00 & 70.30 & 161.00 & $-1,510.00$ & -149.00 & 417.00 \\
\hline 51 & 172.00 & 6.30 & -112.00 & -915.00 & 28.50 & 257.00 & $-1,450.00$ & -256.00 & 590.00 \\
\hline 52 & $-1,400.00$ & -19.70 & 303.00 & -861.00 & -27.00 & 475.00 & $-1,350.00$ & -391.00 & 601.00 \\
\hline 53 & $-1,090.00$ & -48.70 & 429.00 & -788.00 & -97.00 & 567.00 & $-1,240.00$ & -575.00 & 599.00 \\
\hline 54 & -804.00 & -104.00 & 431.00 & -714.00 & -159.00 & 481.00 & $-1,110.00$ & -853.00 & 193.00 \\
\hline 55 & -561.00 & -168.00 & 397.00 & -666.00 & -173.00 & 242.00 & $-1,070.00$ & $-1,230.00$ & -498.00 \\
\hline 56 & -393.00 & -178.00 & 190.00 & -660.00 & -74.80 & 51.50 & $-1,110.00$ & $-1,590.00$ & -226.00 \\
\hline 57 & -326.00 & $1,360.00$ & 349.00 & -672.00 & 409.00 & 136.00 & $-1,080.00$ & $1,560.00$ & 114.00 \\
\hline 58 & -312.00 & $1,180.00$ & 303.00 & -660.00 & 710.00 & 175.00 & -977.00 & $1,360.00$ & 106.00 \\
\hline 59 & -304.00 & 964.00 & 276.00 & -636.00 & 807.00 & 193.00 & -898.00 & $1,160.00$ & 133.00 \\
\hline 60 & -293.00 & 822.00 & 257.00 & -603.00 & 844.00 & 209.00 & -829.00 & $1,020.00$ & 164.00 \\
\hline 61 & -273.00 & 727.00 & 242.00 & -564.00 & 850.00 & 226.00 & -763.00 & 921.00 & 198.00 \\
\hline 62 & -243.00 & 662.00 & 231.00 & -521.00 & 839.00 & 242.00 & -695.00 & 847.00 & 232.00 \\
\hline 63 & & & & & & & & & \\
\hline
\end{tabular}



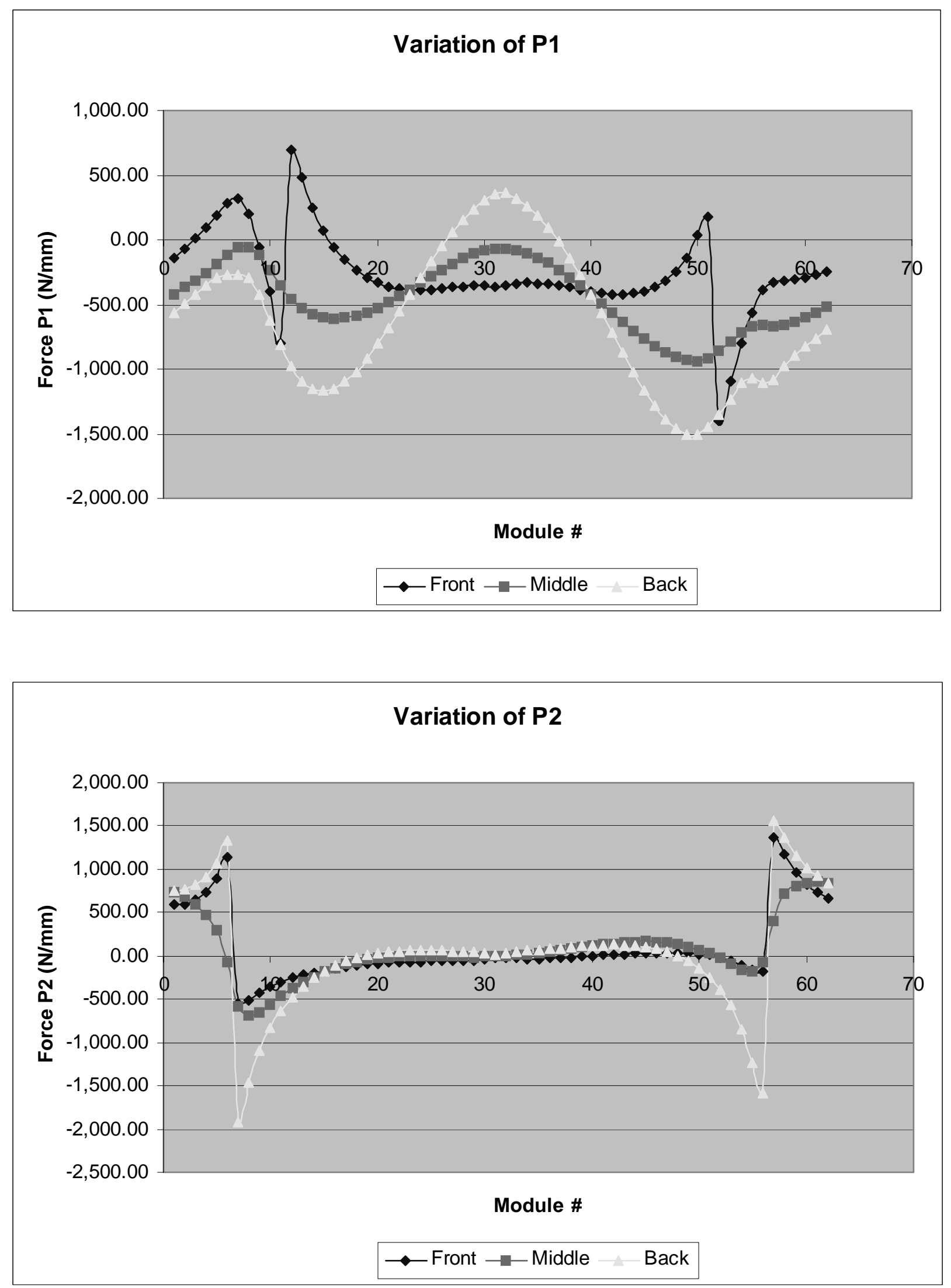


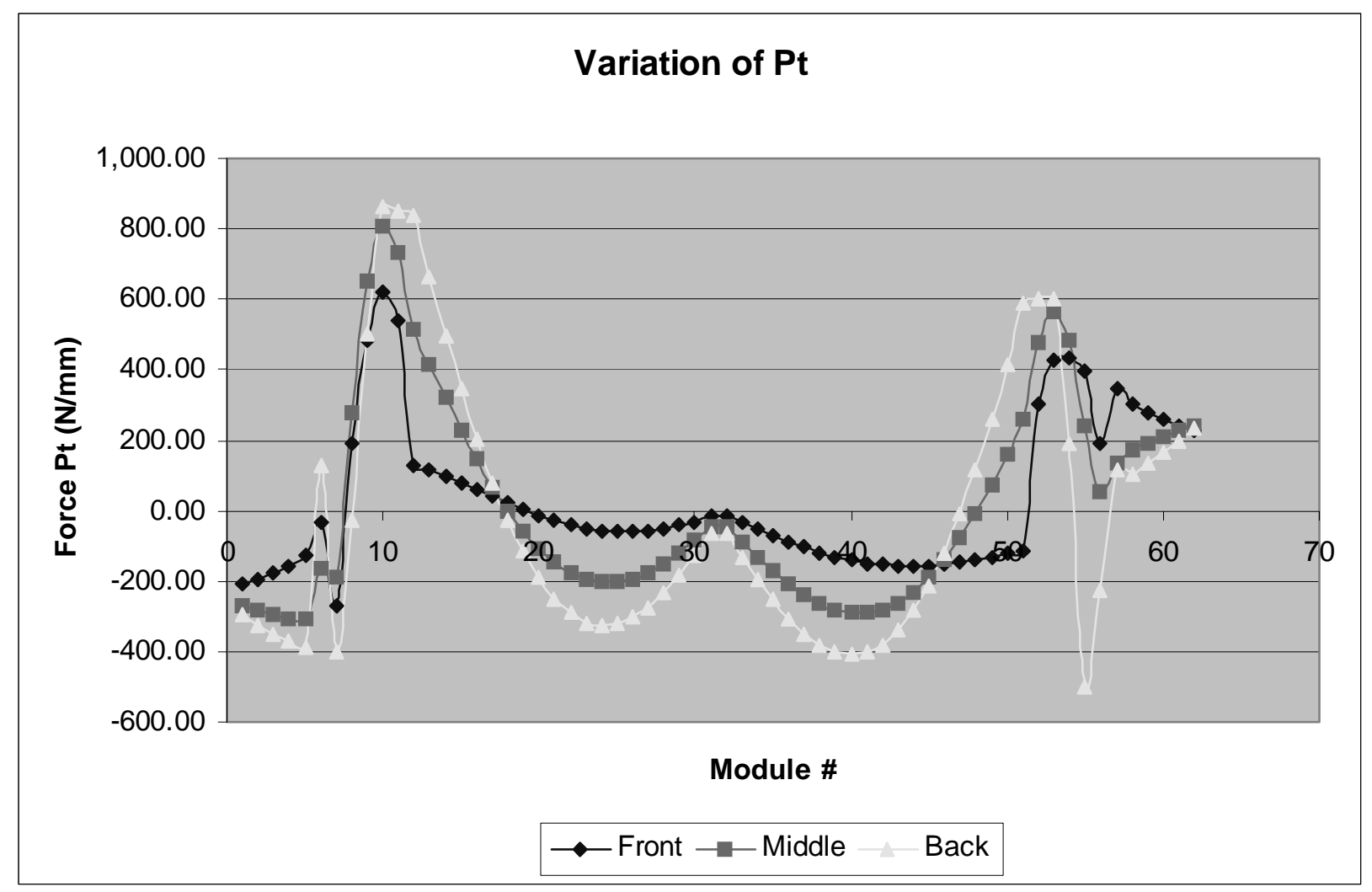


Appendix 4

Seismic Loading Conditions

Variation of Reaction Forces Along Support Beam

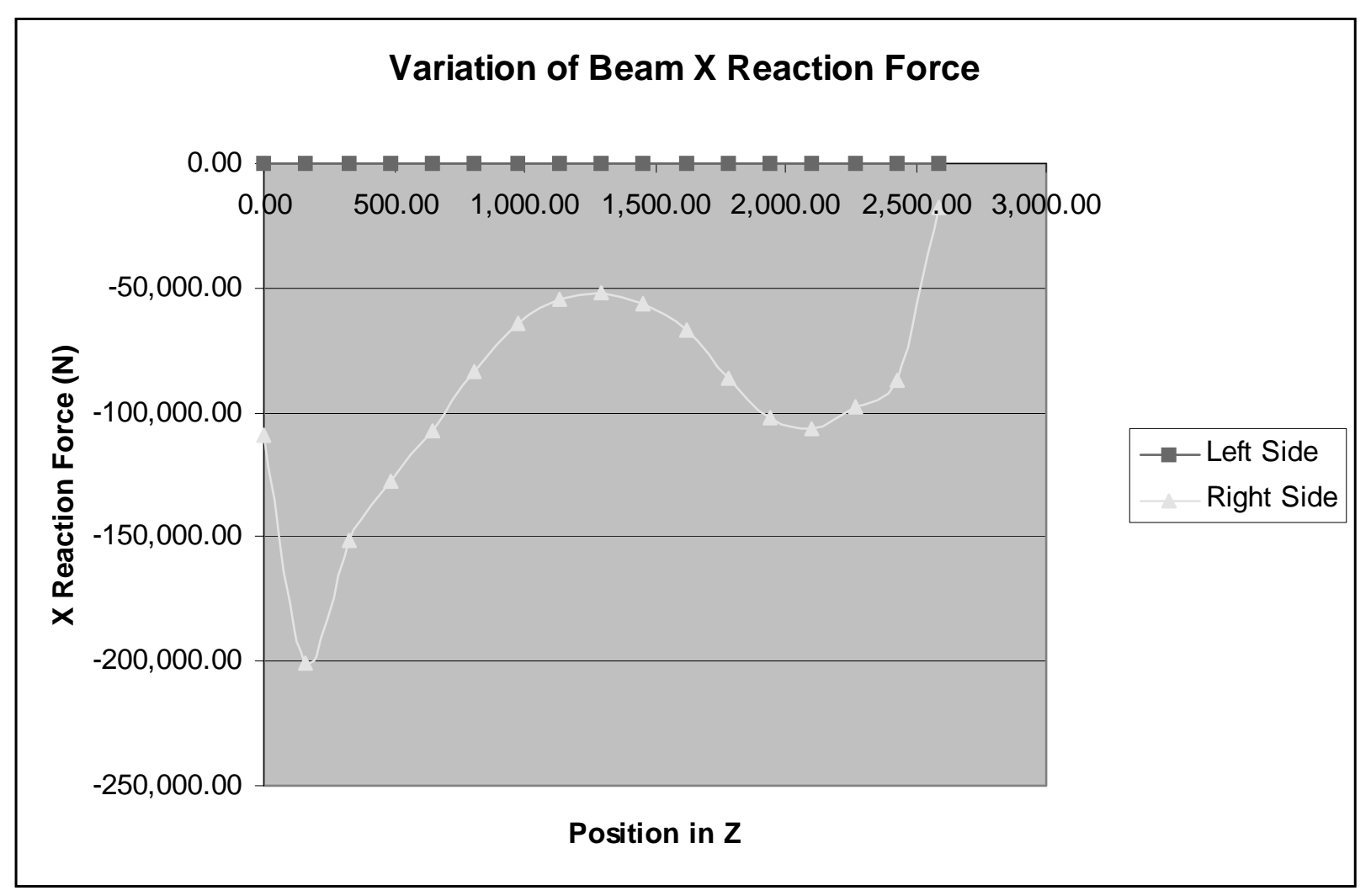



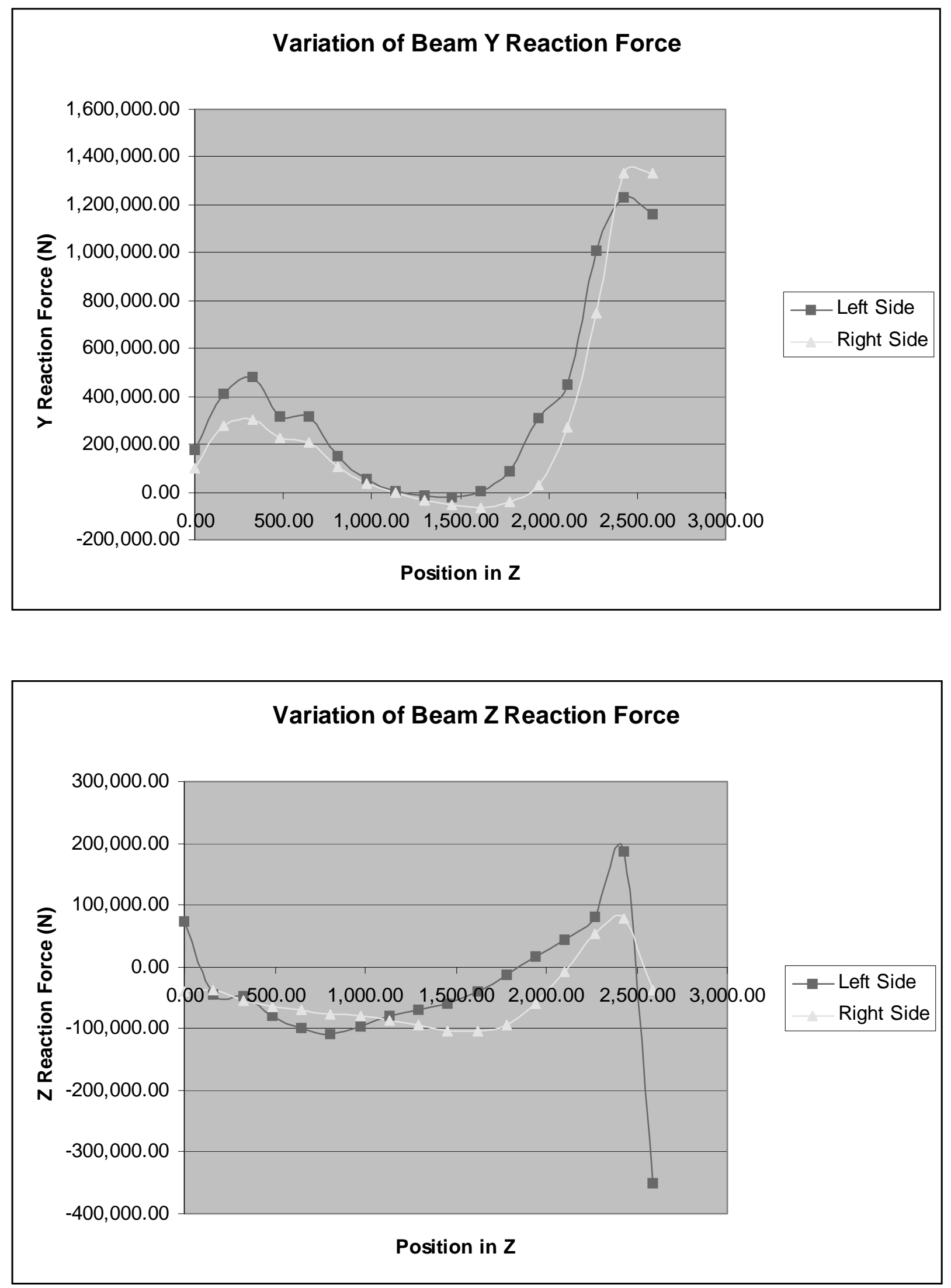



\section{Appendix 5}

\section{Forces Between Modules in Gravity, Magnetic, and Seismic Load Case}

\begin{tabular}{|c|c|c|c|c|c|c|c|c|c|}
\hline & & & & & & & & & \\
\hline & & гrom & & & IVicuse & & & Dacn & \\
\hline Module & P1 & P2 & $\mathbf{P t}$ & P1 & P2 & $\mathbf{P t}$ & P1 & P2 & $\mathbf{P t}$ \\
\hline 1 & -117.00 & 558.00 & -142.00 & -375.00 & 701.00 & -182.00 & -516.00 & 728.00 & -189.00 \\
\hline 2 & -52.90 & 579.00 & -140.00 & -340.00 & 647.00 & -207.00 & -479.00 & 758.00 & -229.00 \\
\hline 3 & 24.20 & 632.00 & -130.00 & -299.00 & 571.00 & -226.00 & -435.00 & 818.00 & -263.00 \\
\hline 4 & 116.00 & 743.00 & -142.00 & -250.00 & 459.00 & -275.00 & -387.00 & 930.00 & -320.00 \\
\hline 5 & 222.00 & 934.00 & -128.00 & -190.00 & 272.00 & -297.00 & -336.00 & $1,110.00$ & -358.00 \\
\hline 6 & 324.00 & $1,190.00$ & 60.80 & -127.00 & -124.00 & -146.00 & -327.00 & $1,420.00$ & 109.00 \\
\hline 7 & 408.00 & -689.00 & -284.00 & -106.00 & -690.00 & -197.00 & -90.30 & $-2,140.00$ & -508.00 \\
\hline 8 & 187.00 & -617.00 & 301.00 & -110.00 & -794.00 & 349.00 & -200.00 & $-1,640.00$ & -100.00 \\
\hline 9 & -83.90 & -504.00 & 644.00 & -200.00 & -753.00 & 767.00 & -413.00 & $-1,250.00$ & 459.00 \\
\hline 10 & -426.00 & -406.00 & 776.00 & -342.00 & -643.00 & 951.00 & -746.00 & -926.00 & 946.00 \\
\hline 11 & -687.00 & -344.00 & 661.00 & -489.00 & -521.00 & 869.00 & 194.00 & -701.00 & 991.00 \\
\hline 12 & -248.00 & -284.00 & 201.00 & -612.00 & -413.00 & 602.00 & -402.00 & -531.00 & 928.00 \\
\hline 13 & 33.50 & -242.00 & 164.00 & -697.00 & -327.00 & 474.00 & -593.00 & -393.00 & 723.00 \\
\hline 14 & -84.80 & -210.00 & 125.00 & -752.00 & -250.00 & 351.00 & -694.00 & -282.00 & 531.00 \\
\hline 15 & -217.00 & -180.00 & 65.70 & -778.00 & -184.00 & 215.00 & -741.00 & -191.00 & 333.00 \\
\hline 16 & -323.00 & -156.00 & 20.50 & -777.00 & -134.00 & 102.00 & -749.00 & -121.00 & 166.00 \\
\hline 17 & -401.00 & -139.00 & -12.70 & -756.00 & -96.80 & 11.10 & -729.00 & -69.60 & 27.50 \\
\hline 18 & -456.00 & -125.00 & -43.50 & -717.00 & -68.90 & -69.30 & -689.00 & -31.00 & -92.80 \\
\hline 19 & -488.00 & -116.00 & -68.20 & -665.00 & -49.80 & -135.00 & -631.00 & -4.45 & -191.00 \\
\hline 20 & -499.00 & -107.00 & -117.00 & -600.00 & -36.70 & -218.00 & -557.00 & 16.40 & -298.00 \\
\hline 21 & -488.00 & -106.00 & -142.00 & -522.00 & -35.00 & -268.00 & -471.00 & 26.80 & -367.00 \\
\hline 22 & -462.00 & -111.00 & -157.00 & -438.00 & -43.00 & -298.00 & -378.00 & 26.70 & -408.00 \\
\hline 23 & -425.00 & -125.00 & -176.00 & -351.00 & -63.50 & -324.00 & -283.00 & 12.30 & -437.00 \\
\hline 24 & -378.00 & -137.00 & -186.00 & -261.00 & -82.50 & -334.00 & -186.00 & 0.82 & -447.00 \\
\hline 25 & -325.00 & -149.00 & -185.00 & -173.00 & -98.80 & -329.00 & -92.90 & -7.60 & -437.00 \\
\hline 26 & -271.00 & -160.00 & -180.00 & -89.10 & -115.00 & -313.00 & -5.09 & -17.60 & -413.00 \\
\hline 27 & -217.00 & -171.00 & -166.00 & -12.10 & -129.00 & -285.00 & 75.80 & -26.40 & -373.00 \\
\hline 28 & -163.00 & -178.00 & -177.00 & 57.80 & -140.00 & -278.00 & 151.00 & -31.50 & -348.00 \\
\hline 29 & -107.00 & -187.00 & -163.00 & 120.00 & -153.00 & -242.00 & 220.00 & -38.20 & -293.00 \\
\hline 30 & -55.10 & -194.00 & -145.00 & 172.00 & -165.00 & -199.00 & 281.00 & -43.30 & -230.00 \\
\hline 31 & -7.68 & -197.00 & -143.00 & 213.00 & -173.00 & -170.00 & 332.00 & -42.50 & -179.00 \\
\hline 32 & 2.01 & -194.50 & -70.04 & 225.67 & -168.00 & -84.06 & 432.67 & -50.40 & -89.75 \\
\hline 33 & 11.71 & -192.00 & 2.93 & 238.33 & -163.00 & 1.89 & 533.33 & -58.30 & -0.51 \\
\hline 34 & 21.40 & -219.00 & 52.30 & 251.00 & -178.00 & -4.14 & 634.00 & -67.40 & -61.40 \\
\hline 35 & 36.30 & -220.00 & 13.50 & 241.00 & -179.00 & -69.70 & 598.00 & -73.60 & -146.00 \\
\hline 36 & 43.10 & -215.00 & 2.15 & 219.00 & -172.00 & -103.00 & 540.00 & -70.80 & -198.00 \\
\hline
\end{tabular}




\begin{tabular}{|c|c|c|c|c|c|c|c|c|c|}
\hline 37 & 46.00 & -214.00 & -28.00 & 187.00 & -167.00 & -153.00 & 463.00 & -71.40 & -263.00 \\
\hline 38 & 41.50 & -212.00 & -57.30 & 143.00 & -158.00 & -198.00 & 364.00 & -70.40 & -320.00 \\
\hline 39 & 33.90 & -204.00 & -65.80 & 91.60 & -144.00 & -216.00 & 249.00 & -64.20 & -346.00 \\
\hline 40 & 26.80 & -199.00 & -86.20 & 33.70 & -132.00 & -242.00 & 122.00 & -60.90 & -374.00 \\
\hline 41 & 16.90 & -196.00 & -115.00 & -31.00 & -122.00 & -271.00 & -18.60 & -60.50 & -399.00 \\
\hline 42 & 4.11 & -192.00 & -140.00 & -102.00 & -111.00 & -289.00 & -172.00 & -60.60 & -409.00 \\
\hline 43 & -10.20 & -189.00 & -166.00 & -177.00 & -100.00 & -300.00 & -334.00 & -63.90 & -405.00 \\
\hline 44 & -20.20 & -181.00 & -159.00 & -253.00 & -85.30 & -270.00 & -497.00 & -63.50 & -354.00 \\
\hline 45 & -20.40 & -178.00 & -169.00 & -326.00 & -79.60 & -248.00 & -654.00 & -73.40 & -305.00 \\
\hline 46 & -12.20 & -177.00 & -174.00 & -396.00 & -77.80 & -215.00 & -804.00 & -89.90 & -237.00 \\
\hline 47 & 11.00 & -173.00 & -157.00 & -459.00 & -78.30 & -148.00 & -938.00 & -110.00 & -129.00 \\
\hline 48 & 55.80 & -174.00 & -151.00 & -511.00 & -90.30 & -85.70 & $-1,050.00$ & -145.00 & -17.50 \\
\hline 49 & 125.00 & -179.00 & -153.00 & -553.00 & -112.00 & -22.90 & $-1,140.00$ & -195.00 & 103.00 \\
\hline 50 & 228.00 & -186.00 & -152.00 & -581.00 & -140.00 & 50.40 & $-1,190.00$ & -262.00 & 241.00 \\
\hline 51 & 384.00 & -196.00 & -153.00 & -590.00 & -174.00 & 130.00 & $-1,210.00$ & -349.00 & 394.00 \\
\hline 52 & 518.00 & -209.00 & -125.00 & -574.00 & -211.00 & 250.00 & $-1,170.00$ & -454.00 & 590.00 \\
\hline 53 & $-1,060.00$ & -243.00 & 292.00 & -524.00 & -266.00 & 472.00 & $-1,090.00$ & -591.00 & 607.00 \\
\hline 54 & -738.00 & -287.00 & 419.00 & -453.00 & -334.00 & 567.00 & -991.00 & -779.00 & 614.00 \\
\hline 55 & -447.00 & -370.00 & 436.00 & -380.00 & -392.00 & 481.00 & -892.00 & $-1,070.00$ & 152.00 \\
\hline 56 & -314.00 & -449.00 & 261.00 & -354.00 & -346.00 & 245.00 & -468.00 & $-1,180.00$ & -396.00 \\
\hline 57 & -158.00 & -406.00 & -79.70 & -362.00 & -259.00 & -119.00 & -542.00 & $-1,640.00$ & -440.00 \\
\hline 58 & -122.00 & $1,310.00$ & 140.00 & -410.00 & 218.00 & -62.80 & -610.00 & $1,330.00$ & -31.20 \\
\hline 59 & -144.00 & $1,100.00$ & 109.00 & -437.00 & 534.00 & -38.90 & -602.00 & $1,160.00$ & -105.00 \\
\hline 60 & -172.00 & 884.00 & 114.00 & -450.00 & 661.00 & 8.41 & -605.00 & $1,000.00$ & -52.10 \\
\hline 61 & -192.00 & 746.00 & 108.00 & -451.00 & 723.00 & 36.40 & -603.00 & 889.00 & -12.70 \\
\hline 62 & -201.00 & 660.00 & 109.00 & -444.00 & 752.00 & 66.00 & -596.00 & 814.00 & 31.00 \\
\hline 63 & -194.00 & 608.00 & 132.00 & -429.00 & 763.00 & 118.00 & -579.00 & 766.00 & 96.70 \\
\hline
\end{tabular}



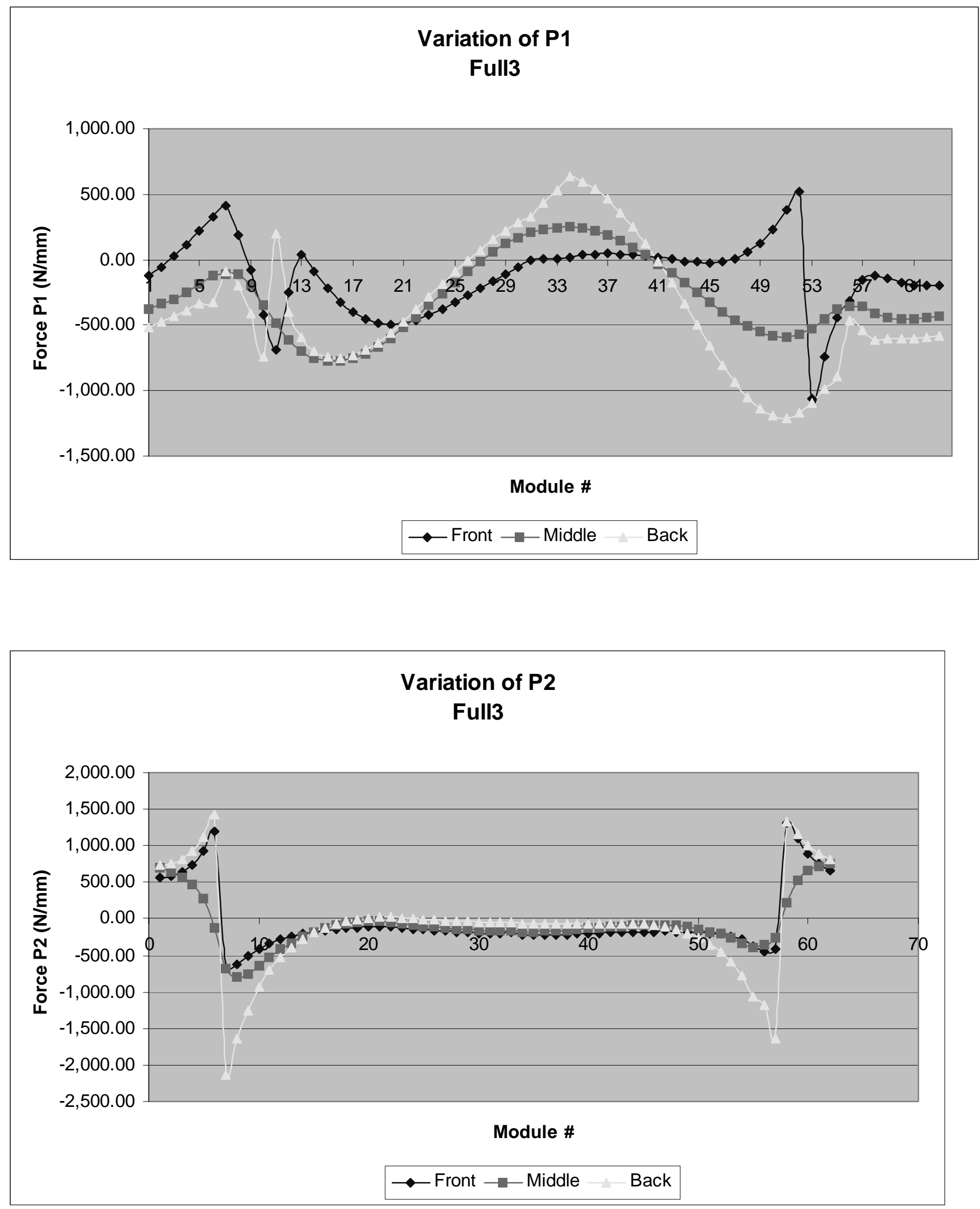


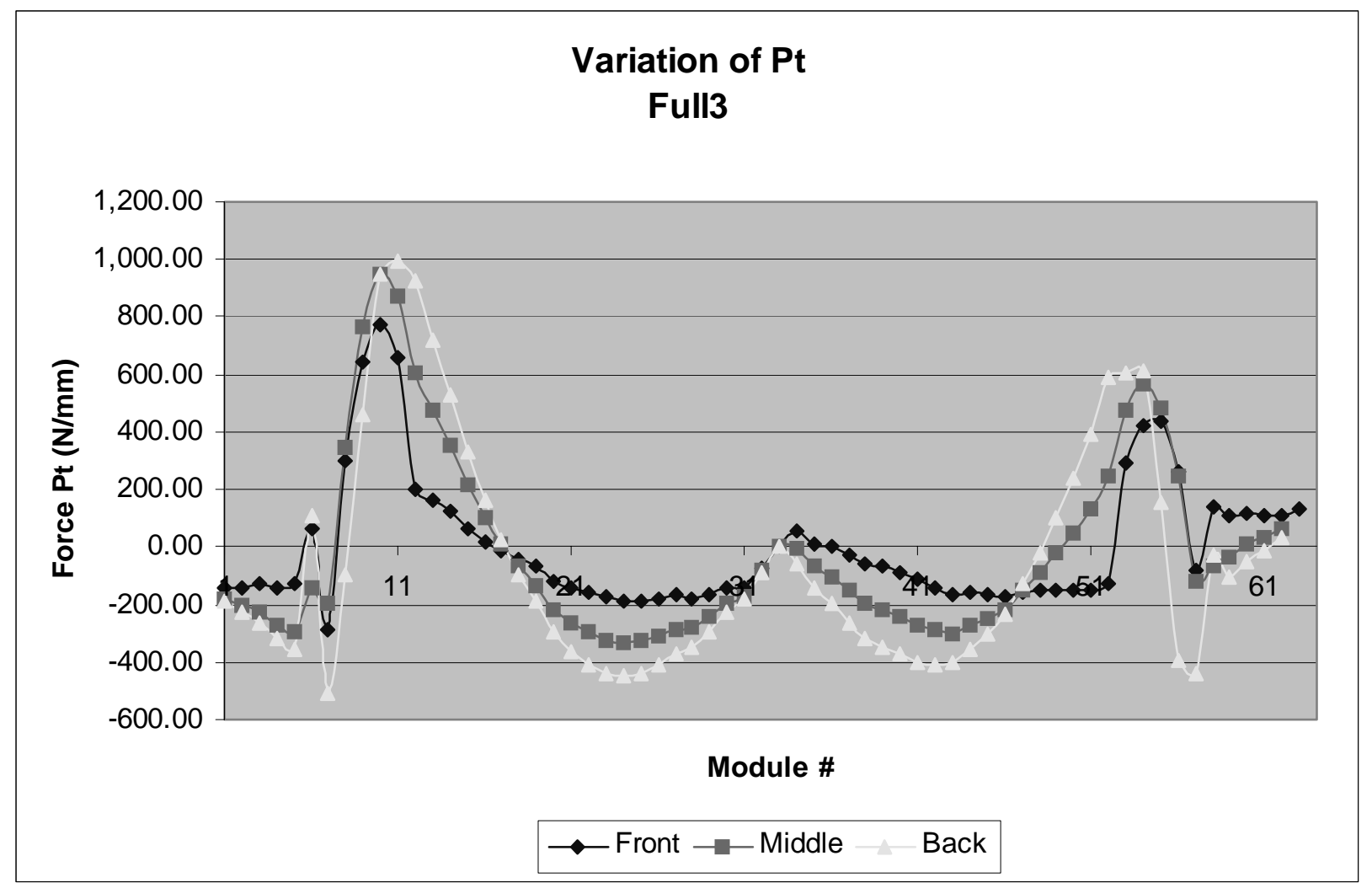

